UNIVERSIDADE DE SÃO PAULO

FACULDADE DE ECONOMIA, ADMINISTRAÇÃO E CONTABILIDADE DEPARTAMENTO DE ADMINISTRAÇÃO PROGRAMA DE PÓS-GRADUAÇÃO EM ADMINISTRAÇÃO

CRIAÇÃO DE VALOR EM FUSÕES E AQUISIÇÕES

- A INFLUÊNCIA DO SENTIMENTO DE MERCADO -

Roberto Yocisuke Soejima Nardi

Orientador: Prof. Dr. Eduardo Kazuo Kayo

Versão Original

São Paulo 
Prof. Dr. João Grandino Rodas Reitor da Universidade de São Paulo

Prof. Dr. Reinaldo Guerreiro

Diretor da Faculdade de Administração, Economia e Contabilidade

Prof. Dr. Adalberto Américo Fischmann

Chefe do Departamento de Administração

Prof. Dr. Lindolfo Galvão de Albuquerque

Coordenador do Programa de Pós-Graduação em Administração 


\section{CRIAÇÃO DE VALOR EM FUSÕES E AQUISIÇÕES}

\section{- A INFLUÊNCIA DO SENTIMENTO DE MERCADO -}

Dissertação apresentada ao departamento de Administração da Faculdade de Economia, Administração e Contabilidade da Universidade de São Paulo como requisito para obtenção de título em Mestre em Ciências.

Orientador: Prof. Dr. Eduardo Kazuo Kayo

\section{SÃO PAULO}


FICHA CATALOGRÁFICA

Elaborada pela Seção de Processamento Técnico do SBD/FEA/USP

Nardi, Roberto Yocisuke Soejima

Criação de valor em fusões e aquisições: a influência do sentimento de mercado / Roberto Yocisuke Soejima Nardi. - São Paulo, 2012. $108 \mathrm{p}$.

Dissertação (Mestrado) - Universidade de São Paulo, 2012.

Orientador: Eduardo Kazuo Kayo.

1. Fusão e aquisição de empresas 2. Valor - Administração 3. Finanças das empresas I. Universidade de São Paulo. Faculdade de Economia, Administração e Contabilidade. II. Título.

CDD - 658.16 
Aos meus pais, esposa e irmão 


\section{Agradecimentos}

- À minha esposa, pela alegria com que preenche minha vida, pelo apoio constante e pela paciência nos momentos difíceis;

- À minha família, simplesmente por tudo que pude alcançar;

- Ao Prof. Dr. Eduardo Kazuo Kayo pela ajuda como orientador e pelas agradáveis conversas durante todo o mestrado;

- À banca examinadora, Prof. Dr. Roy Martelanc e Prof. Dr. Herbert Kimura, pelas contribuições e sugestões de melhoria deste trabalho;

- Aos demais professores da FEA com quem tive a oportunidade de aprender e continuar meu desenvolvimento acadêmico.

- Aos novos amigos que tive a sorte de conhecer durante a vida acadêmica na FEA e que tornaram essa etapa ainda mais agradável;

- Aos velhos e bons amigos, por continuarem velhos e bons amigos. 
"We (...) evaluate a business for acquisition in its entirety. We want the business to be one (a) that we can understand; (b) with favorable longterm prospects; (c) operated by honest and competent people; and (d) available at a very attractive price.”

Warren E. Buffett 


\section{RESUMO}

A literatura na área de finanças relacionada ao tema de fusões e aquisições (F\&As) é abrangente e tem como um dos temas principais de pesquisa os fatores que determinam o grau de criação (ou destruição) de valor nesses processos. Com a evolução dos conhecimentos na área de finanças comportamentais a condição ou estado em que se encontra o mercado acionário no momento em que ocorrem as F\&As também passa a ser foco de estudo.

Dando seguimento aos trabalhos de Bouwman, Fuller e Nain (2009) e Batista e Minardi (2010) que estudam esse tema, este trabalho tem como objetivo central determinar se o sentimento de mercado (mercado em alta ou mercado em baixa) no momento do anúncio de F\&As tem influência no grau de criação de valor para os acionistas das empresas adquirentes. Esta pesquisa analisa, principalmente pelo emprego de regressões cross section, os eventos ocorridos entre 2001 e 2011 de empresas listadas na Bovespa e se diferencia das demais por (i) considerar um robusto processo de identificação e controle de eventos cujos resultados podem ser contaminados por sobreposição de efeitos de outros eventos não relacionados, (ii) propor diferentes proxies para determinação do estado ou condição em que se encontra o mercado (iii) realizar variações metodológicas como forma de avaliar a robustez dos resultados e (iv) expansão dos estudos empíricos pela inclusão de eventos recentes.

Os resultados parecem ser divergentes e dependentes da metodologia empregada. Quando há exclusão de eventos com possibilidade de sobreposição de efeitos, não há evidência estatisticamente significante de que haja influência do sentimento de mercado sobre a criação de valor na maior parte dos resultados. Por outro lado, os resultados obtidos para amostra contendo todos os eventos (mas controlados para sobreposição de efeitos de outros eventos distintos) indicam, em muitos casos com significância estatística, que existe relação entre o sentimento de mercado e a criação de valor, sendo esta menor em períodos de mercado em alta.

As análises realizadas também são úteis para evidenciar que os resultados são sensíveis à forma como o sentimento de mercado é definido (proxy de sentimento de mercado escolhida), já que se constata, em alguns casos, resultados até mesmo contrários. Mesmo sem alteração da proxy empregada, os resultados também parecem se alterar quando os limites (threshold) que segmentam os diferentes níveis de sentimento de mercado são alterados. Por outro lado, de forma geral, os resultados se mostram consistentes para ambas as proxies de mercado utilizadas (Ibovespa e IBRX-50) para estimar a criação de valor e também para as análises onde possíveis outliers são excluídos. 


\begin{abstract}
Mergers and Acquisitions (M\&As) finance literature is vast and extensive, being one of its main themes of research the value creation (or destruction) determinants in these processes. More recently, with behavioral finance theory development, the market condition (bull or bear market) during M\&As announcements has increasinly attracted researches attention.

Continuing Bouwman, Fuller and Nain (2009) and Batista and Minardi (2010) who have already studied this topic, this paper intends to determine whether the market sentiment (bull market or bear market) by the time of M\&As are announced influence the value created for acquiring companies shareholders. This research analyzes, mainly by cross section regressions, the events announced between 2001 and 2011 for companies listed at Bovespa and differs from previous works by (i) considering a robust identification and controlling process of M\&As events whose results can be affected by other unrelated events, (ii) proposing different proxies for determining the market sentiment (condition), (iii) conducting methodological variations in order to assess the results robustness and (iv) extending empirical studies in the area by analysing recent M\&As events.

The results seem to vary and to dependent on the methodology employed. When events with possible confounding effects are excluded, in most results there is no statistically significant evidence that the market sentiment is related to value creation. Nevertheless, results obtained for the sample containing all events (but controlled for confounding effects) indicate, in several cases with statistical significance, that there is a relationship between the market sentiment and value creation, which seems to be higher during bear markets.

This study is also useful to show that results also depend on how market sentiment is defined (which market sentiment proxy is adopted). Even when the proxy employed is not changed, results also seem to change depending on the threshold defined in order to segment market sentiment. In the other hand, results seem to be generally consistent regardless of the market proxy employed to estimate value creation (Ibovespa and IBRX-50) and regardless of the exclusion of potential outliers.
\end{abstract}




\section{SUMÁRIO}

1 Introdução 6

1.1 Definição do Problema de Pesquisa e Objetivos ....................................................... 13

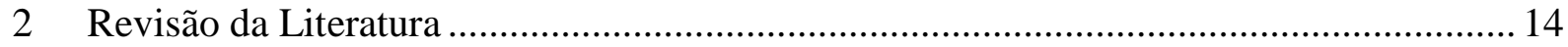

2.1 Definição e Tipos de Fusões e Aquisições ….......................................................... 14

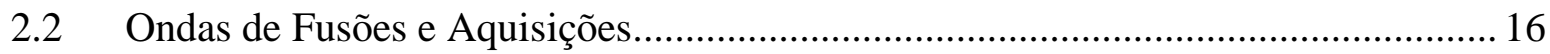

2.3 Motivações que Fomentam Fusões e Aquisições ...................................................... 19

2.3.1 Economias de Escala e de Escopo..................................................................... 20

2.3.2 Concentração Horizontal e Poder de Mercado...................................................... 21

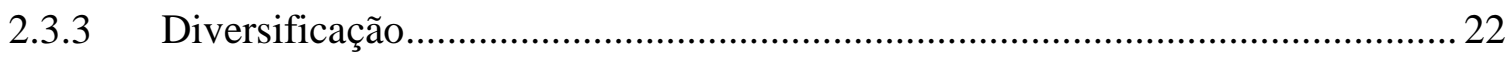

2.3.4 Qualidade dos Gestores e Outros Ativos Intangíveis....................................... 23

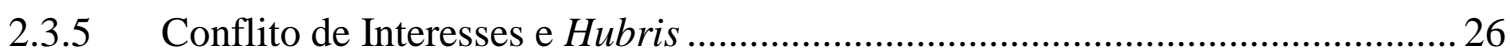

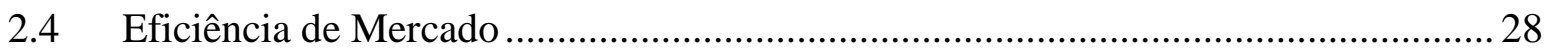

2.5 Finanças Comportamentais e Sentimento de Mercado.............................................. 34

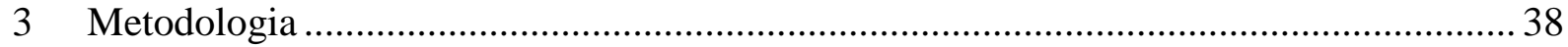

3.1 Fontes de Dados, Definição do Evento e Amostra .................................................... 38

3.2 Estudo de Evento - Emprego Robusto do Método.................................................... 39

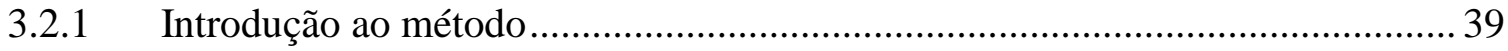

3.2.2 Premissas e Possíveis Erros de Implementação ................................................. 41

3.2.3 Cálculo do Retorno Anormal e de sua Significância ........................................ 45

3.3 Análise do Retorno Anormal e Operacionalização das Variáveis............................. 52

3.4 Sentimento de Mercado: Seleção da Proxy ........................................................... 54

3.4.1 Sentimento de Mercado: Proxies Adotadas ...................................................... 56

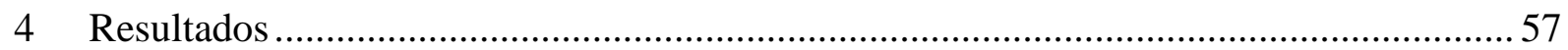

4.1 Criação de Valor em F\&As: Análise Uni-variada.................................................. 57

4.2 Criação de Valor em F\&As: Análise Multivariada .................................................. 63 
4.2.1 Criação de Valor: Correlação com Demais Variáveis. ....................................... 64

4.2.2 Regressão Multivariada: Amostra sem Sobreposição de Efeitos....................... 64

4.2.3 Regressão Multivariada: Amostra com Sobreposição de Efeitos ....................... 70

4.3 Análise de Robustez dos Resultados Obtidos......................................................... 76

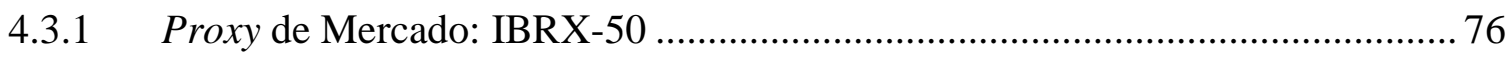

4.3.2 Classificação Sentimento de Mercado pela Mediana......................................... 77

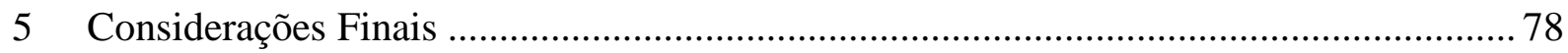

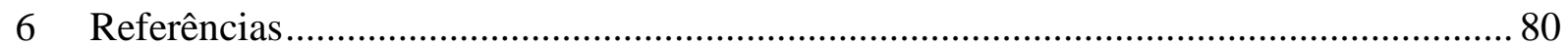

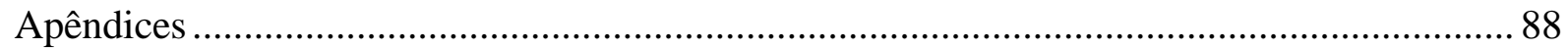




\section{LISTA DE ABREVIATURAS E SIGLAS}

APT: Arbitrage Pricing Model

CAPM: Capital Asset Pricing Model

CVM: Comissão de Valores Mobiliários

F\&A: Fusão e Aquisição

F\&As: Fusões e Aquisições

HME: Hipótese de Mercado Eficiente

MQO: Mínimos Quadrados Ordinários

RBV: resource-based view

VM / VC: Valor de Mercado sobre Valor Contábil

VPL: Valor Presente Líquido 


\section{LISTA DE ILUSTRAÇÕES}

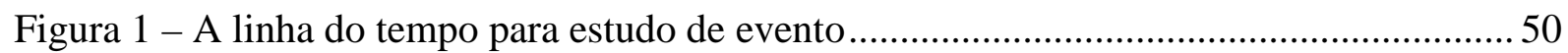

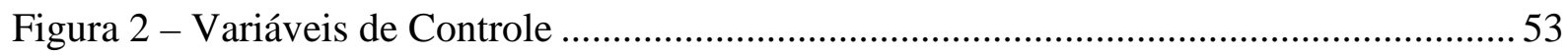

Figura 3 - Análises e Variações Metodológicas ................................................................. 57

Gráfico 1 - Número de Aquisições Mensais no Brasil .............................................................. 8

Gráfico 2 - Percentual de empresas públicas adquiridas por trimestre.................................. 16

Gráfico 3 - Retorno Anormal Acumulado Segundo Proxies de Sentimento de Mercado....... 61

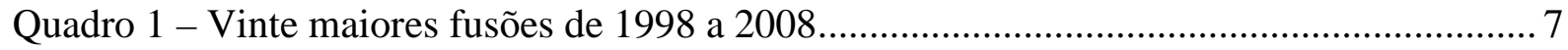




\section{LISTA DE TABELAS}

Tabela 1 - Criação de Valor (Proxy de Mercado Ibovespa) .................................................. 58

Tabela 2 - Teste t e de Wilcoxon para a Criação de Valor (Proxy de Mercado Ibovespa) ..... 60

Tabela 3 - Teste Mann Whitney para duas amostras ............................................................ 62

Tabela 4 - Criação de Valor: Correlação com demais Variáveis ........................................... 63

Tabela 5 - Análise de Regressão dos Determinantes de Criação de Valor - Dia do Anúncio. 66

Tabela 6 - Análise de Regressão dos Determinantes de Criação de Valor - Janela de Três Dias 67

Tabela 7 - Análise de Regressão dos Determinantes de Criação de Valor - Janela de Onze

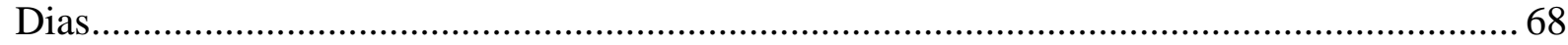

Tabela 8 - Análise de Regressão dos Determinantes de Criação de Valor - Janela de Vinte e Um Dias 69

Tabela 9 - Análise de Regressão dos Determinantes de Criação de Valor - Dia do Anúncio Amostra Completa.... 72

Tabela 10 - Análise de Regressão dos Determinantes de Criação de Valor - Janela Três Dias Amostra Completa.

Tabela 11 - Análise de Regressão dos Determinantes de Criação de Valor - Janela Onze Dias - Amostra Completa.. 74

Tabela 12 - Análise de Regressão dos Determinantes de Criação de Valor - Janela Vinte e Um Dias - Amostra Completa 75 


\section{INTRODUÇÃO}

Operações de fusões e aquisições (F\&As) têm sido parte do cotidiano do mercado corporativo, refletindo desde simples mudanças de controle até reformulações de estratégias corporativas e mudanças no ambiente em que as organizações estão inseridas. Essas transações costumam envolver grande quantidade de capital e normalmente impactam direta ou indiretamente um grande número de agentes (ou stakeholders) relacionados às empresas envolvidas.

Ao longo da história, F\&As têm sido intrinsecamente relacionadas com a cultura e economia do ambiente em que se encontravam inseridas. $\mathrm{O}$ aumento da intensidade dessa atividade foi notório nas últimas duas décadas e é relacionada a importantes forças de mudanças: (i) mudança tecnológica, (ii) economia de escala, de escopo, complementar e necessidade de suprir defasagem tecnológica, (iii) globalização e comércio livre, (iv) mudanças na forma de organização industrial, (v) novas indústrias, (vi) processos de aumento e diminuição de regulação, (vii) condições financeiras e econômicas favoráveis nas últimas duas décadas, (viii) tendências negativas em determinadas indústrias e economias, (ix) aumento da desigualdade de renda e riqueza e (x) avaliação relativamente elevada dos valor do patrimônio líquido na década de 1990 (WESTON; MITCHELL; MULHERIN, 2003, p. 3).

Jensen (1988, p. 21) comenta que existem evidências e análises econômicas indicando que o mercado de F\&As vem beneficiando acionistas, a sociedade e a própria forma como as empresas se organizam. Nesse mesmo trabalho, o autor comenta que as operações ${ }^{1}$ de F\&A ocorridas em 1985 e 1986, com pelo menos uma empresa americana envolvida, movimentaram cerca 180 bilhões de dólares ao ano e que os ganhos dos acionistas das empresas adquirentes nesse tipo de operação na década anterior equivaleria a $51 \%$ de todo o valor distribuído em dividendos em espécie no mesmo período, considerando todo o mercado corporativo.

\footnotetext{
${ }^{1}$ Operações com anúncio do valor da transação, cujo valor fosse superior a 500.000,00 US\$ (a valor presente de 1986) ou $10 \%$ do valor das empresas.
} 
Em estudo mais recente, Moeller, Schlingemann e Stukz (2005, p.762) fazem levantamento somente das operações de F\&A envolvendo empresas adquirentes americanas listadas em bolsa e chegam a um total aproximado de 12.000 operações que movimentaram 3,4 trilhões de dólares ${ }^{2}$ no período de 1980 a 2001.

\section{Quadro 1 - Vinte maiores fusões de 1998 a 2008}

\begin{tabular}{cllc}
\hline Data Anúncio & \multicolumn{1}{c}{ Empresa Alvo } & \multicolumn{1}{c}{ Empresa Adquirente } & Valor (Bilhões US\$) \\
\hline nov/99 & Mannesmann AG & Vodafone AirTouch PLC & 203 \\
out/04 & Shell Transport \& Trading Co. & Royal Dutch Petroleum Co. & 185 \\
jan/00 & Time Warner & America Online Co. & 182 \\
abr/07 & ABN-AMRO Holding NV & RFS Holdings BV & 98 \\
mar/06 & BellSouth Corp. & AT\&T Inc. & 89 \\
nov/99 & Warner-Lambert Co. & Pfizer Inc. & 89 \\
dez/98 & Mobil Corp. & Exxon Corp. & 85 \\
jan/00 & SmithKline Beecham PLC & Glaxo Wellcome PLC & 79 \\
fev/06 & Suez SA & Gas de France SA & 75 \\
abr/98 & Citicorp & Travellers Group Inc. & 73 \\
jul/98 & GTE Corp. & Bell Atlantic Corp. & 71 \\
mai/98 & Ameritech Corp. & SBC Communications Inc. & 70 \\
jun/98 & Tele-Communications Inc. & AT\&T Corp. & 70 \\
jan/99 & AirTouch Communications Inc. & Vodafone Group PLC & 66 \\
jan/04 & Aventis SA & Sanofi-Synthelabo SA & 66 \\
abr/98 & BankAmerica Corp. & NationsBank Corp. & 62 \\
jul/92 & Pharmacia Corp. & Pfizer Inc. & 61 \\
jun/08 & Anheuser-Busch Cos Inc. & Inbev NV & 60 \\
jun/99 & US West & Owest Communications & 59 \\
jan/04 & Bank One Corp. & JPMorgan Chase \& Co. & 59 \\
\hline
\end{tabular}

FONTE: BERK; DEMARZO, 2009, p.891

Finalmente, considerando o mercado global de F\&As, Berk e DeMarzo (2009, p.891) estimam que o mercado total atinja cifras ainda mais expressivas, chegando a movimentar um trilhão de dólares por ano. O Quadro 1 apresenta as vinte maiores operações realizadas entre 1998 e 2008 que somam cerca de 1,8 trilhão de dólares e evidencia que essas operações, mesmo isoladamente, também podem ser expressivas, já que todas apresentam valor acima de 55 bilhões de dólares.

No Brasil a quantidade de operações de F\&A é menor e o valor individual de cada transação também é inferior aos apresentados acima na maioria dos casos. No entanto, o mercado brasileiro de F\&A demonstra estar se desenvolvendo e o número de negócios apresenta

\footnotetext{
${ }^{2}$ A valor presente de 2001.
} 
tendência de crescimento ou mudança de patamar a partir da segunda metade da década de 2000, como mostra o Gráfico 1.

\section{Gráfico 1 - Número de Aquisições Mensais no Brasil}

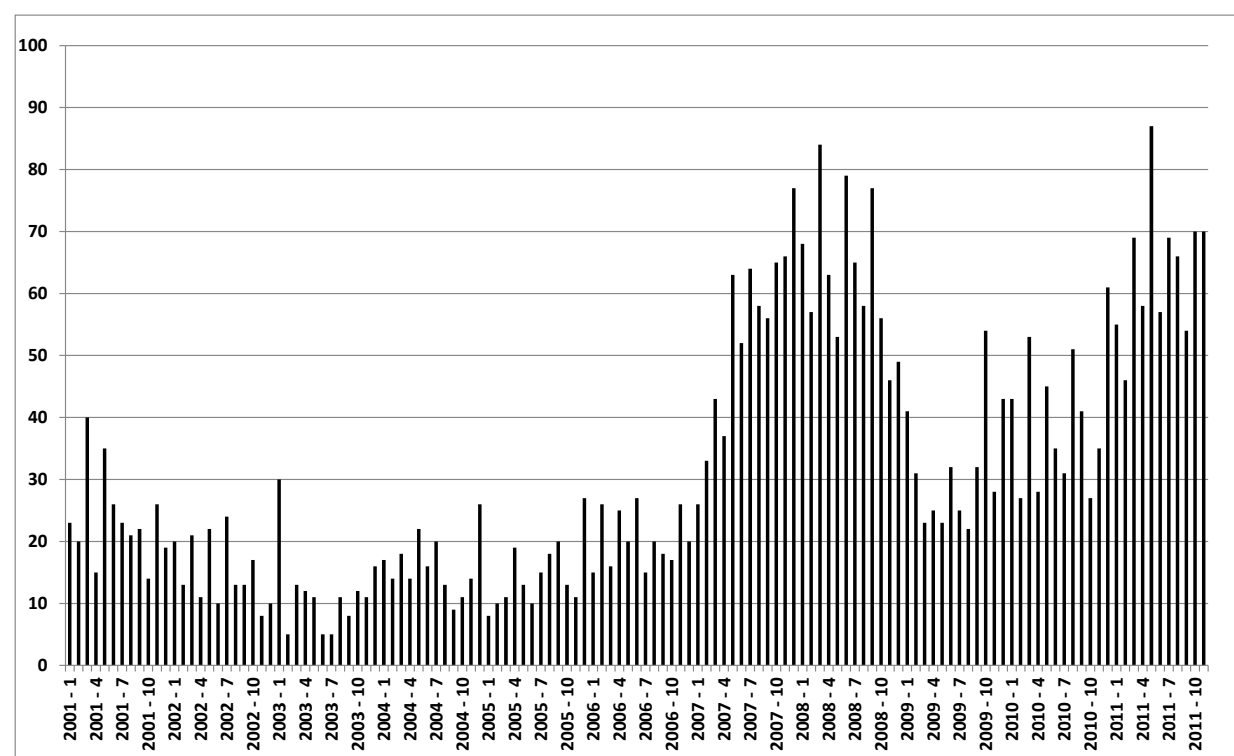

FONTE: THONSON REUTERS

Compartilhando a mesma percepção, o presidente do Subcomitê de Fusões e Aquisições da Anbima, Bruno Amaral, relata:

O ano de 2010 representou uma mudança de patamar no setor de fusões e aquisições. Os dois semestres do ano foram maiores do que qualquer outro da série histórica e a tendência é de continuidade. Este ano já começou forte e deve manter ou superar o volume registrado no ano passado. (ANBIMA, 2011)

Manne (1965) traz a tona o debate sobre a importância das F\&As para a sociedade e mercado corporativo frente ao movimento existente na época de criação e aumento das leis antitruste visando limitar ou até mesmo proibir a realização F\&As. Manne defende que essas leis não podem ser demasiadamente restritivas já que existe também impacto positivo de F\&As, sendo os seguintes aspectos destacados: (i) diminuição do impacto negativo causado por falências, (ii) gerenciamento mais eficiente das corporações, (iii) aumento de proteção aos investidores não detentores de controle, (iv) aumento da mobilidade do capital e (v) alocação mais eficiente de recursos. O autor introduz também o conceito de que o controle de corporações deve ser considerado como um ativo valioso e que o mercado pelo controle corporativo dá poder e proteção aos investidores. 
Finalmente, o autor prevê como deveriam se comportar os preços das ações de empresas envolvidas em processos de F\&As, fazendo a distinção entre duas situações. Nos casos em que as F\&As são motivadas somente pela obtenção de controle, pode-se esperar que o preço das ações da empresa alvo se valorize, enquanto que o preço das ações da empresa adquirente se desvalorize justamente devido ao pagamento de valor prêmio relacionado à transferência de controle. Por outro lado, segundo o autor, quando a F\&A é motivada pela busca de poder de mercado e economia de escala, o preço das ações de ambas as empresas deveria aumentar. No entanto, segundo Manne (1965, p. 120), naquele momento ainda havia a necessidade de desenvolvimento de técnicas estatísticas e de conhecimento a respeito do processo econômico relacionado às F\&As para que se pudesse obter comprovações empíricas dessas previsões.

Na década seguinte ${ }^{3}$ e durante a década de 1980 principalmente, grande parte dos estudos nessa área tem como principal objetivo a análise de criação de valor para os acionistas em processos de F\&As, tendo três focos principais: (i) criação de valor para acionistas de empresas adquirentes, (ii) para acionistas de empresas adquiridas e (iii) criação de valor total considerando ambas as empresas. Esses trabalhos, de forma geral, chegam à conclusão de que existe criação de valor no processo total de F\&As, ou seja, quando ambos os acionistas (das empresas alvo e adquirente) são considerados. No entanto, os acionistas das empresas alvo parecem se beneficiar de parcela significativa da criação de valor, enquanto os acionistas das empresas adquirentes parecem sofrer perdas ou não obter ganhos (JENSEN; RUBACK, 1983) (TRAVLOS, 1987) (BRADLEY; DESAI; KIM, 1988) (JARREL, BRICKLEY; NETTER, 1988).

Trabalhos posteriores e citados a seguir também chegam aos mesmos resultados e contribuem para reforçar a validade das conclusões anteriores. Adicionalmente, esses trabalhos começam a ter enfoques mais específicos e começam a analisar quais fatores e condições são determinantes para criação de valor (para acionistas adquirentes, adquiridos, ou para ambos) e identificar quais sãos os motivadores reais que levam as empresas aos processos de F\&A. A seguir são discutidos alguns desses pontos:

\footnotetext{
${ }^{3}$ Até aquele momento, segundo Haugen e Langetieg (1975, p. 1003), os trabalhos que tentavam analisar F\&As empregavam métodos distintos e não obtiveram conclusões convergentes. Haugen e Langetieg, embora com método de análise e conceito de sinergia não tão desenvolvidos, analisam a criação de valor total para ambas as empresas e não encontram evidência de criação de valor.
} 
Travlos (1987), Servaes (1991) e Andrade, Mitchell e Stafford (2001) adotam amostras de F\&As segregadas em função da forma de pagamento e constatam que quando a transação é efetivada com a troca de ações, os acionistas das empresas adquirentes costumam perder mais valor que quando as transações ocorrem com pagamento em caixa. Uma das explicações possíveis para isso é dada por Travlos (1987, p. 961) que comenta que o mercado reage negativamente (ou mais negativamente) às F\&As financiadas com troca de ações porque entendem esse fato como um sinal de que os gestores das empresas adquirentes acreditam que suas ações estejam sobre valorizadas (hipótese da sinalização).

Seth (1990a) e Seth (1990b) apresenta o conceito de sinergia e alguns fatores (economia de escala e escopo, eficiência operacional, co-seguro, aumento de dívida, diversificação etc.) que possivelmente podem resultar em criação de valor (ou sinergia) em F\&As. Seth também analisa sua amostra de F\&As segmentada, mas em função do grau de semelhança entre as empresas adquirente e adquirida (empresas relacionadas ou não relacionadas) já que a criação de valor em cada grupo seria causada por fatores distintos. Os principais resultados indicam que ambos os tipos de F\&As analisados (entre empresas relacionadas e entre empresas não relacionadas) criam valor e que F\&As entre empresas relacionadas aparentam não criar mais valor que F\&As entre empresas não relacionadas (embora, estas estejam sujeitas a um número menor e mais restrito de fatores potenciais de criação valor). Além disso, Seth encontra indícios mostrando que há criação de valor por economias de escala e escopo, por eficiência operacional e poder de mercado em F\&As relacionadas. Já em F\&As não relacionadas, a criação de valor parece ser resultante do efeito de co-seguro, não havendo criação de valor devido a diversificação.

Berkovitch e Narayanan (1993) e Seth, Song e Pettit (2000) somam à análise outros motivadores possíveis para as F\&As. Além de sinergia (engloba diversos fatores que podem resultar em criação de valor), consideram hubris e conflitos de agência (empire buiding ou managerialism). Ambos são motivadores de F\&As, mas quando presentes levam a perda ou não criação de valor. Os autores concluem que, em sua amostra, F\&As foram realizadas em busca de sinergia, mas que também há indícios de que F\&As também foram motivadas devido a problemas de agência e hubris, sendo o problema de agência notado com maior intensidade que hubris. 
Tem havido aumento de interesse em pesquisas que abordam a criação de valor em F\&As devido a transferências de ativos intangíveis e de como eles podem determinar a criação de valor e estratégias corporativas (empresas podem ter que optar entre, por exemplo, desenvolver determinada competência internamente ou obter no mercado via aquisição de outra empresa detentora dessa competência, ou mesmo podem ter que escolher entre iniciar uma operação totalmente nova em um novo mercado ou comprar empresa já atuante naquele mercado). Alguns estudos indicam que parece haver criação de valor quando há a possibilidade de complementariedade de recursos (ou competências, habilidade, know-how) e que as empresas adquirentes, por isso, incorporam alvos com ativos intangíveis desenvolvidos (ou diferenciados) que elas possam usar e aplicar em suas operações já existentes ou adquirem empresas alvo com deficiências que podem ser sanadas com a migração de recursos intangíveis próprios (CAPRON; DUSSAUGE; MITCHELL, 1998) (ANAND; DELIOS, 2002) (UHLEMBRUCK; HITT; SEMADENI, 2006).

Seguindo o mesmo conceito, Capron e Pistre (2002) evidenciam que quando recursos são transferidos da empresa alvo para as adquirentes não existe criação de valor para os acionistas destas empresas (talvez devido a existência de concorrência pela compra da empresa alvo). Ao contrário, quando os recursos são transferidos da empresa adquirente para a empresa alvo pode-se esperar criação de valor para os acionistas da empresa adquirente (nesses casos haveria concorrência menor para aquisição da empresa alvo, já que os recursos a serem transferidos seriam limitados à empresa adquirente somente, ou seriam limitados a um número menor de potenciais compradores).

Os estudos de Anadrade, Mitchell e Stafford (2001), Hafrod (2005) e McNamara, Haleblian e Dykes (2008) focam seu trabalho em ondas de F\&As, ou seja, em períodos em que há concentração significativamente maior de transações desse tipo. Concluem, por exemplo, que ondas de F\&As são causadas por choques (econômicos, de regulamentação ou desregulamentação, tecnológicos) em determinadas indústrias e que parecem não ser resultado de tentativa de gestores de aproveitar momentos de mercado em alta, ou seja, aproveitar momentos de sobre valorização das ações próprias para financiar a compra de outros negócios. Também chegam a resultados que indicam que a criação de valor para os acionistas de empresas adquirentes pode estar associada ao momento, dentro da onda, em que a F\&A é realizada. Assim, F\&As realizadas no início de ondas resultariam em criação de valor, enquanto que F\&As realizadas no final de ondas resultariam em destruição de valor. 
Apesar do trabalho de Harford (2005) chegar à conclusão de que ondas de F\&As não são geradas por gestores que querem se aproveitar de momentos de sobre valorização de suas ações, existem teorias que propõem justamente isso: erros do mercado na precificação de ativos podem incentivar F\&As. Na verdade, Rhodes-Kropf e Viswanathan (2004) afirmam que erros de precificação (desvio do valor de mercado em relação ao valor fundamental) tem impacto significante nessa questão: erros de precificação (tanto para empresa adquirente como alvo) afetam tanto a forma de pagamento da transação de fusão como a probabilidade de sua ocorrência, havendo correlação entre a atividade de fusões e valorização de mercado. Shleifer e Vishny (2003, p. 296) apresentam modelo semelhante que considera que os mercados são ineficientes e, por isso, existem empresas cujas avaliações de valor pelo mercado estão erradas. Por outro lado, seu modelo considera que os gestores de empresas são racionais e que se aproveitam desses erros de valorização por meio de fusões, sendo F\&As uma forma de arbitragem praticada por gestores racionais em mercados ineficientes.

Rhodes-Kropf, Robinson e Viswanathan (2005, p. 562) mostram que erros de precificação de empresas afetam a atividade de F\&As, a decisão de ser uma empresa adquirente ou alvo e o meio de pagamento da transação. Resultados semelhantes também são obtidos por Chidambaran, John e Shangguan (2010, p. 330) que mostram que momentos de intensa intensidade de F\&As, as ações das empresas adquirentes estão sobre valorizadas, há mais utilização de pagamento via troca de ações e que os retornos para os acionistas das empresas adquirentes são menores.

A possibilidade de mercados imperfeitos e, mais precisamente a existência de erros de precificação ${ }^{4}$, cada vez mais passa a fazer parte dos estudos na área de finanças, sendo exemplos desses estudos Yoshinaga, Castro e Securato (2010), Zhang (2008), Baker e Wurgler (2006), Hirshleifer (2001) e Daniel, Hirshleifer e Subrahmanyam (1998). Relacionado a F\&As e de certa forma similar ao trabalho de Chidambaran, John e Shangguan (2010), Bouwman, Fuller e Nain (2009) focam seu estudo nas condições do mercado no momento em que as F\&As são anunciadas e verificam que essa variável tem influência na criação de valor para os acionistas das empresas adquirentes: em momentos de mercado em alta, existe criação de valor significativamente maior que em momentos de mercado em baixa

\footnotetext{
${ }^{4}$ Esse conceito está diretamente relacionado com o termo sentimento de mercado, que será melhor apresentado durante a revisão de literatura.
} 
para os acionistas das empresas adquirentes. Por outro lado, Batista e Minardi (2010) fazem estudo semelhante para F\&As ocorridas no Brasil entre 1986 e 2007 e encontram resultados contrários.

\subsection{Definição do Problema de Pesquisa e Objetivos}

Essa dissertação tem como cerne de seu trabalho o seguinte problema de pesquisa: A criação de valor em processos de fusão e aquisição é influenciada pelo sentimento do mercado no momento em que é anunciada?

Assim, o objetivo principal desse trabalho é analisar a criação de valor em processos de fusão e aquisição para os acionistas de empresas adquirentes listadas na Bovespa, que foram anunciados ao mercado entre janeiro de 2001 e dezembro de 2011. Nesse estudo, será analisado se essa criação (ou destruição) de valor é influenciada pelo sentimento de mercado no momento em que a operação se torna pública. Serão considerados três níveis de sentimento de mercado: sentimento de mercado em alta (ou períodos de exacerbado otimismo, bonança ou ainda bull market), sentimento de mercado em baixa (ou períodos de exacerbado pessimismo, recessão ou ainda bear market) e sentimento de mercado neutro ou normal (nem em alta e nem em baixa). 


\section{REVISÃO DA LITERATURA}

\subsection{Definição e Tipos de Fusões e Aquisições}

Existem duas formas para que a propriedade e controle de empresas sejam transferidos: a empresa é adquirida por algum grupo de pessoas ou mesmo por outra companhia ou a empresa se funde a outra firma, havendo assim a combinação dos negócios ${ }^{5}$. Apenas para simplificar, ambas as situações serão denominadas de tomada de controle, ou melhor, takeover $^{6}$ (esse termo, assim como F\&As, aquisições, fusões serão usados neste trabalho de forma indistinta e com mesma conotação). Costuma-se denominar a empresa que assume o controle de empresa adquirente, acquirer ou ainda bidder enquanto que a empresa vendida é chamada de empresa alvo, empresa adquirida ou ainda empresa target (BERK; DEMARZO, 2009, p.891)

As F\&As costumam ser classificadas segundo suas características, havendo algumas classificações distintas. As classificações mais comumente usadas se baseiam na forma de pagamento e na semelhança ou relação comercial entre empresa alvo e empresa adquirida.

Em se tratando de forma de pagamento, as operações de F\&A são classificadas em operações com pagamento em caixa, troca de ações (ações da empresa adquirida e da empresa alvo) ou alguma combinação dos dois casos (BERK; DEMARZO, 2009, p.893).

No segundo caso, costumam-se dividir F\&As em horizontais, verticais e conglomerados. Essa segunda classificação está baseada fortemente em conceitos da área da estratégia, mais especificamente no conceito de fronteiras da firma (ou boundaries of the firm), que por sua

\footnotetext{
${ }^{5}$ Segundo Pronunciamento Técnico 04 do Comitê de Pronunciamentos Contábeis, o termo combinação de negócios deve ser entendido como sendo: “uma operação ou outro evento por meio do qual a adquirente obtém o controle de um ou mais negócios, independentemente da forma jurídica da operação.” No mesmo pronunciamento, o termo controle é definido da seguinte forma: “A entidade controla um ativo quando detém o poder de obter benefícios econômicos futuros gerados pelo recurso subjacente e de restringir o acesso de terceiros a esses benefícios.”

${ }^{6}$ Note que o verbo "to take over" pode ser traduzido como: “suceder em, assumir a direção de, tomar conta de (em substituição de um outro), (...)”(VALLANDRO; VALLANDRO, 1957).
} 
vez está intimamente relacionado ao que a empresa faz, quão grande essa empresa deve ser e em que ramo de negócio ela deve estar inserida (BESANKO et al, 2008, p. 5).

As fusões horizontais ocorrem quando tanto a empresa adquirente como a empresa adquirida atuam no mesmo mercado. Ao contrário, as fusões por conglomerados envolvem empresas com atuação em mercados diferentes e são ditas empresas de atuação não relacionada ${ }^{7}$. Já as fusões verticais ocorrem quando operam na mesma indústria, mas em pontos distintos da cadeia de valor ou cadeia de suprimento e são frequentes os casos onde a adquirente compra uma empresa que é seu fornecedor ou seu cliente (BERK; DEMARZO, 2009, p.893).

Segundo o prisma estratégico, Besanko et al (2008, p. 6) apresenta definição semelhante:

As fronteiras da firma podem ser extendidas em três direções; horizontal, veritical e corporativa. A fronteira horizontal da firma está relacionada com o quanto do mercado de seu produto ela atende, ou essencialmente, quão grande ela é. As fronteiras verticais definem quais atividades a empresa realiza e quais atividades ela subcontrata ou adquire de outras empresas. As fronteiras corporativas são definidas pela quantidade de diferentes negócios em que a empresa atua ${ }^{8}$. (BESANKO et al, 2008, p.6)

Segundo Weston, Mitchell e Mulherin (2003, p.6), as F\&As horizontais ocorrem especialmente motivadas por duas razões: busca de maior competitividade (alcançada por maior eficência operacional obtida principalmente por ganhos de escala) e por aumento de poder mercado. Já as F\&As verticais podem ser motivadas por um grande número de fatores. Normalmente, têm o objetivo de reduzir custos associados pela convergência de interesses entre empresa adquirida e adquirente e pela melhoria de processos tais como: tecnológicos (produção fisicamente integrada ou eliminação de transporte de produtos semi-acabados), eliminação de custos relacionados a gestão da área de compras, contratos e pagamentos, melhoria nas atividades de planejamento e produção.

\footnotetext{
${ }^{7}$ Rumelt (1974, apud Seth, 1990b, p. 100) apresenta um conceito mais abrangente de empresa relacionada: empresas podem ser consideradas relacionadas quando uma habilidade, recurso, mercado ou propósito são comuns a ambas as empresas, ou seja, se empregam técnicas de produção similares, atendem a mercados parecidos, utilizam sistemas de distribuição de mesmas características.

8 “The firm's horizontal boundaries refer to how much of the product Market the firm serves, essentially how big it is. The firm's vertical boundaries refer to the set of activities that the firm performs itself and those that it purchases from market specialty firms. The firm's corporate boundaries refer to the set of distinct business the firm competes in.”
} 


\subsection{Ondas de Fusões e Aquisições}

O mercado de takeovers é caracterizado por ondas de F\&A, que são determinados momentos de alta concentração de negócios, normalmente seguidos por momentos com poucas transações, conforme mostra o Gráfico 2. Muitas das condições tecnológicas e econômicas que determinam mercados em alta (bull market) também motivam gestores a rever seu portfólio de ativos através de F\&A. Assim, as mesmas condições que geram expansão econômica muito provavelmente também impulsionam a atividade de F\&A (BERK; DEMARZO, 2009, p.891). As ondas de F\&As têm existido na vida econômica dos Estados Unidos desde o século 19 e, segundo Stearns e Allan (1996, p. 699), mais de 50\% das aquisições realizadas nos cem anos anteriores a seu trabalho ocorreram durante as quatro ondas de F\&A (no início do século vinte, década de 1920, década de 1960 e década de 1980).

\section{Gráfico 2 - Percentual de empresas públicas adquiridas por trimestre}

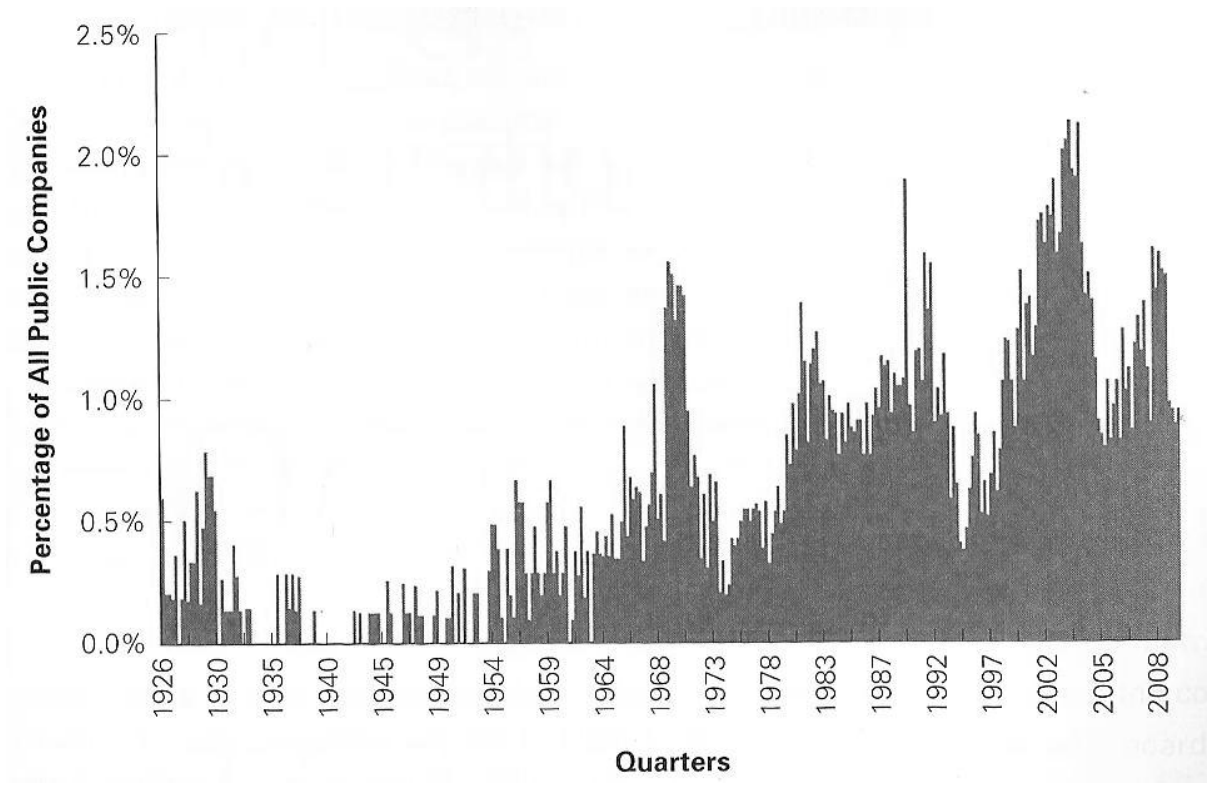

FONTE: BERK; DEMARZO, 2009

Harford (2005) apresenta duas teorias que tentam explicar o surgimento de ondas de F\&A, cada qual respaldada sobre estudos anteriores que tentam evidenciar sua aderência à realidade. A primeira teoria é chamda de teoria neoclássica e considera que uma onda de fusões e aquisições em determinada indústria é a reação coletiva do mercado na tentiva de reorganizar os ativos disponíveis após algum tipo de choque econômico-tecnológico-regulatórico. Por outro lado, motivada pelos trabalhos teóricos que encontraram correlação positiva entre 
atividade de F\&As e valor das ações, surge a teoria comportamental argumentando que uma parcela significativa da atividade de F\&As é impulsionada pelo valor das ações; em momentos em que o mercado erra na avaliação do valor de determinada empresa, gestores racionais percebem o desvio no preço das ações e praticam F\&As como uma forma de arbitragem (SHLEIFER; VISHNY, 2003, p. 296).

A primeira onda ocorreu no início do século 20 com fusões horizontais, onde foram criadas empresas enormes, se destacando aquelas com atuação nos mercados de petróleo, aço e mineração. A segunda onda se inicia a partir de 1920 e teve como principal característica um movimento de cresimento vertical (entre empresas que tinham relação passada de fornecedor e cliente) com o objetivo de aumento de controle sobre recursos escassos e de ganho operacional (MCNAMARA; HALEBLIAN; DYKES, 2008, p. 113).

Além desses dois primeiros momentos de alta atividade em F\&As, Berk e DeMarzo (2009, p.892) destacam quatro momentos posteriores que também podem ser classificados como ondas de F\&A: 1960, 1980, 1990, 2000, sendo cada um deles caracterizado e motivado por fatores distintos. A primeira dessas ondas (1960) é conhecida por onda dos conglomerados sendo a principal característica a predominância de fusões e aquisições envolvendo empresas não relacionadas, ou seja, atuantes em mercados diferentes.

O efeito de diversificação é ainda mais intenso em conglomerados do que em empresas ditas diversificadas, já que estas apesar de atuarem em diversos mercados, normalmente são concentradas em um mercado ou negócio apenas. Os conglomerados, por sua vez, dividem uma grande porção de suas atividades econômicas em distintas indústrias e negócios (GAUGHAN, 2010, p. 44). Weston e Mansinghka (1971, p. 928) sugerem que os conglomerados buscavam essa maior diversificação para evitar: (i) variabilidade de vendas e lucros, (ii) desenvolvimento de crescimento adverso, (iii) mudanças competitivas adversas, (iv) obsolescência tecnológica e (v) incertezas crescentes em sua indústria. Segundo Berk e DeMarzo (2009, p.892), outro fator importante para o movimento de conglomerados foi a crença naquele período de que a experiência dos gestores poderia ser levada aos diferentes negócios facilmente e de que haveria vantagens financeiras interessantes advindas da formação de conglomerados. 
Em 1980 as aquisições têm característica contrária à criação de conglomerados: surge um movimento de aquisições hostis de empreendimentos de desempenho insatisfatório, cujo principal objetivo foi a revenda posterior do mesmo empreendimento, de forma fragmentada em unidades menores com valor total superior ao de compra (BERK; DEMARZO, 2009, p. 892). Outra característica dessa onda é o crescimento dos compradores financeiros (financial buyers) e de compras alavancadas (leveraged buyouts ou LBOs). Nessas operações a compra de empresas abertas se dava por meio da utilização substancial de dívidas; uma vez tomado controle da empresa adquirida, buscava-se melhorar a eficiência operacional, fazer o pagamento da dívida via fluxo de caixa operacional e, finalmente, realizar os lucros tornando as empresas públicas (abertas) novamente (WESTON; MITCHELL; MULHERIN, 2003, p. 176).

Esses autores afirmam que a terceira onda ocorre na década de 1990, quando muitos negócios estratégicos e de âmbito global ocorrem motivados principalmente para aumentar a capacidade competitiva e possibilitar que essas empresas atuem globalmente (WESTON; MITCHELL; MULHERIN, 2003, p. 892). Segundo Weston, Mitchell e Mulherin (2003, p. 178), nesse período sete forças contribuíram para que essa onda atingisse o maior nível de atividade até então: (i) inovações tecnológicas (computação e softwares, sistemas de micro ondas e fibra ótica, internet), (ii) fenômeno da globalização (melhora da comunicação e transporte possibilitaram a integração de vários mercados), (iii) processos de desregulamentação em diversas indústrias, (iv) ambiente econômico favorável, (v) método de pagamento (muitas fusões de porte elevado foram realizadas por meio de troca de ações), (vi) programas de recompra de ações (como meio para sinalizar perspectivas futuras favoráveis) e (vii) programas de stock options.

Por fim em 2004, começa a surgir nova onda marcada por um processo de consolidação em algumas determinadas indústrias como telecomunicações e software (BERK; DEMARZO, 2009, p.892). Além desse fenômeno de consolidação também percebe-se um aumento na atividade de F\&A liderada por empresas de private equity, que perceberam uma oportunidade em sua atividade dadas as condições de baixas taxas de juros nos Estados Unidos (como resposta a período de rescessão após os atentados de 7 de setembro) e movimento de valorização dos mercados de capitais e imobiliário. Naturalmente essa onda chega a seu fim quando se inicia a crise do subprime em 2007. (GAUGHAN, 2010, p.73) 


\subsection{Motivações que Fomentam Fusões e Aquisições}

Em condições de equilíbrio de mercado, para o investidor comum, a compra de ações deveria ser um investimento de valor presente líquido (VPL) nulo. Tendo em vista essa afirmação, pergunta-se porque F\&As são realizadas mesmo quando o VPL esperado é nulo? Ou mesmo em cenários ainda mais adversos, porque F\&As são realizadas se normalmente o valor da compra excede o valor de mercado, o que tornaria o VPL esperado negativo? Na verdade, F\&As ocorrem quando a empresa adquirente acredita ser capaz de adicionar valor econômico por meio da aquisição, o que o investidor comum não seria capaz de fazer. Esse incremento de valor é resultante de sinergia criada pela combinação das duas empresas, sendo essa razão a mais usada para justificar a aquisição de outra empresa, mesmo havendo necessidade de pagamento de prêmio adicional ao valor de mercado da empresa adquirida. (BERK; DEMARZO, 2009, p.894).

Segundo Bradley, Desay e Kim (1988, p.4), espera-se que a aquisição do controle da empresa adquirida permita a empresa adquirente redefinir a utilização dos ativos conjuntos das duas empresas em busca de obtenção de maior valor.

Para Seth (1990b, p. 432) o conceito de criação de valor em F\&As é sinônimo ao conceito de sinergia. Sinergia existe quando o valor das empresas combinadas é maior do que a soma do valor das empresas separadas. Bradley, Desay e Kim (1988, p.4) têm visão semelhante sobre a definição de sinergia aplicada à criação de valor em F\&As: para eles, sinergia é a soma da alteração dos valores das empresas adquirente e adquirida para seus respectivos acionistas.

A sinergia e sua consequente criação de valor é criada a partir de duas fontes: a primeira é o aumento de receita que ocorre quando a união das duas empresas cria a oportunidade de atuação em novos mercados e com novos produtos ou ampliação da base de clientes e consumidores; a segunda, denominada sinergia por redução de custos, é usualmente obtida pela eliminação de áreas duplicadas e otimização da utilização dos recursos remanescentes (BERK; DEMARZO, 2009, p.893). Bradley, Desay e Kim (1988, p.4) elecam diversos fatores que podem resultar em criação de valor devido à combinação de duas empresas: gestores mais eficientes, economias de escala, melhoria nos processos produtivos, a combinação de recursos 
complementares, a redistribuição de ativos e seu melhor aproveitamento e a exploração de aumento de poder de mercado.

Frente às inúmeras fontes distintas que podem culminar em sinergia e criação de valor, Hoberg e Phillips (2010, p. 3774) ressaltam que a importância da sinergia para o sucesso de uma fusão está condicionada à existência de habilidades ou tecnologias na empresa alvo que permitirão a empresa adquirente diferenciar seus produtos dos rivais e aumentar sua rentabilidade.

A seguir são discutidos com um pouco mais de ênfase alguns dos mais importantes motivadores de F\&As.

\subsubsection{Economias de Escala e de Escopo}

Grandes empresas podem se beneficiar de economia de escala, quando conseguem alcançar custos unitários inferiores em função do grande volume de produção de um bem ou de um serviço prestado. Os ganhos de escopo são relacionados aos ganhos de custo obtidos pela combinação dos processos de marketing e distribuição de dois produtos distintos. (BERK; DEMARZO, 2009, p.895).

Weston, Mitchell e Mulherin (2003, p.133) comentam que diversas fontes de ganhos de escala podem resultar das F\&As em função do aumento do tamanho da empresa. Esse aumento possibilita haver, por exemplo, ganho de escala de natureza técnica ou de engenharia, normalmente relacionado à melhor utilização de recursos em termos de volume e área. Uma empresa maior também pode se beneficiar de economia de escala no gerenciamento de estoques já que geralmente a relação do investimento em estoque sobre quantidade vendida tende a diminuir quanto maior forem as vendas. Por fim, o ganho de escala também pode ser consequência da possibilidade de empresas maiores especializarem seus recursos em tarefas únicas ou em número reduzido de tarefas, aumentando assim a produtividade de seus recursos.

Economias de escopo, por outro lado, permitem a empresa produzir novos bens ou prestar serviços adicionais com custo mais reduzido porque sua produção ou prestação de serviço é 
de alguma forma relacionada a produtos e serviços já existentes (WESTON; MITCHELL; MULHERIN, 2003, p.133).

Enquanto economias de escala são normalmente definidas em termos de uma função decrescente de custo médio, economias de escopo são normalmente definidas em termos do custo total relacionado à produção de uma variedade de produtos em uma mesma empresa (ou prestação de uma variedade de serviços por uma mesma empresa) em relação ao custo de produção dos mesmos produtos individualmente em empresas distintas (BESANKO et al, 2008, p. 43).

No entanto, em se tratando de F\&As, é importante fazer a seguinte ressalva: apesar de muitos gestores justificarem processos de F\&As baseados em ganhos de escala e escopo potenciais resultantes do maior tamanho empresa combinada, não há garantia alguma que esses ganhos existirão ou que existirão na magnitude almejada. Em alguns casos, maior pode significar menor eficiência. É necessário, portanto, parcimônia na identificação exata das fontes de ganhos de escala e escopo; também é necessária uma avaliação criteriosa da magnitude do benefício potencial esperado (BESANKO et al, 2008, p.44).

\subsubsection{Concentração Horizontal e Poder de Mercado}

Segundo Devos, Kadapakkam e Krishnamurthy (2009, p. 1184) , a literatura nas áreas de finanças e economia reconhece há muito tempo que empresas podem elevar o valor de seu patrimônio líquido exercendo poder de mercado. Grandes empresas em um mesmo mercado ao se fundirem, podem diminuir de forma significante a competição naquele mercado, permitindo que elas controlem e elevem o preço de seus produtos e serviços a consumidores e clientes.

No entanto, os estudos realizados que tentam analisar o impacto do aumento de poder e mercado sobre criação de valor não são conclusivos, havendo resultados favoráveis e contrários a essa relação. Somente em estudos de algumas indústrias específicas, pode-se confirmar que o aumeto de poder mercado resultou em aumento de valor (DEVOS; KADAPAKKAM; KRISHNAMURTHY, 2009, p. 1184). 
Bhattacharyya e Nain (2011) expandem o conceito acima ao focar seu estudo do impacto sobre o aumento de poder de mercado sobre fornecedores (e não clientes e consumidores apenas). Eles afirmam que a literatura organizacional já evidencia a importância em ser um grande comprador: tamanho do comprador e concentração da indústria dos compradores resultam em lucros menores para a indústria fornecedora. Nesse seu trabalho, os autores encontram fortes evidencias de que F\&As horizontais criam poder de mercado e que os fornecedores dependentes tem seu desempenho impactado.

No entanto, existem dois fatores que contribuem para que essas situações não ocorram de forma muito acentuada: o primeiro deles é o fato de muitos mercados (países) adotarem leis antitrustes, que visam justamente impedir que seus mercados fiquem concentrados demasiadamente em poder de poucos participantes; o segundo é o fato de que apenas a empresa adquirente arca com o custo de eliminar um participante do mercado por meio de aquisição de competidores (nos casos onde há vários participantes), mas todos os demais competidores também se beneficiam da redução de concorrência, apesar do custo onerar somente a empresa adquirente. (BERK; DEMARZO, 2009, p.896).

\subsubsection{Diversificação}

Apesar de haver argumentações contrárias, muito se utiliza o argumento de que empresas podem aumentar o valor para seus acionistas ao adquirir empresas com produtos e serviços distintos e atuantes em mercados diferentes uma vez que o risco total do negócio combinado seria menor que o risco da empresa adquirente sozinha. Assim, poder-se-ia justificar o processo de F\&A e criação de valor para o acionista por meio da redução de risco do negócio. No entanto, esse argumento é normalmente rejeitado pelo fato de que os acionistas não necessitam que suas empresas façam a diversificação e promovam dispendiosos recursos no processo de aquisição e fusão com outras empresas; basta que eles próprios diversifiquem seus portfólios pessoais e passem a ser acionistas das empresas que julgarem mais apropriadas para alcançar eventual diversificação almejada (BERK; DEMARZO, 2009, p.897).

No entanto, de acordo com Seth (1990a, p. 434), o benefício da diversificação não se reflete em menor risco para o acionista, mas sim em maior estabilidade do fluxo de caixa das empresas combinadas (conceito de coseguro ou coinsurance). Essa maior estabilidade do fluxo de caixa pode fazer com que o ponto de endividamento ótimo da empresa combinada se 
torne maior, aumentando sua capacidade de se endividar, trazendo ganhos fiscais e elevando o valor do patrimônio líquido (mesmo sendo descontados eventuais custos incrementais relacionados ao aumento do nível de endividamento).

\subsubsection{Qualidade dos Gestores e Outros Ativos Intangíveis}

Existem casos onde há uma má administração do negócio e consequente não maximização de seu fluxo de caixa e valor de mercado. Embora os acionistas de empresas "má” administradas possam em teoria perceber esse fato e trocar seus gestores, isso não ocorre com a frequência esperada. Para esses casos, um terceiro agente, uma empresa adquirente, pode comprar o controle da empresa com gestão deficiente. Pode então impor novos gestores, estabelecer uma administração mais eficiente, melhorar o desempenho e incrementar o fluxo de caixa do negócio, resultando em aumento do valor de mercado (BERK; DEMARZO, 2009, p.896). Assim, Jensen e Ruback (1983, p. 32) afirmam que, apesar de não ser um controle perfeito, F\&As têm papel importante para evitar que as empresas sejam administradas por seus gestores com um grau de ineficiência demasiadamente alto. ${ }^{9}$

Segundo Copeland, Weston e Shastri (2005, p. 760) o ganho de eficiência também pode ocorrer de forma contrária. Isso ocorre quando a empresa adquirente busca, por meio da aquisição de outros negócios, incorporar gestores mais eficientes que poderão melhorar a forma como sua empresa é administrada. Em ambas as situações, a criação de valor não é resultante de qualquer sinergia operacional, mas apenas da transferência de competências, ou gestores mais capacitados para a empresa menos eficiente. Seth, Song e Pettit (2000, p. 389) tratam de conceito similar que pode ser facilmente extendido a qualquer processo de fusão e aquisição, embora seu estudo seja relacionado a aquisisições internacionais. Eles apresentam o conceito de internalicionalização reversa: empresas adquirem habilidades e recursos através de aquisições internacionais esperando que sejam benéficos a suas operações locais (nacionais).

Como visto acima, a competitividade da empresa (tanto da adquirente, como da adquirida) pode ser influenciada diretamente pela qualidade de seus gestores. Por isso, atribui-se valor a

\footnotetext{
${ }^{9} \mathrm{O}$ mesmo conceito, F\&As como ferramenta de controle e de substituição de gestores ineficientes, já foram considerados nos estudos iniciais nessa área: Manne (1965, p. 113) e Alchian e Demsetz (1972, p.788).
} 
essa qualidade de gestores que pode ser classificada como um ativo intangível da empresa. Sobre os ativos intangíveis ${ }^{10}$, Patrocínio, Kayo e Kimura (2007, p. 206) afirmam:

Quando se fala em aumento da competitividade, é muito comum falar-se também dos ativos intangíveis. Afinal, esses ativos proporcionam a seus proprietários fontes importantes de diferenciação e, portanto, de vantagem competitiva sustentável. Devido a isso, há indicações de que a incorporação de intangíveis seja, atualmente, uma das principais motivações para a realização de operações de fusões e aquisições.

Gupta e Roos (2001, p. 297) também afirmam que ativos intangíveis cada vez mais são os motivadores principais de F\&As que buscam efeitos de sinergia a partir da transferência de conhecimento, competências estratégicas e tecnológicas. Da mesma forma, Arikan (2002, apud Patrocínio, Kayo e Kimura, 2007, p. 207), e Anand e Delios (2002, p. 131) têm todos pensamento semelhante sobre esse tema. Para eles, os ativos intangíveis se apresentam como fonte importante de vantagem competitiva e, quando não podem ser desenvolvidos internamente, passam a ser incorporados por meio de F\&As.

Reforçando a importância de ativos intangíveis, Capron, Dussuage e Mitchell (1998) desenvolvem seu trabalho sobre o conceito de resource-based view ( $R B V$ ou empresas baseadas em recursos) que difere em alguns pontos da corrente tradicional de pesquisa. Esta enfatiza que fusões horizontais ocorrem para aumentar o poder de mercado e a eficiência (ganho de escala). Aquela considera que o diferencial competitivo das empresas advém da singularidade de seus recursos, que precisam ser “ajustados” ou reconfigurados com o passar do tempo justamente para que seja possível a manutenção desse diferencial competitivo. Por outro lado, muitas empresas encontram dificuldade para diferenciar seus recursos seja tentando copiar recursos de terceiros ou desenvolvendo internamente recursos próprios. Assim, elas recorrem ao mercado, também por meio de F\&A, para adquirir recursos novos e novos meios onde possam empregar seus recursos atuais. Os autores argumentam que devido a certas falhas no mercado, muitas vezes as empresas optam por adquirir negócios ou

\footnotetext{
${ }^{10}$ Segundo Kayo (2002, p. 19), também apresentado em Kayo e Famá (2004, p. 165) e em Patrocínio, Kayo e Kimura (2007, p. 206), existem quatro famílias de intangíveis: "os ativos humanos, os ativos de inovação, os ativos estruturais e os ativos de relacionamento com públicos estratégicos. Dos ativos humanos podem fazer parte o conhecimento, o talento, a capacidade, a habilidade e a experiência dos empregados, a administração superior, o treinamento e o desenvolvimento, entre outros. Os ativos de inovação podem ser formados pela pesquisa e desenvolvimento, pelas patentes, pelas fórmulas secretas, pelo know-how tecnológico, entre outros. Os ativos estruturais podem ser formados por software proprietários, por bancos de dados, por sistemas de informação, por sistemas administrativos, entre outros. Por fim, os ativos de relacionamento com públicos estratégicos podem ser formados por ativos como as marcas, os direitos autorais (de obras literárias, de software, etc.), os contratos de licenciamento, os contratos de franquias, os direitos de exploração mineral, entre outros. Como se percebe, a lista de ativos pode ser interminável.”
} 
empresas inteiras mesmo que estejam buscando recursos específicos, já que o processo de compra isolada desses recursos específicos parece ser muitas vezes não possível ou demasiadamente custoso.

Esses autores estudam cinco categorias de ativos intangíveis relacionados à (i) pesquisa e desenvolvimento, (ii) manufatura, (iii) marketing, (iv) gestão e (v) finanças e estudam a migração desses ativos entre empresa adquirente e adquirida após F\&As. Eles constatam que existe migração dos três primeiros ativos em ambos os sentidos (de e para a empresa alvo), mas que ativos relacionados à gestão e finanças normalmente migram para a empresa alvo apenas. Outra constatação, talvez mais importante, é de que parece haver relação entre o sentido da migração de recursos e o nível de desenvolvimento relativo desses recursos na empresa adquirente e na empresa alvo antes da F\&A. Parece que as adquirentes incorporam alvos com ativos intangíveis desenvolvidos (ou diferenciados) de forma a utilizar esses novos recursos em sua operação atual e que empresas adquirentes buscam empresas alvo com deficiências que podem ser sanadas com a migração de seus recursos intangíveis (Capron, Dussuage e Mitchell, 1998).

Um exemplo mais claro e específico da relação do RBV com F\&A é o trabalho de Uhlembruck, Hitt e Semadeni (2006). Eles estudam F\&As de empresas atuantes na indústria da internet (chamadas empresas online) por empresas "tradicionais" não ligadas a esse mercado (chamadas empresas off-line). Constatam que há criação de valor para as empresas adquirentes nesses casos e isso ocorre devido à complementariedade de recursos entre as empresas e possibilidade consequente para criação de sinergias. Por um lado as empresas offline se beneficiam, por exemplo, quando a aquisição pode melhorar ou mesmo trazer habilidades que possibilitam explorar a internet como ferramenta de marketing e como ferramenta para ampliar a base de clientes acessíveis; outro exemplo também relacionado aos clientes é a possível melhora na capacidade de extração de informações sobre clientes e seu comportamento. Por outro lado, em muitos casos o negócio da empresa adquirida pode ser beneficiado com o aporte da credibilidade, estabilidade e reputação da empresa adquirente o que aumenta a força e solidifica o posicionamento de sua marca. 


\subsubsection{Conflito de Interesses e Hubris}

Todos os motivadores para realização de F\&As apresentados anteriormente deveriam resultar, ao menos em tese, em melhor desempenho, fluxo de caixa e valor de mercado, beneficiando diretamente os acionistas das empresas adquirentes. (Considerando que o prêmio eventualmente pago na aquisição para os acionistas da empresa alvo não exceda a sinergia total criada na fusão dos dois negócios.)

A seguir são discutidos alguns conceitos de teorias onde $F \& A s$ são realizadas mesmo havendo destruição de valor para o acionista da empresa adquirente.

Shleifer e Vishny (1988, p.14) afirmam que a maximização de valor nem sempre é o objetivo dos gestores. Em certos momentos, eles orientam as decisões de F\&As baseados em suas percepções ou desejos pessoais de que tipos de empresa querem liderar. Por exemplo, caso façam a gestão de um negócio com baixo potencial de crescimento, podem direcionar F\&As no sentido de adquirir negócios com alto crescimento, mudando a dinâmica da empresa resultante da fusão. Muitas aquisições corporativas parecem ter sido realizadas com esse objetivo, mesmo em situações em que os gestores não pareciam ter grande experiência (ou habilidade) relacionada à gestão do negócio adquirido.

O conflito de interesses ${ }^{11}$ ocorre quando os gestores do negócio priorizam seus interesses próprios em detrimento dos interesses dos acionistas. Dessa forma, mesmo sabendo que uma F\&A não trará ganhos suficientes para justificar o investimento relacionado à aquisição, os gestores seguem adiante com a decisão de realizar a aquisição, sabendo que gozarão de maior prestígio, salários e benefícios uma vez que estarão gerindo uma empresa de maior porte. (BERK; DEMARZO, 2009, p.896). Da mesma forma, Jensen (1986, p. 323) afirma que gerentes têm incentivos para fazer "suas" empresas crescerem além do tamanho ótimo, já que esses crescimento aumenta o poder dos gestores ao aumentar a quantidade de recursos sob sua gestão. Quanto ao aumento de salários e benefícios trazidos pelo aumento do porte da empresa, Murphy (1985, p.22) afirma que diversas teorias sugerem que os salários dos executivos são definidos, pelo menos em parte, pelo tamanho da empresa e de seu crescimento, refeletindo a quantidade de recursos administrados por esses executivos e a

\footnotetext{
${ }^{11}$ Segundo Seth, Song e Pettit (2000, p. 403) a hipótese de conflito de interesse de Seyhun (1990) também é chamado de motivo de gerencialismo (ou melhor, managerialism motive) descrito inicialmente por Marris (1964) e por teoria de agência Berkovich e Narayan (1993).
} 
magnitude de suas responsabilidades. Ainda sobre possível incentivo para executivos buscar o crescimento de suas empresas, Baker, Jensen e Murphy (1988, p. 600) afirmam que em indústrias que recompensam gestores por meio de promoções e apresentam baixas oportunidades de crescimento pode haver um incentivo natural para os gestores expandirem as empresas onde atuam, mesmo que por fusões que destroem valor, de forma a criar novas possibilidades de ascensão de carreira.

Da mesma forma, o modelo de entrincheiramento (ou entrenchment) prevê que os gestores de uma empresa também podem priorizar seus interesses próprios por meio de F\&A, mesmo sabendo que a F\&A não é uma ação maximizadora de valor para o acionista. Esses gestores buscam adquirir ativos cujo valor será maximizado sob sua administração, ou seja, cujo valor será menor sob a administração de qualquer outro executivo do mercado. Assim, os gestores conseguem aumentar seu valor para o acionista e tornar mais custosa qualquer tentativa por parte dos acionistas em substituí-los. Mesmo no caso dos acionistas perceberem a perda de valor pela aquisição já realizada, tem como melhor decisão futura a manutenção dos gestores atuais (SHLEIFER e VISHNY, 1989, p. 123).

Berkovitch e Narayanan (1993, p. 350) resumem esses conceitos da seguinte forma: “A idéia básica na maioria dessas explicações é a de que aquisições resultam na extração de valor dos acionistas das adquirentes em favor dos gestores das empresas adquirentes.”

Segundo a teoria de hubris, gestores de empresas adquirentes podem efetivar a aquisição de uma nova empresa baseados em uma avaliação equivocada do real valor da empresa alvo ou baseados em avaliação equivocada da real magnitude de criação de valor das potenciais fontes de sinergia vislumbradas. Assim, pode haver destruição de valor para os acionistas das empresas adquirentes quando o valor da empresa alvo é sobre avaliado.

Em seu renomado trabalho, Roll (1986, p. 199) assume o cenário onde não existem ganhos potenciais devido a sinergias ou devido a qualquer outra fonte em F\&As. Mesmo nessa situação, algumas empresas podem acreditar, talvez por erro de avaliação, que haverá ganhos com a fusão e, em muitos casos, se dispõem até a pagar valor acima do valor de mercado para adquirir a empresa alvo. Para o autor é importante ressaltar que somente será possível observar erros de avaliação que sobre avaliem o valor da empresa alvo. Eventuais erros de avaliação que subavaliarem o valor da empresa alvo serão descartados automaticamente, pois 
nenhuma oferta de aquisição será aceita pela empresa alvo com valor inferior ao valor de mercado.

O autor ressalta ainda que sua teoria de hubris não afirma que os gestores tomam deliberadamente e conscientemente decisões contra os interesses dos acionistas. Segundo ele, para confirmação da teoria basta apenas que os gestores ajam contra os interesses dos acionistas promovendo a aquisição de novas empresas, devido a um erro de avaliação do valor das empresas alvo. (ROLL, 1986, p. 213)

O erro de avaliação pode ocorrer, segundo Berk e DeMarzo (2009, p. 900), porque as pessoas em geral tendem a sobre estimar suas reais habilidades. Esse problema deriva da necessidade das pessoas em vivenciar algumas situações onde elas cometem erros para que possam mudar sua percepção sobre suas próprias habilidades. No entanto, em F\&A isso não é sempre possível já que grande parte dos gestores vivencia e lidera apenas uma grande aquisição durante sua gestão.

Nesse modelo de excessiva autoconfiança por parte dos gestores, considerando o contexto de F\&As, costuma-se ressaltar o conceito de maldição do vencedor (winners' curse), que pode ocorrer quando há uma série de compradores potenciais disputando a aquisição de determinada empresa. Nessa competição, que tem algumas características similares a um leilão, haverá diversas estimativas para o valor da empresa alvo, que estarão provavelmente distribuídas em torno do valor real da mesma. O vencedor dessa disputa será aquele cuja oferta de compra apresenta maior valor; a maldição do vencedor prevê que esse vencedor, justamente por apresentar maior valor em sua oferta, provavelmente terá adquirido a empresa alvo por valor superior ao seu valor real (WESTON; MITCHELL; MULHERIN, 2003, p.135).

\subsection{Eficiência de Mercado}

A Hipótese de Mercado Eficiente (HME) é um conceito importante e vem sendo cada vez mais aceito desde que o interesse por ele renasceu a partir de 1950 e início de 1960 sob o nome de teoria de passeio aleatório (random walks theory) para a literatura de finanças e sob 
o nome de teoria da expectativa racional (rational expectations theory) para a literatura econômica (JENSEN, 1978).

Segundo Malkiel (2003, p. 59) random walks é um termo utilizado para expressar a idéia de que todas as mudanças futuras de preço de determinado ativo serão aleatórias. Isso ocorreria porque mudanças de preço são geradas por novas informações; assim as mudanças de preço futuras serão determinadas por informações novas futuras que, por sua vez, independem das mudanças de preços que ocorrem hoje.

Fama (1965, p. 56) apresenta uma definição inicial para mercado eficiente ainda na década de 1960:

Mercado eficiente é definido como um mercado onde existe um grande número de participantes racionais, maximizadores de lucro e competidores entre si, cada qual tentando prever o valor individual dos ativos; nesse mercado, a informação disponível é acessível quase que gratuitamente a todos os participantes. (...) Em outras palavras, em um mercado eficiente, o preço de um ativo será, em qualquer momento, uma boa estimativa de seu valor intrínseco. ${ }^{12}$

Posteriormente, Fama (1970, p. 383) desenvolve esse conceito e afirma que a principal função do mercado de capitais é alocar o controle do estoque de recursos disponíveis na economia e que o preço dos ativos é uma sinalização de como esses recursos podem ser alocados. Quando esses preços incorporam de forma integral todas as informações disponíveis, o mercado é chamado de mercado eficiente. Fama afirma que é fácil determinar as condições suficientes para que o mercado seja eficiente: (i) não existem custos de transação na negociação de ativos, (ii) todas a informação disponível é acessível sem custo a todos os participantes do mercado, (iii) todos concordam nas implicações da informação disponível sobre o preço e sobre a distribuição de preços futuros possível para cada ativo. É importante ressaltar, que o próprio autor comenta que essas condições são suficientes e não necessárias ${ }^{13}$ para que o mercado seja eficiente (FAMA, 1970, p. 388).

\footnotetext{
12 'An 'efficient' market is defined as a Market where there are large numbers of rational, profit-maximizers actively competing, with each trying to predict future market values of individual securities, and where important current information is almost freely available to all participants. (...) In other words, in an efficient market at any point in time the actual price of a security will be a good estimate of its intrinsic value.”

${ }^{13}$ Mesmo na presença de custos de transações, preços podem refletir toda a informação disponível. Mesmo que alguns participantes do mercado não tenham acesso a todas as informações, o mercado pode ser eficiente se houver uma "quantidade suficiente" de participantes com acesso a toda a informação. Mesmo que haja discordância sobre as implicações de determinada informação sobre o preço de determinado ativo, o mercado pode ser eficiente se não houver participante de mercado que consiga fazer avaliações corretamente de forma consistente (FAMA, 1970, p. 388).
} 
Continuando a desenvolver o conceito, Jensen (1978) considera que um mercado é eficiente quando, dado um conjunto de informações $\theta_{t}$, não é possível realizar transações no mercado baseado em $\theta_{\mathrm{t}}$ e obter consistentemente lucro econômico (ou seja, lucro ajustado pelo risco e líquido de todos os custos relacionados à sua obtenção).

Existem subclassificações da HME que tem sido amplamente discutidas e testadas na literatura; as diferenças entre essas subclassificações derivam normalmente da forma como $\theta_{\mathrm{t}}$ é definido. São três os subgrupos relevantes de informações $\theta_{t}$ que são normalmente considerados: (i) a forma fraca (weak form) considera apenas informações passadas do preço do ativo como informação relevante, (ii) forma semiforte (semi-strong form) onde além do histórico do preço são consideradas todas as demais informações públicas e (iii) forma forte (strong form) que considera toda a informação existente, ou seja, até mesmo informações disponíveis apenas a determinado grupo de pessoas ou empresas e ainda não divulgadas ao público como um todo (FAMA, 1970, p. 383).

Desde então cada subgrupo de informações vem sendo testado intensamente na tentativa de comprovar ou refutar a hipótese de mercado eficiente. Fama (1970) reúne os resultados de diversos trabalhos e testes realizados e conclui que as evidências encontradas até então respaldam a HME:

a) testes de forma fraca: é o teste com maior volume de trabalhos empíricos realizados e, segundo o autor, parece justo afirmar que os resultados corroboram com a teoria. Existem, no entanto, alguns casos em que se detectaram evidências contra a hipótese: dependência estatística entre mudanças de preço sucessivas e retornos em excesso de estratégias como small fiters ${ }^{14}$ versus estratégia buy-and-hold. $\mathrm{O}$ autor considera que ambas as evidências não são fortes o suficiente para comprometer a hipótese, principalmente porque o lucro resultante da utilização de regras de negociação (trading rules) seria muito pequeno e inviabilizaria qualquer ganho anormal quando custos de transação fossem considerados;

b) testes de forma semiforte: os resultados encontrados em estudos analisando a reação do preço de ações a anúncios de novas informações relevantes também apoiam a HME. O autor comenta que apesar de anúncios de poucos tipos de informação terem sido analisados,

\footnotetext{
${ }^{14}$ Para maiores detalhes, consultar Alexander (1961)
} 
esses tipos estão entre os mais importantes o que seria bom indicativo de que os mesmos resultados seriam também encontrados quando os testes fossem estendidos.

c) testes de forma forte: o autor comenta que existem pelo menos duas situações onde a HME pode ser refutada, mas que para a grande maioria dos investidores a HME parece ser um bom modelo da realidade.

Da mesma forma, Jensen (1978) chega a afirmar que não há outra teoria cuja evidência empírica seja mais sólida que para a HME, já que ela foi testada amplamente e, com muito poucas exceções, foi considerada sempre consistente, mesmo com dados obtidos em diversos mercados distintos: Estados Unidos, Austrália, Inglaterra, Alemanha, vários mercados de futuro, títulos privados e governamentais, mercado de opções, dentre outros. No entanto, apesar dessa sua afirmação, na mesma obra o autor comenta que começam a surgir indícios de contraposição à HME. Isoladamente esses indícios talvez não possam refutar a hipótese, mas quando considerados conjuntamente esses trabalhos servem para chamar atenção ao fato de que existem algumas inadequações no conhecimento daquele momento.

Em trabalho posterior, Fama (1991, p. 1576) faz nova revisão de sua discussão sobre o tema e propõem mudanças nos nomes e escopo ${ }^{15}$ dos subgrupos de informação $\theta_{\mathrm{t}}$ : propõe que os testes realizados para analisar a forma fraca sejam renomeados para testes de previsibilidade de retornos, já que eles buscam descartar a HME comprovando que os preços futuros de determinado ativo podem ser previstos com base em dados históricos (além de preços históricos considerados em sua definição inicial, o autor adiciona naquele momento outras informações "históricas" tais como distribuição de dividendos, lucro e taxa de juros). Para os testes de forma semiforte, Fama adota o nome de testes de estudos de eventos já que os estudos de evento têm sido adotados amplamente, até mesmo nos dias de hoje, para analisar eventuais ajustes de preço frente à divulgação pública de novas informações. Finalmente, os testes de forma forte são renomeados para teste de informação privada, apenas para que seu nome se aproxime de seu conceito. Mais importante que a revisão da nomenclatura associada a cada "nível” de HME, talvez seja a atualização da revisão dos novos trabalhos empíricos, principalmente os que confrontam a HME. Apesar das novas evidências em grande parte serem contrários à HME, Fama (1991) ainda defende a hipótese de HME:

\footnotetext{
${ }^{15}$ Apenas o subgrupo forma fraca tem mudança de escopo; os demais apenas têm seus nomes alterados.
} 
a) Com relação aos testes de forma fraca, para janelas de tempo pequenas, o autor considera que as pesquisas mais recentes não refutam a HME. Os indícios de correlação (auto correlação de primeira ordem) de retornos com seus retornos passados são descartados pelo autor seja porque apresentam baixa magnitude, seja porque pode haver outros problemas (relação espúria nos dados analisados ou negociação não sincrônica) que trazem dúvidas sobre a robustez dos resultados. Para janelas de tempo mais longas, que não haviam sido analisadas nos estudos anteriores, o autor não considera os resultados conclusivos devido a seu baixo poder estatístico. Ainda testando a forma fraca, os trabalhos mais recentes contradizem a HME ao evidenciarem que os retornos dos ativos podem ser, ao menos em parte, previstos com base em informações históricas distintas de retornos passados, tais como: nível de dividendo, índices tais como lucro sobre preço etc.;

b) A evidência mais forte de HME é obtida por meio dos estudos de evento que mostram que o preço das ações se ajusta rapidamente a novas informações, ou seja, corrobora com o conceito de HME semiforte e

c) Se confirmam alguns casos onde há ganho anormal para agentes com acesso a informações “privadas” (ainda não divulgadas ao público) e a HME é contrariada.

Como se pode perceber, a partir de 1970 quando a HME ganha notoriedade e principalmente após a década de 1980, inúmeros trabalhos empíricos começam a surgir e evidências a favor e contrárias a hipótese de mercado eficiente são encontradas. Sobre as evidências contrárias, já era possível se esperar que fossem também encontradas, uma vez que nenhuma teoria pode explicar de forma integral todo o conjunto de dados reais existentes. De fato, sobre resultados contrários à HME, vem-se documentando uma série de anomalias para o comportamento dos preços dos ativos. Essas anomalias estão associadas a aparente sub valorização de ativos, sobre valorização de ativos e previsibilidade do retorno de ativos em função de: dia da semana, mês do ano, tamanho da empresa, índice valor de mercado sobre valor contábil (VM/VC), dividendos, lucro e outras variáveis BALL (1994, p. 31).

Devido ao grande número de trabalhos comprovando anomalias contrárias à HME no comportamento do retorno dos ativos, parece não haver dúvidas sobre o fato de que existem 
limitações e lacunas relacionadas à teoria de mercados eficientes e ao conhecimento sobre a forma como o preço dos ativos é determinado BALL (1994, p. 36).

Malkiel (2003) faz uma análise ampla a respeito das anomalias encontradas e faz uma reflexão a respeito da aplicabilidade da HME uma vez que são claras várias de suas limitações. Suas principais considerações são expostas a seguir:

Para ele não se pode argumentar que o mercado seja sempre perfeito e não se pode negar que parece haver influência de fatores psicológicos sobre o comportamento dos preços dos ativos; sem dúvida alguma, alguns participantes do mercado demonstram comportamento não perfeitamente racional e, como resultado, anomalias na formação de preço e até mesmo padrões previsíveis de comportamento do retorno de ativos podem aparecer em certos momentos e perdurar por curtos períodos.

No entanto, Malkiel (2003) faz uma ressalva sobre o uso dos já evidenciados padrões de comportamento de retornos de ativos como argumento para refutar integralmente a HME. Esse argumento pode ser falho ou não totalmente válido por diversos motivos: (i) alguns dos padrões encontrados podem ser dependentes e específicos à amostra e ao período em que foram evidenciados, (ii) podem ser relevantes estatisticamente apenas devido à relação espúria entre as variáveis estudas, (iii) padrões de retornos baseados em medidas de valor de empresas (fundamental valuation measures) podem apenas refletir melhores proxies para medir o risco ${ }^{16}$ e, finalmente, (iv) qualquer padrão "verdadeiro” para estimar retornos futuros de forma repetida e consistente que seja descoberto pelo mercado está fadado a auto destruição por mecanismos de arbitragem ${ }^{17}$ do próprio mercado. Sobre este último ponto, Timmermann e Granger (2004, p. 26) têm a mesma opinião e afirmam que é provável que possa haver, por pouco tempo, ganhos para os investidores que adotam novos métodos de previsão financeira. No entanto, a possibilidade de se manter esse ganho deixa de existir

\footnotetext{
${ }^{16}$ Como exemplo pode-se adotar o tamanho da empresa. Apesar de se ter evidenciado que empresas de tamanho menor tem tendência de gerar retornos mais elevados, pode-se argumentar que esses retornos mais elevados ainda não são ajustados ao maior risco de empresas pequenas. Fama e French (1993) sugerem que o tamanho da empresa pode ser uma proxy melhor para o risco da empresa que o próprio beta.
}

17 Segundo Berk e DeMarzo (2009, p. 64) arbitragem pode ser definida como a prática de compra e venda de bens equivalentes em mercados diferentes com intuito de se aproveitar da diferença de preços entre esses mercados. 
assim que esses métodos passam a ser adotados por outros participantes do mercado e sua informação é incorporada aos preços dos ativos.

Expandido essa sua última ressalva, o autor afirma que qualquer padrão de retorno evidenciado ou irracionalidade de mercado já demonstrada apresentam baixa probabilidade de perdurar e não fornecem a investidor algum um método capaz de obter retornos extraordinários $^{18}$. Assim, ele suspeita que o resultado final não será o abandono da crença de muitos no mercado e em sua eficiência na utilização da informação; no final, o valor verdadeiro dos ativos prevalecerá (MALKIEL, 2003).

\subsection{Finanças Comportamentais e Sentimento de Mercado}

O conhecimento na área de finanças teve um grande avanço desenvolvendo o conceito de racionalidade do investidor que permitiu que fossem propostas teorias tais como: (i) alocação de recursos e formação de portfolios baseados em risco e retorno esperado, (ii) modelos de apreçamento de ativos baseados em risco e (iiii) teorema de Miller-Modigliani. No entanto, parece que algumas lacunas foram deixadas sem explicação pela teoria. Essas lacunas de conhecimento parecem indicar que o ramo tradicional de pesquisas em finanças ainda não resolveu questões como: (i) porque investidores individuais negociam nos mercados, (ii) como é seu desempenho, (iii) como eles escolhem seus portfólios e (iv) porque os retornos variam entre ações por motivos diferentes de seu risco. Como consequência começa a surgir uma nova área de conhecimento chamada finanças comportamentais, que busca explicar fenômenos financeiros com base em comportamentos não racionais entre investidores. (SUBRAHMANYAM, 2007, p.12).

De fato, em sua revisão sobre a literatura sobre esse tema, Subrahmanyam (2007) relata uma série de resultados empíricos associados aos retornos de ações e tendências de comportamento dos investidores individuais e corporativos que vão ao encontro da teoria das finanças comportamentais e, em muitos casos, se opõem à teoria tradicional. São exemplos desses resultados e comportamentos: (i) previsibilidade de retornos futuros em função de

\footnotetext{
${ }^{18} \mathrm{O}$ autor adota a seguinte definição de mercado eficiente como contexto para o termo extraordinário: mercados eficientes não permitem investidores obter retornos acima da média sem se expor a riscos também acima da média (Malkiel, 2003, p. 60).
} 
características não relacionadas a risco, (ii) comportamento ou tendência de retornos não condizentes com a teoria tradicional (momento ${ }^{19}$, correlação negativa de retornos de curto e longo prazo, covariação positiva de ativos agrupados segundo mesma classificação ${ }^{20}$ ), (iii) comportamento não racional dos investidores (decisões influenciadas pelo estado de espírito do investidor, tendência a vender rapidamente ações que valorizam e a demorar demasiadamente para vender ações que perdem valor, pequenos investidores parecem sobre reagir a informações novas e há indícios de que gestores de empresas consideram o grau de valorização das ações de suas empresas quando decidem emitir ou recomprar ações, promover aquisição de outras empresas e definir as fontes de financiamento de seu negócio).

Kahneman e Tversky (1979) analisam empiricamente a tomada de decisão em condições de risco e propõem nova teoria (prospect theory) que diverge da teoria tradicional (expected utility theory) em pontos tais como: (i) as pessoas preferem decisões com certeza (são avessas a risco) quando há possibilidade de ganhos e quando há possibilidade de perdas se portam de forma contrária e preferem situações que envolvem maior incerteza (overweighting of certainty) e, (ii) no processo de avaliação das alternativas, na fase de "edição", há simplificações que podem levar a escolha de uma alternativa não ótima (isolation effect). Assim, os autores afirmam que em seu processo de decisão as pessoas associam valor a variação de valor (ganhos ou perdas) e não à condição final e que também consideram probabilidades (na verdade, pesos para cada alternativa) que diferem das probabilidades reais esperadas; essas condições levariam a decisões contrárias às previstas pela teoria de utilidades esperada, que quando não percebidas e corrigidas pelo tomador da decisão, possibilitam assim a existência de anomalias. (KAHNEMAN; TVERSKY, 1979, p. 277)

Havendo tantos indícios pró e contra as novas idéias relacionadas a finanças comportamentais, o debate sobre sua validade também se tornou mais intenso e seus pesquisadores passaram a defendê-la da seguinte maneira dos argumentos contrários propostos pelos acadêmicos tradicionais.

\footnotetext{
19 Ações com retornos baixo no ultimo ano tendem a ter retornos baixos nos próximos meses e ações com retornos altos no ultimo ano tendem a ter retornos altos nos próximos meses (FAMA; FRENCH, 2008, p. 1653)

${ }^{20}$ Muitos investidores tendem a agrupar ações segundo características comuns (tamanho da empresa, indústria, tecnologia etc.) e passam a tomar decisões de investimento considerando os grupos de ações e não as ações individualmente. Em certas condições, esses investidores podem induzir fatores comuns nos retornos desses ativos classificados em um mesmo grupo, mesmo os fluxos de caixa desses ativos não sendo correlacionados (BARBERIS; SHLEIFER; WURGLER, 2005, p. 284).
} 
Subramnian (2007), Scheleifer (2000) e Long (1990, p. 705) fazem a seguinte defesa: primeiramente, muito se argumenta que os modelos são específicos e que explicam fenômenos particulares; a resposta usada se baseia no fato de que esses modelos explicam melhor o comportamento desses fenômenos, são baseados na real forma como as pessoas se comportam e que há ampla evidência empírica em seu favor. Segundo, costuma-se afirmar que os resultados encontrados em favor da teoria de finanças comportamentais podem ser baseados em dados obtidos por mera chance do acaso (obtidos, por exemplo, por extensiva utilização de data mining em uma vasta quantidade de dados históricos) e não por refletirem algum fenômeno econômico; o contra argumento está baseado na afirmação de que muitos desses resultados contestados já foram validados por outros resultados semelhantes obtidos em épocas diferentes e em outros mercados. Terceiro, mesmo aceitando-se a existência de algumas “anomalias”, a eficiência de mercado seria mantida através de mecanismos de arbitragem que as eliminariam evitando a possibilidade de obtenção de retornos excessivos; seu contra argumento é de que a prática de arbitragem (sem risco para seu agente) é muito limitada quando não impossível uma vez que: (i) existe grande dificuldade em se encontrar ativos equivalentes para realizar o hedge, (ii) há possibilidade de haver perdas (mesmo que temporárias) até a convergência dos preços e (iii) não se pode prever quanto tempo será necessário até que os ativos atinjam os preços considerados corretos. Finalmente, a teoria tradicional não pode ser considerada superior simplesmente porque considera como as pessoas deveriam se comportar, já que os investidores parecem não se comportar dessa forma.

De acordo como Hirshleifer (2001, p.1533), a abordagem puramente racional vem sendo subsumida a uma abordagem que considera a psicologia dos investidores. Seguindo mesma abordagem, Long et al (1990) afirmam que os preços de mercado seriam definidos tanto pela atuação de agentes racionais como de agentes não racionais (noise traders $^{21}$ ). Dessa maneira, uma vez que o papel de arbitragem desempenhado pelos agentes racionais é limitado, os preços dos ativos negociados no mercado também são influenciados pelas expectativas e atuação dos agentes não racionais, o que pode causar uma divergência entre o preço negociado dos ativos e seus valores fundamentais.

De forma parecida, Hong e Stein (1999), propõem a existência de investidores de características diferentes e que, devido a sua forma distinta de atuar no mercado, acabam por

\footnotetext{
${ }^{21}$ O conceito de noise traders é introduzido por Black (1986).
} 
causar a ocorrência anomalias tais como sobre e sub reação dos mercados. Segundo os autores, essas anomalias resultam de três fatores: (i) a difusão lenta de novas informações a respeito do valor das empresas, (ii) existência de investidores que atuam no mercado à medida que tomam ciência dessas novas informações (promovendo alteração dos preços da ações) e (iii) a existência investidores que atuam baseados na alteração histórica dos preços das ações.

Assim, o retorno esperado de ativos é determinado tanto por risco como por erros de avaliação, sendo necessário, portanto, que os modelos de precificação de ativo considerem ambos os fatores (HIRSHLEIFER; 2001, p.1534).

Dessa forma, surgem os termos sentimento de mercado, sentimento ou mesmo investidores sentimentais. Eles passam a indicar a existência da influência de investidores não racionais, servindo para descrever, por exemplo, situações onde há tendência desses investidores para especular, sobre reagir em momentos de otimismo ou em momentos de pessimismo (Baker e Wurgler, 2006) e até mesmo servindo para justificar “bolhas” especulativas (Smidt, 1968, p. 257). De forma mais acurada, pode-se afirmar que esses termos são usados para caracterizar erros de avaliação de investidores e seu impacto nos preços dos ativos. Assim, refletem crenças errôneas de investidores sobre determinados ativos e podem ser expressos pela componente da expectativa sobre o retorno de ativos que não está relacionada com seu valor fundamental (ZHANG, 2008, p. 9) (LEE; SCHLEIFER; THALER, 1991, p.76). 


\section{METODOLOGIA}

\subsection{Fontes de Dados, Definição do Evento e Amostra}

Todas as informações financeiras de mercado (preço diário de fechamento das ações, valor diário de fechamento do índice Ibovespa, receitas, nível de endividamento, valor de mercado da empresa adquirente, valor contábil da empresa adquirente etc.) foram extraídas da fonte de dados ECONOMATICA.

Tal como definido no problema de pesquisa, o evento analisado neste trabalho trata da aquisição promovida por empresas listadas na bolsa de valores (Bovespa) de participação acionária em outras empresas (de capital aberto ou fechado). A amostra de eventos foi definida a partir das informações obtidas na base de dados da Thomson Reuters de operações de fusões e aquisições realizadas no Brasil no período de 2001 a 2011.

Sobre a base original de dados contendo 4.302 eventos distintos, foi realizado um processo de identificação dos eventos para os quais as informações necessárias à realização do estudo estavam disponíveis. Esse trabalho acabou por eliminar a maior parte dos eventos, resultando em uma amostra final que contém 346 eventos. Foram eliminados eventos segundo os seguintes critérios:

1. Exclusão dos eventos cujas empresas adquirentes não eram listadas em bolsa: - 2.271 eventos;

2. Operações cuja situação (status) é classificada como rumor, pretendida ou cancelada: 86 eventos;

3. Retirada dos eventos cujas empresas adquirentes atuem nos setores de "administração de empresas e empreendimentos" e "serviços financeiros e seguros", segundo classificação setorial da Comissão de Valores Mobiliários (CVM): -324 eventos

4. Ação da empresa adquirente de maior liquidez, com índice de liquidez inferior a 2,5\% da ação mais líquida: -437 eventos

5. Patrimônio Líquido da empresa adquirente negativo no balanço do ano anterior ao evento: -8 eventos;

6. Sem valor da operação de F\&A informado: - 653 eventos e

7. Outros (falta de dados, eventos de recompra de ações próprias): -173 eventos. 
Por fim, foi feita uma revisão criteriosa para identificar os eventos sobre cujas empresas adquirentes existem outros fatos relevantes anunciados durante a janela de estudo definida no item 3.2.3. Foram utilizadas as três bases de dados abaixo para identificar esses eventos:

1. A própria base de dados extraída da Thomson Reuters com os eventos de F\&As;

2. Banco de dados obtido na CVM com todos os fatos relevantes anunciados após 2003 e

3. Banco de dados da ECONOMATICA (Notícias) para os anos de 2001 e 2002.

Dessa forma foram criadas duas amostras: (i) amostra completa com 346 eventos incluindo eventos que apresentam sobreposição de efeitos de outros eventos e (ii) amostra sem sobreposição de efeitos com 113 eventos.

\subsection{Estudo de Evento - Emprego Robusto do Método}

\subsubsection{Introdução ao método}

McWilliams e Siegel (1997) afirmam que esse método tem sido usado intensamente nas áreas de finanças e contabilidade para medir o impacto de mudanças de controle corporativo e, de maneira mais ampla, no campo da administração essa forma de análise vem sendo empregada tanto para avaliar efeitos de decisões corporativas endógenas (desinvestimento em determinada região, alteração de foco do negócio corporativo, fechamento de fábricas, decisões de investimento estratégicas etc.), bem como de efeitos exógenos às empresas (mudanças importantes na legislação, mudanças econômico-tecnológicas, desastres naturais etc.).

Usando dados do mercado financeiro, estudos de evento medem o impacto no valor de uma empresa de um evento específico. A utilidade desse tipo de estudo vem do fato de que, dada racionalidade de mercado, os efeitos de um evento serão refletidos imediatamente no preço das ações (MacKinlay, 1997). Reiterando o conceito, Elton et al (2009, p. 416) afirmam que muitos autores aceitam que novas informações a respeito de eventos relevantes são incorporadas rapidamente ao preço da ações e que o estudo de evento tenta identificar quais informações (eventos) influenciam verdadeiramente o preço das ações (valor da empresa) e que tipo de impacto existe (positivo ou negativo). 
O estudo de evento se tornou popular porque ele dispensa a análise de medidas contábeis de lucro, que são criticadas por não serem boas medidas de desempenho em muitos casos, principalmente quando estão sujeitas a manipulação por parte dos gestores do negócio. Por outro lado, preços de ações estão menos sucetíveis a manipulações e considera-se que refletem o valor presente de todos os fluxos de caixa futuros esperados. Portanto, estudos de evento, que são baseados no preços de ações, deveriam medir o impacto financeiro de mudanças relevantes de forma mais eficiente que metodologias baseadas em retornos contábeis. Além disso, outro motivo pelo qual essa metodologia se tornou popular é o fato de que é relativamente simples de ser implementada, porque os únicos dados necessários são: nome de empresas abertas negociadas em bolsa, datas dos eventos e preço de negociação das ações (MCWILLIAMS; SIEGEL, 1997).

Apenas para exemplificar sua relevância fora do contexto acadêmico, MacKinlay (1997) comenta como marco importante na área de finanças corporativas a aceitação do método de estudo de eventos pela Suprema Corte Americana (caso de 1988: Basic, Incorporated vs. Levinson).

MacKinlay (1997) afirma que o estudo de Dolley (1933) pode ter sido o primeiro estudo de evento, embora ainda com metodologia mais simplificada. Nesse mesmo trabalho o autor relata que desde então o método vem sendo aperfeiçoado até que no final da década de 1960 os artigos de Fama et al (1969) e de Ball e Brown (1968) introduziram novos aspectos à metodologia que definiram a base do método utilizado atualmente e que pode ser resumido da seguinte maneira, segundo Elton et al (2009, p. 416)

a) coletar amostra de empresas que tenham tido anúncio inesperado a respeito de um mesmo tipo de evento;

b) determinar o dia preciso da data do anúncio;

c) definir o período de tempo a ser estudado;

d) para cada empresa, calcular o retorno real diário para o período definido em (c);

e) calcular o retorno anormal diário ${ }^{22}$ para cada empresa;

f) calcular o retorno anormal médio diário, considerando todas as empresas da amostra;

\footnotetext{
${ }^{22}$ Retorno anormal diário é definido como a diferença entre retorno real diário, calculado em (d), e o retorno diário esperado. Tem-se adotado diferentes modelos para estimar o retorno diário esperado: Capital Asset Pricing Model (CAPM), Arbitrage Pricing Model (APT), modelo de mercado, retorno de mercado (ou de determinado índice de mercado) (Elton et al, 2009, p 416).
} 
g) acumular o retorno anormal médio diário calculado em (e), de forma a se obter o retorno anormal médio acumulado para o período definido em (c) e

h) examinar e discutir os resultados.

A seguir serão ressaltados alguns pontos importantes necessários para que os resultados obtidos nos estudos de evento possam ser considerados válidos e será apresentado breve detalhamento de parte do método relacionada ao cálculo e avaliação do retorno anormal.

\subsubsection{Premissas e Possíveis Erros de Implementação}

McWilliams e Siegel (1997) apresentam três premissas importantes necessárias à validade do método: (i) eficiência de mercado, (ii) que o evento não tenha sido antecipado e (iii) que não haja efeitos de outros eventos sobre a empresa estudada durante o período de estudo.

Segundo a premissa de existência de eficiência de mercado, afirmam Bromiley, Govekar e Marcus (1988), os preços das ações rapidamente refletem as alterações esperadas para o fluxo de caixa associadas às novas informações divulgadas. Dessa forma, o impacto do evento pode ser mensurado através da alteração no preço das ações no período próximo ao anúncio do evento.

Bromiley, Govekar e Marcus (1988) também comentam que já que os preços de ações incorporam os efeitos (sobre o fluxo de caixa futuro) de todas as informações disponíveis, somente eventos cujo anúncio seja novo e não esperado podem ser avaliados adequadamente por estudos de evento. Confirmando esse pensamento, McWilliams e Siegel (1997) ressaltam que é possível que um evento seja antecipado ou que haja "vazamento" de informação privilegiada para o mercado antes do anúncio oficial. Nesses casos é difícil o emprego do estudo de evento, porque também é difícil determinar quando exatamente o mercado recebeu a nova informação.

Por fim, a última premissa requer que não haja efeitos de outros eventos sobre a empresa estudada no período analisado pelo estudo de evento. Se houver sobreposição de eventos, mesmo que o estudo de evento venha a determinar que existe retorno anormal relevante no período, não há como determinar qual é a contribuição individual de cada um dos eventos na 
magnitude do retorno anormal observado. McWilliams e Siegel (1997) citam como possíveis outros eventos relevantes: anúnio de dividendos, anúncio de fusões, assinatura de contrato importante com o governo, anúncio de novo produto etc.

Vários aspectos da pesquisa são relevantes quando um estudo de evento é implementado, sendo que os seguintes pontos críticos deveriam ser sempre abordados, pois podem ser determinantes para validade ou não dos resultados obtidos: (1) tamanho da amostra, (2) teste não paramétrico para identificar outliers, (3) o tamanho do período de estudo (janela do evento), (4) efeitos combinados de eventos sobrepostos e (5) explicação dos retornos anormais (MCWILLIAMS; SIEGEL, 1997).

O tamanho da amostra é importante porque os testes estatísticos mais comumente usados durante o estudo de evento consideram comportamento normal (segundo distribuição de probabilidade normal), o que é usualmente observado quando o tamanho da amostra é grande (MCWILLIAMS; SIEGEL, 1997). Quando for necessário o estudo de amostras onde a variável de estudo tem distribuição não conhecida, pesquisadores deveriam usar métodos bootstrap (BARCLAY; LITZENBERGER, 1988, p. 79). Em estudo empírico, Brown e Warner (1985) reforçam essa preocupação com o tamanho da amostra, quando comentam os resultados obtidos em alguns de seus estudos:

Para amostras de cinco ou 20 títulos mobiliários, a especificação dos testes estatísticos não é dramaticamente alterada. O grau de adequação não indica má especificação. No entanto, o grau de "skewness" e "kurtosis" é maior para as amostras de tamanho cinco e vinte do que para amostras maiores. (...) Assim, os níveis de significância obtidos não devem ser considerados de forma literal. $^{23}$

A estimativa de retornos anormais em estudos de eventos é muitas vezes baseada em regressões de MQO (Mínimos Quadrados Ordinários). Sabe-se que esses parâmetros estimados são muito sensíveis a outliers. Uma solução para esse problema, utilizada por Jacobson (1994, p. 446), é identificar possíveis outliers pelo método de Cook (1977 e 1979), de forma que a análise não seja comprometida em função de poucas observação que não refletem o comportamento usual do fenômeno. Outra solução é aplicar testes não paramétricos

\footnotetext{
23 "For samples of either five or 20 securities, the specification of the test statistics is not dramatically altered. The goodness of fit tests do not indicate misspecification. However, the degree of skewness and kurtosis in the test statistics is higher for samples of size five and 20 than for samples of 50. For example, kurtosis is typically in excess of four for test statistics from samples of size five. Thus, stated significance levels should not be taken literally."
} 
como o teste estatístico da binomial Z, que se baseia na proporção relativa de resultados positivos e negativos obtidos para os retornos anormais (MCWILLIAMS; SIEGEL, 1997, p. 635).

Existem pelo menos três motivos para que o tamanho do período de estudo (janela do evento) seja o menor possível. O primeiro deles, comentam Brown e Warner (1985), é a diminuição do poder dos testes estatísticos de detectar retornos anormais em janelas de tempo maiores, havendo mais chances de retornos anormais existentes não serem observados pelos testes. Em seu estudo os autores demonstram que o poder dos testes estatíticos para detectar a existência de retornos anormais quando eles ocorrem pontualmente ao longo de uma janela de estudo de onze dias é menor do que quando o retorno anormal ocorre em janela de estudo de um dia apenas. MacKinlay (1997) corrobora com esse ponto:

Como pode-se esperar considerando a análise da seção 7, a queda no poder estatístico de um intervalo de um dia para um intervalo de trinta dias é severa. (....) A mensagem clara é de que existe um ganho substancial em termos de maior poder estatístico quando se reduz o intervalo. ${ }^{24}$

O segundo motivo está relacionado com a premissa de mercado eficiente, que assume que novas informações são incorporadas instantaneamente (ou muito rapidamente) ao preços das ações. Por isso, McWilliams e Siegel (1997) afirmam que é muito difícil aceitar ou assumir a premissa de mercado eficiente com janelas de evento muito longas.

Finalmente, a terceira razão pela qual se deve tentar diminuir ao máximo a janela de estudo é a possibilidade de existirem efeitos sobrepostos de outros eventos, o que impossibilitaria analisar precisamente o impacto efetivo do evento escolhido para estudo. McWilliams e Siegel (1997) consideram que é difícil controlar os efeitos de eventos sobrepostos decorrentes de janelas de estudo mais longas, recomendando assim que as janelas de estudo sejam longas o suficiente para capturar o efeito do evento, mas curtas de forma a evitar efeitos de outros eventos. No entanto, o autor também traz a ressalva de que nos casos onde é possível evidenciadar que há vazamento de informação antes do anúncio oficial, a janela de estudo deveria incluir algum tempo antes do anúncio de forma a capturar retornos anormais associados com o vazamento de informação. Da mesma forma, MacKinlay (1997) comenta que restringir a janela do evento apenas ao dia do anúncio, em se tratando de eventos

\footnotetext{
24 "As one would expect given analysis in Section 7, the decrease in power going from a daily interval to a monthly interval is severe. (...) The clear message is that there is a substantial payoff in terms of increased power from reducing the sampling interval."
} 
anunciados em jornal por exemplo, pode ser um problema porque não há como garantir que a informação não tenha sido disponibilizada no dia anterior, sendo publicada em jornal somente no dia seguinte. Nesse caso, o autor recomenda que a janela seja de dois dias.

Nos casos em que é detectada a sobreposição de eventos, algum tratamento deve ser utilizado de forma a não comprometer a validade do estudo. Foster (1980, apud McWilliams e Siegel, 1997) discute alguns tratamentos que podem ser aplicados, dentre eles: eliminar empresas que têm eventos sobrepostos, segmentar amostra de forma a agrupar empresas que apresentem mesmo tipo de eventos sobrepostos, eliminar a empresa da amostra no dia em que ela tem eventos sobrepostos e, finalmente, subtrair ou expurgar do evento sobreposto durante o cálculo do retorno anormal.

Tendo em vista as considerações acima, MacKinlay (1997) conclui que uma característica importante dos estudos de evento exitosos é a capacidade de identificar precisamente em que dia (momento) a informação se tornou pública.

Por fim, o quinto aspecto importante refere-se a necessidade de haver uma explicação a respeito dos retornos anormais observados. Quando o pesquisador comprova que existe relação entre o padrão de comportamento do retorno anormal encontrado com alguma teoria, o trabalho se torna ainda mais crível (MCWILLIAMS; SIEGEL, 1997). Essa afirmação é consistente com o comentário de MacKinlay (1997, p.33) onde o autor afirma que pode haver benefícios importantes quando o retorno anormal é examinado frente características do evento em estudo e que isso pode ser feito por meio de uma regressão cross section dos retornos anormais em relação às carcaterísticas de interesse.

Em relação a ferramenta proposta acima, regressão cross section, McWilliams e Siegel (1997, p.638) fazem um comentário adicional defendendo a consistência dos estimadores obtidos por essa ferramenta, uma vez que poderia haver problemas em se utilizar os retornos anormais como variável dependente em uma regressão por MQO, caso eles fossem resíduos heterocedásticos e correlacionados com as variáveis independentes. Os autores se apóiam no trabalho de Karafiath (1994) para afirmar que os estimadores obtidos por MQO têm desempenho muito bom nessas circunstâncias e que não há melhorias notáveis quando métodos mais complexos são adotados. Apesar disso, MacKinlay (1997, p.33) recomenda que 
estimadores consistentes sejam adotados, uma vez que não há razão para se esperar que os resíduos sejam de fato homocedásticos.

Tendo em vista essas considerações, McWilliams e Siegel (1997) propoêm os seguintes passos para garantir a robustez dos resultados obtidos por estudos de evento: (i) definir um evento que traga informações novas ao mercado, (ii) apresentar uma teoria que justifique a reação do mercado a essa nova informação, (iii) identificar uma série de empresas que passaram por esse evento, bem como a data dos eventos, (iv) escolher uma janela de estudo apropriada (justificar seu tamanho caso exceda dois dias), (v) eliminar eventos que estejam sujeitos à influência de outros eventos relevantes durante a janela de estudo, (vi) calcular o retorno anormal durante a janela de estudo e sua significância, (vii) relatar o o percentual de retornos negativos e a estatítica binomial $\mathrm{Z}$ ou teste de Wilcoxon, (viii) para amostras pequenas adotar método de bootstrap e discutir impacto de outliers, (ix) apresentar uma teoria que explique o comportamento dos retornos anormais e teste econometricamente e (x) apresentar nomes das empresas e datas dos eventos no apêndice.

\subsubsection{Cálculo do Retorno Anormal e de sua Significância}

O retorno ${ }^{25}$ anormal está relacionado com o efeito da reação do mercado de capitais sobre o valor das ações resultante da divulgação de novas informações (MCWILLIAMS; SIEGEL, 1997, p. 628). O estudo de evento tem como objetivo central, portanto, tentar mesurar esse retorno anormal e, quando é encontrada evidência suficientemente forte de que ele seja não nulo, afirma-se que o evento estudado ao se tornar público altera o valor das empresas analisadas.

Como comentado anteriormente, o retorno anormal pode ser calculado como a diferença entre retorno real e o retorno esperado (ou normal) de determinado ativo.

$A R_{i, t}=R_{i, t}-E R_{i, t}$

Onde:

25 Segundo Soares, Rostagno e Soares (2002) há benefícios (distribuição simétrica é mais próxima a uma distribuição t) em se calcular o retorno de forma contínua: $\operatorname{RET}_{\mathrm{CONTí} U \mathrm{O}}=\ln \left(\mathrm{PREÇO}_{\mathrm{T}}\right)-\ln \left(\mathrm{PREÇO}_{\mathrm{T}-1}\right)$ 
$A R_{i, t}$ : abnormal return, ou melhor, retorno anormal da ação da empresa adquirente do evento "i” na data "t"

$R_{i, t}$ : retorno real da ação da empresa adquirente do evento “i” na data “t”. ${ }^{26}$

$E R_{i, t}$ : expected return, ou melhor, retorno esperado ou retorno normal da ação da empresa adquirente do evento "i” na data " $t$ ”

O retorno real é obtido pela observação direta do comportamento dos preços reais de negociação em bolsa, enquanto que o retorno esperado não pode ser observado e deve ser estimado de alguma forma.

MacKinlay (1997, p.17) comenta que diferentes modelos são empregados para estimar o retorno esperado, sendo possível dividi-los em dois grupos: modelos estatísticos e modelos econométricos. Aqueles assumem unicamente premissas estatísticas e baseiam-se sobre o comportamento passado do preço do ativo para determinar o preço esperado do mesmo; a premissa principal usualmente adotada é a de que o retorno dos ativos apresenta comportamento de distribuições normais, independentes e idênticas ao longo do tempo. Já os modelos econométricos, além das premissas estatísticas, incorporam também premissas relacionadas ao comportamento do mercado e de seus participantes, tendo como principal vantagem (teórica) uma maior eficiência na estimação do retorno esperado e não a eliminação da necessidade do uso de ferramentas estatísticas.

Além do modelo de retorno médio apresentado por MacKinlay (1997, p. 17) e avaliado por Brown e Warner (1985, p. 6), costumam-se adotar diversos modelos distintos, tais como: “Capital Asset Pricing Model” (CAPM $\left.{ }^{27}\right)$, “Arbitrage Pricing Model” (APT ${ }^{28}$ ), modelo de

\footnotetext{
${ }^{26}$ Nos casos onde a empresa adquirente possui mais de uma ação negociada em bolsa, foi adotada a ação de maior liquidez de cada empresa para o cálculo do retorno real. O mesmo critério foi adotado para escolha das ações (preços) utilizadas na parametrização do modelo de mercado e cálculo do retorno anormal que serão apresentados a seguir.

${ }^{27}$ O CAPM apresentado por Sharpe (1964) e Lintner (1965) baseia-se na teoria de equilíbrio onde o retorno esperado de determinado ativo é definido pela sua covariância em relação a um portifolio que represente o mercado (MacKinlay, 1997, p. 19).

${ }^{28}$ O APT apresentado por Ross (1976) é uma teoria de apressamento de ativos que define o retorno esperado de um ativo como a combinação linear de múltiplos fatores de risco (MacKinlay, 1997, p. 19).
} 
mercado, retorno de mercado (ou de determinado índice de mercado) (Elton et al, 2009, p 416).

Assim, o retorno anormal pode ser estimado com base em diferentes modelos distintos, bastando substituir o termo $E R_{i, t}$ na Equação ( 1 ) pelo modelo considerado mais adequado pelo pesquisador. Brown e Warner (1980, p.205, apud Bromiley, Govekar e Marcus, 1988, p. 28) lembram que independentemente do modelo escolhido, é importante notar que o estudo de evento não avalia simplesmente se determinado evento tem impacto positivo ou negativo sobre o fluxo de caixa esperado da empresa estudada. De fato, o estudo de evento constitui um teste de hipótese conjunto do modelo adotado para estimar o retorno esperado e da teoria financeira associada ao evento estudado.

MacKinlay (1997, p. 19) comenta que a utilização do CAPM em estudos de evento foi muito comum na década de 1970. No entanto, imperfeições do modelo CAPM têm sido estudadas e constadas em trabalhos empíricos, o que tem levantado questionamentos na validade das restrições impostas por ele. Como consequência, também se questiona se os resultados obtidos nos estudos de evento que adotam o CAPM não sejam sensíveis às premissas específicas desse modelo. Finalmente, como esse problema pode ser evitado com pouco prejuízo adotando-se o modelo de mercado, o CAPM quase não tem sido mais utilizado.

Já sobre o APT o autor afirma que uma constatação comum é a de que o fator de risco mais importante se comporta como o mercado (ou portifólio que o represente) e que os demais fatores de risco têm, relativamente, baixo poder explicativo. Assim, os benefícios trazidos pelo APT em relação ao modelo de mercado são pequenos; o maior ganho potencial obtido com o emprego do APT é a eliminação de possíveis vieses introduzidos pelo CAPM. No entanto, como os modelos de base estatística também o fazem, estes modelos são os mais empregados em estudos de evento (MACKINLAY, 1997, p. 19).

Brown e Warner (1980, p.207) comentam que os modelos retorno médio, retorno de mercado e o modelo de mercado são os modelos que têm sido usados em estudos de evento e concentram, por isso, seu estudo sobre o desempenho deles.

Brown e Warner (1985) continuam sua avaliação do desempenho de diferentes metodologias de estudo de eventos considerando retornos diários, após terem adotado retornos mensais em 
sua obra anterior (BROWN; WARNER, 1980). Naquele estudo, os autores avaliam a capacidade de detectar retornos anormais de alguns modelos ${ }^{29}$ em condições genéricas e em algumas situações específicas tais como comportamento não normal de retornos diários; negociação não sincronizada ${ }^{30}$ de ativos, problemas na estimação da variância devido a autocorrelação, dependência cross section e aumento da variância durante evento, chegando às seguintes conclusões, que de forma geral, não indicam problemas de especificação para o modelo de mercado:

- Apesar de retornos anormais diários apresentarem comportamento não normal, há evidência de que o retorno anormal médio tende a comportamento normal conforme o número de ativos aumenta.

- Os modelos que estimam retorno esperado por retorno médio, retorno de mercado e pelo modelo de mercado são bem especificados.

- O poder de detectar retornos anormais dos modelos estudados é maior quando se utiliza retornos diários e não mensais. Os modelos de retorno de mercado e modelo de mercado apresentam maior capacidade para captar retornos anormais que o modelo de retorno médio.

- Outros procedimentos diferentes do modelo de mercado para estimar o retorno anormal, como os modelos propostos por Dimson (1979) e Scholes e Williams (1977), não apresentam benefícios notórios para detectar retornos anormais.

- Em casos de negociação não sincronizada, que pode causar auto-correlação, a escolha do método pode causar diferenças na capacidade de detectar retornos anormais. No entanto, esse impacto é limitado.

- Metodologias que usam MQO (com modelo de mercado) e testes paramétricos são bem especificados em um grande número de condições.

Considerando os resultados expostos acima e a sua grande utilização em estudos de evento, os modelos retorno médio, retorno de mercado e modelo de mercado são apresentados com mais detalhes a seguir.

O modelo de retorno médio considera que o retorno esperado, termo $E R_{i, t}$ na Equação ( 1 ), de um determinado ativo é dado uma por constante $\mathrm{K}_{\mathrm{i}}$, que pode ser diferente para cada ativo “i” (BROWN; WARNER, 1980, p. 207). Para determinar o valor de $\mathrm{K}_{\mathrm{i}}$, é calculada a média

\footnotetext{
${ }^{29}$ Modelos testados: retorno médio, retorno de mercado, modelo de mercado, modelos propostos por Dimson (1979) e Scholes e Williams (1977).

${ }^{30}$ Negociação não sincronizada, segundo Brown e Warner (1985, p.5), ocorre quando o retorno do ativo de interesse e o retorno do índice de mercado são negociados em intervalos de tempo distintos. Nesses casos, os estimadores obtidos por MQO poderiam ser enviesados.
} 
dos 239 retornos diários do ativo "i” anteriores a janela do evento (BROWN; WARNER, 1985, p. 6).

O retorno de mercado assume que o retorno esperado é igual para todos os ativos, mas que não tem valor constante. O termo $E R_{i, t}$ na Equação ( 1 ) tem valor igual ao retorno do mercado na data “t”, sendo necessário portanto a adoção de um portifólio de ativos (ou índice de mercado) que represente o mercado como um todo (BROWN; WARNER, 1980, p. 207).

O modelo adotato neste trabalho é o modelo de mercado, já que McWilliams e Siegel (1997, p.628) afirmam que o procedimento padrão para cáculo do retorno esperado é através do desse modelo. Da mesma forma, Kayo, Patrocíonio e Martin (2009, p. 630) adotam o mesmo modelo e afirmam que o retorno anormal obtido é “ajustado ao risco e ao mercado”:

$E R_{i, t}=\alpha_{i}+\beta_{i} * R_{M, t}+\varepsilon_{i t}$

Onde:

$E R_{i, t}$ : retorno esperado da ação da empresa adquirente do evento "i” na data " $\mathrm{t}$ ”;

$R_{M, t}$ : retorno do mercado na data " $\mathrm{t}$ ", dado por um portifólio que represente o mercado ou índice de mercado. Neste trabalho será adotado o índice IBOVESPA e, como teste de robustez, o índice IBRX-50;

$\alpha$ é o intercepto e $\beta$ é o risco sistemático do ativo “i”. São estimados na regressão por MQO do retorno diário real $R_{i, t}$, sobre o retorno de mercado real diário $R_{M, t}$, para um período denominado de janela de estimação (normalmente anterior ao evento) e

$\varepsilon_{\mathrm{it}}$ : termo de erro, sendo o seu valor esperado igual a zero. $\left(\mathrm{E}\left(\varepsilon_{\mathrm{it}}\right)=0 ; \operatorname{var}\left(\varepsilon_{i t}\right)=\sigma_{\varepsilon_{i}}^{2}\right)$.

O método de estudo de evento costuma dividir o tempo em três períodos: janela de estimação (cujas informações são normalmente usadas para estimar os parâmetros do modelo adotado para calcular o retorno esperado), janela do evento ou janela de estudo (período de análise efetiva que contém a data de anúncio do evento) e janela pós evento (período posterior ao final da janela do evento) conforme Figura 1. 
Figura 1 - A linha do tempo para estudo de evento

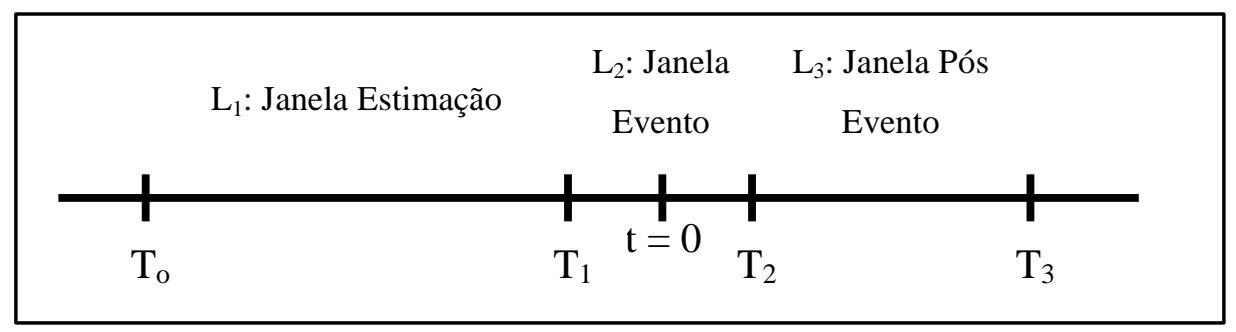

FONTE: MCKINLAY, 1997, p.20

Como discutido anteriormente, existem benefícios quando o tamanho da janela de evento, $\mathrm{L}_{2}$, é pequeno uma vez que há menos chances de que existam problemas relacionados à sobreposição de eventos e de seus efeitos sobre o ativo, contradição da premissa de eficiência de mercado e velocidade de incorporação de novas informações ao preço dos ativos e, por fim, redução do poder dos testes estatísticos de detectar retornos anormais. De forma contrária, McKinlay (1997, p. 21) afirma que a variância do retorno anormal é minimizado quando a janela de estimação, $\mathrm{L}_{1}$, é suficientemente grande.

Neste trabalho $\mathrm{L}_{1}$ e $\mathrm{L}_{2}$ serão as mesmas de Kayo, Patrocínio e Martins (2009, p.63): para $\mathrm{L}_{1}$ será considerado "um período de 180 dias, que começa 210 dias antes do anúncio da aquisição e termina 31 dias antes dele” e para L2 será adota a janela de um dia, dia do anúncio do evento. Além dessa janela, as janelas de três dias, recomendada por McWilliams e Siegel (1997, p. 652), onze e vinte e um dias em torno da data do anúncio tambem serão consideradas.

McKinlay (1997) adota os seguintes passos para cálculo do retorno anormal da amostra de eventos. Da mesma forma, neste trabalho os passos a seguir “a” a "e” serão realizados quatro vezes: uma vez para cada janela $\mathrm{L}_{2}$ definida.

a) Para cada evento "i” da amostra, calcular o retorno anormal diário, $A R_{i, t}$, para todos os dias “t” presentes em $\mathrm{L}_{2}$ :

$A R_{i, t}=R_{i, t}-a_{i}+b_{i} * R_{M, t}$ 


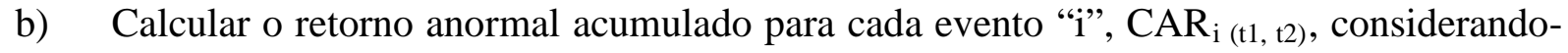
se os retornos anormais diários durante todos os dias da janela de tempo $\mathrm{L}_{2}$ :

$C A R_{i\left(t_{1}, t_{2}\right)}=\sum_{t=t_{1}}^{t_{2}} A R_{i, t}$

c) Calcular o retorno anormal médio acumulado, $\overline{C A R_{\left(t_{1}, t_{2}\right)}}$, considerando-se todos os "N" eventos "i":

$\overline{\operatorname{CAR}_{\left(t_{1}, t_{2}\right)}}=\frac{1}{N} * \sum_{i=1}^{N} C A R_{i\left(t_{1}, t_{2}\right)}$

d) Calcular a variância do retorno anormal médio acumulado, var $\left(\overline{C A R_{\left(t_{1}, t_{2}\right)}}\right)$ :

$\operatorname{var}\left(\overline{\operatorname{CAR}_{\left(t_{1}, t_{2}\right)}}\right)=\frac{1}{N^{2}} * \sum_{1=1}^{N}\left(\operatorname{CAR}_{i\left(t_{1}, t_{2}\right)}-\overline{\operatorname{CAR}_{\left(t_{1}, t_{2}\right)}}\right)^{2}$

e) Realizar teste de hipótese para avaliar a hipótese nula $\left(\mathrm{H}_{0}\right)$ de que retorno anormal médio acumulado é nulo através da estatística a seguir: (MCKINLAY, 1997, p.24).

$\theta_{1}=\frac{\overline{\operatorname{CAR}_{\left(t_{1}, t_{2}\right)}}}{\sqrt{\operatorname{var}\left(\overline{C A R_{\left(t_{1}, t_{2}\right)}}\right)}} \sim N(0,1)$

É importante ressaltar três premissas importantes, necessárias para a validade das fórmulas e estatística apresentadas acima: (1) a amostra de eventos e ativos deve ser grande o suficiente, (2) o tamanho da janela de estimação $\mathrm{L}_{1}$ também deve ser grande o suficiente e (3) as janelas dos diferentes eventos não devem se sobrepor (MCKINLAY, 1997, p. 24).

É comum ${ }^{31}$ que testes não paramétricos também sejam utilizados para avaliar a hipótese nula de retorno anormal acumulado nulo, em conjunto com os testes paramétricos. Sua inclusão aumenta a robustez dos resultados das conclusões obtidas na análise do retorno anormal pelos métodos paramétricos. Assim, os testes não paramétricos mais comumente utilizados em

\footnotetext{
${ }^{31}$ Outros autores, McWilliams e Siegel (1997, p, 636), Brown e Warner (1985, p. 24), Gubbi et al (2010, p. 407), Uhlenbruck, Hitt e Semadeni (2006, p. 907) e Mulherin e Boone (2000, passim), cujos trabalhos também são relacionados à criação de valor em aquisições, adotam testes não paramétricos, sendo os mais comuns o teste de sinais e o de postos de Wilcoxon.
} 
estudos de eventos são o teste do sinal e o teste de postos (rank test), sendo este mais apropriado em alguns casos, principalmente quando a distribuição de retornos anormais não é simétrica (MCKINLAY, 1997, p. 32).

\subsection{Análise do Retorno Anormal e Operacionalização das Variáveis}

Assim como recomendam McWilliams e Siegel (1997, p. 653) e MacKinlay (1997, p. 33), o estudo de evento ganha robustez quando se analisa o retorno anormal obtido de forma a se conseguir explicar, ao menos em parte, sua variação. O método básico utilizado para isso é o de regressão cross section dos retornos anormais (variável dependente) sobre as características de interesse (variáveis independentes). Será adotada a seguinte relação, segundo espírito utilizado por Bouwman, Fuller e Nain (2009, p. 647).

$\operatorname{CAR}_{i\left(t_{1}, t_{2}\right)}=a_{1}+a_{2} *$ Mercado Alta $+a_{3} *$ Mercado Neutro $+\sum_{n=4}^{P} a_{n} * V C_{i}$

Onde:

$C A R_{i\left(t_{1}, t_{2}\right)}$ : retorno anormal acumulado da ação da empresa adquirente do evento "i”, na janela de evento “ $\mathrm{t}_{1}$ ” a “ $\mathrm{t}_{2}$ ”, dado por $\sum_{t_{1}}^{t_{2}} A R_{i, t}$ definido na Equação ( 1 ). Como exposto anteriormente serão consideradas quatro janelas de tempo, com um, três, onze e vinte e um dias, sendo o dia do anúncio do evento sempre o dia central do período;

Mercado em Alta: proxy de sentimento de mercado em alta, conforme descrito abaixo no item 3.4;

Mercado Neutro: proxy de sentimento de mercado neutro, conforme descrito abaixo no item 3.4;

$V C_{i:}$ variáveis de controle são apresentados na Figura 2: 
Figura 2 - Variáveis de Controle

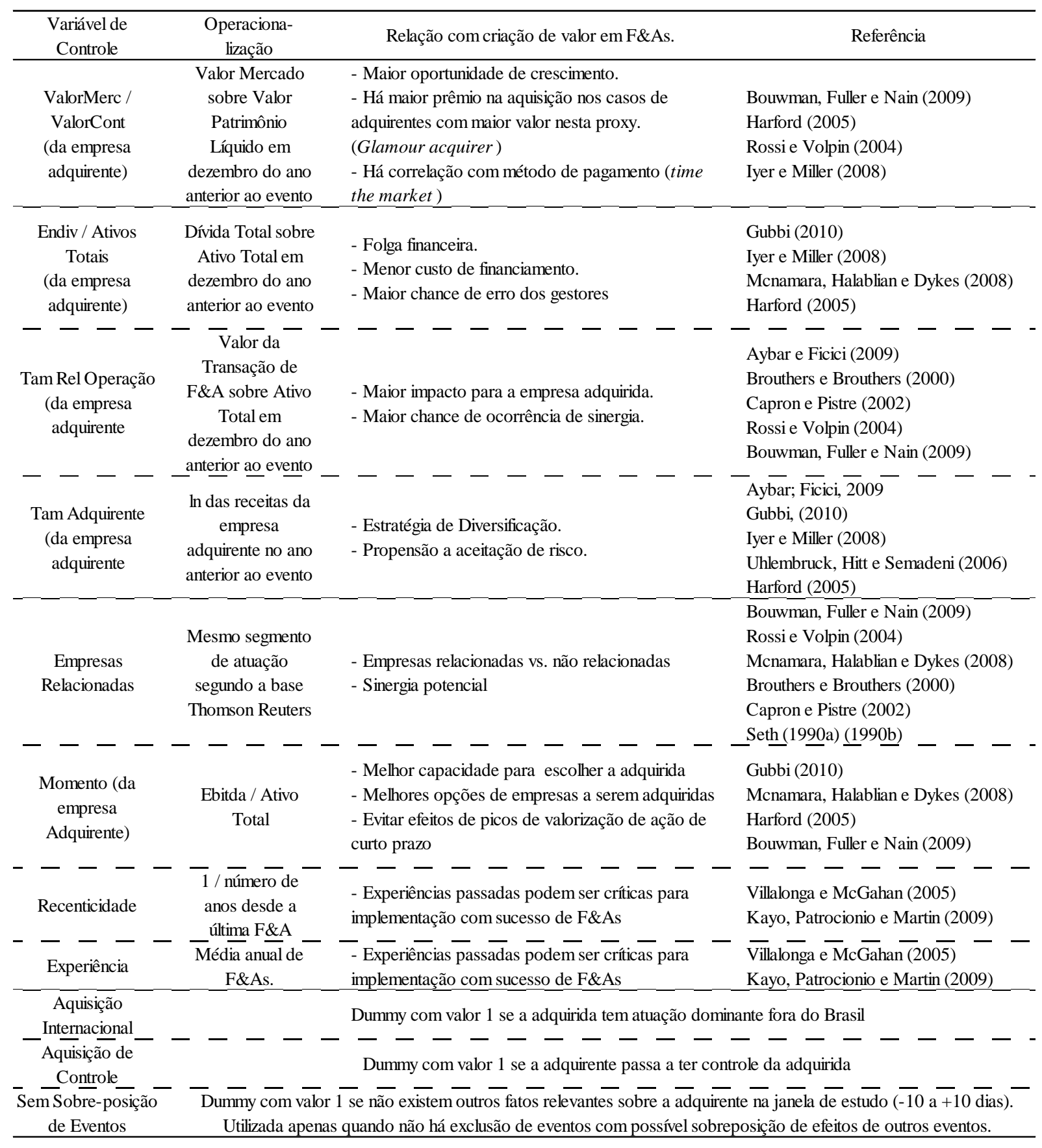

Fonte: Elaborado pelo Autor

Nota. A tabela apresenta as variáveis de controle utilizadas nas análises, bem como sua forma de cálculo e motivo de utilização. Também são citados alguns trabalhos que empregam essas mesmas variáveis de controle. Embora, em alguns casos, sua forma de cálculo possa ser diferente nos trabalhos citados.

Todas as análises de regressão, para cada proxy de sentimento de mercado e para cada janela de estudo, foram realizadas também excluindo-se possíveis outliers e ambos os resultados são 
sempre apresentados; os outliers foram excluídos quando detectou-se studentized residuals maiores que módulo de três, de forma semelhante a Kayo, Patrocínio e Martin (2009, p. 65).

As análises econométricas foram realizadas com a utilização do software "R” (versão 2.12.2 GUI 1.36 Leopard), enquanto que os demais cálculos, elaboração de tabelas e gráficos foram realizados com o software Microsoft Office 2010.

\subsection{Sentimento de Mercado: Seleção da Proxy}

Para realização das análises necessárias ao estudo do problema de pesquisa deste trabalho é necessário que o estado do mercado, sentimento de mercado, associado a cada evento estudado seja identificado e classificado de alguma forma. Baker e Wurgler (2006, p. 1646) afirmam que não há forma perfeita ou não controversa para fazê-lo.

Por isso, uma grande variedade de formas distintas tem sido empregada para representar as condições de sentimento mercado nos estudos acadêmicos. Através da revisão da literatura ${ }^{32}$, foi feito um levantamento exploratório de forma a identificar as proxies sugeridas ou utilizadas com o objetivo de indicar a condição de mercado (mercado em alta ou bull market, neutro e mercado em baixa ou bear market).

Han (2008, p.388) afirma que proxies baseadas em pesquisas de opinião junto a investidores, indicadores do nível de negociação do mercado e erros de avaliação de valor do S\&P 500 são usadas para tentar medir o nível de sentimento de mercado. De forma semelhante às pesquisas de opinião junto a investidores, Charoenrook (2003, p. 3) adota um indicador do nível de confiança do consumidor; ambos os indicadores estao alinhados com Ljungqvist, Nanda e Singh (2006, p. 1668) que afirmam que mercado em alta ocorrem em períodos de otimismo excessivo.

\footnotetext{
${ }^{32}$ Principalmente de artigos abordando questões relacionadas ao processo de emissão de ação (IPO - Initial Public Offer), uma vez que há grande quantidade de estudos nessa área que buscam analisar a relação do sentimento de mercado e comportamento do preço das ações emitidas.
} 
Fama e French (1989), Ljungqvist (1997, p. 1318), Choe, Masulis e Nanda (1993, apud Waker e Lin, 2007) e Lakonishok, Shleifer e Vishny (1994) associam, dentre outras formas, a condição (sentimento) de mercado ao nível de atividade econômica ou expansão econômica.

Outros trabalhos que estudam aspectos relacionados a oferta pública de ações adotam a quantidade de IPOs como proxy do sentimento de mercado, já que os gestores se aproveitariam de momentos de mercado em alta para vender suas ações (YUNG; ÇOLAK; WANG, 2008, p.193), (WALKER; 2007), (HELWEGE; LIANG, 2004, p.542). De forma análoga, Chidambaran, John e Shangguan (2010, p. 327) adotam o número de F\&As para definir períodos de mercado em alta e de mercado em baixa.

Han (2008) afirma que erros de avaliação de valor do S\&P500 podem ser indicadores do sentimento de mercado. Bouwman, Fuller e Nain (2009, p. 635), Harford (2005) e Chidambaran, John e Shangguan (2010, p. 329) adotam vários indicadores associados a esse conceito, sendo os principais baseados em: Preço/Lucro do S\&P 500, Valor Mercado / Valor Contábil geral do mercado, o próprio índice S\&P 500, retorno acumulado do mercado (um e três anos), bem como a variância desse retorno nesse período.

Tendo em vista a dificuldade em se medir o sentimento de mercado e grande quantidade de proxies adotadas, alguns autores propoem a criação de indicadores compostos a partir da “soma” de várias das proxies acima.

Nós formamos um índice composto de sentimento que é baseado na variação comum de seis proxies de sentimento: desconto dos "closed-end fund", nível de negociação de ações na bolsa de Nova Iorque, a quantide de IPOs e seu retorno no primeiro dia, a quantide de capital próprio remanecente após IPOs e o pêmio de dividendo (BAKER; WURGLER, 2006, p. 1655). ${ }^{33}$

Seguindo mesmo conceito, Yoshinaga, Castro e Securato (2010, p. 6) formam seu indicador de sentimeto de mercado (para o mercado brasileiro) a partir das seguintes proxies: percentual de capital próprio em novas emissões de acões, quantidade trimestral de IPOs, nível de negociação de ações, diferença logarítimica do índice valor de mercado sobre valor contábil de empresas pagadoras de dividendo e empresas não pagadoras de dividendos e, finalmente, trin ou índice de Arms.

\footnotetext{
33 "We therefore form a composite index of sentiment that is based on the common variation in six underlying proxies for sentiment: the closed-end fund discount, NYSE share turnover, the number and average first-day returns on IPOs, the equity share in new issues, and the dividend premium."
} 


\subsubsection{Sentimento de Mercado: Proxies Adotadas}

Foram adotadas as seguintes proxies:

a) ICEI: indicador trimestral de confiança do empresário industrial, medido pela Confederação Nacional da Indústria.

b) ICEI expectativa: mesmo indicador acima, mas com foco na expectativa da indústria para os próximos 6 meses.

c) Retorno de Mercado: retorno do mercado acumulado nos doze meses anteriores à data de anúncio da F\&A, medido pela variação do índice Ibovespa no período.

d) Quantidade de F\&A: quantidade de F\&As anunciadas segundo base de dados Thomson Reuters, incluindo todas as operações presentes nesse banco de dados.

e) Utilização da Capacidade Instalada: Índice de utilização capacidade instalada geral da Fundação Getúlio Vargas, extraído do site do Banco Central do Brasil.

f) IBC-BR: Índice de Atividade Econômica do Banco Central Sazonal, extraído do site do Banco Central do Brasil. (dados disponíveis a partir de 2003 apenas)

Uma vez determinados os valores das diferentes proxies para cada período (meses ou trimestres), os períodos foram ordenados de forma crescente segundo o valor de cada proxy. Os períodos iniciais (os primeiros 30\%) foram classificados como períodos de mercado em baixa; os períodos finais (os últimos 30\%) foram classificados como períodos de mercado em alta. Os demais períodos são os de mercado neutro. Esse critério arbitrário segue o mesmo critério adotado por Lakonishok, Shleifer e Vishny (1994) e foi adotado para todas as proxies acima.

Como teste de robustez, a mediana das proxies acima também será adotada para segmentar as amostras em dois grupos: Mercado em Alta e Mercado em Baixa. 


\section{RESULTADOS}

Os resultados obtidos são apresentados em três seções. Na primeira, a criação de valor é estudada e é feita uma análise inicial para se verificar se existe diferença na criação de valor em função do estado do mercado no momento em que os eventos são anunciados. Na seção 4.2 as demais variáveis de controle são também incorporadas ao estudo e por meio de regressão cross section busca-se determinar a influência do sentimento de mercado sobre a criação de valor. Por fim, a seção 4.3 apresenta a maioria das análises novamente, mas com alterações metodológicas com intuito de avaliar a robustez dos resultados quanto ao método escolhido. A Figura 3 resume as principais escolhas metodológicas empregadas em cada seção:

Figura 3 - Análises e Variações Metodológicas

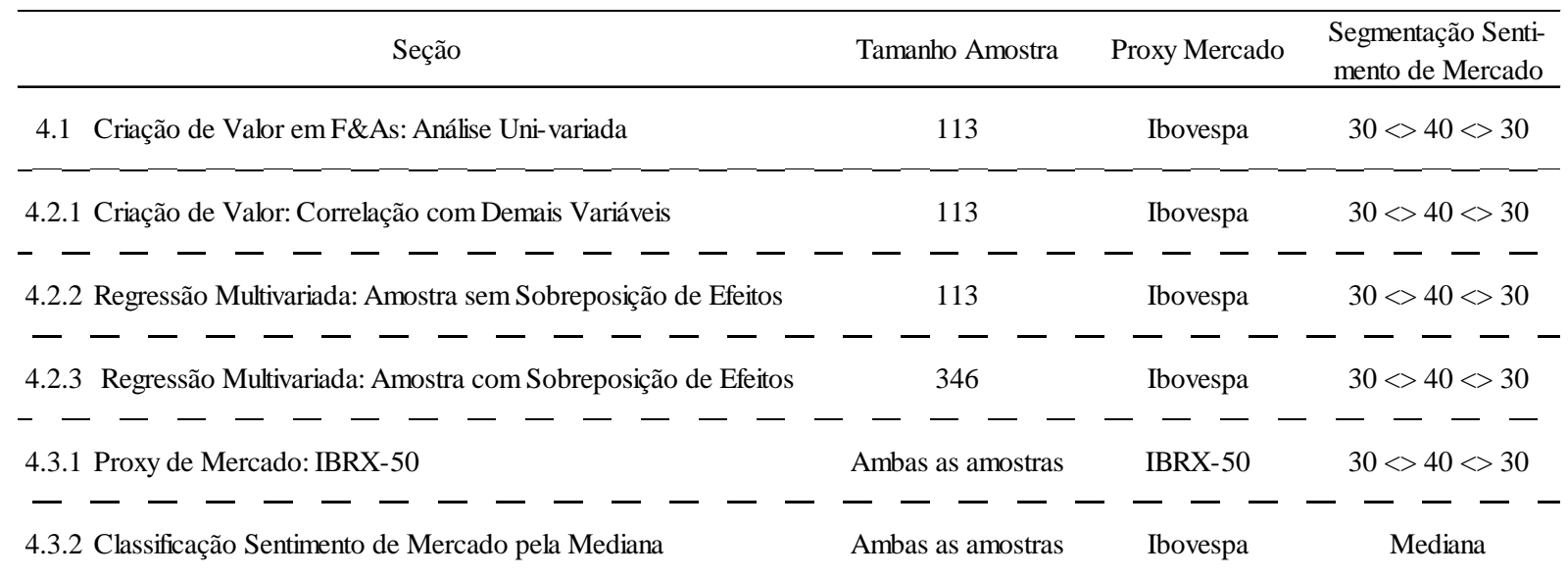

Fonte: Elaborado pelo Autor

\subsection{Criação de Valor em F\&As: Análise Uni-variada}

Apenas a amostra sem eventos com sobre posição de efeitos de outros fatos relevantes é estudada nesta seção já que os testes e análises realizados não são capazes de isolar eventuais efeitos resultantes de outros fatos relevantes (não relacionados com F\&As).

A partir da amostra definida pelos critérios citados na metodologia, os retornos anormais médios diários foram calculados para todos os dias da janela de estudo. Na Tabela 1 a criação de valor no dia do anúncio é apresentada e são descritas sua média, mediana, variação total e 
Tabela 1 - Criação de Valor (Proxy de Mercado Ibovespa)

\begin{tabular}{|c|c|c|c|c|c|c|c|c|c|c|c|c|c|}
\hline \multirow[b]{2}{*}{$\begin{array}{l}\text { Sentimento de } \\
\text { Mercado }\end{array}$} & \multirow[t]{2}{*}{$\begin{array}{c}\text { Amostra } \\
\text { Total }\end{array}$} & \multicolumn{2}{|c|}{ ICEI } & \multicolumn{2}{|c|}{ ICEI Expectativa } & \multicolumn{2}{|c|}{ Retorno Ibovespa } & \multicolumn{2}{|c|}{ Número de F\&As } & \multicolumn{2}{|c|}{$\begin{array}{c}\text { Utilização Capacidade } \\
\text { Instalada }\end{array}$} & \multicolumn{2}{|c|}{ IBC - BR } \\
\hline & & Alta & Baixa & & & Alta & & Alta & Baixa & Alta & Baixa & Alta & Baixa \\
\hline Número de Eventos & 113 & 36 & 34 & 31 & 30 & 42 & 20 & 51 & 23 & 56 & 14 & 23 & 33 \\
\hline \multicolumn{14}{|l|}{ Dia Anúncio } \\
\hline Mediana & $0,3 \%$ & $0,3 \%$ & $0,6 \%$ & $0,3 \%$ & $0,4 \%$ & $0,5 \%$ & $0,2 \%$ & $0,3 \%$ & $0,3 \%$ & $0,3 \%$ & $1,5 \%$ & $-0,3 \%$ & $0,2 \%$ \\
\hline Média & $0,6 \%$ & $0,4 \%$ & $0,8 \%$ & $0,4 \%$ & $0,9 \%$ & $0,8 \%$ & $0,3 \%$ & $0,5 \%$ & $0,7 \%$ & $0,8 \%$ & $0,7 \%$ & $0,1 \%$ & $0,2 \%$ \\
\hline Desvio Padrão & $2,9 \%$ & $2,9 \%$ & $3,3 \%$ & $3,0 \%$ & $3,6 \%$ & $2,3 \%$ & $3,3 \%$ & $2,3 \%$ & $1,8 \%$ & $3,2 \%$ & $4,1 \%$ & $1,4 \%$ & $3,3 \%$ \\
\hline $\begin{array}{l}\text { Variação } \\
\text { ("range") }\end{array}$ & $23,2 \%$ & $19,5 \%$ & $20,6 \%$ & $19,5 \%$ & $20,6 \%$ & $11,4 \%$ & $18,1 \%$ & $10,9 \%$ & $7,8 \%$ & $23,2 \%$ & $18,1 \%$ & $6,5 \%$ & $19,5 \%$ \\
\hline \multicolumn{14}{|l|}{ CAR_3 } \\
\hline Mediana & $0,1 \%$ & $-0,1 \%$ & $0,2 \%$ & $-0,3 \%$ & $-0,1 \%$ & $0,7 \%$ & $-0,2 \%$ & $0,3 \%$ & $0,1 \%$ & $0,9 \%$ & $0,3 \%$ & $-1,2 \%$ & $0,1 \%$ \\
\hline Média & $1,0 \%$ & $1,1 \%$ & $0,8 \%$ & $1,1 \%$ & $0,4 \%$ & $1,0 \%$ & $-0,4 \%$ & $0,7 \%$ & $1,1 \%$ & $1,6 \%$ & $1,2 \%$ & $-0,2 \%$ & $0,9 \%$ \\
\hline Desvio Padrão & $4,8 \%$ & $4,3 \%$ & $5,9 \%$ & $4,4 \%$ & $5,2 \%$ & $4,6 \%$ & $4,2 \%$ & $4,3 \%$ & $3,3 \%$ & $4,8 \%$ & $5,6 \%$ & $4,0 \%$ & $4,5 \%$ \\
\hline $\begin{array}{l}\text { Variação } \\
\text { ("range") }\end{array}$ & $30,7 \%$ & $18,4 \%$ & $30,7 \%$ & $18,4 \%$ & $28,1 \%$ & $26,2 \%$ & $19,4 \%$ & $20,6 \%$ & $11,4 \%$ & $28,1 \%$ & $19,0 \%$ & $17,3 \%$ & $18,7 \%$ \\
\hline \multicolumn{14}{|l|}{ CAR_11 } \\
\hline Mediana & $-0,0 \%$ & $1,3 \%$ & $-1,0 \%$ & $-0,1 \%$ & $-1,4 \%$ & $0,3 \%$ & $-1,6 \%$ & $-0,1 \%$ & $0,4 \%$ & $0,7 \%$ & $-0,8 \%$ & $-1,1 \%$ & $1,3 \%$ \\
\hline Média & $0,7 \%$ & $2,6 \%$ & $-0,7 \%$ & $2,0 \%$ & $-0,6 \%$ & $0,4 \%$ & $-0,3 \%$ & $0,9 \%$ & $0,5 \%$ & $1,7 \%$ & $0,2 \%$ & $-0,3 \%$ & $2,6 \%$ \\
\hline Desvio Padrão & $6,4 \%$ & $6,0 \%$ & $7,0 \%$ & $6,1 \%$ & $7,2 \%$ & $6,1 \%$ & $7,7 \%$ & $5,9 \%$ & $5,0 \%$ & $6,6 \%$ & $8,6 \%$ & $4,9 \%$ & $6,9 \%$ \\
\hline $\begin{array}{l}\text { Variação } \\
\text { ("range") }\end{array}$ & $35,9 \%$ & $21,1 \%$ & $31,7 \%$ & $21,1 \%$ & $29,4 \%$ & $30,7 \%$ & $29,4 \%$ & $26,5 \%$ & $23,6 \%$ & $29,9 \%$ & $29,4 \%$ & $21,1 \%$ & $26,3 \%$ \\
\hline \multicolumn{14}{|l|}{ CAR 21} \\
\hline Mediana & $0,7 \%$ & $2,7 \%$ & $1,2 \%$ & $3,2 \%$ & $1,7 \%$ & $-1,3 \%$ & $1,8 \%$ & $1,3 \%$ & $-0,7 \%$ & $3,2 \%$ & $3,5 \%$ & $-0,9 \%$ & $2,7 \%$ \\
\hline Média & $0,9 \%$ & $1,9 \%$ & $0,6 \%$ & $1,6 \%$ & $1,6 \%$ & $-0,8 \%$ & $1,8 \%$ & $1,9 \%$ & $0,2 \%$ & $3,1 \%$ & $1,2 \%$ & $-0,3 \%$ & $1,9 \%$ \\
\hline Desvio Padrão & $7,7 \%$ & $7,3 \%$ & $9,1 \%$ & $7,3 \%$ & $9,6 \%$ & $6,7 \%$ & $10,6 \%$ & $7,6 \%$ & $5,9 \%$ & $7,7 \%$ & $10,4 \%$ & $7,4 \%$ & $8,2 \%$ \\
\hline $\begin{array}{l}\text { Variação } \\
\text { ("range") }\end{array}$ & $39,9 \%$ & $31,6 \%$ & $39,4 \%$ & $31,6 \%$ & $39,4 \%$ & $27,8 \%$ & $39,4 \%$ & $28,5 \%$ & $21,6 \%$ & $32,1 \%$ & $39,4 \%$ & $21,7 \%$ & $31,6 \%$ \\
\hline
\end{tabular}

Fonte: Elaborado pelo Autor

Nota: a tabela resume a criação de valor para a amostra total de 113 elementos e para cada sub amostra obtida segundo o sentimento de mercado e suas diferentes proxies. São apresentados: a mediana, média, desvio padrão, variação e número de elementos de cada amostra. 
desvio padrão tanto da amostra completa com 113 elementos como de doze sub amostras das F\&As anunciadas em momentos de mercado em alta e de mercado em baixa, classificados segundo as seis proxies distintas de sentimento de mercado apresentadas no item (3.4.1). Por fim, a tabela também apresenta o retorno anormal acumulado considerando as janelas de tempo estudadas de três, onze e vinte e um dias (CAR_3, CAR_11 e CAR_21 respectivamente).

Pelo menos três resultados podem ser destacados nessa tabela: (i) a maioria dos resultados indicam criação de valor positiva, (ii) existe uma variabilidade aparentemente grande nos resultados obtidos para criação de valor e (iii) o tamanho de cada sub amostra é altamente impactado pela proxy adotada.

Na Tabela 2 é relatada a criação média de valor para todos os dias da janela de estudo, bem como para os períodos acumulados de três, onze e vinte e um dias em torno do dia do anúncio do evento. Adicionalmente, foram realizados dois testes de hipótese (tanto teste paramétrico como o teste não paramétrico de Wilcoxon) com hipótese nula de criação de valor nula.

Considerando a amostra completa com os 113 elementos, no dia do anúncio de F\&As dos eventos selecionados, parece haver indícios de criação de valor para os acionistas das empresas adquirentes (+0,6\%), uma vez que o retorno anormal é positivo e estatisticamente significativo (tanto segundo teste paramétrico quanto segundo teste não paramétrico). Já os resultados obtidos para retorno anormal acumulado, nas três janelas de estudo, também indicam criação de valor para a totalidade dos eventos, embora haja significância estatística apenas na janela menor, de três dias.

A criação de valor no dia do anúncio do evento parece ser maior quando o mercado está em baixa que em momentos de mercado em alta (observado em quatro dos seis pares de sub amostras formadas a partir das seis proxies de sentimento de mercado). De forma contrária, esse resultado parece se inverter quando a janela de estudo é aumentada para três, onze ou vinte e um dias havendo mais casos onde a criação de valor aparenta ser maior para amostras formadas com eventos anunciados durante mercado em alta. 
Tabela 1 - Teste t e de Wilcoxon para a Criação de Valor (Proxy de Mercado Ibovespa)

\begin{tabular}{|c|c|c|c|c|c|c|c|c|c|c|c|c|c|c|c|c|c|c|}
\hline \multirow{3}{*}{$\begin{array}{c}\begin{array}{c}\text { Sentimento } \\
\text { de Mercado }\end{array} \\
\text { Número de } \\
\text { Eventos }\end{array}$} & \multirow[t]{2}{*}{$\begin{array}{c}\text { Amostra } \\
\text { Total }\end{array}$} & \multicolumn{2}{|c|}{ ICEI } & \multicolumn{3}{|c|}{ ICEI Expectativa } & \multicolumn{2}{|c|}{ Retorno Ibovespa } & \multicolumn{3}{|c|}{ Número de F\&As } & \multicolumn{3}{|c|}{$\begin{array}{l}\text { Utilização Capacidade } \\
\text { Instalada }\end{array}$} & \multicolumn{4}{|c|}{ IBC - BR } \\
\hline & & Alta & Baixa & \multicolumn{2}{|l|}{ Alta } & Baixa & \multirow{2}{*}{$\begin{array}{l}\text { Alta } \\
42\end{array}$} & \multirow{2}{*}{$\begin{array}{c}\text { Baixa } \\
20\end{array}$} & \multirow{2}{*}{$\begin{array}{l}\text { Alta } \\
51\end{array}$} & \multicolumn{2}{|l|}{ Baixa } & Alta & \multicolumn{2}{|l|}{ Baixa } & \multicolumn{2}{|l|}{ Alta } & \multicolumn{2}{|l|}{ Baixa } \\
\hline & 113 & 36 & 34 & 31 & & 30 & & & & 23 & & 56 & 14 & & 23 & & 33 & \\
\hline Dia & & & & & & & & & & & & & & & & & & \\
\hline-10 & $0.1 \%$ & $-0.2 \%$ & $0.2 \%$ & $-0.2 \%$ & & $0.1 \%$ & $0.1 \%$ & $-0.5 \%$ & $0.2 \%$ & $0.1 \%$ & & $0.2 \%$ & $-0.5 \%$ & & $-0.3 \%$ & & $0.5 \%$ & \\
\hline-9 & $0.0 \%$ & $0.2 \%$ & $0.3 \%$ & $0.0 \%$ & & $0.5 \%$ & $-0.3 \%$ & $0.2 \%$ & $0.1 \%$ & $-0.7 \%$ & & $0.4 \%$ & $0.0 \%$ & & $-0.1 \%$ & & $0.4 \%$ & \\
\hline-8 & $-0.1 \%$ & $0.1 \%$ & $0.0 \%$ & $-0.1 \%$ & & $-0.2 \%$ & $0.0 \%$ & $0.0 \%$ & $0.4 \%$ & $0.1 \%$ & & $0.1 \%$ & $-0.6 \%$ & & $-0.2 \%$ & & $-0.3 \%$ & \\
\hline-7 & $0.0 \%$ & $-0.2 \%$ & $0.2 \%$ & $0.0 \%$ & & $0.4 \%$ & $-0.3 \%$ & $0.9 \%$ & $0.2 \%$ & $0.0 \%$ & & $0.3 \%$ & $0.1 \%$ & & $-0.7 \%$ & v & $-0.1 \%$ & \\
\hline-6 & $0.2 \%$ & $0.1 \%$ & $0.2 \%$ & $0.6 \%$ * & $\sqrt{ }$ & $0.5 \%$ & $-0.4 \%$ & $0.2 \%$ & $-0.2 \%$ & $0.5 \%$ & & $0.0 \%$ & $0.0 \%$ & & $0.6 \% *$ & $\sqrt{ } V$ & $0.4 \%$ & \\
\hline-5 & $0.2 \%$ & $0.1 \%$ & $0.3 \%$ & $0.1 \%$ & & $0.5 \%$ & $0.1 \%$ & $0.3 \%$ & $0.4 \%$ & $-0.1 \%$ & & $0.3 \%$ & $0.0 \%$ & & $0.1 \%$ & & $0.7 \% *$ & \\
\hline-4 & $-0.3 \% \quad \sqrt{ } \sqrt{ }$ & $-0.2 \%$ & $-0.5 \%$ & $-0.3 \%$ & & $-0.4 \%$ & $-0.1 \%$ & $-0.2 \%$ & $0.0 \%$ & $-0.5 \%$ & $\sqrt{ }$ & $-0.3 \%$ & $-0.7 \%$ & & $-0.5 \% *$ & $\sqrt{ } V$ & $-0.5 \% *$ & $\sqrt{ } \mathrm{V}$ \\
\hline-3 & $-0.1 \%$ & $0.6 \% *$ & $-0.4 \%$ & $0.4 \%$ & & $-0.3 \%$ & $-0.3 \%$ & $0.1 \%$ & $-0.1 \%$ & $-0.1 \%$ & & $-0.2 \%$ & $1.4 \%$ & & $0.0 \%$ & & $0.4 \%$ & \\
\hline-2 & $-0.3 \%$ & $0.2 \%$ & $-0.9 \% * * \sqrt{ }$ & $-0.1 \%$ & & $-0.8 \%$ & $-0.2 \%$ & $-0.6 \%$ & $-0.4 \%$ & $0.1 \%$ & & $-0.3 \%$ & $-0.4 \%$ & & $-0.4 \%$ & & $-0.1 \%$ & \\
\hline-1 & $0.2 \%$ & $0.7 \%$ & $-0.5 \%$ & $0.9 \%$ & & $-0.7 \%$ & $0.2 \%$ & $-0.7 \%$ & $0.3 \%$ & $-0.5 \%$ & & $0.7 \% *$ & $-0.9 \%$ & & $-0.3 \%$ & & $0.8 \%$ & \\
\hline $\begin{array}{l}\text { Anúncio } \\
\text { Evento }\end{array}$ & $0.6 \% * * \sqrt{ }$ & $0.4 \%$ & $0.8 \%$ & $0.4 \%$ & & $0.9 \%$ & $0.8 \% * * \quad \sqrt{ }$ & $0.3 \%$ & $0.5 \%$ & $0.7 \% *$ & & $0.8 \% * \quad \sqrt{ }$ & $0.7 \%$ & & $0.1 \%$ & & $0.2 \%$ & \\
\hline 1 & $0.2 \%$ & $0.0 \%$ & $0.5 \%$ & $-0.2 \%$ & & $0.3 \%$ & $0.0 \%$ & $0.0 \%$ & $-0.1 \%$ & $0.9 \% * *$ & $\sqrt{ }$ & $0.1 \%$ & $1.4 \% *$ & v & $0.0 \%$ & & $-0.1 \%$ & \\
\hline 2 & $0.0 \%$ & $0.4 \% *$ & $-0.6 \%$ & $0.2 \%$ & & $-0.7 \%$ & $0.0 \%$ & $-0.4 \%$ & $0.2 \%$ & $-0.1 \%$ & & $-0.1 \%$ & $-0.2 \%$ & & $0.4 \%$ & & $0.4 \%$ & \\
\hline 3 & $0.1 \%$ & $0.0 \%$ & $0.3 \%$ & $0.0 \%$ & & $0.0 \%$ & $0.2 \%$ & $0.4 \%$ & $0.3 \%$ & $-0.6 \% *$ & & $0.1 \%$ & $-0.5 \%$ & & $-0.2 \%$ & & $0.7 \%$ & \\
\hline 4 & $0.1 \%$ & $0.2 \%$ & $0.2 \%$ & $0.1 \%$ & & $0.4 \%$ & $0.2 \%$ & $0.6 \%$ & $0.5 \%$ & $0.3 \%$ & & $0.5 \%$ & $-0.4 \%$ & & $-0.1 \%$ & & $0.1 \%$ & \\
\hline 5 & $-0.1 \%$ & $0.1 \%$ & $0.1 \%$ & $0.5 \%$ & & $0.3 \%$ & $-0.5 \%$ & $-0.2 \%$ & $-0.6 \% *$ & $0.5 \%$ & & $0.2 \%$ & $-0.4 \%$ & & $0.7 \%$ & & $0.0 \%$ & \\
\hline 6 & $-0.3 \%$ & $-0.1 \%$ & $-0.3 \%$ & $0.0 \%$ & & $-0.4 \%$ & $-0.2 \%$ & $0.0 \%$ & $-0.2 \%$ & $-0.6 \% *$ & & $-0.4 \%$ & $0.9 \%$ & & $0.3 \%$ & & $-0.7 \%$ & \\
\hline 7 & $0.3 \% *$ & $-0.2 \%$ & $0.0 \%$ & $-0.1 \%$ & & $0.5 \%$ & $-0.2 \%$ & $0.3 \%$ & $0.4 \%$ & $0.4 \%$ & & $0.5 \%$ * & $0.6 \%$ & & $0.2 \%$ & & $0.3 \%$ & \\
\hline 8 & $-0.2 \%$ & $-0.7 \% * * \quad \sqrt{ }$ & $0.0 \%$ & $-0.5 \% * *$ & v & $0.3 \%$ & $-0.5 \%$ & $0.1 \%$ & $-0.1 \%$ & $0.2 \%$ & & $0.1 \%$ & $-1.3 \%$ & $\sqrt{ } V$ & $-0.2 \%$ & & $-0.5 \% *$ & V \\
\hline 9 & $0.1 \%$ & $0.1 \%$ & $0.7 \%$ & $0.1 \%$ & & $0.4 \%$ & $0.2 \%$ & $0.3 \%$ & $-0.3 \%$ & $-0.1 \%$ & & $-0.2 \%$ & $1.6 \%$ & & $0.2 \%$ & & $-0.1 \%$ & \\
\hline 10 & $0.0 \%$ & $0.1 \%$ & $0.1 \%$ & $0.0 \%$ & & $0.0 \%$ & $0.5 \%$ & $0.6 \%$ & $0.4 \%$ & $-0.2 \%$ & & $0.3 \%$ & $0.3 \%$ & & $0.1 \%$ & & $-0.5 \%$ & \\
\hline CAR_3 & $1.0 \% * *$ & $1.1 \%$ & $0.8 \%$ & $1.1 \%$ & & $0.4 \%$ & $1.0 \%$ & $-0.4 \%$ & $0.7 \%$ & $1.1 \%$ & & $1.6 \% * * \quad \sqrt{ } \sqrt{ }$ & $1.2 \%$ & & $-0.2 \%$ & & $0.9 \%$ & \\
\hline CAR_11 & $0.7 \%$ & $2.6 \% * * \quad \sqrt{ } \sqrt{ }$ & $-0.7 \%$ & $2.0 \% *$ & & $-0.6 \%$ & $0.4 \%$ & $-0.3 \%$ & $0.9 \%$ & $0.5 \%$ & & $1.7 \% *$ & $0.2 \%$ & & $-0.3 \%$ & & $2.6 \% * *$ & \\
\hline CAR 21 & $0.9 \%$ & $1.9 \%$ & $0.6 \%$ & $1.6 \%$ & & $1.6 \%$ & $-0.8 \%$ & $1.8 \%$ & $1.9 \% *$ & $0.2 \%$ & & $3.1 \% * * * \quad \sqrt{ } \sqrt{ }$ & $1.2 \%$ & & $-0.3 \%$ & & $1.9 \%$ & \\
\hline
\end{tabular}

Fonte: Elaborado pelo Autor

Notas: $\quad *$ denota significância estatística para o teste t: * p-value $<10 \% ; \quad * *$ p-value $<5 \% ; \quad * * *$ p-value $<1 \%$

$\sqrt{ }$ denota significância estatística para o teste de Wilcoxon: $\sqrt{ }$ p-value $<10 \% ; \quad \sqrt{ } \sqrt{ }$-value $<5 \% ; \quad \sqrt{ } \sqrt{ }$ p-value $<1 \%$

A tabela mostra os retornos anormais diários médios (para dez dias em torno do dia do anúncio da F\&A) e acumulado para as janelas de três, onze e vinte e um dias (CAR_3, CAR_11 e CAR_21).

O retorno anormal médio é apresentado para a amostra de eventos sem sobreposição de efeitos de outros fatos relevantes e para sub amostras desses mesmos eventos obtidas com base no estado do sentimento de mercado (em alta ou baixa), quando classificado segundo as proxies: ICEI, ICEI Expectativa, Retorno Ibovespa, Número de F\&A, Nível de Utilização da Capacidade Instalada e IBC-BR 
No Gráfico 3 é apresentada a criação de valor média acumulada iniciando no décimo dia anterior ao anúncio do evento até o décimo dia posterior ao anúncio. A linha contínua demonstra a criação de valor média de todos os 113 eventos; o comportamento do retorno anormal das sub amostras de mercado em alta e de mercado em baixa pode ser visualizado respectivamente pela linha tracejada e pela linha pontilhada. Cada uma das seis áreas do gráfico utiliza uma proxy distinta para segmentar o estado do mercado: ICEI, ICEI EXPECTATIVA, RETORNO IBOVESPA, NÚMERO DE F\&As, UTILIZAÇÃO CAPACIDADE INSTALADA e IBC-BR.

\section{Gráfico 3 - Retorno Anormal Acumulado Segundo Proxies de Sentimento de Mercado}
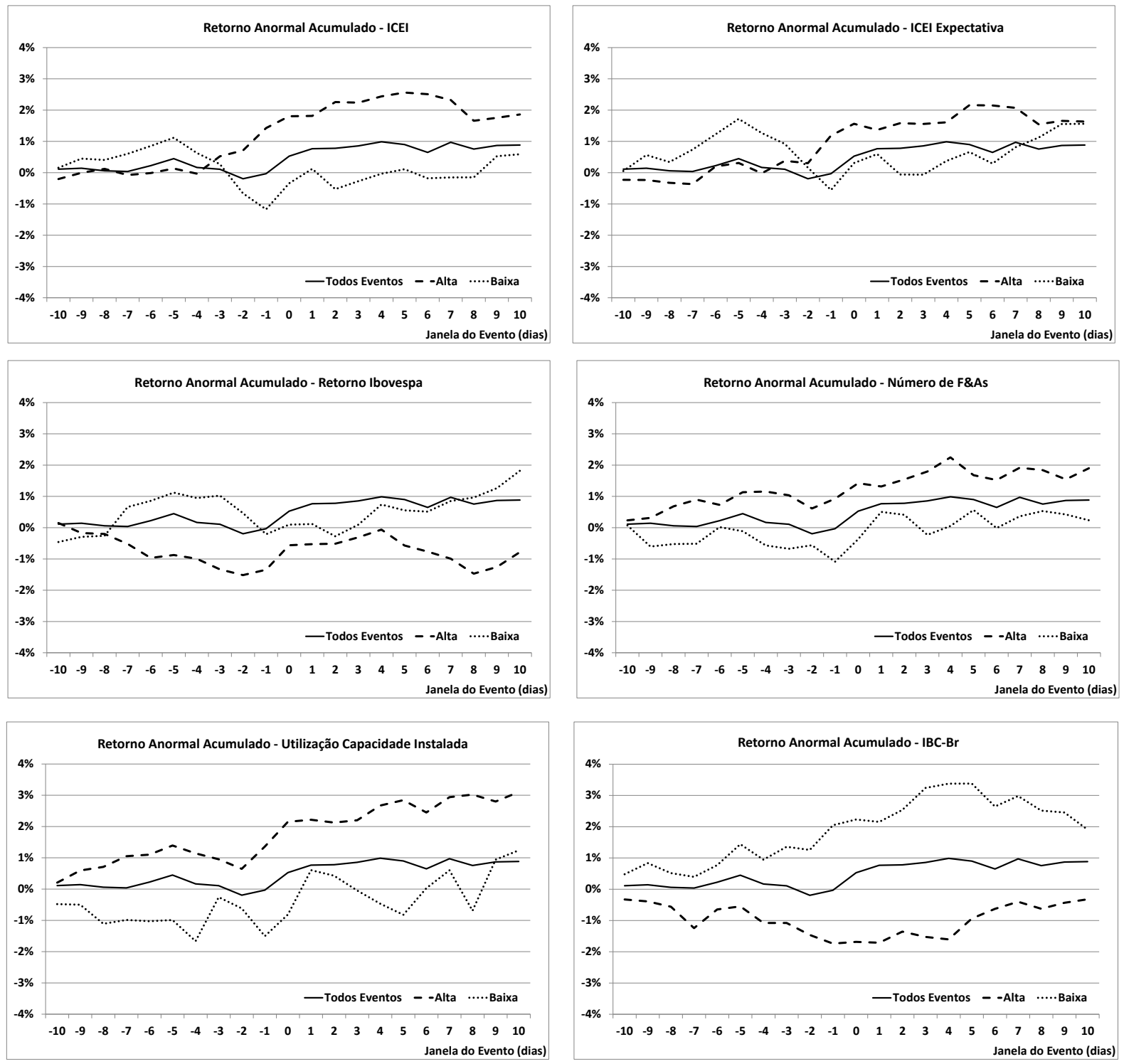

FONTE: Elaborado pelo autor 
Para a amostra total, o retorno anormal acumulado médio oscila em torno do zero até o anúncio do evento. Parece haver criação de valor no dia do anúncio e no dia seguinte, a partir do qual a criação de valor acumulada oscila em torno do patamar alcançado.

Os resultados são distintos quando as sub amostras são analisadas e existe variabilidade dos mesmos em função da forma como o sentimento de mercado é determinado. Não é possível observar a dominância de um comportamento único: ora as sub amostras de eventos anunciados durante momentos de mercado em alta parecem apresentar maior criação de valor, ora ocorre o contrário.

A Tabela 3 apresenta os resultados do teste de médias de Mann Whitney do retorno anormal para cada par de sub amostras (mercado em alta vs. mercado em baixa) na data do anúncio dos eventos e para as janelas de estudo de três, onze e vinte e um dias. De forma geral, segundo esse teste, para as amostras estudadas não haveria indício de criação de valor estatisticamente distinta em função do estado do mercado.

Há apenas um caso onde se poderia afirmar que a criação de valor é distinta entre momentos de mercado em alta e de mercado em baixa com significância estatística de 10\%; nesse caso a criação de valor é menor em momentos de mercado em baixa.

Tabela 3 - Teste Mann Whitney para duas amostras

\begin{tabular}{|c|c|c|c|c|c|c|}
\hline & ICEI & ICEI Exp & $\begin{array}{l}\text { Retorno } \\
\text { Ibovespa }\end{array}$ & $\begin{array}{c}\text { Número de } \\
\text { F\&As }\end{array}$ & $\begin{array}{l}\text { Utilização Capa- } \\
\text { cidade Instalada }\end{array}$ & IBC-BR \\
\hline \multicolumn{7}{|c|}{ Criação de Valor: Mercado em Alta } \\
\hline Dia Anúncio & $0.4 \%$ & $0.4 \%$ & $0.8 \%$ & $0.5 \%$ & $0.8 \%$ & $0.1 \%$ \\
\hline CAR_3 & $1.1 \%$ & $1.1 \%$ & $1.0 \%$ & $0.7 \%$ & $1.6 \%$ & $-0.2 \%$ \\
\hline CAR_11 & $2.6 \%$ & $2.0 \%$ & $0.4 \%$ & $0.9 \%$ & $1.7 \%$ & $-0.3 \%$ \\
\hline CAR_21 & $1.9 \%$ & $1.6 \%$ & $-0.8 \%$ & $1.9 \%$ & $3.1 \%$ & $-0.3 \%$ \\
\hline \multicolumn{7}{|c|}{ Criação de Valor: Mercado em Baixa } \\
\hline Dia Anúncio & $0.8 \%$ & $0.9 \%$ & $0.3 \%$ & $0.7 \%$ & $0.7 \%$ & $0.2 \%$ \\
\hline CAR_3 & $0.8 \%$ & $0.4 \%$ & $-0.4 \%$ & $1.1 \%$ & $1.2 \%$ & $0.9 \%$ \\
\hline CAR_11 & $-0.7 \%$ & $-0.6 \%$ & $-0.3 \%$ & $0.5 \%$ & $0.2 \%$ & $2.6 \%$ \\
\hline CAR_21 & $0.6 \%$ & $1.6 \%$ & $1.8 \%$ & $0.2 \%$ & $1.2 \%$ & $1.9 \%$ \\
\hline \multicolumn{7}{|l|}{ P-Value } \\
\hline Dia Anúncio & 0.410 & 0.683 & 0.805 & 0.491 & 0.415 & 0.704 \\
\hline CAR_3 & 0.653 & 0.514 & 0.174 & 0.683 & 0.763 & 0.201 \\
\hline CAR_11 & 0.067 & 0.183 & 0.459 & 0.779 & 0.644 & 0.201 \\
\hline CAR_21 & 0.517 & 0.971 & 0.211 & 0.387 & 0.676 & 0.437 \\
\hline
\end{tabular}

Fonte: Elaborado pelo Autor

Nota. A tabela apresenta o resultado ( $p$-value) do teste de Mann-Whitney para a hipótese nula de que a criação de valor em momentos de mercado em baixa é igual à criação de valor em momentos de mercado em alta. 


\subsection{Criação de Valor em F\&As: Análise Multivariada}

Nas análises 4.2.1 e 4.2.2 a amostra com 113 elementos é mantida, ou seja, desconsideram-se todos os eventos que poderiam ter seu retorno anormal impactado pela sobreposição de outros fatores (fatos relevantes), diferentes do estudado neste trabalho. A análise 4.2.3 utiliza uma variável de controle adicional no modelo de regressão e a amostra passa a incorporar 346 eventos.

\section{Tabela 4 - Criação de Valor: Correlação com demais Variáveis}

\begin{tabular}{|c|c|c|c|c|c|c|c|}
\hline & Dia Anúncio & Janela 3 dias & & Janela 11 dias & & Janela 21 dias & \\
\hline \multicolumn{8}{|l|}{$\underline{\text { Mercado em Alta }}$} \\
\hline ICEI & -0.04 & 0.02 & & 0.19 & $* *$ & 0.09 & \\
\hline ICEI Expectativa & -0.04 & 0.02 & & 0.11 & & 0.06 & \\
\hline Número Aquisições & -0.02 & -0.04 & & 0.02 & & 0.13 & \\
\hline Retorno Ibovespa & 0.06 & 0.01 & & -0.06 & & -0.16 & $*$ \\
\hline Utilização Capacidade Instalada & 0.08 & 0.13 & & 0.15 & & 0.30 & $* *$ \\
\hline IBCBR & -0.09 & -0.13 & & -0.09 & & -0.08 & \\
\hline \multicolumn{8}{|l|}{ Mercado em Baixa } \\
\hline ICEI & 0.06 & -0.03 & & -0.11 & & -0.04 & \\
\hline ICEI Expectativa & 0.06 & -0.08 & & -0.08 & & 0.04 & \\
\hline Número Aquisições & 0.02 & 0.00 & & -0.01 & & -0.04 & \\
\hline Retorno Ibovespa & -0.05 & -0.14 & & -0.02 & & 0.05 & \\
\hline Utilização Capacidade Instalada & 0.01 & 0.01 & & 0.05 & & 0.00 & \\
\hline IBCBR & -0.08 & -0.01 & & 0.18 & $*$ & 0.09 & \\
\hline \multicolumn{8}{|l|}{$\underline{\text { Variáveis de Controle }}$} \\
\hline ValorMerc / ValorCont & 0.04 & 0.09 & & -0.05 & & -0.10 & \\
\hline Endividamento / Ativos Totais & 0.04 & 0.10 & & 0.06 & & -0.04 & \\
\hline Tamanho Relativo Operação & -0.01 & 0.07 & & 0.09 & & -0.10 & \\
\hline Tamanho Adquirente & -0.08 & -0.13 & & -0.06 & & -0.09 & \\
\hline Empresas Relacionadas & 0.10 & -0.05 & & -0.07 & & 0.00 & \\
\hline Momento (Ebitda / Ativo Total) & -0.07 & -0.11 & & -0.25 & $* *$ & -0.22 & $* *$ \\
\hline Aquisição Internacional & 0.05 & -0.03 & & -0.10 & & 0.06 & \\
\hline Aquisição Controle & 0.13 & 0.10 & & 0.03 & & 0.03 & \\
\hline Recenticidade & -0.05 & -0.19 & $*$ & -0.10 & & 0.09 & \\
\hline Experiência & -0.09 & -0.09 & & -0.17 & $*$ & -0.05 & \\
\hline
\end{tabular}

Fonte: Elaborado pelo Autor

Notas: * denota significância estatística: * p-value $<10 \%$; $\quad * *$ p-value $<5 \%$; $\quad * * *$ p-value $<1 \%$

Correlação de Pearson da criação de valor no dia do anúncio e nas janelas de três, onze e vinte e um dias como sentimento de mercado e demais variáveis de controle. 


\subsubsection{Criação de Valor: Correlação com Demais Variáveis.}

A criação de valor no dia do anúncio dos eventos e nas janelas de três, onze e vinte e um dias tem sua correlação analisada segundo o teste de Pearson frente o sentimento de mercado e as diferentes variáveis de controle do estudo, como mostra a Tabela 4.

Pode-se notar que não parece haver um nível de correlação elevado das variáveis com a criação de valor e em apenas alguns poucos casos há evidência estatística para se afirmar que existe de fato correlação; nota-se correlação estatisticamente significante entre criação de valor e as variáveis de mercado em alta, mercado em baixa, momento, recenticidade e experiência.

Um ponto interessante é o fato de que a correlação entre criação de valor e mercado em alta parece ter relação contrária, na maioria dos casos, do que a correlação entre criação de valor e mercado em baixa.

\subsubsection{Regressão Multivariada: Amostra sem Sobreposição de Efeitos}

As quatro tabelas apresentadas no final desta seção (Tabela 5, Tabela 6, Tabela 7 e Tabela 8) trazem os resultados das regressões cross section realizadas para as quatro janelas de tempo estudadas, para seis modelos distintos (cada qual baseado em uma proxy de sentimento de mercado) e duas análises (com e sem a exclusão de possíveis outliers).

Embora sem significância estatística, no dia do anúncio das F\&As, a criação de valor que ocorre em momentos de mercado em alta parece ser mais negativa que o valor criado em F\&As que ocorrem em momentos de mercado em baixa para cinco dos seis modelos.

Para janelas de tempo maiores, principalmente na janela de estudo de três e onze dias, parece haver inversão dos resultados notando-se predomínio de criação de valor mais elevada em momentos de mercado em alta. A maioria dos coeficientes obtidos para a variável de sentimento de mercado em alta se apresenta sem significância estatística, havendo uma única 
exceção na análise da janela de onze dias e, neste caso, há indicação de maior criação de valor em momentos de mercado em alta. (modelo com proxy ICEI)

De forma geral, é possível observar que há grande variabilidade nos resultados encontrados para a variável de sentimento de mercado em alta; de fato, cerca de metade dos coeficientes obtidos nas regressões realizadas apresenta sinal negativo e a outra metade indica comportamento contrário.

Nas análises com exclusão de possíveis outliers há pequena alteração nos resultados obtidos para a variável de sentimento de mercado em alta nas janelas de um e três dias. Os resultados continuam sem significância estatística, mas há a mudança de sinal do coeficiente da variável em alguns casos. Nas janelas de estudo de onze e vinte e um dias, por outro lado, não há exclusão de nenhum evento e as tabelas apenas repetem os mesmos resultados.

Em alguns modelos também existe significância estatística para os resultados obtidos para algumas variáveis de controle, dentre elas: momento, recenticidade, experiência, aquisição de controle e tamanho relativo da operação. Exceto pela variável aquisição de controle, em todos os casos parece haver contribuição negativa dessas variáveis, ou seja, menor criação de valor para empresas de melhor desempenho recente (momento), que se envolveram em um maior número de F\&As (experiência) ou que o fizeram recentemente (recenticidade) e quando o valor da operação de F\&A é representativo (mais relevante) para a empresa adquirente.

Três variáveis de controle apresentam resultados com significância estatística em todos os seis modelos (independentemente da proxy adotada para representar o sentimento de mercado): recenticidade na análise do retorno anormal da janela de três dias (com ou sem exclusão de outliers), momento nas janelas de onze e vinte e um dias (com ou sem exclusão de outliers) e tamanho relativo da operação na janela de vinte e um dias (com ou sem exclusão de outliers). 
Tabela 5 - Análise de Regressão dos Determinantes de Criação de Valor - Dia do Anúncio

\begin{tabular}{|c|c|c|c|c|c|c|}
\hline Amostra Completa & 1) ICEI & $\begin{array}{c}\text { 2) ICEI } \\
\text { Expectativa }\end{array}$ & $\begin{array}{l}\text { 3) Num } \\
\text { F\&As }\end{array}$ & $\begin{array}{l}\text { 4) Retorno } \\
\text { Ibovespa }\end{array}$ & $\begin{array}{l}\text { 5) Util. Cap. } \\
\text { Instalada }\end{array}$ & 6) IBC-BR \\
\hline Mercado em Alta & $-0.3 \%$ & $-0.2 \%$ & $-0.4 \%$ & $0.4 \%$ & $-0.1 \%$ & $-0.4 \%$ \\
\hline Mercado Neutro & $-0.5 \%$ & $-0.4 \%$ & $-0.2 \%$ & $0.0 \%$ & $-0.5 \%$ & $0.6 \%$ \\
\hline \multicolumn{7}{|l|}{ Variáveis de Controle } \\
\hline ValorMerc / ValorCont & $0.0 \%$ & $0.0 \%$ & $0.0 \%$ & $0.0 \%$ & $0.0 \%$ & $0.0 \%$ \\
\hline Endiv / Ativos Totais & $0.8 \%$ & $0.9 \%$ & $0.6 \%$ & $0.5 \%$ & $0.7 \%$ & $-0.2 \%$ \\
\hline Tam Rel Operação & $-0.8 \%$ & $-0.9 \%$ & $-1.1 \%$ & $-1.3 \%$ & $-0.8 \%$ & $-0.6 \%$ \\
\hline Tam Adquirente & $0.3 \%$ & $0.3 \%$ & $0.3 \%$ & $0.2 \%$ & $0.2 \%$ & $0.3 \%$ \\
\hline Empresas Relacionadas & $0.6 \%$ & $0.6 \%$ & $0.6 \%$ & $0.6 \%$ & $0.6 \%$ & $0.4 \%$ \\
\hline Momento (Ebitda / Ativ Total) & $-4.7 \%$ & $-4.5 \%$ & $-5.2 \%$ & $-5.3 \%$ & $-4.2 \%$ & $-4.0 \%$ \\
\hline Aquisição Internacional & $0.4 \%$ & $0.4 \%$ & $0.4 \%$ & $0.4 \%$ & $0.4 \%$ & $0.4 \%$ \\
\hline Aquisição Controle & $0.9 \%$ & $0.9 \%$ & $0.8 \%$ & $0.8 \%$ & $0.8 \%$ & $1.0 \%$ \\
\hline Recenticidade & $-0.4 \%$ & $-0.4 \%$ & $-0.3 \%$ & $-0.4 \%$ & $-0.5 \%$ & $-0.5 \%$ \\
\hline Experiência & $-0.2 \%$ & $-0.2 \%$ & $-0.2 \%$ & $-0.2 \%$ & $-0.2 \%$ & $-0.2 \%$ \\
\hline$-\overline{\text { Tamanho }} \overline{\text { Amostra }}---$ & $-11 \overline{3}$ & $\overline{113}--$ & $-\overline{113}-$ & $\overline{113}-$ & $-11 \overline{3}-$ & $\overline{111}-$ \\
\hline $\mathrm{R}^{2}$ Ajustado & -0.052 & -0.053 & -0.055 & -0.053 & -0.053 & -0.040 \\
\hline Estatítica F & 0.541 & 0.530 & 0.516 & 0.531 & 0.529 & 0.648 \\
\hline Teste Breusch-Pagan & 0.080 & 0.067 & 0.062 & 0.142 & 0.080 & 0.047 \\
\hline Teste Reset & 0.616 & 0.456 & 0.435 & 0.670 & 0.646 & 0.913 \\
\hline
\end{tabular}

\begin{tabular}{|c|c|c|c|c|c|c|c|c|c|c|c|}
\hline Exclusão Outliers & \multicolumn{2}{|c|}{ 1) ICEI } & \multicolumn{2}{|c|}{$\begin{array}{c}\text { 2) ICEI } \\
\text { Expectativa }\end{array}$} & \multicolumn{2}{|c|}{$\begin{array}{l}\text { 3) Num } \\
\text { F\&As }\end{array}$} & $\begin{array}{l}\text { 4) Retorno } \\
\text { Ibovespa }\end{array}$ & \multicolumn{2}{|c|}{$\begin{array}{l}\text { 5) Util. Cap. } \\
\text { Instalada }\end{array}$} & \multicolumn{2}{|c|}{ 6) IBC-BR } \\
\hline Mercado em Alta & $0.3 \%$ & & $0.3 \%$ & & $-0.4 \%$ & & $0.8 \%$ & $-0.7 \%$ & & $-0.4 \%$ & \\
\hline Mercado Neutro & $0.0 \%$ & & $0.0 \%$ & & $-0.7 \%$ & & $0.6 \%$ & $-1.3 \%$ & & $0.6 \%$ & \\
\hline \multicolumn{12}{|l|}{ Variáveis de Controle } \\
\hline ValorMerc / ValorCont & $0.0 \%$ & & $0.0 \%$ & & $0.0 \%$ & & $0.0 \%$ & $0.0 \%$ & & $0.0 \%$ & \\
\hline Endiv / Ativos Totais & $0.1 \%$ & & $0.2 \%$ & & $0.0 \%$ & & $-0.7 \%$ & $-0.5 \%$ & & $-1.9 \%$ & \\
\hline Tam Rel Operação & $-1.8 \%$ & & $-1.8 \%$ & & $-1.7 \%$ & & $-1.4 \%$ & $-0.8 \%$ & & $-1.0 \%$ & \\
\hline Tam Adquirente & $0.3 \%$ & & $0.3 \%$ & & $0.3 \%$ & & $0.1 \%$ & $0.3 \%$ & & $0.3 \%$ & \\
\hline Empresas Relacionadas & $0.7 \%$ & & $0.7 \%$ & & $0.5 \%$ & & $0.8 \%$ & $0.3 \%$ & & $0.1 \%$ & \\
\hline Momento (Ebitda / Ativ Total) & $-7.7 \%$ & $* *$ & $-7.6 \%$ & $* *$ & $-8.4 \%$ & $* *$ & $-6.0 \%$ & $-4.6 \%$ & & $-5.5 \%$ & \\
\hline Aquisição Internacional & $0.6 \%$ & & $0.6 \%$ & & $0.6 \%$ & & $0.6 \%$ & $0.5 \%$ & & $0.4 \%$ & \\
\hline Aquisição Controle & $0.7 \%$ & & $0.7 \%$ & & $0.6 \%$ & & $0.3 \%$ & $0.5 \%$ & & $0.7 \%$ & \\
\hline Recenticidade & $-1.5 \%$ & $* *$ & $-1.5 \%$ & $* *$ & $-1.5 \%$ & * & $-1.1 \%$ & $-1.3 \%$ & * & $-1.3 \%$ & * \\
\hline Experiência & $-0.1 \%$ & & $-0.2 \%$ & & $-0.2 \%$ & & $-0.2 \%$ & $-0.2 \%$ & & $-0.2 \%$ & \\
\hline$\overline{\text { Tamanho Amostra }}---$ & $-\overline{110}-$ & - & $-11 \overline{0}$ & -- & $\overline{110}-$ & - & $-{ }_{109}-$ & $-\overline{109}-$ & - & $-10 \overline{7}$ & - \\
\hline $\mathrm{R}^{2}$ Ajustado & 0.021 & & 0.021 & & 0.028 & & 0.015 & 0.025 & & 0.035 & \\
\hline Estatítica F & 1.196 & & 1.199 & & 1.263 & & 1.141 & 1.233 & & 1.319 & \\
\hline Teste Breusch-Pagan & 0.174 & & 0.244 & & 0.361 & & 0.499 & 0.037 & & 0.040 & \\
\hline Teste Reset & 0.363 & & 0.356 & & 0.936 & & 0.095 & 0.339 & & 0.026 & \\
\hline
\end{tabular}

Fonte: Elaborado pelo Autor

Notas: * denota significância estatística: * p-value $<10 \% ; \quad * *$ p-value $<5 \% ; \quad * * *$ p-value $<1 \%$ Quando o Teste de Breusch-Pagan indica heterocedasticidade, a significância estatística adota a metodologia de erros robustos.

A tabela apresenta os resultados da regressão cross section do retorno anormal no dia do anúncio da F\&A. São apresentados os resultados de seis modelos, cada qual assumindo uma proxy diferente para classificação do estado de mercado. 
Tabela 6 - Análise de Regressão dos Determinantes de Criação de Valor - Janela de Três Dias

\begin{tabular}{|c|c|c|c|c|c|c|c|c|c|c|c|c|}
\hline Amostra Completa & \multicolumn{2}{|c|}{ 1) ICEI } & \multicolumn{2}{|c|}{$\begin{array}{l}\text { 2) ICEI } \\
\text { Expectativa }\end{array}$} & \multicolumn{2}{|c|}{$\begin{array}{l}\text { 3) Num } \\
\text { F\&As }\end{array}$} & \multicolumn{2}{|c|}{$\begin{array}{l}\text { 4) Retorno } \\
\text { Ibovespa }\end{array}$} & \multicolumn{2}{|c|}{$\begin{array}{l}\text { 5) Util. Cap. } \\
\text { Instalada }\end{array}$} & \multicolumn{2}{|c|}{ 6) IBC-BR } \\
\hline Mercado em Alta & $0.3 \%$ & & $0.6 \%$ & & $0.1 \%$ & & $0.9 \%$ & & $-0.1 \%$ & & $-1.8 \%$ & \\
\hline Mercado Neutro & $-0.1 \%$ & & $0.5 \%$ & & $0.0 \%$ & & $1.2 \%$ & & $-1.7 \%$ & & $0.3 \%$ & \\
\hline \multicolumn{13}{|l|}{ Variáveis de Controle } \\
\hline ValorMerc / ValorCont & $0.1 \%$ & & $0.1 \%$ & & $0.1 \%$ & & $0.1 \%$ & & $0.1 \%$ & & $0.1 \%$ & \\
\hline Endiv / Ativos Totais & $4.5 \%$ & & $4.2 \%$ & & $4.4 \%$ & & $4.1 \%$ & & $4.5 \%$ & & $2.9 \%$ & \\
\hline Tam Rel Operação & $0.1 \%$ & & $0.0 \%$ & & $0.4 \%$ & & $-0.2 \%$ & & $1.2 \%$ & & $0.8 \%$ & \\
\hline Tam Adquirente & $-0.1 \%$ & & $-0.1 \%$ & & $-0.1 \%$ & & $-0.1 \%$ & & $-0.1 \%$ & & $-0.1 \%$ & \\
\hline Empresas Relacionadas & $0.0 \%$ & & $0.0 \%$ & & $-0.1 \%$ & & $0.0 \%$ & & $-0.2 \%$ & & $-0.3 \%$ & \\
\hline Momento (Ebitda / Ativ Total) & $-6.2 \%$ & & $-6.4 \%$ & & $-6.1 \%$ & & $-6.9 \%$ & & $-3.9 \%$ & & $-3.5 \%$ & \\
\hline Aquisição Internacional & $0.5 \%$ & & $0.5 \%$ & & $0.4 \%$ & & $0.3 \%$ & & $0.5 \%$ & & $0.6 \%$ & \\
\hline Aquisição Controle & $1.1 \%$ & & $1.0 \%$ & & $1.0 \%$ & & $0.8 \%$ & & $1.0 \%$ & & $1.4 \%$ & \\
\hline Recenticidade & $-2.7 \%$ & * & $-2.6 \%$ & * & $-2.7 \%$ & $*$ & $-2.5 \%$ & $*$ & $-2.9 \%$ & $*$ & $-3.2 \%$ & $* *$ \\
\hline Experiência & $0.2 \%$ & & $0.2 \%$ & & $0.2 \%$ & & $0.2 \%$ & & $0.3 \%$ & & $0.2 \%$ & \\
\hline$-\overline{\text { Tamanho }} \overline{\text { Amostra }}---$ & $-1 \overline{3}$ & 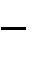 & $\overline{113}$ & & $-\overline{113}$ & & $\overline{113}-$ & & $-11 \overline{3}$ & - & $\overline{111}$ & - \\
\hline $\mathrm{R}^{2}$ Ajustado & -0.043 & & -0.043 & & -0.045 & & -0.036 & & -0.019 & & -0.015 & \\
\hline Estatítica F & 0.614 & & 0.619 & & 0.600 & & 0.675 & & 0.829 & & 0.865 & \\
\hline Teste Breusch-Pagan & 0.249 & & 0.497 & & 0.174 & & 0.473 & & 0.602 & & 0.340 & \\
\hline Teste Reset & 0.593 & & 0.689 & & 0.579 & & 0.443 & & 0.220 & & 0.564 & \\
\hline
\end{tabular}

\begin{tabular}{|c|c|c|c|c|c|c|c|c|c|c|c|c|c|}
\hline Exclusão Outliers & \multicolumn{2}{|c|}{ 1) ICEI } & \multicolumn{3}{|c|}{$\begin{array}{c}\text { 2) ICEI } \\
\text { Expectativa }\end{array}$} & \multicolumn{2}{|c|}{$\begin{array}{l}\text { 3) Num } \\
\text { F\&As }\end{array}$} & \multicolumn{2}{|c|}{$\begin{array}{l}\text { 4) Retorno } \\
\text { Ibovespa }\end{array}$} & \multicolumn{2}{|c|}{$\begin{array}{l}\text { 5) Util. Cap. } \\
\text { Instalada } \\
\end{array}$} & \multicolumn{2}{|c|}{ 6) IBC-BR } \\
\hline Mercado em Alta & $1.0 \%$ & & $1.3 \%$ & & & $-0.1 \%$ & & $1.0 \%$ & & $-0.4 \%$ & & $-1.8 \%$ & \\
\hline Mercado Neutro & $0.5 \%$ & & $1.1 \%$ & & & $-0.6 \%$ & & $1.0 \%$ & & $-1.9 \%$ & & $-0.3 \%$ & \\
\hline \multicolumn{14}{|l|}{ Variáveis de Controle } \\
\hline ValorMerc / ValorCont & $0.0 \%$ & & $0.0 \%$ & & & $0.0 \%$ & & $0.0 \%$ & & $0.1 \%$ & & $0.0 \%$ & \\
\hline Endiv / Ativos Totais & $4.9 \%$ & & $4.6 \%$ & & & $4.9 \%$ & & $4.6 \%$ & & $4.2 \%$ & & $4.1 \%$ & \\
\hline Tam Rel Operação & $-0.2 \%$ & & $-0.4 \%$ & & & $0.6 \%$ & & $-0.2 \%$ & & $1.9 \%$ & & $0.7 \%$ & \\
\hline Tam Adquirente & $0.3 \%$ & & $0.2 \%$ & & & $0.3 \%$ & & $0.3 \%$ & & $0.3 \%$ & & $0.3 \%$ & \\
\hline Empresas Relacionadas & $0.6 \%$ & & $0.7 \%$ & & & $0.3 \%$ & & $0.4 \%$ & & $0.0 \%$ & & $0.3 \%$ & \\
\hline Momento (Ebitda / Ativ Total) & $-8.4 \%$ & & $-8.9 \%$ & & & $-8.8 \%$ & & $-9.3 \%$ & & $-5.4 \%$ & & $-5.5 \%$ & \\
\hline Aquisição Internacional & $0.4 \%$ & & $0.3 \%$ & & & $0.3 \%$ & & $0.1 \%$ & & $0.4 \%$ & & $0.5 \%$ & \\
\hline Aquisição Controle & $0.9 \%$ & & $0.9 \%$ & & & $0.9 \%$ & & $0.8 \%$ & & $0.6 \%$ & & $1.2 \%$ & \\
\hline Recenticidade & $-3.3 \%$ & $* *$ & $-3.1 \%$ & ** & & $-3.3 \%$ & $* *$ & $-3.1 \%$ & $* *$ & $-2.7 \%$ & $* *$ & $-3.8 \%$ & $* * *$ \\
\hline Experiência & $0.1 \%$ & & $0.1 \%$ & & & $0.1 \%$ & & $0.1 \%$ & & $0.1 \%$ & & $0.1 \%$ & \\
\hline$\overline{\text { Tamanho Amostra }}---$ & $-\overline{112}-$ & - & -112 & - & - & $\overline{112}-$ & - & $-\overline{112}$ & - & $\overline{111}-$ & - & $-\overline{110}$ & - \\
\hline $\mathrm{R}^{2}$ Ajustado & -0.008 & & -0.002 & & & -0.012 & & -0.009 & & -0.004 & & 0.008 & \\
\hline Estatítica F & 0.924 & & 0.982 & & & 0.891 & & 0.920 & & 0.960 & & 1.070 & \\
\hline Teste Breusch-Pagan & 0.433 & & 0.396 & & & 0.250 & & 0.447 & & 0.214 & & 0.549 & \\
\hline Teste Reset & 0.662 & & 0.741 & & & 0.350 & & 0.747 & & 0.596 & & 0.510 & \\
\hline
\end{tabular}

Fonte: Elaborado pelo Autor

Notas: * denota significância estatística: * p-value $<10 \% ; \quad * *$ p-value $<5 \%$; $\quad * * *$ p-value $<1 \%$ Quando o Teste de Breusch-Pagan indica heterocedasticidade, a significância estatística adota a metodologia de erros robustos.

A tabela apresenta os resultados da regressão cross section do retorno anormal acumulado para a janela de três dias. São apresentados os resultados de seis modelos, cada qual assumindo uma proxy diferente para classificação do estado de mercado. 


\section{Tabela 7 - Análise de Regressão dos Determinantes de Criação de Valor - Janela de Onze Dias}

\begin{tabular}{|c|c|c|c|c|c|c|c|c|c|c|c|}
\hline Amostra Completa & \multicolumn{2}{|c|}{ 1) ICEI } & \multicolumn{2}{|c|}{$\begin{array}{c}\text { 2) ICEI } \\
\text { Expectativa }\end{array}$} & \multicolumn{2}{|c|}{$\begin{array}{l}\text { 3) Num } \\
\text { F\&As }\end{array}$} & \multicolumn{2}{|c|}{$\begin{array}{l}\text { 4) Retorno } \\
\text { Ibovespa }\end{array}$} & $\begin{array}{l}\text { 5) Util. Cap. } \\
\text { Instalada }\end{array}$ & \multicolumn{2}{|c|}{ 6) IBC-BR } \\
\hline Mercado em Alta & $2.9 \%$ & $*$ & $2.2 \%$ & & $-1.6 \%$ & & $1.5 \%$ & & $1.7 \%$ & $-1.8 \%$ & \\
\hline Mercado Neutro & $0.3 \%$ & & $0.6 \%$ & & $-1.9 \%$ & & $1.9 \%$ & & $0.1 \%$ & $-1.7 \%$ & \\
\hline Variáveis de Controle & & & & & & & & & & & \\
\hline ValorMerc / ValorCont & $0.0 \%$ & & $-0.1 \%$ & & $-0.1 \%$ & & $-0.1 \%$ & & $0.0 \%$ & $-0.1 \%$ & \\
\hline Endiv / Ativos Totais & $3.4 \%$ & & $3.4 \%$ & & $2.8 \%$ & & $2.5 \%$ & & $2.5 \%$ & $0.0 \%$ & \\
\hline Tam Rel Operação & $-1.7 \%$ & & $-1.0 \%$ & & $0.2 \%$ & & $-0.7 \%$ & & $0.6 \%$ & $-2.3 \%$ & \\
\hline Tam Adquirente & $0.8 \%$ & & $0.8 \%$ & & $1.0 \%$ & & $1.0 \%$ & & $1.0 \%$ & $0.7 \%$ & \\
\hline Empresas Relacionadas & $0.4 \%$ & & $0.2 \%$ & & $-0.5 \%$ & & $0.0 \%$ & & $-0.2 \%$ & $0.1 \%$ & \\
\hline Momento (Ebitda / Ativ Total) & $-19.8 \%$ & $*$ & $-19.7 \%$ & * & $-22.0 \%$ & $*$ & $-20.9 \%$ & $*$ & $-18.6 \% \quad *$ & $-21.7 \%$ & $* *$ \\
\hline Aquisição Internacional & $-1.0 \%$ & & $-1.2 \%$ & & $-1.4 \%$ & & $-1.7 \%$ & & $-1.6 \%$ & $-1.2 \%$ & \\
\hline Aquisição Controle & $0.5 \%$ & & $0.5 \%$ & & $0.3 \%$ & & $0.1 \%$ & & $0.1 \%$ & $0.6 \%$ & \\
\hline Recenticidade & $-0.2 \%$ & & $0.1 \%$ & & $0.3 \%$ & & $0.1 \%$ & & $-0.2 \%$ & $-1.3 \%$ & \\
\hline Experiência & $-0.7 \%$ & & $-0.7 \%$ & & $-0.8 \%$ & * & $-0.7 \%$ & & $-0.6 \%$ & $-0.6 \%$ & \\
\hline$\overline{\text { Tamanho }} \overline{\text { Amostra }}---$ & $-1 \overline{3}$ & 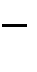 & $\overline{113}-$ & & $-\overline{113}$ & & $\overline{113}-$ & & $-{ }_{113}-$ & $\overline{111}-$ & - \\
\hline $\mathrm{R}^{2}$ Ajustado & 0.022 & & 0.000 & & -0.005 & & -0.005 & & -0.001 & 0.015 & \\
\hline Estatítica F & 1.211 & & 1.003 & & 0.950 & & 0.949 & & 0.995 & 1.137 & \\
\hline Teste Breusch-Pagan & 0.019 & & 0.046 & & 0.009 & & 0.030 & & 0.010 & 0.331 & \\
\hline Teste Reset & 0.353 & & 0.226 & & 0.055 & & 0.144 & & 0.132 & 0.056 & \\
\hline
\end{tabular}

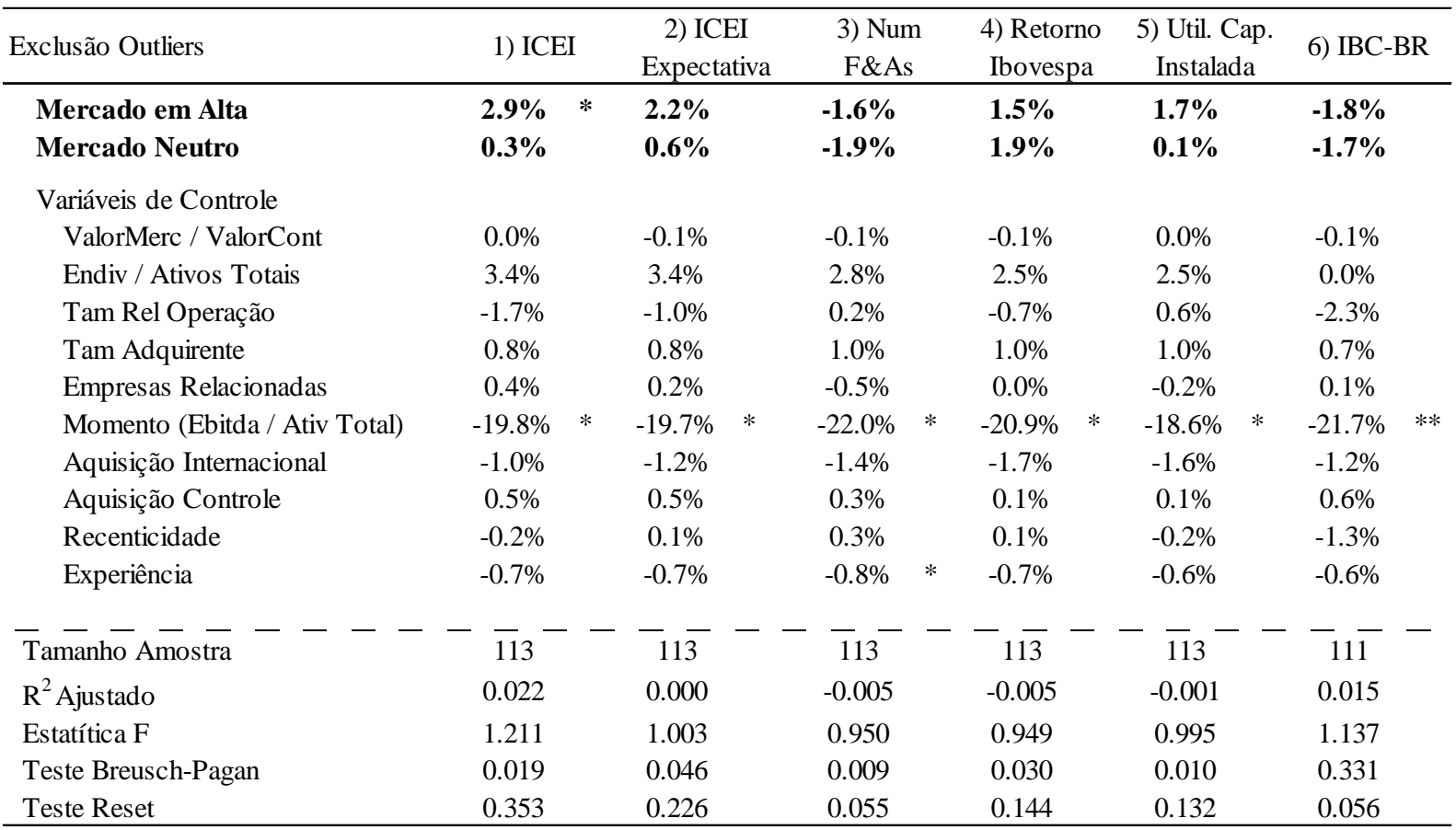

Fonte: Elaborado pelo Autor

Notas: * denota significância estatística: * p-value $<10 \% ; \quad$ ** p-value $<5 \%$; $\quad * * *$ p-value $<1 \%$ Quando o Teste de Breusch-Pagan indica heterocedasticidade, a significância estatística adota a metodologia de erros robustos.

A tabela apresenta os resultados da regressão cross section do retorno anormal acumulado para a janela de onze dias. São apresentados os resultados de seis modelos, cada qual assumindo uma proxy diferente para classificação do estado de mercado. 


\section{Tabela 8 - Análise de Regressão dos Determinantes de Criação de Valor - Janela de Vinte e Um Dias}

\begin{tabular}{|c|c|c|c|c|c|c|c|c|c|c|c|c|}
\hline \multirow{2}{*}{$\begin{array}{l}\text { Amostra Completa } \\
\text { Mercado em Alta }\end{array}$} & \multicolumn{2}{|c|}{ 1) ICEI } & \multicolumn{2}{|c|}{$\begin{array}{c}\text { 2) ICEI } \\
\text { Expectativa } \\
\end{array}$} & \multicolumn{2}{|c|}{ 3) Num F\&As } & \multicolumn{2}{|c|}{$\begin{array}{l}\text { 4) Retorno } \\
\text { Ibovespa }\end{array}$} & \multicolumn{2}{|c|}{$\begin{array}{l}\text { 5) Util. Cap. } \\
\text { Instalada }\end{array}$} & \multicolumn{2}{|c|}{ 6) IBC-BR } \\
\hline & $2,4 \%$ & & $1,5 \%$ & & $-0,5 \%$ & & $-0,4 \%$ & & $2,5 \%$ & & $-0,6 \%$ & \\
\hline Mercado Neutro & $0,1 \%$ & & $-0,7 \%$ & & $-1,9 \%$ & & $1,1 \%$ & & $-1,8 \%$ & & $-1,0 \%$ & \\
\hline \multicolumn{13}{|l|}{ Variáveis de Controle } \\
\hline ValorMerc / ValorCont & $-0,1 \%$ & & $-0,2 \%$ & & $-0,1 \%$ & & $-0,1 \%$ & & $-0,1 \%$ & & $-0,1 \%$ & \\
\hline Endiv / Ativos Totais & $-5,6 \%$ & & $-4,8 \%$ & & $-6,2 \%$ & & $-5,6 \%$ & & $-6,6 \%$ & & $-5,9 \%$ & \\
\hline Tam Rel Operação & $-15,1 \%$ & $* *$ & $-14,3 \%$ & $* *$ & $-13,0 \%$ & $* *$ & $-13,0 \%$ & $* *$ & $-12,1 \%$ & $*$ & $-14,0 \%$ & $* *$ \\
\hline Tam Adquirente & $-0,5 \%$ & & $-0,4 \%$ & & $-0,4 \%$ & & $-0,3 \%$ & & $-0,3 \%$ & & $-0,4 \%$ & \\
\hline Empresas Relacionadas & $0,9 \%$ & & $0,6 \%$ & & $0,2 \%$ & & $0,7 \%$ & & $0,2 \%$ & & $0,7 \%$ & \\
\hline Momento (Ebitda / Ativ Total) & $-33,4 \%$ & $* * *$ & $-32,8 \%$ & $* * *$ & $-34,7 \%$ & $* * *$ & $-32,2 \%$ & $* * *$ & $-29,1 \%$ & $* *$ & $-32,9 \%$ & $* * *$ \\
\hline Aquisição Internacional & $1,4 \%$ & & $1,3 \%$ & & $1,1 \%$ & & $1,0 \%$ & & $0,8 \%$ & & $1,1 \%$ & \\
\hline Aquisição Controle & $0,3 \%$ & & $0,4 \%$ & & $0,0 \%$ & & $0,0 \%$ & & $-0,3 \%$ & & $0,2 \%$ & \\
\hline Recenticidade & $1,8 \%$ & & $1,9 \%$ & & $1,9 \%$ & & $1,9 \%$ & & $1,5 \%$ & & $1,6 \%$ & \\
\hline Experiência & $-0,3 \%$ & & $-0,4 \%$ & & $-0,4 \%$ & & $-0,3 \%$ & & $0,0 \%$ & & $-0,3 \%$ & \\
\hline$-\overline{\text { Tamanho Amostra }}----$ & $-11 \overline{3}$ & -- & $\overline{113}$ & - & $-\overline{113}-$ & - & $-\overline{113}$ & - & $-\overline{113}$ & - & $\overline{111}-$ & - \\
\hline $\mathrm{R}^{2}$ Ajustado & 0,039 & & 0,034 & & 0,029 & & 0,029 & & 0,088 & & 0,018 & \\
\hline Estatítica F & 1,379 & & 1,330 & & 1,280 & & 1,274 & & 1,903 & $* *$ & 1,169 & \\
\hline Teste Breusch-Pagan & 0,011 & & 0,013 & & 0,048 & & 0,012 & & 0,021 & & 0,046 & \\
\hline Teste Reset & 0,114 & & 0,057 & & 0,051 & & 0,099 & & 0,122 & & 0,018 & \\
\hline
\end{tabular}

\begin{tabular}{|c|c|c|c|c|c|c|c|c|c|c|c|c|}
\hline \multirow{2}{*}{$\begin{array}{l}\text { Exclusão Outliers } \\
\text { Mercado em Alta }\end{array}$} & \multicolumn{2}{|c|}{ 1) ICEI } & \multicolumn{2}{|c|}{$\begin{array}{c}\text { 2) ICEI } \\
\text { Expectativa }\end{array}$} & \multicolumn{2}{|c|}{ 3) Num F\&As } & \multicolumn{2}{|c|}{$\begin{array}{l}\text { 4) Retorno } \\
\text { Ibovespa }\end{array}$} & \multicolumn{2}{|c|}{$\begin{array}{l}\text { 5) Util. Cap. } \\
\text { Instalada } \\
\end{array}$} & \multicolumn{2}{|c|}{ 6) IBC-BR } \\
\hline & $2,4 \%$ & & $1,5 \%$ & & $-0,5 \%$ & & $-0,4 \%$ & & $2,5 \%$ & & $-0,6 \%$ & \\
\hline Mercado Neutro & $0,1 \%$ & & $-0,7 \%$ & & $-1,9 \%$ & & $1,1 \%$ & & $-1,8 \%$ & & $-1,0 \%$ & \\
\hline \multicolumn{13}{|l|}{ Variáveis de Controle } \\
\hline ValorMerc / ValorCont & $-0,1 \%$ & & $-0,2 \%$ & & $-0,1 \%$ & & $-0,1 \%$ & & $-0,1 \%$ & & $-0,1 \%$ & \\
\hline Endiv / Ativos Totais & $-5,6 \%$ & & $-4,8 \%$ & & $-6,2 \%$ & & $-5,6 \%$ & & $-6,6 \%$ & & $-5,9 \%$ & \\
\hline Tam Rel Operação & $-15,1 \%$ & $* *$ & $-14,3 \%$ & $* *$ & $-13,0 \%$ & $* *$ & $-13,0 \%$ & $* *$ & $-12,1 \%$ & $*$ & $-14,0 \%$ & $* *$ \\
\hline Tam Adquirente & $-0,5 \%$ & & $-0,4 \%$ & & $-0,4 \%$ & & $-0,3 \%$ & & $-0,3 \%$ & & $-0,4 \%$ & \\
\hline Empresas Relacionadas & $0,9 \%$ & & $0,6 \%$ & & $0,2 \%$ & & $0,7 \%$ & & $0,2 \%$ & & $0,7 \%$ & \\
\hline Momento (Ebitda / Ativ Total) & $-33,4 \%$ & $* * *$ & $-32,8 \%$ & $* * *$ & $-34,7 \%$ & $* * *$ & $-32,2 \%$ & $* * *$ & $-29,1 \%$ & $* *$ & $-32,9 \%$ & $* * *$ \\
\hline Aquisição Internacional & $1,4 \%$ & & $1,3 \%$ & & $1,1 \%$ & & $1,0 \%$ & & $0,8 \%$ & & $1,1 \%$ & \\
\hline Aquisição Controle & $0,3 \%$ & & $0,4 \%$ & & $0,0 \%$ & & $0,0 \%$ & & $-0,3 \%$ & & $0,2 \%$ & \\
\hline Recenticidade & $1,8 \%$ & & $1,9 \%$ & & $1,9 \%$ & & $1,9 \%$ & & $1,5 \%$ & & $1,6 \%$ & \\
\hline Experiência & $-0,3 \%$ & & $-0,4 \%$ & & $-0,4 \%$ & & $-0,3 \%$ & & $0,0 \%$ & & $-0,3 \%$ & \\
\hline $\bar{T}-\overline{-} \overline{-}-\overline{-}---$ & $-\overline{113}-$ & - & $-\overline{113}-$ & - & $-\overline{113}$ & - - & -113 & - & $\overline{113}-$ & - & $-\overline{111}$ & -- \\
\hline $\mathrm{R}^{2}$ Ajustado & 0,039 & & 0,034 & & 0,029 & & 0,029 & & 0,088 & & 0,018 & \\
\hline Estatítica F & 1,379 & & 1,330 & & 1,280 & & 1,274 & & 1,903 & $* *$ & 1,169 & \\
\hline Teste Breusch-Pagan & 0,011 & & 0,013 & & 0,048 & & 0,012 & & 0,021 & & 0,046 & \\
\hline Teste Reset & 0,114 & & 0,057 & & 0,051 & & 0,099 & & 0,122 & & 0,018 & \\
\hline
\end{tabular}

Fonte: Elaborado pelo Autor

Notas: * denota significância estatística: * p-value $<10 \% ; \quad * *$ p-value $<5 \%$; $\quad * * *$ p-value $<1 \%$

Quando o Teste de Breusch-Pagan indica heterocedasticidade, a significância estatística adota a metodologia de erros robustos.

A tabela apresenta os resultados da regressão cross section do retorno anormal acumulado para a janela de vinte e um dias. São apresentados os resultados de seis modelos, cada qual assumindo uma proxy diferente para classificação do estado de mercado. 


\subsubsection{Regressão Multivariada: Amostra com Sobreposição de Efeitos}

Nessa amostra são considerados todos os 346 eventos de F\&As, mesmo aqueles onde houve mais de um fato relevante associado à empresa adquirente durante a maior janela de estudo (dez dias antes e depois do anúncio do evento). Para controlar a possível sobreposição de efeitos nesses eventos, foi incorporada mais uma variável de controle na regressão que assume o valor de "0" quando o evento tem outros fatos relevantes durante a janela de estudo e “1” quando não há sobreposição de eventos.

Da mesma forma que na seção anterior, a Tabela 9, Tabela 10, Tabela 11 e Tabela 12 trazem os resultados das regressões cross section realizadas para as quatro janelas de tempo estudadas, para seis modelos distintos (cada qual baseado em uma proxy de sentimento de mercado) e duas análises (com e sem a exclusão de possíveis outliers).

Os resultados das regressões para esta amostra parecem indicar com menor divergência aparente que a criação de valor em momentos de mercado em alta é menor que em momentos de mercado em baixa. De fato, quase $80 \%$ dos modelos apresentam coeficiente negativo para a variável "Sentimento de Mercado em Alta” e 47\% destes têm resultado estatisticamente significante.

Assim como na análise da amostra sem sobreposição de eventos do item 4.2.1, a criação de valor no dia do anúncio do evento (Tabela 9) parece ser menor quando as F\&As ocorrem em momentos de mercado em alta. Diferentemente dos resultados anteriores, em três dos seis modelos há significância estatística corroborando com esses resultados.

Quando a janela de estudo é ampliada, os resultados passam a ser distintos aos anteriores para a variável de sentimento de mercado em alta. Ao contrário do constatado na análise do item 4.2.1, a criação de valor em momentos de mercado em baixa continua sendo maior que em momentos de mercado em alta mesmo para janelas de estudo maiores na maioria dos resultados. De fato, na maior janela de estudo (vinte e um dias) cinco dos seis modelos indicam maior criação de valor em momentos de mercado em baixa e, em quase todos eles, há significância estatística (principalmente quando possíveis outliers são retirados). 
No entanto, como na análise anterior (seção 4.2.2), a escolha da proxy de sentimento de mercado pode trazer resultados contrários: por exemplo, o sexto modelo (IBC-BR) indica com significância estatística resultado contrário; na janela de vinte e um dias, esse modelo apresenta criação de valor em momentos de mercado em alta maior que em momentos de mercado em baixa.

Diferentemente da análise da amostra sem sobreposição de eventos do item 4.2.1 que mostrou grande divergência nos resultados (coeficientes positivos e negativos) para a variável de sentimento de mercado neutro e ausência de significância estatística, há maior número de resultados com coeficiente negativos para a variável de sentimento de mercado neutro (alguns desses com significância estatística) quando a amostra maior é estudada. Isso poderia indicar que a criação de valor também é maior em momentos de mercado em baixa que em momentos de mercado neutro; é importante ressaltar, no entanto, que embora seja menor, continua havendo divergência nos resultados encontrados para a influência dessa variável.

Nas análises das janelas de tempo menores (dia do anúncio e três dias) as variáveis de controle recenticidade e momento novamente indicam influência negativa na criação de valor de F\&As e, em muitos desses casos, significância estatística é constatada. Assim como na maioria dos resultados obtidos na análise da amostra sem eventos com sobreposição de efeitos (item 4.2.1), as variáveis de controle aquisições internacionais e empresas relacionadas continuam com coeficientes positivos indicando influência também positiva na criação de valor. No entanto, nesta análise é possível verificar significância estatística para empresas relacionadas em todas as janelas de tempo estudadas e, para aquisições internacionais, na janela de vinte e um dias. 
Tabela 9 - Análise de Regressão dos Determinantes de Criação de Valor - Dia do
Anúncio - Amostra Completa

\begin{tabular}{|c|c|c|c|c|c|c|c|c|c|c|c|c|}
\hline \multirow{2}{*}{$\begin{array}{l}\text { Amostra Completa } \\
\text { Mercado em Alta }\end{array}$} & \multicolumn{2}{|c|}{ 1) ICEI } & \multicolumn{2}{|c|}{$\begin{array}{c}\text { 2) ICEI } \\
\text { Expectativa }\end{array}$} & \multicolumn{2}{|c|}{ 3) Num F\&As } & \multicolumn{2}{|c|}{$\begin{array}{l}\text { 4) Retorno } \\
\text { Ibovespa }\end{array}$} & \multicolumn{2}{|c|}{$\begin{array}{l}\text { 5) Util. Cap. } \\
\text { Instalada }\end{array}$} & \multicolumn{2}{|c|}{ 6) IBC-BR } \\
\hline & $-1.1 \%$ & $* *$ & $-1.1 \%$ & $* *$ & $0.2 \%$ & & $-0.2 \%$ & & $0.6 \%$ & & $-1.0 \%$ & $*$ \\
\hline Mercado Neutro & $-0.8 \%$ & & $-0.7 \%$ & & $0.3 \%$ & & $0.2 \%$ & & $-0.6 \%$ & & $1.1 \%$ & $* *$ \\
\hline \multicolumn{13}{|l|}{ Variáveis de Controle } \\
\hline ValorMerc / ValorCont & $0.0 \%$ & & $0.0 \%$ & & $0.0 \%$ & & $0.0 \%$ & & $0.0 \%$ & & $0.0 \%$ & \\
\hline Endiv / Ativos Totais & $0.4 \%$ & & $0.4 \%$ & & $0.4 \%$ & & $0.3 \%$ & & $0.7 \%$ & & $0.0 \%$ & \\
\hline Tam Rel Operacao & $-0.9 \%$ & & $-1.0 \%$ & & $-1.3 \%$ & & $-1.2 \%$ & & $-1.3 \%$ & & $-0.4 \%$ & \\
\hline Tam Adquirente & $0.1 \%$ & & $0.1 \%$ & & $0.0 \%$ & & $0.1 \%$ & & $0.0 \%$ & & $0.0 \%$ & \\
\hline Empresas Relacionadas & $0.6 \%$ & $*$ & $0.5 \%$ & & $0.8 \%$ & $* *$ & $0.8 \%$ & $* *$ & $0.7 \%$ & $* *$ & $0.5 \%$ & \\
\hline Momento (Ebitda / Ativ Total) & $-4.2 \%$ & & $-4.2 \%$ & & $-3.1 \%$ & & $-3.1 \%$ & & $-2.9 \%$ & & $-2.6 \%$ & \\
\hline Aquisição Internacional & $-0.4 \%$ & & $-0.4 \%$ & & $-0.4 \%$ & & $-0.4 \%$ & & $-0.4 \%$ & & $-0.1 \%$ & \\
\hline Aquisição Controle & $0.2 \%$ & & $0.2 \%$ & & $0.2 \%$ & & $0.2 \%$ & & $0.2 \%$ & & $0.3 \%$ & \\
\hline Recenticidade & $-0.5 \%$ & & $-0.7 \%$ & & $-0.7 \%$ & & $-0.6 \%$ & & $-0.8 \%$ & & $-0.5 \%$ & \\
\hline Experiência & $-0.1 \%$ & & $-0.1 \%$ & & $-0.1 \%$ & & $-0.1 \%$ & & $-0.1 \%$ & & $-0.1 \%$ & \\
\hline Sem Sobreposição Eventos & $0.0 \%$ & & $0.0 \%$ & & $0.0 \%$ & & $0.0 \%$ & & $0.0 \%$ & & $0.0 \%$ & \\
\hline Tamanho Amostra & $\overline{346}$ & & $\overline{346}$ & & 346 & & 346 & & 346 & & 291 & \\
\hline $\mathrm{R}^{2}$ Ajustado & 0.009 & & 0.010 & & -0.007 & & -0.004 & & 0.021 & & 0.036 & \\
\hline Estatítica F & 1.250 & & 1.264 & & 0.812 & & 0.896 & & 1.567 & $*$ & 1.832 & $* *$ \\
\hline Teste Breusch-Pagan & 0.000 & & 0.000 & & 0.000 & & 0.000 & & 0.000 & & 0.000 & \\
\hline Teste Reset & 0.042 & & 0.080 & & 0.854 & & 0.721 & & 0.082 & & 0.013 & \\
\hline
\end{tabular}

\begin{tabular}{|c|c|c|c|c|c|c|c|c|c|c|c|c|}
\hline \multirow{2}{*}{$\begin{array}{l}\text { Exclusão Outliers } \\
\text { Mercado em Alta }\end{array}$} & \multicolumn{2}{|c|}{ 1) ICEI } & \multicolumn{2}{|c|}{$\begin{array}{c}\text { 2) ICEI } \\
\text { Expectativa }\end{array}$} & \multicolumn{2}{|c|}{ 3) Num F\&As } & \multicolumn{2}{|c|}{$\begin{array}{l}\text { 4) Retorno } \\
\text { Ibovespa }\end{array}$} & \multicolumn{2}{|c|}{$\begin{array}{c}\text { 5) Util. Cap. } \\
\text { Instalada }\end{array}$} & \multicolumn{2}{|c|}{ 6) IBC-BR } \\
\hline & $0.1 \%$ & & $0.0 \%$ & & $0.1 \%$ & & $0.1 \%$ & & $0.2 \%$ & & $-0.6 \%$ & \\
\hline Mercado Neutro & $0.3 \%$ & & $0.4 \%$ & & $-0.3 \%$ & & $-0.1 \%$ & & $-0.7 \%$ & $*$ & $0.5 \%$ & \\
\hline \multicolumn{13}{|l|}{ Variáveis de Controle } \\
\hline ValorMerc / ValorCont & $0.0 \%$ & & $0.0 \%$ & & $0.0 \%$ & & $0.0 \%$ & & $0.0 \%$ & & $0.0 \%$ & \\
\hline Endiv / Ativos Totais & $-0.5 \%$ & & $-0.9 \%$ & & $-0.6 \%$ & & $-0.6 \%$ & & $-0.5 \%$ & & $-1.4 \%$ & \\
\hline Tam Rel Operacao & $3.0 \%$ & & $2.9 \%$ & & $3.1 \%$ & & $3.1 \%$ & & $1.7 \%$ & & $4.0 \%$ & \\
\hline Tam Adquirente & $0.1 \%$ & & $0.0 \%$ & & $0.1 \%$ & & $0.1 \%$ & & $0.0 \%$ & & $0.1 \%$ & \\
\hline Empresas Relacionadas & $0.4 \%$ & & $0.4 \%$ & & $0.4 \%$ & & $0.4 \%$ & & $0.3 \%$ & & $0.2 \%$ & \\
\hline Momento (Ebitda / Ativ Total) & $-6.1 \%$ & $* *$ & $-5.6 \%$ & $* *$ & $-6.0 \%$ & $* *$ & $-6.2 \%$ & $* *$ & $-5.3 \%$ & $* *$ & $-4.7 \%$ & \\
\hline Aquisição Internacional & $0.3 \%$ & & $0.3 \%$ & & $0.3 \%$ & & $0.3 \%$ & & $0.2 \%$ & & $0.6 \%$ & $* *$ \\
\hline Aquisição Controle & $-0.1 \%$ & & $-0.1 \%$ & & $-0.1 \%$ & & $-0.1 \%$ & & $-0.1 \%$ & & $0.1 \%$ & \\
\hline Recenticidade & $-0.9 \%$ & $* *$ & $-1.0 \%$ & $* *$ & $-0.9 \%$ & $* *$ & $-0.9 \%$ & $* *$ & $-1.1 \%$ & $* *$ & $-0.8 \%$ & \\
\hline Experiência & $0.0 \%$ & & $0.0 \%$ & & $0.0 \%$ & & $0.0 \%$ & & $0.0 \%$ & & $-0.1 \%$ & \\
\hline Sem Sobreposição Eventos & $0.2 \%$ & & $0.2 \%$ & & $0.1 \%$ & & $0.2 \%$ & & $0.1 \%$ & & $0.3 \%$ & \\
\hline$\overline{\text { Tamanho Amostra }}---$ & $-\overline{336}-$ & - & $-\overline{337}$ & - & $-\overline{336}$ & - & $-\overline{336}$ & -- & $-\overline{335}$ & - - & $\overline{2} 82$ & - \\
\hline $\mathrm{R}^{2}$ Ajustado & 0.045 & & 0.038 & & 0.049 & & 0.045 & & 0.061 & & 0.075 & \\
\hline Estatítica F & 2.224 & $* * *$ & 2.031 & $* *$ & 2.337 & $* * *$ & 2.222 & $* * *$ & 2.668 & $* * *$ & 2.765 & $* * *$ \\
\hline Teste Breusch-Pagan & 0.000 & & 0.000 & & 0.000 & & 0.000 & & 0.000 & & 0.000 & \\
\hline Teste Reset & 0.004 & & 0.001 & & 0.007 & & 0.004 & & 0.006 & & 0.000 & \\
\hline
\end{tabular}

Fonte: Elaborado pelo Autor

Notas: * denota significância estatística: * p-value $<10 \% ; \quad * *$ p-value $<5 \% ; \quad * * *$ p-value $<1 \%$

Quando o Teste de Breusch-Pagan indica heterocedasticidade, a significância estatística adota a metodologia de erros robustos.

A tabela apresenta os resultados da regressão cross section do retorno anormal no dia do anúncio da F\&A. São apresentados os resultados de seis modelos, cada qual assumindo uma proxy diferente para classificação do estado de mercado. 


\section{Tabela 10 - Análise de Regressão dos Determinantes de Criação de Valor - Janela Três Dias - Amostra Completa}

\begin{tabular}{|c|c|c|c|c|c|c|c|c|c|c|c|c|}
\hline \multirow{2}{*}{$\begin{array}{l}\text { Amostra Completa } \\
\text { Mercado em Alta }\end{array}$} & \multicolumn{2}{|c|}{ 1) ICEI } & \multicolumn{2}{|c|}{$\begin{array}{c}\text { 2) ICEI } \\
\text { Expectativa }\end{array}$} & \multicolumn{2}{|c|}{ 3) Num F\&As } & \multicolumn{2}{|c|}{$\begin{array}{l}\text { 4) Retorno } \\
\text { Ibovespa }\end{array}$} & \multicolumn{2}{|c|}{$\begin{array}{l}\text { 5) Util. Cap. } \\
\text { Instalada }\end{array}$} & \multicolumn{2}{|c|}{ 6) IBC-BR } \\
\hline & $-1.1 \%$ & & $-1.2 \%$ & $*$ & $0.0 \%$ & & $-0.4 \%$ & & $0.2 \%$ & & $-1.1 \%$ & \\
\hline Mercado Neutro & $-0.7 \%$ & & $-0.4 \%$ & & $0.3 \%$ & & $0.3 \%$ & & $-1.1 \%$ & & $1.0 \%$ & \\
\hline \multicolumn{13}{|l|}{ Variáveis de Controle } \\
\hline ValorMerc / ValorCont & $0.1 \%$ & & $0.0 \%$ & & $0.0 \%$ & & $0.1 \%$ & & $0.1 \%$ & & $0.0 \%$ & \\
\hline Endiv / Ativos Totais & $0.1 \%$ & & $0.1 \%$ & & $0.2 \%$ & & $0.1 \%$ & & $0.4 \%$ & & $-0.2 \%$ & \\
\hline Tam Rel Operacao & $-3.8 \%$ & & $-3.9 \%$ & & $-4.2 \%$ & & $-4.1 \%$ & & $-4.2 \%$ & & $-2.9 \%$ & \\
\hline Tam Adquirente & $-0.2 \%$ & & $-0.3 \%$ & & $-0.3 \%$ & & $-0.2 \%$ & & $-0.3 \%$ & & $-0.3 \%$ & \\
\hline Empresas Relacionadas & $0.5 \%$ & & $0.4 \%$ & & $0.7 \%$ & & $0.7 \%$ & & $0.6 \%$ & & $0.4 \%$ & \\
\hline Momento (Ebitda / Ativ Total) & $-3.9 \%$ & & $-4.2 \%$ & & $-3.1 \%$ & & $-2.6 \%$ & & $-2.3 \%$ & & $-2.6 \%$ & \\
\hline Aquisição Internacional & $-0.3 \%$ & & $-0.3 \%$ & & $-0.3 \%$ & & $-0.3 \%$ & & $-0.4 \%$ & & $0.0 \%$ & \\
\hline Aquisição Controle & $0.0 \%$ & & $0.0 \%$ & & $0.1 \%$ & & $0.1 \%$ & & $0.0 \%$ & & $0.3 \%$ & \\
\hline Recenticidade & $-1.8 \%$ & $* *$ & $-2.0 \%$ & $* *$ & $-1.9 \%$ & $* *$ & $-1.9 \%$ & $* *$ & $-2.1 \%$ & $* *$ & $-2.1 \%$ & $*$ \\
\hline Experiência & $0.0 \%$ & & $0.1 \%$ & & $0.1 \%$ & & $0.0 \%$ & & $0.1 \%$ & & $0.1 \%$ & \\
\hline Sem Sobreposição Eventos & $0.4 \%$ & & $0.4 \%$ & & $0.5 \%$ & & $0.5 \%$ & & $0.5 \%$ & & $0.7 \%$ & \\
\hline Tamanho Amostra & 346 & & 346 & & 346 & & 346 & & 346 & & 291 & \\
\hline $\mathrm{R}^{2}$ Ajustado & 0.015 & & 0.016 & & 0.008 & & 0.011 & & 0.023 & & 0.020 & \\
\hline Estatítica F & 1.398 & & 1.441 & & 1.213 & & 1.299 & & 1.635 & $*$ & 1.457 & \\
\hline Teste Breusch-Pagan & 0.000 & & 0.000 & & 0.000 & & 0.000 & & 0.000 & & 0.000 & \\
\hline Teste Reset & 0.004 & & 0.003 & & 0.003 & & 0.001 & & 0.706 & & 0.161 & \\
\hline
\end{tabular}

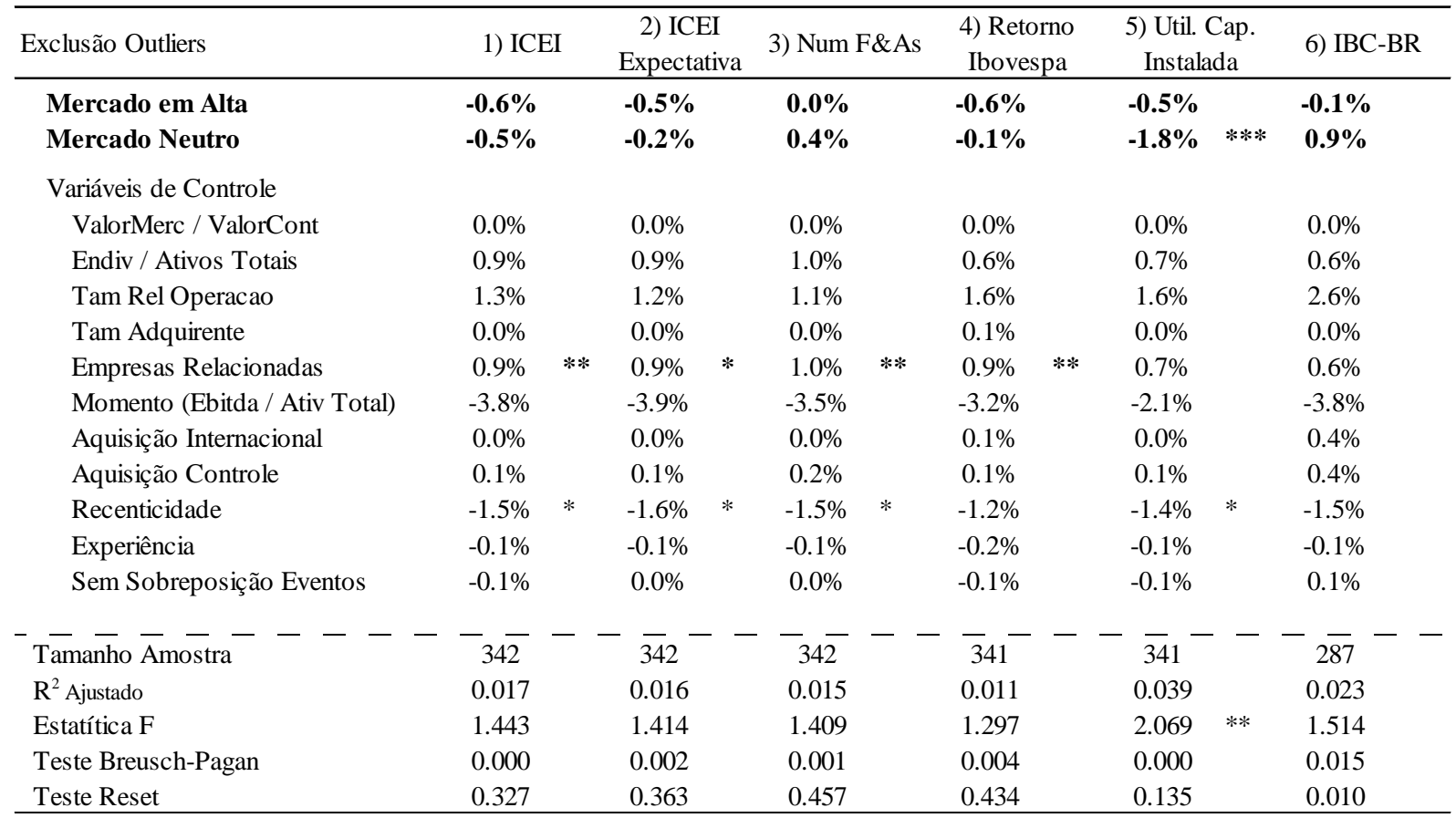

Fonte: Elaborado pelo Autor

Notas: * denota significância estatística: * p-value $<10 \%$; $\quad * *$ p-value $<5 \%$; $\quad * * *$ p-value $<1 \%$ Quando o Teste de Breusch-Pagan indica heterocedasticidade, a significância estatística adota a metodologia de erros robustos.

A tabela apresenta os resultados da regressão cross section do retorno anormal acumulado para a janela de três dias. São apresentados os resultados de seis modelos, cada qual assumindo uma proxy diferente para classificação do estado de mercado. 
Tabela 11 - Análise de Regressão dos Determinantes de Criação de Valor - Janela Onze Dias - Amostra Completa

\begin{tabular}{|c|c|c|c|c|c|c|c|c|c|c|c|}
\hline Amostra Completa & 1) ICEI & & $\begin{array}{c}\text { 2) ICEI } \\
\text { Expectati }\end{array}$ & & $\begin{array}{l}\text { 3) Num } \\
\text { F\&As }\end{array}$ & & $\begin{array}{c}4) \\
\text { Retorno }\end{array}$ & & $\begin{array}{l}\text { 5) Util. } \\
\text { Cap. }\end{array}$ & & $\begin{array}{c}\text { 6) IBC- } \\
\text { BR }\end{array}$ \\
\hline Mercado em Alta & $-1.8 \%$ & $*$ & $-2.3 \%$ & $* *$ & $-0.5 \%$ & & $-2.0 \%$ & $* *$ & $-0.6 \%$ & & $-0.8 \%$ \\
\hline Mercado Neutro & $-1.0 \%$ & & $-1.3 \%$ & & $-0.3 \%$ & & $-0.4 \%$ & & $-3.1 \%$ & $* * *$ & $0.2 \%$ \\
\hline \multicolumn{12}{|l|}{ Variáveis de Controle } \\
\hline ValorMerc / ValorCont & $0.0 \%$ & & $0.0 \%$ & & $0.0 \%$ & & $0.0 \%$ & & $0.0 \%$ & & $0.0 \%$ \\
\hline Endiv / Ativos Totais & $0.0 \%$ & & $0.1 \%$ & & $-0.2 \%$ & & $-0.2 \%$ & & $0.2 \%$ & & $-2.5 \%$ \\
\hline Tam Rel Operacao & $-2.9 \%$ & & $-2.8 \%$ & & $-3.5 \%$ & & $-2.9 \%$ & & $-3.5 \%$ & & $-2.0 \%$ \\
\hline Tam Adquirente & $0.0 \%$ & & $0.0 \%$ & & $0.0 \%$ & & $0.2 \%$ & & $0.0 \%$ & & $0.1 \%$ \\
\hline Empresas Relacionadas & $1.1 \%$ & & $0.9 \%$ & & $1.3 \%$ & $*$ & $1.5 \%$ & $* *$ & $1.0 \%$ & & $1.2 \%$ \\
\hline Momento (Ebitda / Ativ Total) & $4.5 \%$ & & $4.3 \%$ & & $5.4 \%$ & & $7.2 \%$ & & $8.5 \%$ & & $5.4 \%$ \\
\hline Aquisição Internacional & $-0.6 \%$ & & $-0.7 \%$ & & $-0.6 \%$ & & $-0.7 \%$ & & $-0.8 \%$ & & $-0.2 \%$ \\
\hline Aquisição Controle & $-0.2 \%$ & & $-0.3 \%$ & & $-0.2 \%$ & & $0.0 \%$ & & $-0.2 \%$ & & $0.1 \%$ \\
\hline Recenticidade & $1.8 \%$ & & $1.6 \%$ & & $1.8 \%$ & & $1.9 \%$ & & $1.4 \%$ & & $0.8 \%$ \\
\hline Experiência & $-0.3 \%$ & & $-0.3 \%$ & & $-0.4 \%$ & & $-0.4 \%$ & * & $-0.4 \%$ & & $-0.4 \%$ \\
\hline Sem Sobreposição Eventos & $0.2 \%$ & & $0.2 \%$ & & $0.3 \%$ & & $0.3 \%$ & & $0.4 \%$ & & $0.5 \%$ \\
\hline Tamanho Amostra & 346 & & 346 & & 346 & & 346 & & 346 & & 291 \\
\hline $\mathrm{R}^{2}$ Ajustado & 0.001 & & 0.007 & & -0.008 & & 0.007 & & 0.028 & & -0.016 \\
\hline Estatítica F & 1.029 & & 1.179 & & 0.776 & & 1.179 & & 1.773 & $* *$ & 0.653 \\
\hline Teste Breusch-Pagan & 0.001 & & 0.002 & & 0.002 & & 0.003 & & 0.000 & & 0.002 \\
\hline Teste Reset & 0.452 & & 0.778 & & 0.628 & & 0.984 & & 0.928 & & 0.602 \\
\hline
\end{tabular}

\begin{tabular}{|c|c|c|c|c|c|c|c|c|c|c|c|c|}
\hline Exclusão Outliers & \multicolumn{2}{|l|}{ 1) ICEI } & \multicolumn{2}{|l|}{$\begin{array}{c}\text { 2) ICEI } \\
\text { Expectati }\end{array}$} & \multicolumn{2}{|l|}{$\begin{array}{l}\text { 3) Num } \\
\text { F\&As }\end{array}$} & \multicolumn{2}{|c|}{$\begin{array}{c}\text { 4) } \\
\text { Retorno }\end{array}$} & \multicolumn{2}{|l|}{$\begin{array}{l}\text { 5) Util. } \\
\text { Cap. }\end{array}$} & \multicolumn{2}{|l|}{$\begin{array}{l}\text { 6) IBC- } \\
\text { BR }\end{array}$} \\
\hline Mercado em Alta & $-1.6 \%$ & $*$ & $-2.0 \%$ & $* *$ & $-0.6 \%$ & & $-2.0 \%$ & $* *$ & $-1.2 \%$ & & $-0.1 \%$ & \\
\hline Mercado Neutro & $-1.2 \%$ & & $-1.3 \%$ & & $-0.2 \%$ & & $-0.6 \%$ & & $-3.5 \%$ & $* * *$ & $0.3 \%$ & \\
\hline \multicolumn{13}{|l|}{ Variáveis de Controle } \\
\hline ValorMerc / ValorCont & $0.0 \%$ & & $0.0 \%$ & & $0.0 \%$ & & $0.0 \%$ & & $0.0 \%$ & & $0.0 \%$ & \\
\hline Endiv / Ativos Totais & $-0.9 \%$ & & $-0.8 \%$ & & $-1.1 \%$ & & $-0.9 \%$ & & $-0.9 \%$ & & $-3.7 \%$ & \\
\hline Tam Rel Operacao & $2.5 \%$ & & $2.5 \%$ & & $1.9 \%$ & & $2.1 \%$ & & $2.3 \%$ & & $3.9 \%$ & \\
\hline Tam Adquirente & $0.1 \%$ & & $0.1 \%$ & & $0.1 \%$ & & $0.2 \%$ & & $0.1 \%$ & & $0.2 \%$ & \\
\hline Empresas Relacionadas & $1.2 \%$ & & $1.0 \%$ & & $1.4 \%$ & $*$ & $1.6 \%$ & $* *$ & $1.0 \%$ & & $1.2 \%$ & \\
\hline Momento (Ebitda / Ativ Total) & $5.4 \%$ & & $5.2 \%$ & & $5.9 \%$ & & $7.6 \%$ & & $9.4 \%$ & & $5.3 \%$ & \\
\hline Aquisição Internacional & $-0.1 \%$ & & $-0.1 \%$ & & $0.0 \%$ & & $-0.1 \%$ & & $-0.2 \%$ & & $0.5 \%$ & \\
\hline Aquisição Controle & $0.0 \%$ & & $-0.1 \%$ & & $0.0 \%$ & & $0.0 \%$ & & $0.0 \%$ & & $0.4 \%$ & \\
\hline Recenticidade & $2.2 \%$ & $*$ & $2.0 \%$ & * & $2.2 \%$ & $*$ & $1.8 \%$ & & $1.8 \%$ & & $1.4 \%$ & \\
\hline Experiência & $-0.4 \%$ & $*$ & $-0.4 \%$ & & $-0.4 \%$ & $*$ & $-0.5 \%$ & $*$ & $-0.4 \%$ & $*$ & $-0.5 \%$ & $*$ \\
\hline Sem Sobreposição Eventos & $-0.1 \%$ & & $0.0 \%$ & & $0.0 \%$ & & $0.0 \%$ & & $0.1 \%$ & & $0.2 \%$ & \\
\hline$\overline{\text { Tamanho Amostra }}---$ & $-\overline{345}-$ & - & $-\overline{345}$ & -- & $-\overline{345}$ & -- & $-\overline{344}$ & - & $\overline{345}-$ & - & $-\overline{290}-$ & - \\
\hline $\mathrm{R}^{2}$ Ajustado & 0.002 & & 0.006 & & -0.006 & & 0.008 & & 0.038 & & -0.009 & \\
\hline Estatítica F & 1.045 & & 1.157 & & 0.834 & & 1.207 & & 2.033 & $* *$ & 0.809 & \\
\hline Teste Breusch-Pagan & 0.175 & & 0.177 & & 0.292 & & 0.376 & & 0.161 & & 0.217 & \\
\hline Teste Reset & 0.035 & & 0.042 & & 0.159 & & 0.826 & & 0.695 & & 0.252 & \\
\hline
\end{tabular}

Fonte: Elaborado pelo Autor

Notas: * denota significância estatística: * p-value $<10 \% ; \quad * *$ p-value $<5 \%$; $\quad * * *$ p-value $<1 \%$ Quando o Teste de Breusch-Pagan indica heterocedasticidade, a significância estatística adota a metodologia de erros robustos. A tabela apresenta os resultados da regressão cross section do retorno anormal acumulado para a janela de onze dias. São apresentados os resultados de seis modelos, cada qual assumindo uma proxy diferente para classificação do estado de mercado. 
Tabela 12 - Análise de Regressão dos Determinantes de Criação de Valor - Janela Vinte e Um Dias - Amostra Completa

\begin{tabular}{|c|c|c|c|c|c|c|c|c|c|c|c|c|}
\hline \multirow{2}{*}{$\begin{array}{c}\text { Amostra Completa } \\
\text { Mercado em Alta }\end{array}$} & \multicolumn{2}{|c|}{ 1) ICEI } & \multicolumn{2}{|c|}{$\begin{array}{c}\text { 2) ICEI } \\
\text { Expectativa }\end{array}$} & \multicolumn{2}{|c|}{ 3) Num F\&As } & \multicolumn{2}{|c|}{$\begin{array}{l}\text { 4) Retorno } \\
\text { Ibovespa }\end{array}$} & \multicolumn{2}{|c|}{$\begin{array}{l}\text { 5) Util. Cap. } \\
\text { Instalada }\end{array}$} & \multicolumn{2}{|c|}{ 6) IBC-BR } \\
\hline & $-2.6 \%$ & $* *$ & $-3.9 \%$ & $* * *$ & $-1.6 \%$ & & $-3.1 \%$ & $* *$ & $-2.0 \%$ & & $1.6 \%$ & \\
\hline Mercado Neutro & $-0.9 \%$ & & $-2.3 \%$ & $*$ & $-2.4 \%$ & $*$ & $-0.7 \%$ & & $-5.5 \%$ & $* * *$ & $1.6 \%$ & \\
\hline \multicolumn{13}{|l|}{ Variáveis de Controle } \\
\hline ValorMerc / ValorCont & $0.0 \%$ & & $0.0 \%$ & & $0.0 \%$ & & $0.1 \%$ & & $0.0 \%$ & & $0.0 \%$ & \\
\hline Endiv / Ativos Totais & $-3.4 \%$ & & $-3.3 \%$ & & $-4.5 \%$ & & $-3.9 \%$ & & $-3.4 \%$ & & $-6.3 \%$ & \\
\hline Tam Rel Operacao & $-2.8 \%$ & & $-2.6 \%$ & & $-3.6 \%$ & & $-2.7 \%$ & & $-3.6 \%$ & & $-1.7 \%$ & \\
\hline Tam Adquirente & $-0.5 \%$ & & $-0.5 \%$ & & $-0.5 \%$ & & $-0.2 \%$ & & $-0.6 \%$ & & $-0.3 \%$ & \\
\hline Empresas Relacionadas & $1.9 \%$ & $*$ & $1.6 \%$ & $*$ & $2.1 \%$ & $* *$ & $2.5 \%$ & $* * *$ & $1.7 \%$ & $*$ & $1.6 \%$ & \\
\hline Momento (Ebitda / Ativ Total) & $-5.9 \%$ & & $-6.2 \%$ & & $-5.5 \%$ & & $-1.8 \%$ & & $0.9 \%$ & & $-7.1 \%$ & \\
\hline Aquisição Internacional & $2.6 \%$ & $*$ & $2.5 \%$ & * & $3.0 \%$ & ** & $2.5 \%$ & $*$ & $2.4 \%$ & * & $2.5 \%$ & $*$ \\
\hline Aquisição Controle & $0.0 \%$ & & $-0.1 \%$ & & $-0.1 \%$ & & $0.3 \%$ & & $0.1 \%$ & & $0.2 \%$ & \\
\hline Recenticidade & $1.1 \%$ & & $1.0 \%$ & & $1.3 \%$ & & $1.4 \%$ & & $0.7 \%$ & & $0.9 \%$ & \\
\hline Experiência & $0.0 \%$ & & $0.0 \%$ & & $-0.1 \%$ & & $-0.2 \%$ & & $-0.1 \%$ & & $-0.1 \%$ & \\
\hline Sem Sobreposição Eventos & $0.2 \%$ & & $0.2 \%$ & & $0.1 \%$ & & $0.4 \%$ & & $0.5 \%$ & & $0.5 \%$ & \\
\hline Tamanho Amostra & $34 \overline{6}$ & & 346 & & $\overline{346}$ & & 346 & & 346 & & 291 & \\
\hline $\mathrm{R}^{2}$ Ajustado & 0.017 & & 0.030 & & 0.011 & & 0.025 & & 0.063 & & -0.003 & \\
\hline Estatítica F & 1.457 & & 1.821 & $* *$ & 1.299 & & 1.674 & $*$ & 2.798 & $* * *$ & 0.936 & \\
\hline Teste Breusch-Pagan & 0.000 & & 0.000 & & 0.000 & & 0.000 & & 0.000 & & 0.000 & \\
\hline Teste Reset & 0.044 & & 0.016 & & 0.464 & & 0.975 & & 0.971 & & 0.720 & \\
\hline
\end{tabular}

\begin{tabular}{|c|c|c|c|c|c|c|c|c|c|c|c|c|c|}
\hline \multirow{2}{*}{$\begin{array}{l}\text { Exclusão Outliers } \\
\text { Mercado em Alta }\end{array}$} & \multicolumn{2}{|c|}{ 1) ICEI } & \multicolumn{2}{|c|}{$\begin{array}{c}\text { 2) ICEI } \\
\text { Expectativa }\end{array}$} & \multicolumn{2}{|c|}{ 3) Num F\&As } & \multicolumn{2}{|c|}{$\begin{array}{l}\text { 4) Retorno } \\
\text { Ibovespa }\end{array}$} & \multicolumn{2}{|c|}{$\begin{array}{l}\text { 5) Util. Cap. } \\
\text { Instalada }\end{array}$} & \multicolumn{3}{|c|}{ 6) IBC-BR } \\
\hline & $-3.5 \%$ & $* * *$ & $-3.9 \%$ & $* * *$ & $-2.3 \%$ & $*$ & $-3.4 \%$ & $* * *$ & $-3.1 \%$ & $* *$ & $2.6 \%$ & $*$ & \\
\hline Mercado Neutro & $-1.1 \%$ & & $-2.7 \%$ & $* *$ & $-2.1 \%$ & & $-1.0 \%$ & & $-6.2 \%$ & $* * *$ & $1.6 \%$ & & \\
\hline \multicolumn{14}{|l|}{ Variáveis de Controle } \\
\hline ValorMerc / ValorCont & $-0.1 \%$ & & $-0.1 \%$ & & $0.0 \%$ & & $0.0 \%$ & & $0.0 \%$ & & $-0.1 \%$ & & \\
\hline Endiv / Ativos Totais & $-3.4 \%$ & & $-4.2 \%$ & & $-5.7 \%$ & & $-5.0 \%$ & & $-5.2 \%$ & & $-8.1 \%$ & & \\
\hline Tam Rel Operacao & $-3.8 \%$ & & $-3.5 \%$ & & $-4.6 \%$ & & $-3.0 \%$ & & $-1.6 \%$ & & $-2.3 \%$ & & \\
\hline Tam Adquirente & $-0.5 \%$ & & $-0.5 \%$ & & $-0.5 \%$ & & $-0.3 \%$ & & $-0.6 \%$ & $*$ & $-0.2 \%$ & & \\
\hline Empresas Relacionadas & $1.2 \%$ & & $1.4 \%$ & & $1.9 \%$ & $* *$ & $2.3 \%$ & $* *$ & $1.2 \%$ & & $1.3 \%$ & & \\
\hline Momento (Ebitda / Ativ Total) & $-3.0 \%$ & & $-3.1 \%$ & & $-3.5 \%$ & & $1.4 \%$ & & $3.7 \%$ & & $-5.9 \%$ & & \\
\hline Aquisição Internacional & $2.1 \%$ & $*$ & $2.1 \%$ & * & $2.6 \%$ & $* *$ & $2.1 \%$ & $*$ & $2.2 \%$ & $* *$ & $2.2 \%$ & $*$ & \\
\hline Aquisição Controle & $0.1 \%$ & & $-0.1 \%$ & & $-0.1 \%$ & & $0.3 \%$ & & $-0.1 \%$ & & $0.2 \%$ & & \\
\hline Recenticidade & $1.0 \%$ & & $1.2 \%$ & & $1.7 \%$ & & $1.6 \%$ & & $1.3 \%$ & & $1.6 \%$ & & \\
\hline Experiência & $0.0 \%$ & & $0.0 \%$ & & $-0.1 \%$ & & $-0.2 \%$ & & $-0.1 \%$ & & $-0.2 \%$ & & \\
\hline Sem Sobreposição Eventos & $0.4 \%$ & & $0.6 \%$ & & $0.6 \%$ & & $0.8 \%$ & & $0.8 \%$ & & $0.9 \%$ & & \\
\hline$-{ }_{\text {Tamanho }} \overline{\text { Amostra }}----$ & $-\overline{341}$ & -- & $\overline{3} 42$ & - & $\overline{342}-$ & - & $-\overline{342}$ & - & $-\overline{341}$ & - - & $-\overline{287}$ & - & - \\
\hline $\mathrm{R}^{2}$ Ajustado & 0.027 & & 0.035 & & 0.012 & & 0.031 & & 0.081 & & 0.005 & & \\
\hline Estatítica F & 1.738 & $*$ & 1.947 & $* *$ & 1.317 & & 1.826 & $* *$ & 3.314 & $* * *$ & 1.103 & & \\
\hline Teste Breusch-Pagan & 0.015 & & 0.054 & & 0.109 & & 0.046 & & 0.011 & & 0.030 & & \\
\hline Teste Reset & 0.116 & & 0.405 & & 0.135 & & 0.672 & & 0.650 & & 0.479 & & \\
\hline
\end{tabular}

Fonte: Elaborado pelo Autor

Notas: * denota significância estatística: * p-value $<10 \%$; $\quad * *$ p-value $<5 \%$; $\quad$ *** p-value $<1 \%$ Quando o Teste de Breusch-Pagan indica heterocedasticidade, a significância estatística adota a metodologia de erros robustos A tabela apresenta os resultados da regressão cross section do retorno anormal acumulado para a janela de vinte e um dias. São apresentados os resultados de seis modelos, cada qual assumindo uma proxy diferente para classificação do estado de mercado. 


\subsection{Análise de Robustez dos Resultados Obtidos}

\subsubsection{Proxy de Mercado: IBRX-50}

O Apêndice 1 apresenta os resultados de praticamente todas as análises realizadas nos itens 4.1 e 4.2 considerando como proxy de mercado o índice IBRX-50 em substituição ao índice Ibovespa para cálculo do retorno anormal, ou seja, para cálculo da criação de valor em F\&As. De forma geral, pode-se dizer que os resultados são muito semelhantes. Assim como esperado os valores numéricos encontrados são distintos, mas, na maioria dos casos, levam às mesmas conclusões.

Nas análises por regressão cross section, o sinal do coeficiente da variável principal deste estudo, “Sentimento Mercado em Alta”, geralmente continua o mesmo e não se percebe alteração drástica dos resultados pela adoção do índice IBRX-50. Duas alterações podem ser destacadas: na análise da amostra de 113 eventos, quando possíveis outliers são desconsiderados, passa a haver maior número de resultados indicando (também sem significância estatística) maior criação de valor durante momentos de mercado em alta (na análise 4.2.2 havia praticamente mesmo número de resultados indicando maior e menor criação de valor em momentos de mercado em alta). A segunda alteração ocorre na análise da amostra com 346; ainda parece haver dominância de resultados indicando maior criação de valor durante momentos de mercado em baixa, no entanto, há redução do número de resultados com significância estatística.

Analisando os resultados obtidos para as variáveis de controle, com maior ênfase para aquelas com resultados estatisticamente significante, é possível afirmar que a troca da proxy de mercado (IBRX-50 em substituição ao Ibovespa) não altera o significado econômico dos resultados obtidos, ou seja, o sinal dos coeficientes dessas variáveis de controle não se altera. Embora haja um pouco mais de alterações, talvez ainda seja possível afirmar que a troca da proxy de mercado, na maioria dos resultados, também não altera os casos onde significância estatística pode ser notada. 


\subsubsection{Classificação Sentimento de Mercado pela Mediana}

Uma vez mais, grande parte das análises realizadas nos itens 4.1 e 4.2 foi realizada novamente e seus resultados são mostrados no Apêndice 2. Nessa análise o índice Ibovespa volta a representar o mercado, mas o estado do mercado passa a ter duas classificações apenas (mercado em alta e mercado em baixa) sendo o ponto de divisão entre as duas classificações a mediana de cada proxy utilizada para classificar o estado do mercado.

Com relação a variável "Sentimento de Mercado em Alta" pode-se notar duas alterações principais nos resultados obtidos: (i) de forma geral há uma redução na magnitude de seu coeficiente e seus valores tendem a ser mais próximos de zero e (ii), da mesma forma, há diminuição dos casos onde essa variável é significante estatisticamente: tanto quando os resultados sugerem maior criação de valor em momentos de mercado em alta, como quando os resultados sugerem relação contrária.

Dessa maneira, comparado aos resultados anteriores, parece haver indicação de menor diferenciação entre a criação de valor durante momentos de mercado em alta e momentos de mercado em baixa. Isso pode ser consequência justamente da adoção da mediana para segmentar a amostra que poderia resultar em sub amostras com elementos de características mais similares.

Quando as demais variáveis de controle são analisadas não é possível identificar, em geral, alteração muito grande dos resultados obtidos nos itens 4.1 e 4.2. 


\section{CONSIDERAÇÕES FINAIS}

O objetivo central deste trabalho é o de avaliar se a criação de valor em processos de fusão e aquisição, para o acionista de empresas adquirentes listadas na Bovespa, é influenciada pelo sentimento do mercado no momento em que é anunciada. As operações de F\&A anunciadas entre 2001 e 2011 foram estudadas (principalmente) por meio da técnica de regressão cross section e uma gama significante de variações metodológicas que possibilitam uma análise de robustez importante aos resultados obtidos.

Dentre os procedimentos e variações metodológicos pode-se citar como os mais importantes: (i) seleção criteriosa da amostra estudada por meio da identificação e controle dos eventos possivelmente influenciados por outros eventos diferentes das F\&As estudadas (embora esse processo seja amplamente recomendado em estudos de evento, é importante ressaltar que nem sempre é notado, ao menos de forma tão explícita), (ii) análise adicional sem exclusão dos eventos com sobreposição de efeitos (que são apenas “controlados” na regressão cross sectional), (iii) proposta e adoção de diferentes proxies para Sentimento de Mercado e (iv) emprego de testes de robustez com variação da proxy de mercado para cálculo do retorno anormal e alteração do critério para segmentação do estado de mercado (mercado em alta vs. mercado em baixa).

Primeiramente foi determinado que a criação de valor na amostra de F\&As realizadas entre 2001 e 2011 é não nula e positiva. O impacto observado sobre o valor das empresas adquirentes é da ordem de $0,6 \%$ no dia do anúncio e da ordem de $1 \%$ nas janelas maiores estudadas. Há, dessa maneira, contribuição para ampliar os resultados já obtidos nessa área de pesquisa, já que há vários estudos indicando a criação de valor negativa ou nula. Essa constatação pode ser importante para fomentar a discussão teórica e gerencial desse tema, pois haver pouca evidência de criação de valor para os acionistas das empresas adquirentes, ou haver evidência de destruição de valor para eles, pareceria ser uma contradição importante, já que são justamente os acionistas das empresas adquirentes que de uma forma ou de outra deveriam influenciar e decidir pela realização de F\&As. Não o fariam, ou não o permitiriam caso fosse comprovado que esse tipo de curso de ação não lhes favorece, ou seja, não aumenta o valor de suas empresas. 
Com relação a variável principal deste estudo, sentimento de mercado, os resultados parecem ser divergentes e dependentes da metodologia empregada. Na análise da amostra menor, sem eventos com possibilidade de sobreposição de efeitos, quase não há evidência estatisticamente significante de que haja influência do sentimento de mercado sobre a criação de valor na maior parte das análises. Além disso, mesmo que fosse aceito por hipótese como existente, o sentimento de mercado parece ter influência contrária sobre a criação de valor dependendo do tamanho da janela estudada.

Por outro lado, os resultados obtidos para a amostra maior, controlada para sobreposição de efeitos de outros eventos, parecem indicar que existe relação entre o sentimento de mercado e que a criação de valor em momentos de mercado em alta é menor que durante períodos de mercado em baixa e muitos desses resultados apresentam significância estatística. Esses resultados estão alinhados com as conclusões obtidas por Batista e Minardi (2010) em análise de F\&As ocorridas no Brasil entre 1986 e 2007; é importante notar que os autores não explicitam nesse trabalho se foi feito e como foi feito o tratamento da amostra para isolar possíveis sobreposições de efeitos para os casos onde há mais de um evento associado à mesma empresa na janela de estudo determinada.

As análises realizadas também são úteis para evidenciar que os resultados são sensíveis à forma como o sentimento de mercado é definido (proxy de sentimento de mercado), já que existem, em alguns casos, até mesmo resultados contrários e, ambos, com significância estatística. Da mesma forma, os resultados também parecem se alterar (mesmo mantendo-se a mesma proxy de sentimento de mercado) quando os limites (threshold) que separam os diferentes níveis de sentimento de mercado são alterados. Por outro lado, os resultados se mostram, de forma geral, consistentes para ambas as proxies de mercado utilizadas (Ibovespa e IBRX-50) e nas análises em que possíveis outliers são excluídos.

Em se tratando de estudos futuros, pode haver benefício para as análises realizadas o desenvolvimento de uma variável de sentimento de mercado por meio de análise fatorial segundo espírito de Yoshinaga, Castro e Securato (2010) ou de Baker e Wurgler (2006) para aplicação aos estudos de criação de valor em F\&As no mercado brasileiro. 


\section{REFERÊNCIAS}

ACHARYA, S. Value of Latent Information: Alternative Event Study Methods. The Journal of Finance, v. 48, n. 1, p. 363-385, 1993.

ALCHIAN, A. A.; DEMSETZ, H. Production, information costs, and economic organizations. The American Economic Review, v. 62, p. 777-795, dez. 1972.

ALEXANDER, S. S. Price movements in speculative markets: trends or random walks. Industrial Management Review, p. 7-25, 1961.

AMBIMA. Especial fusões e aquisições, Rio de Janeiro, n. II, mar. 2011.

ANAND, J.; DELIOS, A. Absolute and relative resources as determinants of internation acquisitions. Strategic Management Journal, v. 23, p. 119-134, 2002.

ANDRADE, G.; MITCHELL, M.; STAFFORD, E. New Evidence and Perspectives on Mergers. The Journal of Economic Perspectives, v. 15, n. 2, p. 103-120, spring 2001.

ARIKAN, A. M. Does it pay-off to capture intangible assets through mergers and acquisitions? In: Academy of Management Proceedings. Denver: [s.n.], 2002.

AYBAR, B.; AYSUN, F. Cross-borderacquisitions and firm value: An analysis of emergingmarket multinationals. Journal of International Business Studies, v. 40, p. 1317-1338, 2009.

BAKER, G. Compensation and hierarchies. Harvard Business School, jan. 1986.

BAKER, G. P.; JENSEN, M. C.; MURPHY, K. J. Compensantion and Incentives: Practice vs. Theory. The Journal of Finance, v. 43, p. 593-616, 1988.

BAKER, M.; WURGLER, J. Investor sentiment and the cross-section of stock returns. The Journal of Finance, p. 1645-1680, ago. 2006.

BALL, R. The development, accomplishments and limitations of the theory of stock market efficiency. Managerial Finance, p. 3-48, 1994.

BALL, R.; BROWN, P. An empirical evaluation of accounting income numbers. Journal of Accounting Research, v. 22, n. 1., p. 159-178, 1968.

BARBERIS, N.; SHLEIFER, A.; WURGLER, J. Comovement. Journal of Financial Economics, v. 75, p. 283-317, 2005.

BARCLAY, M.; LITZENBERGER, R. Announcements effects of new equity issues and the use of the intraday price day data. Journal of Financial Economics, v. 21, p. 71-99, 1988. 
BATISTA, D. B.; MINARDI, A. M. A. F. Uma investigação sobre como a valoração do mercado (momentos de alta e de baixa) influencia o desempenho das operações de fusões e aquisições no Brasil. In: X Encontro Brasileiro de Finanças, 2010, Anais X EBFin, São Paulo, 2010.

BERK, D.; DEMARZO, P. Corporate Finance. 2. ed. Boston: Pearson, 2009.

BERKOVITCH, E.; NARAYANAN, M. P. Motives for takeovers: an empirical investigation. Journal of Financial and Quantitative Analysis, v. 28, n. 3., p. 347-362, set. 1993.

BESANKO, D. et al. Economics of strategy. 5. ed. Hoboken: John Wiley \& Sons, 2008.

BHATTACHARYYA, S.; NAIN, A. Horizontal acquisitions and buying power: a product market analysis. Journal of Financial Economics, p. 97-115, 2011.

BILLINGSLEY, P. Probability and measure. New York: Wiley, 1979.

BOUWMAN, C. H. S.; FULLER, K.; NAIN, A. S. Market valuation and acquisition quality: empirical evidence. The Review of Financial Studies, v. 22, n. 2., p. 633-679, 2009.

BRADLEY, M.; DESAI, A.; KIM, E. H. Synergistic gains from corporate acquisitons and their division between the stockholders of target and acquiring firms. Journal of Financial Economics, v. 21, p. 3-40, 1988.

BROMILEY, P.; GOVEKAR, M.; MARCUS, A. On using event study methodology in strategic management research. Technovation, v. 8, p. 25-42, 1988.

BROUTHERS, K. D.; BROUTHERS, L. E. Acquisition of greenfield start-up? Institutional, cultural and transaction cost influences. Strategic Management Journal, v. 21, p. 89-97, Jan 2000 .

BROWN, S.; WARNER, J. Measuring security price performance. Journal of Financial Economics, v. 8, p. 205-258, 1980.

Using Daily Stock Returns: The case of Event Studies. Journal of Financial Economics, v. 14, p. 3-31, 1985.

CAPRON, L.; DUSSAUGE, P.; MITCHELL, W. Resource redeployment following horizontal acquisitions in Europe and North America, 1988-1992. Strategic Management Journal, v. 19, p. 631-661, 1998.

CAPRON, L.; PISTRE, N. When do acquires earn abnormal returns? Strategic Management Journal, v. 23, p. 781-794, 2002.

CHAROENROOK, A. Change in the consumer sentiment index and aggregate stock returns. Working Paper, Vanderbilt University, Nashville, TN., 2003.

CHIDAMBARAN, N. K.; JOHN, K.; SHANGGUAN, Z. Hot and cold merger markets. Review of Quantitative Finance and Accounting, p. 327-349, 2010. 
CHOE, H.; MASULIS, R.; NANDA, V. Common stock offerings across the business cycle. Common stock offerings across the business cycle, v. 1, n. 1, p. 3-33, 1993.

COMITÊ DE PRONUNCIAMENTOS CONTABEIS. Pronunciamento Técnico CPC 04. Brasilia. 2011.

COOK, R. D. Detection of influential observations in linear regressions. Technometrics, v. 19, p. 15-18, 1977.

Influential observations in linear regressions. Journal of American Statistical Association, v. 74, p. 169-174, 1979.

COPELAND, T.; WESTON, J.; SHASTRI, K. Financial Theory and Corporate Policy. [S.l.]: Pearson, 2005.

DAMODARAN, A. Avaliação de Empresas. São Paulo: Pearson Hall, 2007.

DANIEL, K.; HIRSHLEIFER, D.; SUBRAHMANYAM, A. Investor psycology and security market under and overreactions. The Journal of Finance, p. 1839-1885, dez. 1998.

DEVOS, E.; KADAPAKKAM, P.-R.; KRISHNAMURTHY, S. How do meregrs create value? A comparison of taxes, market power and efficiency improvements as explanations for synergies. The Review of Financial Studies, v. 22, n. 3, p. 1179-1211, 2009.

DIMSON, E. Risk measurement when shares are subject to infrequent trading. Journal of Financial Economics, v. 9, p. 197-226, 1979.

DOLLEY, J. C. Characteristics and Procedure of Common Stock Split-Ups. Harvard Business Review, v. 11, p. 316-326, abr. 1933.

ELTON, E. J. et al. Modern Portfolio Theory and Investment Analysis. 8th International student edition. ed. Hoboken: John Wiley \& Sons Ltd, 2009.

FAMA, E. F. Random walks in stock market prices. Financial Analysts Journal, p. 55-59, 1965.

Efficient capital markets: a review of theory and empirical work. The Journal of Finance, v. 25, n. 2, p. 383-417, mai. 1970.

Foundations of finance: portfolio decisions and securities prices. New York: Basic Books, 1976.

. Efficient capital markets: II. The Journal of Finance, v. 46, n. 5, p. 1575-1617, dez. 1991.

Market efficiency, long-term returns, and behavioral finance. Journal of Financial Economics, v. 49, p. 283-306, 1998.

FAMA, E. F. et al. The adjustment of stock prices to new information. International Economic Review, v. 10, p. 1-21, 1969. 
FAMA, E. F.; FRENCH, K. R. Business conditions and expected returns on stocks and bonds. Journal of Financial Economics, v. 25, n. 1, p. 1089-1108, 1989.

. Common risk factors in stock and bonds returns. Journal of Financial Economics, v. 33, p. 3-56, 1993.

Dissecting anomalies. The Journal of Finance, p. 1653-1678, ago. 2008.

FOSTER, G. Accounting policy decisions and capital market research. Journal of Accounting and Economics, v. 2, p. 29-62, 1980.

GAUGHAN, P. A. Mergeres, acquisitions and corporate restructurings. 5. ed. New Jersey: John Wiley \& Sons, 2010.

GUBBI, A. et al. Do international acquisitions by emerging-economy firms create shareholder value? The case of Indian firms. Journal of International Business Studies, v. 41, p. 397418, 2010.

GUPTA, O.; ROOS, G. Mergers and acquisitions through an intellectual capital perspective. Journal of Intellectual Capital, v. 2, n. 3, p. 297-309, 2001.

HAN, B. Investor sentiment and option prices. The Review of Financial Studies, v. 21, p. 387-414, 2008.

HARFORD, J. What drives merger waves? Journal of Financial Economics, v. 77, p. 529560, 2005.

HAUGEN, R. A.; LANGETIEG, T. C. An empirical test for synergism in merger. The Journal of Finance, v. 40, n. 4, p. 1003-1014, 1975.

HELWEGE, J.; LIANG, N. Initial public offerings in hot and cold markets. Journal of Financial and Quantitative Analysis, v. 39, p. 541-569, 2004.

HIRSHLEIFER, D. Investor psycology and asset pricing. The Journal of Finance, p. 15331597, ago. 2001.

HOBERG, G.; PHILLIPS, G. Product Market Synergies and competition in mergers and acquisitions: a text-based analysis. The Review of Financial Studies, v. 23, p. 3773-3811, 2010 .

HONG, H.; STEIN, J. C. A unified theory od underreaction, momentum trading, and overreaction in asset markets. The Journal of Finance, v. 6, p. 2143-2184, dez 1999.

IYER, D. N.; MILLER, K. D. Performance feedback, slack, and the timing of acquisitions. Academy of Management Journal, v. 51, n. 4, p. 808-822, 2008.

JACOBSON, C. K. Investor response to health care cost containment legislation: Is American policy designed to fail? Academy of Management Journal, v. 37, p. 440-452, 1994. 
JARREL, G. A.; BRICKLEY, J. A.; NETTER, J. M. The market for corporante control: the empirical evidence since 1980. Journal of Economic Perspectives, v. 2, n. 1, p. 49-68, 1988.

JENSEN, M. C. Some anomalous evidence regarding market efficiency. Journal of Financial Economics, v. 6, p. 95-101, 1978.

Agency costs of free cash flow, corporate finance and takeovers. The American Economic Review, v. 76, n. 2, p. 323-329, 1986.

Takeovers: their causes and consequences. The Journal of Economic Perspectives, v. 2, n. 1, p. 21-48, 1988.

JENSEN, M. C.; RUBACK, R. S. The market for corporate control: the scientific evidence. Journal of Financial Economics, v. 11, p. 5-50, 1983.

KAHNEMAN, D.; TVERSKY, A. Prospect theory: an analysis of decision under risk. Econometrica, v. 47, n. 2, p. 263-292, Mar 1979.

KARAFIATH, I. On the efficiency of least squares regression with security abnormal returns as the dependent variable. Journal of Financial and Quantitative Analysis, v. 29, n. 279300, 1994.

KAYO, E. K. A estrutura de capital e o risco das empresas tangível e intangível-intensivas: uma contribuição ao estudo da valoração de empresas. 2002. Tese (Doutorado em Administração) - Faculdade de Economia, Administração e Contabilidade da Universidade de São Paulo, São Paulo, São Paulo, Brasil., 2002.

KAYO, E. K.; FAMÁ, R. A estrutura de capital e o risco das empresas tangível-intensivas e intangível-intensivas. Revista de Administração da Universidade de São Paulo, v. 39, n. 2, p. 164-176, 2004.

KAYO, E. K.; PATROCÍNIO, M. R.; MARTIN, D. M. L. Intangibilidade e criação de valor em aquisições: o paple moderador do endividamento. Revista de Admistração da Universidade de São Paulo, p. 59-69, 2009.

LAKONISHOK, J.; SHLEIFER, A.; VISHNY, R. W. Contrarian investment, extrapolation, and risk. The Journal of Finance, v. 49, n. 5, p. 1541-1578, Dez 1994.

LATHAM, M. Defining Capital Market Efficiency. Finance Working Paper 150, Institute for Business and Economic Research, University of California, Berkeley, CA., 1985.

LEE, C. M. C.; SHLEIFER, A.; THALER, R. H. Investor Sentiment and the Closed-End Fund Puzzle. The Journal of Finance, v. 46, n. 1, p. 75-109, mar. 1991.

LINTNER, J. The valuation of risky assets and the selection of risky investments in stock portfolios and capital budgets. Review of Economics and Statistics, v. 47, n. 1, p. 13-37, fev. 1965.

LJUNGQVIST, A. The pricing of initial public offerings: further evidence from Germany. European Economic Review, v. 41, n. 7, p. 1309-1320, 1997. 
LJUNGQVIST, A.; NANDA, V.; SINGH, R. Hot Markets, Investor Sentiment and IPO Pricing. Journal of Business, v. 79, p. 1667-1702, 2006.

LONG, B. et al. Noise trader risk in financial markets. Journal of Political Economy, v. 98, n. 4, p. 703-738, ago. 1990.

MACKINLAY, A. C. Event Studies in Economics and Finance. Journal of Economic Literature, v. 35, n. 1, p. 13-39, mar. 1997.

MALKIEL, B. G. The efficient market hypothesis and its critics. The Journal of Economic Perspectives, v. 17, n. 1, p. 59-82, 2003.

MANNE, H. G. Mergers and the market for corporate control. The Journal of Political Economy, v. 73, n. 2, p. 110-120, abr. 1965.

MARRIS, R. L. The economic theory of managerial capitalism. London, U.K.: Macmillan, 1964.

MCNAMARA, G. M.; HALEBLIAN, J. J.; DYKES, B. J. The Performance Implications of Participating in an Acquisition Wave: Early Mover Advantages, Bandwagon Effects, and the Moderating Influence of Industry Characteristics and Acquirer Tactics. Academy of Management Journal, v. 51, n. 1, p. 113-130, 2008.

MCWILliAMS, A.; SIEGEL, D. Event Studies in Management Research: Theoretical and Empirical Issues. Academy of Management Journal, v. 40, n. 3, p. 626-657, 1997.

MOELLER, S. B.; SCHLINGEMANN, F. P.; STULZ, R. M. Wealth destruction on a massive scale? A study of acquiring-firm returns in the recent merger wave. Journal of Finance, Apr 2005. 757-782.

MULHERIN, J. H.; BOONE, A. L. Comparing acquisitions and divestitures. Journal of Corporate Finance, v. 6, p. 117-139, 2000.

MURPHY, K. J. Corporate performance and managerial remuneration: and empirical analysis. Journal of Accounting and Economics, v. 7, p. 11-42, abr. 1985.

PASTOR, L.; VERONESI, P. Stock prices and IPO waves. Working Paper, University of Chicago, Chicago, IL., 2003.

PATROCÍNIO, M. R.; KAYO, E. K.; KIMURA, H. Aquisição de empresas, intangibilidade e criação de valor: um estudo de evento. Revista de Administração da Universidade de São Paulo, v. 42, n. 2, p. 205-215, 2007.

RHODES-KROPF, M.; ROBINSON, D. T.; VISWANATHAN, S. Valuation waves and merger activity: the empirical evidence. Journal of Financial Economics, v. 77, p. 561-603, 2005.

RHODES-KROPF, M.; VISWANATHAN, S. Market valuation and merger waves. The Journal of Finance, p. 2685-2718, dez. 2004. 
RITTER, J.; WELCH, I. A review of IPO activity, pricing, and allocations. Journal of Finance, v. 47, n. 4, p. 1795-1828, 2002.

ROLL, R. The Hubris Hypothesis of Corporate Takeovers. The Journal of Business, v. 59, n. 2, p. 197-216, abr. 1986.

ROSS, S. A. The arbitrage theory of capital asset pricing. Journal of Economic Theory, v. 13, n. 3, p. 341-360, dez. 1976.

ROSSI, S.; VOLPIN, P. F. Cross-country determinants of mergers and acquisitions. Journal of Financial Economics, v. 74, p. 277-304, 2004.

RUBINSTEIN, M. Securities Market Efficiency in an Arrow-Debreu Economy. American Economy Review, p. 812-824, dez. 1975.

RUMELT, R. P. Stretegy, Structure and Economic Performance. Harvard University Press, Cambridge, 1974.

SCHLEIFER, A. Inneficient Markets. 1. ed. New York: Oxford University Press Inc., 2000.

SCHOLES, M.; WILLIAMS, J. Estimating betas from nonsynchronous data. Journal of Financial Economics, v. 5, p. 309-328, 1977.

SERVAES, H. Tobin's Q and the gains from takeovers. The Journal of Finance, v. 46, n. 1, p. 409-419, Mar 1001.

SETH, A. Sources of value creation in acquisitions: an empirical investigation. Strategic Management Journal, n. 11, p. 431-446, out. 1990a.

Value creation in acquisitions: a re-examination of performance issues. Strategic Managment Journal, p. 99-115, 1990b.

SETH, A.; SONG, K. P.; PETTIT, R. Synergy, managerialism or hubris? An empirical examination of motives for foreign acquisitions of U.S. firms. Journal of International Business Studies, v. 31, n. 3, p. 387-405, 2000.

SEYHUN, H. N. Do bidder managers pay too much for target firms? Journal of Business, v. 63, n. 4, p. 439-464, 1990.

SHARPE, W. F. Capital asset prices: theory of market equilibrium under conditions of risk. Journal of Finance, v. 19, n. 3, p. 425-442, set. 1964.

SHLEIFER, A.; VISHNY, R. W. Value maximization and the acquisition process. The Journal of Economic Perspectives, v. 2, n. 1, p. 7-20, 1988.

1989.

. Management Entrenchment. Journal of Financial Economics, v. 25, p. 123-139,

Stock market driven acquisitons. Journal of Financial Economics, v. 70, p. 295311, 2003. 
SMIDT, S. A new look at the random walk hypothesis. The Journal of Financial and Quantitative Analysis, p. 235-261, set. 1968.

SOARES, R. S.; ROSTAGNO, L. M.; SOARES, K. T. C. Estudo de evento: o método e as formas de cálculo do retorno anormal. In: Enanpad, XXVI, 2002. Anais.

STEARNS, L. B.; ALLAN, K. D. Economic Behavior In Institutional Enviroments: the Corporate Merger Wave of the 1980s. American Sociological Review, v. 61, p. 699-718, ago 1996.

SUBRAHMANYAM, A. Behavioural finance: a review and synthesis. European Financial Management, v. 14, n. 1, p. 12-29, 2007.

TIMMERMANN, A.; GRANGER, C. W. J. Efficient market hypothesis and forecasting. International Journal of Forecasting, v. 20, p. 15-27, 2004.

TRAVLOS, N. G. Corporate takeover bids, methods of payment, and bidding firms' stock returns. The Journal of Fiannce, v. 42, n. 4, p. 943-963, set. 1987.

UHLENBRUCK, K.; HITT, M.; SEMADENI, M. Market value effects of acquisitions involving internet firms: a resource-based analysis. Strategic Management Journal, v. 27, p. 899-913, jul. 2006.

VALLANDRO, L.; VALLANDRO, L. Dicionário Inglês-Português. Rio de Janeiro: Editora Globo, 1957.

VILLALONGA, B.; MCGAHAN, A. M. The choice among acquisitions, alliances, and divestitures. Strategic Management Journal, v. 26, p. 1183-1208, 2005.

WALKER, T. J.; LIN, M. Y. Dynamic relationships and technological innovation in hot and cold issue markets. International Journal of Managerial Finance, v. 3, n. 3, p. 200-228, 2007.

WESTON, J. F.; MANSINGHKA, K. Tests of the efficiency performance of conglomerate firms. The Journal of Finance, v. 26, p. 919-936, Sep 1971.

WESTON, J. F.; MITCHELL, L. M.; MULHERIN, J. H. Takeovers, restructuring, and corporate governance. 4a. ed. New Jersey: Pearson Prentice Hall, 2003.

YOSHINAGA, C. E.; CASTRO, F. H.; SECURATO, J. R. The relationship between market sentiment index and stock rate returns: a panel data analysis. Oxford Business \& Economics Conference Program. Oxford: Oxford University. 2010. p. 1-30.

YUNG, C.; ÇOLAK, G.; WEI, W. Cycles in the IPO market. Journal of Financial Economics, v. 89, p. 192-208, 2008.

ZHANG, C. Defining, modeling, and measuring investor sentiment. Berkeley: University of California, 2008, Doctoral Thesis. 


\section{APÊNDICES}

Apêndice 1 - IBRX-50 como Proxy de Mercado 89

Apêndice 2 - Classificação Sentimento de Mercado pela Mediana .99 
Apêndice I - IBRX-50 como Proxy de Mercado

Tabela 1 - Criação de Valor - Proxy de Mercado IBRX-50

\begin{tabular}{|c|c|c|c|c|c|c|c|c|c|c|c|c|c|c|c|c|c|c|c|}
\hline \multirow{3}{*}{$\begin{array}{c}\text { Sentimento } \\
\text { de Mercado } \\
\text { Número de } \\
\text { Eventos }\end{array}$} & \multirow[t]{2}{*}{$\begin{array}{c}\text { Amostra } \\
\text { Total }\end{array}$} & \multicolumn{4}{|c|}{ ICEI } & \multicolumn{3}{|c|}{ ICEI Expectativa } & \multicolumn{2}{|c|}{ Retorno Ibovespa } & \multicolumn{3}{|c|}{ Número de F\&As } & \multicolumn{2}{|c|}{$\begin{array}{c}\text { Utilização Capacidade } \\
\text { Instalada }\end{array}$} & \multicolumn{4}{|c|}{ IBC - BR } \\
\hline & & \multicolumn{2}{|c|}{ Alta } & \multicolumn{2}{|c|}{ Baixa } & Alta & \multicolumn{2}{|c|}{ Baixa } & \multirow{2}{*}{$\begin{array}{l}\text { Alta } \\
42\end{array}$} & \multirow{2}{*}{$\begin{array}{c}\text { Baixa } \\
20\end{array}$} & Alta & \multicolumn{2}{|c|}{ Baixa } & Alta & Baixa & \multicolumn{2}{|l|}{ Alta } & \multicolumn{2}{|l|}{ Baixa } \\
\hline & 113 & 36 & & 34 & & 31 & 30 & & & & 51 & 23 & & 56 & 14 & 23 & & 33 & \\
\hline Dia & & & & & & & & & & & & & & & & & & & \\
\hline-10 & $0.1 \%$ & $-0.3 \%$ & & $0.1 \%$ & & $-0.3 \%$ & $-0.1 \%$ & & $0.2 \%$ & $-0.5 \%$ & $0.3 \%$ & $0.1 \%$ & & $0.2 \%$ & $-0.5 \%$ & $-0.6 \% *$ & v & $0.5 \%$ & \\
\hline-9 & $0.0 \%$ & $0.1 \%$ & & $0.2 \%$ & & $-0.1 \%$ & $0.5 \%$ & & $-0.3 \%$ & $0.1 \%$ & $0.0 \%$ & $-0.7 \%$ & & $0.3 \%$ & $0.0 \%$ & $-0.3 \%$ & & $0.3 \%$ & \\
\hline-8 & $-0.1 \%$ & $0.1 \%$ & & $-0.1 \%$ & & $-0.1 \%$ & $-0.2 \%$ & & $-0.1 \%$ & $0.0 \%$ & $0.4 \%$ & $0.2 \%$ & & $0.1 \%$ & $-0.7 \%$ & $-0.2 \%$ & & $-0.3 \%$ & \\
\hline-7 & $-0.1 \%$ & $-0.2 \%$ & & $0.2 \%$ & & $0.0 \%$ & $0.3 \%$ & & $-0.4 \%$ & $0.8 \%$ & $0.1 \%$ & $0.0 \%$ & & $0.3 \%$ & $-0.2 \%$ & $-0.7 \%$ & & $-0.2 \%$ & \\
\hline-6 & $0.1 \%$ & $0.1 \%$ & & $0.2 \%$ & & $0.6 \% * \quad \sqrt{ }$ & $0.4 \%$ & & $-0.6 \% * * \quad \sqrt{ }$ & $0.1 \%$ & $-0.2 \%$ & $0.4 \%$ & & $0.0 \%$ & $-0.3 \%$ & $0.6 \%$ & & $0.4 \%$ & \\
\hline-5 & $0.2 \%$ & $0.1 \%$ & & $0.2 \%$ & & $0.1 \%$ & $0.4 \%$ & & $0.1 \%$ & $0.2 \%$ & $0.3 \%$ & $-0.2 \%$ & & $0.2 \%$ & $0.3 \%$ & $0.1 \%$ & & $0.6 \%$ & \\
\hline-4 & $-0.3 \% * \quad \sqrt{ }$ & $-0.1 \%$ & & $-0.6 \% *$ & $\sqrt{ }$ & $-0.3 \%$ & $-0.6 \%$ & $\checkmark$ & $-0.2 \%$ & $-0.3 \%$ & $0.0 \%$ & $-0.4 \%$ & v & $-0.2 \%$ & $-0.8 \%$ & $-0.5 \% *$ & 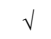 & $-0.4 \% *$ & v \\
\hline-3 & $-0.1 \%$ & $0.5 \%$ & & $-0.3 \%$ & & $0.4 \%$ & $-0.2 \%$ & & $-0.4 \%$ & $0.1 \%$ & $-0.1 \%$ & $-0.1 \%$ & & $-0.2 \%$ & $1.5 \%$ & $0.0 \%$ & & $0.4 \%$ & \\
\hline-2 & $-0.4 \% *$ & $0.1 \%$ & & $-1.1 \% * *$ & $\sqrt{ }$ & $-0.1 \%$ & $-0.9 \% *$ & $\checkmark$ & $-0.3 \%$ & $-0.7 \%$ & $-0.5 \%$ & $0.0 \%$ & & $-0.4 \%$ & $-0.5 \%$ & $-0.5 \%$ & & $-0.2 \%$ & \\
\hline-1 & $0.1 \%$ & $0.7 \%$ & & $-0.6 \%$ & & $0.9 \%$ & $-0.9 \%$ & & $0.2 \%$ & $-0.8 \%$ & $0.3 \%$ & $-0.7 \% * *$ & $\sqrt{ } V$ & $0.6 \%$ & $-1.0 \%$ & $-0.4 \%$ & v & $0.8 \%$ & \\
\hline $\begin{array}{c}\text { Anúncio } \\
\text { Evento }\end{array}$ & $0.5 \%$ * & $0.3 \%$ & & $0.8 \%$ & & $0.3 \%$ & $0.8 \%$ & & $0.8 \% * * \quad \checkmark$ & $0.3 \%$ & $0.5 \%$ & $0.5 \%$ & & $0.7 \%$ & $0.6 \%$ & $-0.2 \%$ & & $0.2 \%$ & \\
\hline 1 & $0.2 \%$ & $0.0 \%$ & & $0.4 \%$ & & $-0.2 \%$ & $0.3 \%$ & & $0.0 \%$ & $0.1 \%$ & $-0.1 \%$ & $0.9 \% * *$ & $\sqrt{ } V$ & $0.0 \%$ & $1.8 \% * * \quad \downarrow \downarrow V$ & $0.0 \%$ & & $-0.1 \%$ & \\
\hline 2 & $0.0 \%$ & $0.4 \% *$ & & $-0.7 \%$ & $\sqrt{ }$ & $0.2 \%$ & $-0.7 \%$ & & $-0.1 \%$ & $-0.4 \%$ & $0.2 \%$ & $-0.1 \%$ & & $-0.1 \%$ & $-0.2 \%$ & $0.4 \%$ & & $0.4 \%$ & \\
\hline 3 & $0.0 \%$ & $0.0 \%$ & & $0.1 \%$ & & $0.0 \%$ & $-0.2 \%$ & & $0.2 \%$ & $0.2 \%$ & $0.2 \%$ & $-0.7 \% * *$ & v & $0.0 \%$ & $-0.6 \%$ & $-0.2 \%$ & & $0.6 \%$ & \\
\hline 4 & $0.1 \%$ & $0.3 \%$ & & $0.2 \%$ & & $0.1 \%$ & $0.4 \%$ & & $0.2 \%$ & $0.7 \%$ & $0.5 \%$ & $0.2 \%$ & & $0.5 \%$ & $-0.4 \%$ & $-0.2 \%$ & & $0.1 \%$ & \\
\hline 5 & $-0.1 \%$ & $0.2 \%$ & & $0.0 \%$ & & $0.6 \%$ & $0.2 \%$ & & $-0.5 \%$ & $-0.2 \%$ & $-0.6 \% * \quad \sqrt{ }$ & $0.5 \%$ & & $0.1 \%$ & $-0.2 \%$ & $0.6 \%$ & & $0.0 \%$ & \\
\hline 6 & $-0.3 \%$ & $-0.1 \%$ & & $-0.2 \%$ & & $-0.1 \%$ & $-0.3 \%$ & & $-0.2 \%$ & $0.0 \%$ & $-0.2 \%$ & $-0.6 \% *$ & & $-0.4 \%$ & $1.0 \%$ & $0.2 \%$ & & $-0.7 \%$ & \\
\hline 7 & $0.4 \% * *$ & $-0.2 \%$ & & $0.1 \%$ & & $-0.1 \%$ & $0.5 \%$ & & $-0.2 \%$ & $0.4 \%$ & $0.5 \%$ * $\quad \sqrt{ }$ & $0.5 \%$ & & $0.6 \% * * \quad \checkmark$ & $0.3 \%$ & $0.2 \%$ & & $0.3 \%$ & \\
\hline 8 & $-0.2 \%$ & $-0.6 \% *$ & v & $0.1 \%$ & & $-0.5 \% *$ & $0.4 \%$ & & $-0.4 \%$ & $0.2 \%$ & $-0.1 \%$ & $0.1 \%$ & & $0.0 \%$ & $-1.0 \%$ & $-0.1 \%$ & & $-0.5 \% *$ & $\sqrt{ }$ \\
\hline 9 & $0.1 \%$ & $0.0 \%$ & & $0.6 \%$ & & $0.1 \%$ & $0.4 \%$ & & $0.1 \%$ & $0.3 \%$ & $-0.3 \%$ & $-0.2 \%$ & & $-0.2 \%$ & $1.6 \%$ & $0.1 \%$ & & $-0.1 \%$ & \\
\hline 10 & $0.0 \%$ & $0.1 \%$ & & $0.1 \%$ & & $0.0 \%$ & $0.1 \%$ & & $0.5 \%$ & $0.7 \%$ & $0.4 \%$ & $-0.2 \%$ & & $0.3 \%$ & $0.4 \%$ & $0.1 \%$ & & $-0.6 \%$ & \\
\hline CAR_3 & $0.9 \% *$ & $1.1 \%$ & & $0.6 \%$ & & $1.0 \%$ & $0.2 \%$ & & $0.9 \%$ & $-0.4 \%$ & $0.8 \%$ & $0.6 \%$ & & $1.4 \% * * \quad \checkmark$ & $1.4 \%$ & $-0.6 \%$ & v & $0.9 \%$ & \\
\hline CAR_11 & $0.3 \%$ & $2.6 \% * *$ & $\sqrt{ } \sqrt{ }$ & $-1.7 \%$ & $\sqrt{ }$ & $2.0 \% *$ & $-1.3 \%$ & & $0.1 \%$ & $-0.8 \%$ & $0.7 \%$ & $-0.1 \%$ & & $1.4 \%$ & $0.5 \%$ & $-0.8 \%$ & & $2.5 \% * *$ & \\
\hline CAR 11 & $0.3 \%$ & $1.7 \%$ & & $-0.5 \%$ & & $1.4 \%$ & $0.7 \%$ & & $-1.4 \%$ & $1.4 \%$ & $1.6 \%$ & $-0.6 \%$ & & $2.5 \% * * \quad \sqrt{ }$ & $1.1 \%$ & $-1.6 \%$ & & $1.7 \%$ & \\
\hline
\end{tabular}

Fonte: Elaborado pelo Autor

Notas: $\quad *$ denota significância estatística para o teste t: * p-value $<10 \% ; \quad * *$ p-value $<5 \% ; \quad * * *$ p-value $<1 \%$

$\sqrt{ }$ denota significância estatística para o teste de Wilcoxon: $\sqrt{ }$ p-value $<10 \% ; \quad \sqrt{ }$ p-value $<5 \% ; \quad \sqrt{ } \sqrt{ }$ p-value $<1 \%$

A tabela mostra os retornos anormais diários médios (para dez dias em torno do dia do anúncio da F\&A) e acumulado para as janelas de três, onze e vinte e um dias (CAR_3, CAR_11 e

CAR_21).

O retorno anormal médio é apresentado para a amostra de eventos sem sobreposição de efeitos de outros fatos relevantes e para sub amostras desses mesmos eventos obtidas com base no estado do sentimento de mercado (em alta ou baixa), quando classificado segundo as proxies: ICEI, ICEI Expectativa, Retorno Ibovespa, Número de F\&A, Nível de Utilização da Capacidade Instalada e IBC-BR 
Tabela 14 - Teste Mann Whitney para Duas Amostras - Proxy de Mercado IBRX-50

\begin{tabular}{|c|c|c|c|c|c|c|}
\hline & ICEI & ICEI Exp & $\begin{array}{l}\text { Retorno } \\
\text { Ibovespa }\end{array}$ & $\begin{array}{l}\text { Número de } \\
\text { F\&As }\end{array}$ & $\begin{array}{l}\text { Utilização Capa- } \\
\text { cidade Instalada }\end{array}$ & IBC-BR \\
\hline \multicolumn{7}{|c|}{ Criação de Valor: Mercado em Alta } \\
\hline Dia Anúncio & $0.3 \%$ & $0.3 \%$ & $0.8 \%$ & $0.5 \%$ & $0.7 \%$ & $-0.2 \%$ \\
\hline CAR_3 & $1.1 \%$ & $1.0 \%$ & $0.9 \%$ & $0.8 \%$ & $1.4 \%$ & $-0.6 \%$ \\
\hline CAR_11 & $2.6 \%$ & $2.0 \%$ & $0.1 \%$ & $0.7 \%$ & $1.4 \%$ & $-0.8 \%$ \\
\hline CAR_21 & $1.7 \%$ & $1.4 \%$ & $-1.4 \%$ & $1.6 \%$ & $2.5 \%$ & $-1.6 \%$ \\
\hline \multicolumn{7}{|c|}{ Criação de Valor: Mercado em Baixa } \\
\hline Dia Anúncio & $0.8 \%$ & $0.8 \%$ & $0.3 \%$ & $0.5 \%$ & $0.6 \%$ & $0.2 \%$ \\
\hline CAR_3 & $0.6 \%$ & $0.2 \%$ & $-0.4 \%$ & $0.6 \%$ & $1.4 \%$ & $0.9 \%$ \\
\hline CAR_11 & $-1.7 \%$ & $-1.3 \%$ & $-0.8 \%$ & $-0.1 \%$ & $0.5 \%$ & $2.5 \%$ \\
\hline CAR_21 & $-0.5 \%$ & $0.7 \%$ & $1.4 \%$ & $-0.6 \%$ & $1.1 \%$ & $1.7 \%$ \\
\hline \multicolumn{7}{|l|}{$\mathrm{P}$-Value } \\
\hline Dia Anúncio & 0.451 & 0.641 & 0.782 & 0.935 & 0.533 & 0.427 \\
\hline CAR_3 & 0.524 & 0.452 & 0.200 & 0.770 & 0.809 & 0.110 \\
\hline CAR_11 & 0.012 & 0.070 & 0.398 & 0.926 & 0.982 & 0.148 \\
\hline CAR_21 & 0.208 & 0.704 & 0.264 & 0.262 & 0.797 & 0.246 \\
\hline
\end{tabular}

Fonte: Elaborado pelo Autor

Nota. A tabela apresenta o resultado ( $p$-value) do teste de Mann-Whitney para a hipótese nula de que a criação de valor em momentos de mercado em baixa é igual à criação de valor em momentos de mercado em alta. 
Tabela 15 - Análise de Regressão dos Determinantes de Criação de Valor - Dia do Anúncio da F\&A - Proxy de Mercado IBRX-50

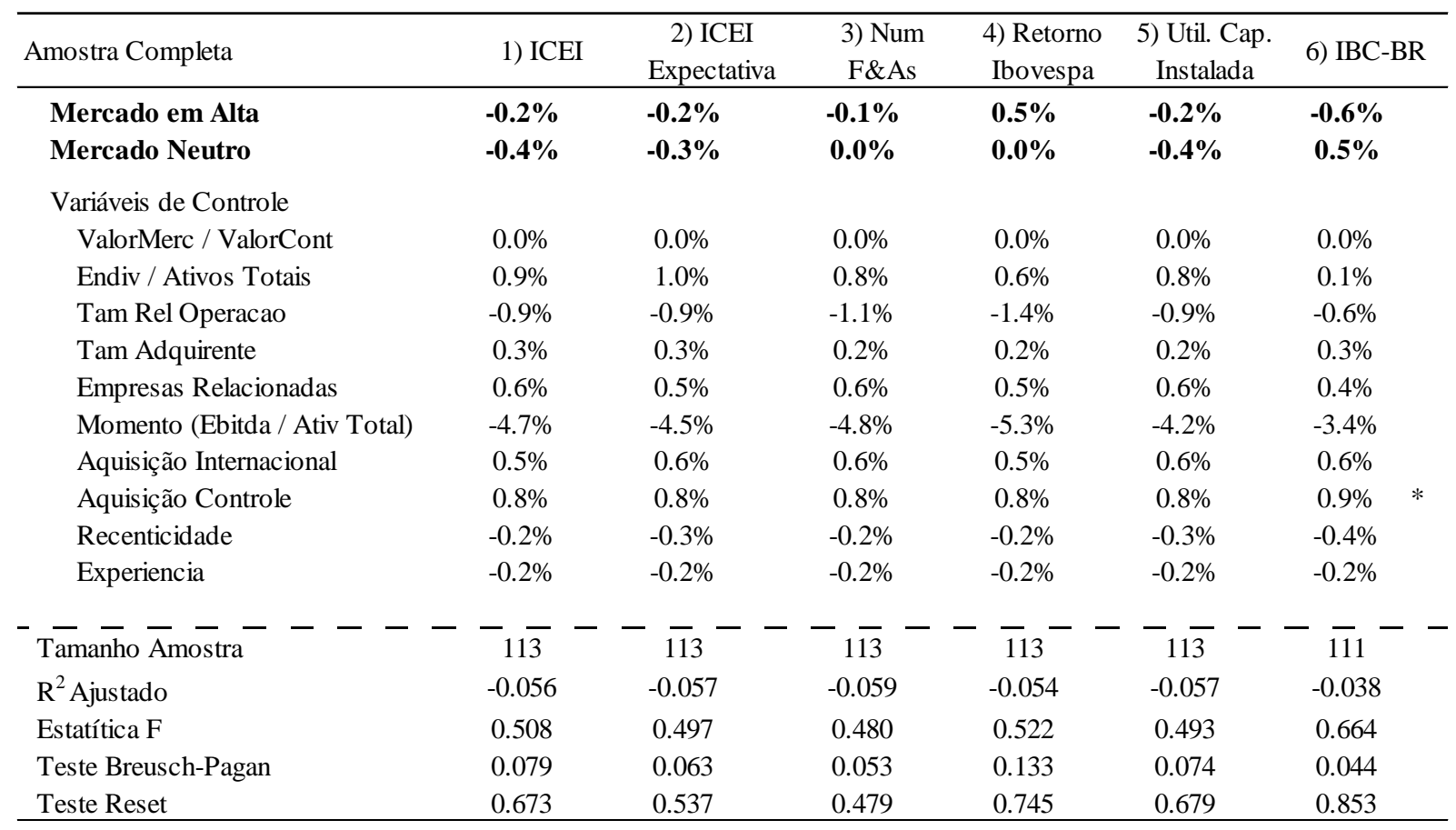

\begin{tabular}{|c|c|c|c|c|c|c|c|c|c|}
\hline Exclusão Outliers & \multicolumn{2}{|l|}{ 1) ICEI } & \multicolumn{2}{|c|}{$\begin{array}{c}\text { 2) ICEI } \\
\text { Expectativa }\end{array}$} & \multicolumn{2}{|l|}{$\begin{array}{l}\text { 3) Num } \\
\text { F\&As }\end{array}$} & $\begin{array}{l}\text { 4) Retorno } \\
\text { Ibovespa }\end{array}$ & $\begin{array}{l}\text { 5) Util. Cap. } \\
\text { Instalada }\end{array}$ & 6) IBC-BR \\
\hline Mercado em Alta & $0.3 \%$ & & $0.3 \%$ & & $0.1 \%$ & & $0.8 \%$ & $0.6 \%$ & $-0.6 \%$ \\
\hline Mercado Neutro & $0.1 \%$ & & $0.1 \%$ & & $-0.6 \%$ & & $0.6 \%$ & $0.2 \%$ & $0.6 \%$ \\
\hline \multicolumn{10}{|l|}{ Variáveis de Controle } \\
\hline ValorMerc / ValorCont & $0.0 \%$ & & $0.0 \%$ & & $0.0 \%$ & & $0.0 \%$ & $0.0 \%$ & $0.0 \%$ \\
\hline Endiv / Ativos Totais & $0.2 \%$ & & $0.2 \%$ & & $-0.4 \%$ & & $-0.6 \%$ & $-0.6 \%$ & $-1.7 \%$ \\
\hline Tam Rel Operacao & $-1.8 \%$ & & $-1.8 \%$ & & $-0.8 \%$ & & $-1.4 \%$ & $-0.9 \%$ & $-0.9 \%$ \\
\hline Tam Adquirente & $0.2 \%$ & & $0.3 \%$ & & $0.1 \%$ & & $0.1 \%$ & $0.1 \%$ & $0.3 \%$ \\
\hline Empresas Relacionadas & $0.6 \%$ & & $0.6 \%$ & & $0.7 \%$ & & $0.7 \%$ & $0.7 \%$ & $0.1 \%$ \\
\hline Momento (Ebitda / Ativ Total) & $-7.7 \%$ & $*$ & $-7.7 \%$ & $*$ & $-5.4 \%$ & & $-6.0 \%$ & $-4.9 \%$ & $-4.9 \%$ \\
\hline Aquisição Internacional & $0.7 \%$ & & $0.7 \%$ & & $0.9 \%$ & & $0.7 \%$ & $0.8 \%$ & $0.6 \%$ \\
\hline Aquisição Controle & $0.6 \%$ & & $0.6 \%$ & & $0.3 \%$ & & $0.2 \%$ & $0.2 \%$ & $0.6 \%$ \\
\hline Recenticidade & $-1.4 \%$ & $*$ & $-1.3 \%$ & $*$ & $-1.2 \%$ & & $-0.9 \%$ & $-1.0 \%$ & $-1.2 \%$ \\
\hline Experiencia & $-0.2 \%$ & & $-0.2 \%$ & & $-0.2 \%$ & & $-0.2 \%$ & $-0.1 \%$ & $-0.3 \%$ \\
\hline$\overline{\text { Tamanho Amostra }}---$ & $-\overline{110}-$ & - & $-1 \overline{0}$ & - & $-\frac{-}{109}$ & - & $-\overline{109}-$ & $-\overline{109}--$ & $-\overline{107}-$ \\
\hline $\mathrm{R}^{2}$ Ajustado & 0.012 & & 0.011 & & 0.015 & & 0.010 & 0.006 & 0.032 \\
\hline Estatítica F & 1.109 & & 1.103 & & 1.140 & & 1.090 & 1.052 & 1.292 \\
\hline Teste Breusch-Pagan & 0.181 & & 0.244 & & 0.514 & & 0.434 & 0.231 & 0.039 \\
\hline Teste Reset & 0.310 & & 0.375 & & 0.230 & & 0.108 & 0.066 & 0.012 \\
\hline
\end{tabular}

Fonte: Elaborado pelo Autor

Notas: * denota significância estatística: * p-value $<10 \% ; \quad$ ** p-value $<5 \%$; $\quad * * *$ p-value $<1 \%$ Quando o Teste de Breusch-Pagan indica heterocedasticidade, a significância estatística adota a metodologia de erros robustos.

A tabela apresenta os resultados da regressão cross section do retorno anormal no dia do anúncio da F\&A. São apresentados os resultados de seis modelos, cada qual assumindo uma proxy diferente para classificação do estado de mercado. 
Tabela 16 - Análise de Regressão dos Determinantes de Criação de Valor - Janela de Três Dias - Proxy de Mercado IBRX-50

\begin{tabular}{|c|c|c|c|c|c|c|}
\hline Amostra Completa & 1) ICEI & $\begin{array}{l}\text { 2) ICEI } \\
\text { Expectativa }\end{array}$ & $\begin{array}{l}\text { 3) Num } \\
\text { F\&As }\end{array}$ & $\begin{array}{l}\text { 4) Retorno } \\
\text { Ibovespa }\end{array}$ & $\begin{array}{l}\text { 5) Util. Cap. } \\
\text { Instalada }\end{array}$ & 6) IBC-B \\
\hline Mercado em Alta & $0.4 \%$ & $0.7 \%$ & $0.4 \%$ & $0.9 \%$ & $-0.5 \%$ & $-2.0 \%$ \\
\hline Mercado Neutro & $0.1 \%$ & $0.6 \%$ & $0.4 \%$ & $1.1 \%$ & $-1.9 \%$ & $0.4 \%$ \\
\hline \multicolumn{7}{|l|}{ Variáveis de Controle } \\
\hline ValorMerc / ValorCont & $0.0 \%$ & $0.0 \%$ & $0.0 \%$ & $0.0 \%$ & $0.1 \%$ & $0.0 \%$ \\
\hline Endiv / Ativos Totais & $4.8 \%$ & $4.5 \%$ & $4.8 \%$ & $4.4 \%$ & $5.1 \%$ & $3.3 \%$ \\
\hline Tam Rel Operacao & $0.6 \%$ & $0.5 \%$ & $1.0 \%$ & $0.3 \%$ & $1.8 \%$ & $1.5 \%$ \\
\hline Tam Adquirente & $0.0 \%$ & $-0.1 \%$ & $0.0 \%$ & $0.0 \%$ & $0.0 \%$ & $0.0 \%$ \\
\hline Empresas Relacionadas & $-0.2 \%$ & $-0.1 \%$ & $-0.2 \%$ & $-0.2 \%$ & $-0.4 \%$ & $-0.5 \%$ \\
\hline Momento (Ebitda / Ativ Total) & $-6.3 \%$ & $-6.5 \%$ & $-5.7 \%$ & $-7.0 \%$ & $-4.0 \%$ & $-3.1 \%$ \\
\hline Aquisição Internacional & $0.7 \%$ & $0.7 \%$ & $0.6 \%$ & $0.6 \%$ & $0.7 \%$ & $0.8 \%$ \\
\hline Aquisição Controle & $1.1 \%$ & $1.1 \%$ & $1.1 \%$ & $0.9 \%$ & $1.1 \%$ & $1.4 \%$ \\
\hline Recenticidade & $-2.2 \%$ & $-2.1 \%$ & $-2.3 \%$ & $-2.1 \%$ & $-2.4 \%$ & $-2.7 \%$ \\
\hline Experiencia & $0.1 \%$ & $0.1 \%$ & $0.2 \%$ & $0.1 \%$ & $0.3 \%$ & $0.1 \%$ \\
\hline$-\overline{\text { Tamanho }}$ Amostra --- & $-\frac{1}{113}-$ & $-\overline{113}--$ & $-\overline{113}-$ & $-\overline{113}-$ & $-{ }_{113}-$ & $-\overline{111}-$ \\
\hline $\mathrm{R}^{2}$ Ajustado & -0.053 & -0.051 & -0.054 & -0.048 & -0.031 & -0.019 \\
\hline Estatítica F & 0.528 & 0.544 & 0.524 & 0.577 & 0.719 & 0.832 \\
\hline Teste Breusch-Pagan & 0.246 & 0.460 & 0.136 & 0.448 & 0.555 & 0.322 \\
\hline Teste Reset & 0.408 & 0.528 & 0.336 & 0.284 & 0.243 & 0.345 \\
\hline
\end{tabular}

\begin{tabular}{|c|c|c|c|c|c|c|c|c|c|c|}
\hline Exclusão Outliers & \multicolumn{2}{|l|}{ 1) ICEI } & \multicolumn{2}{|c|}{$\begin{array}{c}\text { 2) ICEI } \\
\text { Expectativa }\end{array}$} & \multicolumn{2}{|c|}{$\begin{array}{l}\text { 3) Num } \\
\text { F\&As }\end{array}$} & $\begin{array}{l}\text { 4) Retorno } \\
\text { Ibovespa }\end{array}$ & $\begin{array}{l}\text { 5) Util. Cap. } \\
\text { Instalada }\end{array}$ & \multicolumn{2}{|c|}{ 6) IBC-BR } \\
\hline Mercado em Alta & $1.1 \%$ & & $1.4 \%$ & & $0.2 \%$ & & $1.0 \%$ & $-0.8 \%$ & $-2.0 \%$ & \\
\hline Mercado Neutro & $0.8 \%$ & & $1.3 \%$ & & $-0.3 \%$ & & $0.9 \%$ & $-2.1 \%$ & $-0.2 \%$ & \\
\hline Variáveis de Controle & & & & & & & & & & \\
\hline ValorMerc / ValorCont & $0.0 \%$ & & $0.0 \%$ & & $0.0 \%$ & & $0.0 \%$ & $0.0 \%$ & $0.0 \%$ & \\
\hline Endiv / Ativos Totais & $5.2 \%$ & & $4.9 \%$ & & $5.4 \%$ & & $5.0 \%$ & $4.7 \%$ & $4.5 \%$ & \\
\hline Tam Rel Operacao & $0.3 \%$ & & $0.1 \%$ & & $1.2 \%$ & & $0.4 \%$ & $2.6 \%$ & $1.4 \%$ & \\
\hline Tam Adquirente & $0.3 \%$ & & $0.3 \%$ & & $0.4 \%$ & & $0.4 \%$ & $0.4 \%$ & $0.4 \%$ & \\
\hline Empresas Relacionadas & $0.4 \%$ & & $0.5 \%$ & & $0.2 \%$ & & $0.2 \%$ & $-0.2 \%$ & $0.1 \%$ & \\
\hline Momento (Ebitda / Ativ Total) & $-8.5 \%$ & & $-9.0 \%$ & & $-8.4 \%$ & & $-9.4 \%$ & $-5.4 \%$ & $-5.1 \%$ & \\
\hline Aquisição Internacional & $0.6 \%$ & & $0.5 \%$ & & $0.5 \%$ & & $0.4 \%$ & $0.7 \%$ & $0.7 \%$ & \\
\hline Aquisição Controle & $0.9 \%$ & & $0.9 \%$ & & $0.9 \%$ & & $0.8 \%$ & $0.7 \%$ & $1.3 \%$ & \\
\hline Recenticidade & $-2.9 \%$ & $* *$ & $-2.7 \%$ & $*$ & $-2.9 \%$ & $* *$ & $-2.7 \%$ & $-2.2 \%$ & $-3.3 \%$ & $* *$ \\
\hline Experiencia & $0.0 \%$ & & $0.0 \%$ & & $0.0 \%$ & & $0.0 \%$ & $0.0 \%$ & $0.0 \%$ & \\
\hline$\overline{\text { Tamanho Amostra }}---$ & $-\overline{112}-$ & - & $-11 \overline{2}$ & -- & $\overline{112}-$ & - & $-\overline{112}$ & $-\overline{111}--$ & $-\overline{110}$ & - \\
\hline $\mathrm{R}^{2}$ Ajustado & -0.016 & & -0.009 & & -0.023 & & -0.020 & -0.011 & 0.003 & \\
\hline Estatítica F & 0.855 & & 0.918 & & 0.792 & & 0.823 & 0.900 & 1.027 & \\
\hline Teste Breusch-Pagan & 0.378 & & 0.326 & & 0.185 & & 0.406 & 0.204 & 0.532 & \\
\hline Teste Reset & 0.483 & & 0.568 & & 0.166 & & 0.400 & 0.690 & 0.292 & \\
\hline
\end{tabular}

Fonte: Elaborado pelo Autor

Notas: * denota significância estatística: * p-value $<10 \% ; \quad * *$ p-value $<5 \%$; $\quad * * *$ p-value $<1 \%$ Quando o Teste de Breusch-Pagan indica heterocedasticidade, a significância estatística adota a metodologia de erros robustos.

A tabela apresenta os resultados da regressão cross section do retorno anormal acumulado para a janela de três dias. São apresentados os resultados de seis modelos, cada qual assumindo uma proxy diferente para classificação do estado de mercado. 
Tabela 17 - Análise de Regressão dos Determinantes de Criação de Valor - Janela de Onze Dias - Proxy de Mercado IBRX-50

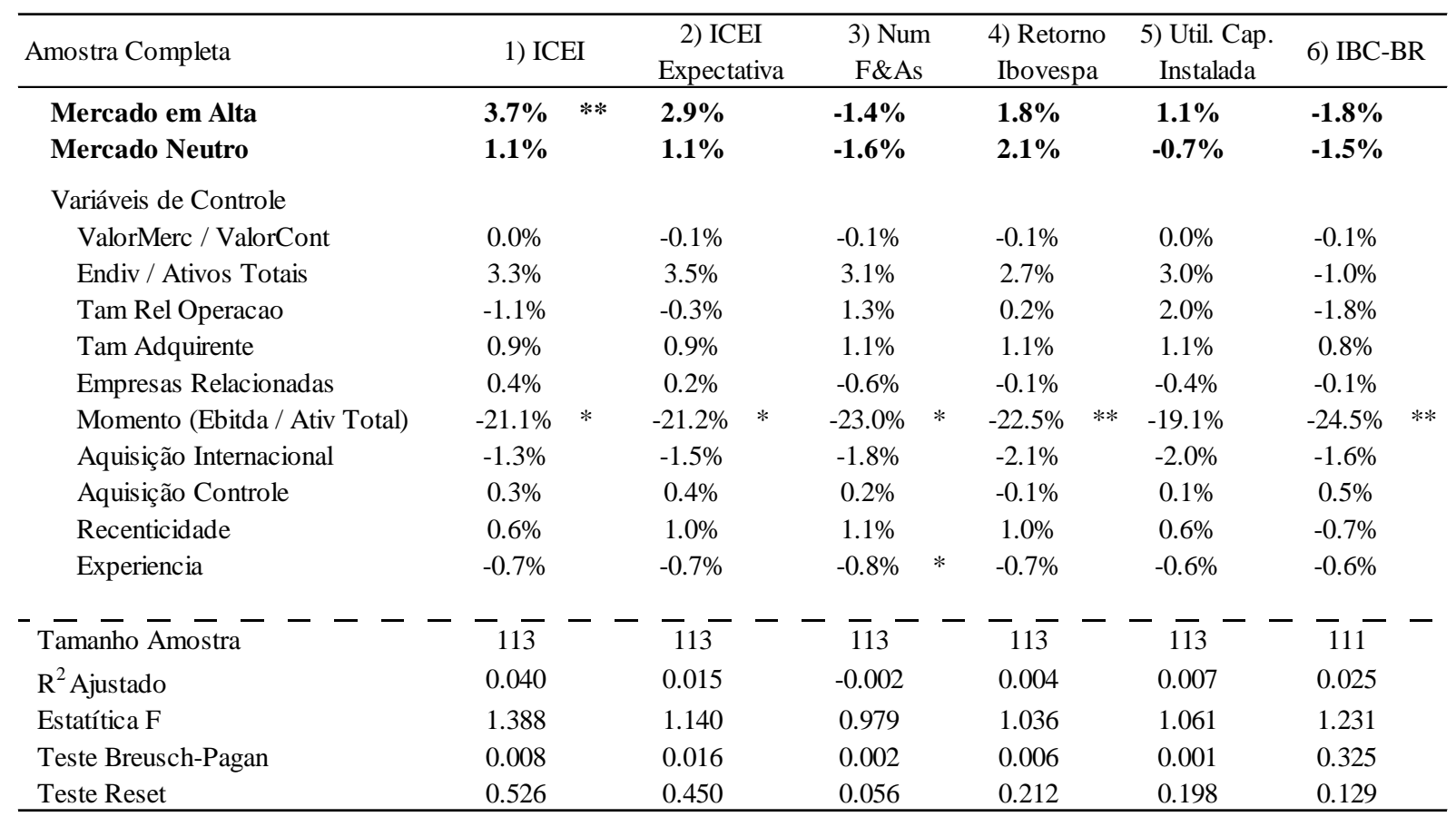

\begin{tabular}{|c|c|c|c|c|c|c|c|c|c|c|c|c|}
\hline \multirow{2}{*}{$\begin{array}{l}\text { Exclusão Outliers } \\
\text { Mercado em Alta }\end{array}$} & \multicolumn{2}{|c|}{ 1) ICEI } & \multicolumn{2}{|c|}{$\begin{array}{c}\text { 2) ICEI } \\
\text { Expectativa }\end{array}$} & \multicolumn{2}{|c|}{$\begin{array}{l}\text { 3) Num } \\
\text { F\&As }\end{array}$} & \multicolumn{2}{|c|}{$\begin{array}{l}\text { 4) Retorno } \\
\text { Ibovespa }\end{array}$} & \multicolumn{2}{|c|}{$\begin{array}{l}\text { 5) Util. Cap. } \\
\text { Instalada }\end{array}$} & \multicolumn{2}{|c|}{ 6) IBC-BR } \\
\hline & $3.0 \%$ & $*$ & $2.0 \%$ & & $-1.4 \%$ & & $0.9 \%$ & & $-0.8 \%$ & & $-1.8 \%$ & \\
\hline Mercado Neutro & $0.5 \%$ & & $0.4 \%$ & & $-1.1 \%$ & & $0.7 \%$ & & $-2.4 \%$ & & $-1.5 \%$ & \\
\hline \multicolumn{13}{|l|}{ Variáveis de Controle } \\
\hline ValorMerc / ValorCont & $-0.1 \%$ & & $-0.1 \%$ & & $-0.1 \%$ & & $-0.1 \%$ & & $-0.1 \%$ & & $-0.1 \%$ & \\
\hline Endiv / Ativos Totais & $-1.4 \%$ & & $-1.2 \%$ & & $-2.0 \%$ & & $-2.1 \%$ & & $-1.6 \%$ & & $-1.0 \%$ & \\
\hline Tam Rel Operacao & $-3.1 \%$ & & $-2.2 \%$ & & $-1.4 \%$ & & $-1.7 \%$ & & $-0.2 \%$ & & $-1.8 \%$ & \\
\hline Tam Adquirente & $0.7 \%$ & & $0.8 \%$ & & $0.9 \%$ & & $0.9 \%$ & & $0.8 \%$ & & $0.8 \%$ & \\
\hline Empresas Relacionadas & $-0.1 \%$ & & $-0.4 \%$ & & $-0.9 \%$ & & $-0.6 \%$ & & $-0.8 \%$ & & $-0.1 \%$ & \\
\hline Momento (Ebitda / Ativ Total) & $-26.6 \%$ & $* * *$ & $-26.5 \%$ & $* *$ & $-28.5 \%$ & $* *$ & $-27.4 \%$ & $* *$ & $-24.1 \%$ & $* *$ & $-24.5 \%$ & $* *$ \\
\hline Aquisição Internacional & $-1.3 \%$ & & $-1.5 \%$ & & $-1.8 \%$ & & $-1.9 \%$ & & $-1.7 \%$ & & $-1.6 \%$ & \\
\hline Aquisição Controle & $0.6 \%$ & & $0.7 \%$ & & $0.5 \%$ & & $0.5 \%$ & & $0.6 \%$ & & $0.5 \%$ & \\
\hline Recenticidade & $-0.5 \%$ & & $-0.3 \%$ & & $0.0 \%$ & & $-0.3 \%$ & & $-0.8 \%$ & & $-0.7 \%$ & \\
\hline Experiencia & $-0.6 \%$ & & $-0.7 \%$ & & $-0.8 \%$ & & $-0.7 \%$ & & $-0.5 \%$ & & $-0.6 \%$ & \\
\hline$\overline{\text { Tamanho Amostra }}---$ & $-\overline{112}-$ & - & $-\overline{112}$ & - - & $-\overline{112}$ & - & $\overline{112}-$ & - & -112 & - & $-\overline{111}-$ & - \\
\hline $\mathrm{R}^{2}$ Ajustado & 0.055 & & 0.030 & & 0.022 & & 0.018 & & 0.035 & & 0.025 & \\
\hline Estatítica F & 1.540 & & 1.288 & & 1.204 & & 1.169 & & 1.334 & & 1.231 & \\
\hline Teste Breusch-Pagan & 0.166 & & 0.299 & & 0.067 & & 0.216 & & 0.090 & & 0.325 & \\
\hline Teste Reset & 0.724 & & 0.385 & & 0.239 & & 0.209 & & 0.600 & & 0.129 & \\
\hline
\end{tabular}

Fonte: Elaborado pelo Autor

Notas: * denota significância estatística: * p-value $<10 \% ; \quad * *$ p-value $<5 \%$; $\quad * * *$ p-value $<1 \%$ Quando o Teste de Breusch-Pagan indica heterocedasticidade, a significância estatística adota a metodologia de erros robustos.

A tabela apresenta os resultados da regressão cross section do retorno anormal acumulado para a janela de onze dias. São apresentados os resultados de seis modelos, cada qual assumindo uma proxy diferente para classificação do estado de mercado. 
Tabela 18 - Análise de Regressão dos Determinantes de Criação de Valor - Janela de Vinte e Um Dias - Proxy de Mercado IBRX-50

\begin{tabular}{|c|c|c|c|c|c|c|c|c|c|c|c|c|}
\hline \multirow{2}{*}{$\begin{array}{l}\text { Amostra Completa } \\
\text { Mercado em Alta }\end{array}$} & \multicolumn{2}{|c|}{ 1) ICEI } & \multicolumn{2}{|c|}{$\begin{array}{c}\text { 2) ICEI } \\
\text { Expectativa }\end{array}$} & \multicolumn{2}{|c|}{$\begin{array}{l}\text { 3) Num } \\
\text { F\&As }\end{array}$} & \multicolumn{2}{|c|}{$\begin{array}{l}\text { 4) Retorno } \\
\text { Ibovespa }\end{array}$} & \multicolumn{2}{|c|}{$\begin{array}{l}\text { 5) Util. Cap. } \\
\text { Instalada } \\
\end{array}$} & \multicolumn{2}{|c|}{ 6) IBC-BR } \\
\hline & $3.2 \%$ & & $2.1 \%$ & & $0.0 \%$ & & $-0.4 \%$ & & $2.3 \%$ & & $-1.5 \%$ & \\
\hline Mercado Neutro & $0.8 \%$ & & $-0.2 \%$ & & $-1.8 \%$ & & $1.2 \%$ & & $-2.3 \%$ & & $-1.1 \%$ & \\
\hline \multicolumn{13}{|l|}{ Variáveis de Controle } \\
\hline ValorMerc / ValorCont & $-0.1 \%$ & & $-0.1 \%$ & & $-0.1 \%$ & & $-0.1 \%$ & & $-0.1 \%$ & & $-0.1 \%$ & \\
\hline Endiv / Ativos Totais & $-6.4 \%$ & & $-5.6 \%$ & & $-6.8 \%$ & & $-6.2 \%$ & & $-7.1 \%$ & & $-6.9 \%$ & \\
\hline Tam Rel Operacao & $-14.9 \%$ & $* * *$ & $-14.0 \%$ & $* *$ & $-12.1 \%$ & $* *$ & $-12.4 \%$ & $* *$ & $-11.3 \%$ & $*$ & $-13.5 \%$ & $* *$ \\
\hline Tam Adquirente & $-0.4 \%$ & & $-0.3 \%$ & & $-0.3 \%$ & & $-0.2 \%$ & & $-0.2 \%$ & & $-0.4 \%$ & \\
\hline Empresas Relacionadas & $1.1 \%$ & & $0.8 \%$ & & $0.5 \%$ & & $0.8 \%$ & & $0.3 \%$ & & $0.9 \%$ & \\
\hline Momento (Ebitda / Ativ Total) & $-35.8 \%$ & $* * *$ & $-35.3 \%$ & $* * *$ & $-36.4 \%$ & $* * *$ & $-34.5 \%$ & $* * *$ & $-31.0 \%$ & $* * *$ & $-34.4 \%$ & $* *$ \\
\hline Aquisição Internacional & $0.8 \%$ & & $0.6 \%$ & & $0.3 \%$ & & $0.2 \%$ & & $0.0 \%$ & & $0.4 \%$ & \\
\hline Aquisição Controle & $-0.1 \%$ & & $0.0 \%$ & & $-0.3 \%$ & & $-0.4 \%$ & & $-0.6 \%$ & & $-0.1 \%$ & \\
\hline Recenticidade & $2.3 \%$ & & $2.5 \%$ & & $2.2 \%$ & & $2.4 \%$ & & $2.0 \%$ & & $2.0 \%$ & \\
\hline Experiencia & $-0.3 \%$ & & $-0.4 \%$ & & $-0.3 \%$ & & $-0.3 \%$ & & $0.0 \%$ & & $-0.2 \%$ & \\
\hline$\overline{\text { Tamanho }} \overline{\text { Amostra }}---$ & -113 & & $\overline{11}{ }^{-}$ & - & $\overline{113}-$ & - & $-11 \overline{3}$ & - & $\overline{113}$ & & $\overline{1} 11$ & \\
\hline $\mathrm{R}^{2}$ Ajustado & 0.048 & & 0.036 & & 0.032 & & 0.030 & & 0.092 & & 0.024 & \\
\hline Estatítica F & 1.472 & & 1.353 & & 1.307 & & 1.289 & & 1.946 & $* *$ & 1.230 & \\
\hline Teste Breusch-Pagan & 0.004 & & 0.005 & & 0.019 & & 0.007 & & 0.015 & & 0.020 & \\
\hline Teste Reset & 0.094 & & 0.028 & & 0.038 & & 0.033 & & 0.036 & & 0.007 & \\
\hline
\end{tabular}

\begin{tabular}{|c|c|c|c|c|c|c|c|c|c|c|c|c|}
\hline \multirow{2}{*}{$\begin{array}{l}\text { Exclusão Outliers } \\
\text { Mercado em Alta }\end{array}$} & \multicolumn{2}{|c|}{ 1) ICEI } & \multicolumn{2}{|c|}{$\begin{array}{c}\text { 2) ICEI } \\
\text { Expectativa }\end{array}$} & \multicolumn{2}{|l|}{$\begin{array}{l}\text { 3) Num } \\
\text { F\&As }\end{array}$} & \multicolumn{2}{|c|}{$\begin{array}{l}\text { 4) Retorno } \\
\text { Ibovespa }\end{array}$} & \multicolumn{2}{|c|}{$\begin{array}{l}\text { 5) Util. Cap. } \\
\text { Instalada }\end{array}$} & \multicolumn{2}{|c|}{ 6) IBC-BR } \\
\hline & $3.2 \%$ & & $2.1 \%$ & & $0.0 \%$ & & $-0.4 \%$ & & $2.3 \%$ & & $-1.5 \%$ & \\
\hline Mercado Neutro & $0.8 \%$ & & $-0.2 \%$ & & $-1.8 \%$ & & $1.2 \%$ & & $-2.3 \%$ & & $-1.1 \%$ & \\
\hline \multicolumn{13}{|l|}{ Variáveis de Controle } \\
\hline ValorMerc / ValorCont & $-0.1 \%$ & & $-0.1 \%$ & & $-0.1 \%$ & & $-0.1 \%$ & & $-0.1 \%$ & & $-0.1 \%$ & \\
\hline Endiv / Ativos Totais & $-6.4 \%$ & & $-5.6 \%$ & & $-6.8 \%$ & & $-6.2 \%$ & & $-7.1 \%$ & & $-6.9 \%$ & \\
\hline Tam Rel Operacao & $-14.9 \%$ & $* * *$ & $-14.0 \%$ & $* *$ & $-12.1 \%$ & $* *$ & $-12.4 \%$ & $* *$ & $-11.3 \%$ & $*$ & $-13.5 \%$ & $* *$ \\
\hline Tam Adquirente & $-0.4 \%$ & & $-0.3 \%$ & & $-0.3 \%$ & & $-0.2 \%$ & & $-0.2 \%$ & & $-0.4 \%$ & \\
\hline Empresas Relacionadas & $1.1 \%$ & & $0.8 \%$ & & $0.5 \%$ & & $0.8 \%$ & & $0.3 \%$ & & $0.9 \%$ & \\
\hline Momento (Ebitda / Ativ Total) & $-35.8 \%$ & $* * *$ & $-35.3 \%$ & $* * *$ & $-36.4 \%$ & $* * *$ & $-34.5 \%$ & $* * *$ & $-31.0 \%$ & $* * *$ & $-34.4 \%$ & $* * *$ \\
\hline Aquisição Internacional & $0.8 \%$ & & $0.6 \%$ & & $0.3 \%$ & & $0.2 \%$ & & $0.0 \%$ & & $0.4 \%$ & \\
\hline Aquisição Controle & $-0.1 \%$ & & $0.0 \%$ & & $-0.3 \%$ & & $-0.4 \%$ & & $-0.6 \%$ & & $-0.1 \%$ & \\
\hline Recenticidade & $2.3 \%$ & & $2.5 \%$ & & $2.2 \%$ & & $2.4 \%$ & & $2.0 \%$ & & $2.0 \%$ & \\
\hline Experiencia & $-0.3 \%$ & & $-0.4 \%$ & & $-0.3 \%$ & & $-0.3 \%$ & & $0.0 \%$ & & $-0.2 \%$ & \\
\hline$\overline{\text { Tamanho Amostra }}---$ & $\overline{113}-$ & - & $\overline{113}$ & - & $-\overline{113}$ & - & $\overline{113}-$ & - & -113 & - & $-\overline{111}$ & \\
\hline $\mathrm{R}^{2}$ Ajustado & 0.048 & & 0.036 & & 0.032 & & 0.030 & & 0.092 & & 0.024 & \\
\hline Estatítica F & 1.472 & & 1.353 & & 1.307 & & 1.289 & & 1.946 & $* *$ & 1.230 & \\
\hline Teste Breusch-Pagan & 0.004 & & 0.005 & & 0.019 & & 0.007 & & 0.015 & & 0.020 & \\
\hline Teste Reset & 0.094 & & 0.028 & & 0.038 & & 0.033 & & 0.036 & & 0.007 & \\
\hline
\end{tabular}

Fonte: Elaborado pelo Autor

Notas: * denota significância estatística: * p-value $<10 \% ; \quad * *$ p-value $<5 \%$; $\quad * * *$ p-value $<1 \%$ Quando o Teste de Breusch-Pagan indica heterocedasticidade, a significância estatística adota a metodologia de erros robustos.

A tabela apresenta os resultados da regressão cross section do retorno anormal acumulado para a janela de vinte e um dias. São apresentados os resultados de seis modelos, cada qual assumindo uma proxy diferente para classificação do estado de mercado. 
Tabela 19 - Análise de Regressão dos Determinantes de Criação de Valor - Dia do Anúncio da F\&A - Proxy de Mercado IBRX-50 - Amostra Completa

\begin{tabular}{|c|c|c|c|c|c|c|c|c|c|c|c|c|}
\hline \multirow{2}{*}{$\begin{array}{l}\text { Amostra Completa } \\
\text { Mercado em Alta }\end{array}$} & \multicolumn{2}{|c|}{ 1) ICEI } & \multicolumn{2}{|c|}{$\begin{array}{c}\text { 2) ICEI } \\
\text { Expectativa }\end{array}$} & \multicolumn{2}{|c|}{ 3) Num F\&As } & \multicolumn{2}{|c|}{$\begin{array}{l}\text { 4) Retorno } \\
\text { Ibovespa }\end{array}$} & \multicolumn{2}{|c|}{$\begin{array}{l}\text { 5) Util. Cap. } \\
\text { Instalada }\end{array}$} & \multicolumn{2}{|c|}{ 6) IBC-BR } \\
\hline & $-1.1 \%$ & $* *$ & $-1.2 \%$ & $* *$ & $0.3 \%$ & & $-0.2 \%$ & & $0.5 \%$ & & $-1.0 \%$ & $*$ \\
\hline Mercado Neutro & $-0.8 \%$ & & $-0.7 \%$ & & $0.3 \%$ & & $0.2 \%$ & & $-0.6 \%$ & & $1.1 \%$ & $* *$ \\
\hline \multicolumn{13}{|l|}{ Variáveis de Controle } \\
\hline ValorMerc / ValorCont & $0.0 \%$ & & $0.0 \%$ & & $0.0 \%$ & & $0.0 \%$ & & $0.0 \%$ & & $0.0 \%$ & \\
\hline Endiv / Ativos Totais & $0.1 \%$ & & $0.1 \%$ & & $0.1 \%$ & & $0.0 \%$ & & $0.3 \%$ & & $-0.2 \%$ & \\
\hline Tam Rel Operacao & $-0.9 \%$ & & $-0.9 \%$ & & $-1.2 \%$ & & $-1.1 \%$ & & $-1.2 \%$ & & $-0.3 \%$ & \\
\hline Tam Adquirente & $0.1 \%$ & & $0.1 \%$ & & $0.0 \%$ & & $0.1 \%$ & & $0.0 \%$ & & $0.0 \%$ & \\
\hline Empresas Relacionadas & $0.6 \%$ & $*$ & $0.5 \%$ & & $0.8 \%$ & $* *$ & $0.8 \%$ & $* *$ & $0.7 \%$ & $* *$ & $0.5 \%$ & \\
\hline Momento (Ebitda / Ativ Total) & $-3.9 \%$ & & $-4.0 \%$ & & $-2.7 \%$ & & $-2.8 \%$ & & $-2.6 \%$ & & $-2.3 \%$ & \\
\hline Aquisição Internacional & $-0.2 \%$ & & $-0.2 \%$ & & $-0.2 \%$ & & $-0.2 \%$ & & $-0.3 \%$ & & $-0.1 \%$ & \\
\hline Aquisição Controle & $0.2 \%$ & & $0.2 \%$ & & $0.3 \%$ & & $0.3 \%$ & & $0.2 \%$ & & $0.3 \%$ & \\
\hline Recenticidade & $-0.5 \%$ & & $-0.6 \%$ & & $-0.6 \%$ & & $-0.5 \%$ & & $-0.7 \%$ & & $-0.4 \%$ & \\
\hline Experiência & $-0.1 \%$ & & $-0.1 \%$ & & $-0.1 \%$ & & $-0.1 \%$ & & $-0.1 \%$ & & $-0.1 \%$ & \\
\hline Sem Sobreposição Eventos & $-0.1 \%$ & & $-0.1 \%$ & & $0.0 \%$ & & $-0.1 \%$ & & $-0.1 \%$ & & $0.0 \%$ & \\
\hline Tamanho Amostra & 346 & & 346 & & $\overline{346}$ & & 346 & & 346 & & 291 & \\
\hline $\mathrm{R}^{2}$ Ajustado & 0.007 & & 0.009 & & -0.008 & & -0.007 & & 0.016 & & 0.038 & \\
\hline Estatítica F & 1.199 & & 1.231 & & 0.778 & & 0.825 & & 1.429 & & 1.873 & $* *$ \\
\hline Teste Breusch-Pagan & 0.000 & & 0.000 & & 0.000 & & 0.000 & & 0.000 & & 0.000 & \\
\hline Teste Reset & 0.024 & & 0.043 & & 0.700 & & 0.635 & & 0.170 & & 0.004 & \\
\hline
\end{tabular}

\begin{tabular}{|c|c|c|c|c|c|c|c|c|c|c|c|c|}
\hline \multirow{2}{*}{$\begin{array}{l}\text { Exclusão Outliers } \\
\text { Mercado em Alta }\end{array}$} & \multicolumn{2}{|c|}{ 1) ICEI } & \multicolumn{2}{|c|}{$\begin{array}{c}\text { 2) ICEI } \\
\text { Expectativa }\end{array}$} & \multicolumn{2}{|c|}{ 3) Num F\&As } & \multicolumn{2}{|c|}{$\begin{array}{l}\text { 4) Retorno } \\
\text { Ibovespa }\end{array}$} & \multicolumn{2}{|c|}{$\begin{array}{l}\text { 5) Util. Cap. } \\
\text { Instalada }\end{array}$} & \multicolumn{2}{|c|}{ 6) IBC-BR } \\
\hline & $0.1 \%$ & & $0.0 \%$ & & $0.1 \%$ & & $0.1 \%$ & & $0.1 \%$ & & $-0.6 \%$ & \\
\hline Mercado Neutro & $0.3 \%$ & & $0.4 \%$ & & $-0.3 \%$ & & $-0.2 \%$ & & $-0.7 \%$ & * & $0.5 \%$ & \\
\hline \multicolumn{13}{|l|}{ Variáveis de Controle } \\
\hline ValorMerc / ValorCont & $0.0 \%$ & & $0.0 \%$ & & $0.0 \%$ & & $0.0 \%$ & & $0.0 \%$ & & $0.0 \%$ & \\
\hline Endiv / Ativos Totais & $-0.8 \%$ & & $-1.3 \%$ & & $-0.8 \%$ & & $-0.8 \%$ & & $-0.8 \%$ & & $-1.6 \%$ & \\
\hline Tam Rel Operacao & $3.1 \%$ & & $1.4 \%$ & & $3.2 \%$ & & $3.1 \%$ & & $1.7 \%$ & & $4.0 \%$ & \\
\hline Tam Adquirente & $0.1 \%$ & & $0.0 \%$ & & $0.1 \%$ & & $0.1 \%$ & & $0.0 \%$ & & $0.1 \%$ & \\
\hline Empresas Relacionadas & $0.4 \%$ & & $0.3 \%$ & & $0.4 \%$ & & $0.4 \%$ & & $0.3 \%$ & & $0.2 \%$ & \\
\hline Momento (Ebitda / Ativ Total) & $-5.8 \%$ & $* *$ & $-5.4 \%$ & $* *$ & $-5.6 \%$ & $* *$ & $-6.0 \%$ & $* *$ & $-5.1 \%$ & $* *$ & $-4.3 \%$ & \\
\hline Aquisição Internacional & $0.4 \%$ & & $0.4 \%$ & & $0.4 \%$ & & $0.4 \%$ & & $0.3 \%$ & & $0.7 \%$ & $* *$ \\
\hline Aquisição Controle & $-0.1 \%$ & & $0.0 \%$ & & $-0.1 \%$ & & $-0.1 \%$ & & $0.0 \%$ & & $0.1 \%$ & \\
\hline Recenticidade & $-0.8 \%$ & $*$ & $-1.0 \%$ & $* *$ & $-0.8 \%$ & $*$ & $-0.8 \%$ & $*$ & $-1.0 \%$ & $* *$ & $-0.7 \%$ & \\
\hline Experiência & $-0.1 \%$ & & $0.0 \%$ & & $-0.1 \%$ & & $-0.1 \%$ & & $0.0 \%$ & & $-0.1 \%$ & \\
\hline Sem Sobreposição Eventos & $0.1 \%$ & & $0.1 \%$ & & $0.1 \%$ & & $0.1 \%$ & & $0.0 \%$ & & $0.2 \%$ & \\
\hline$\overline{\text { Tamanho Amostra }}----$ & $-\overline{336}-$ & - & $-\overline{336}$ & - & $-\overline{336}-$ & - & $-\overline{336}$ & $-\quad-$ & $-\overline{335}$ & - - & $\overline{2} 82$ & - \\
\hline $\mathrm{R}^{2}$ Ajustado & 0.043 & & 0.027 & & 0.046 & & 0.043 & & 0.054 & & 0.074 & \\
\hline Estatítica F & 2.145 & $* *$ & 1.705 & $*$ & 2.247 & $* * *$ & 2.157 & $* *$ & 2.459 & $* * *$ & 2.718 & $* * *$ \\
\hline Teste Breusch-Pagan & 0.000 & & 0.000 & & 0.000 & & 0.000 & & 0.000 & & 0.000 & \\
\hline Teste Reset & 0.002 & & 0.003 & & 0.005 & & 0.003 & & 0.009 & & 0.000 & \\
\hline
\end{tabular}

Fonte: Elaborado pelo Autor

Notas: * denota significância estatística: * p-value $<10 \% ; \quad * *$ p-value $<5 \%$; $\quad * * *$ p-value $<1 \%$

Quando o Teste de Breusch-Pagan indica heterocedasticidade, a significância estatística adota a metodologia de erros robustos.

A tabela apresenta os resultados da regressão cross section do retorno anormal no dia do anúncio da F\&A. São apresentados os resultados de seis modelos, cada qual assumindo uma proxy diferente para classificação do estado de mercado. 
Tabela 20 - Análise de Regressão dos Determinantes de Criação de Valor - Janela de Três Dias - Proxy de Mercado IBRX-50 - Amostra Completa

\begin{tabular}{|c|c|c|c|c|c|c|}
\hline Amostra Completa & 1) ICEI & $\begin{array}{c}\text { 2) ICEI } \\
\text { Expectativa }\end{array}$ & 3) Num F\&As & $\begin{array}{l}\text { 4) Retorno } \\
\text { Ibovespa }\end{array}$ & $\begin{array}{l}\text { 5) Util. Cap. } \\
\text { Instalada }\end{array}$ & 6) IBC-BR \\
\hline Mercado em Alta & $-0.9 \%$ & $-1.1 \%$ & $0.1 \%$ & $-0.5 \%$ & $0.1 \%$ & $-1.4 \%$ \\
\hline Mercado Neutro & $-0.7 \%$ & $-0.3 \%$ & $0.5 \%$ & $0.1 \%$ & $-1.0 \%$ & $1.0 \%$ \\
\hline \multicolumn{7}{|l|}{ Variáveis de Controle } \\
\hline ValorMerc / ValorCont & $0.0 \%$ & $0.0 \%$ & $0.0 \%$ & $0.1 \%$ & $0.0 \%$ & $0.0 \%$ \\
\hline Endiv / Ativos Totais & $-0.3 \%$ & $-0.4 \%$ & $-0.2 \%$ & $-0.4 \%$ & $-0.2 \%$ & $-0.5 \%$ \\
\hline Tam Rel Operacao & $-3.7 \%$ & $-3.7 \%$ & $-4.0 \%$ & $-3.8 \%$ & $-4.0 \%$ & $-2.5 \%$ \\
\hline Tam Adquirente & $-0.1 \%$ & $-0.2 \%$ & $-0.2 \%$ & $-0.1 \%$ & $-0.2 \%$ & $-0.2 \%$ \\
\hline Empresas Relacionadas & $0.3 \%$ & $0.2 \%$ & $0.5 \%$ & $0.5 \%$ & $0.3 \%$ & $0.3 \%$ \\
\hline Momento (Ebitda / Ativ Total) & $-3.8 \%$ & $-4.1 \%$ & $-2.8 \%$ & $-2.6 \%$ & $-2.2 \%$ & $-2.5 \%$ \\
\hline Aquisição Internacional & $-0.2 \%$ & $-0.2 \%$ & $-0.2 \%$ & $-0.2 \%$ & $-0.2 \%$ & $0.0 \%$ \\
\hline Aquisição Controle & $0.1 \%$ & $0.0 \%$ & $0.1 \%$ & $0.1 \%$ & $0.1 \%$ & $0.4 \%$ \\
\hline Recenticidade & $-1.4 \%$ & $-1.5 \%$ & $-1.4 \%$ & $-1.4 \%$ & $-1.6 \%$ & $-1.8 \%$ \\
\hline Experiência & $0.0 \%$ & $0.0 \%$ & $0.0 \%$ & $-0.1 \%$ & $0.0 \%$ & $0.0 \%$ \\
\hline Sem Sobreposição Eventos & $0.4 \%$ & $0.4 \%$ & $0.6 \%$ & $0.5 \%$ & $0.5 \%$ & $0.7 \%$ \\
\hline Tamanho Amostra & $\overline{346}$ & 346 & $\overline{346}$ & 346 & 346 & 291 \\
\hline $\mathrm{R}^{2}$ Ajustado & -0.001 & 0.001 & -0.005 & -0.004 & 0.007 & 0.019 \\
\hline Estatítica F & 0.983 & 1.040 & 0.869 & 0.904 & 1.176 & 1.430 \\
\hline Teste Breusch-Pagan & 0.000 & 0.000 & 0.000 & 0.000 & 0.000 & 0.000 \\
\hline Teste Reset & 0.022 & 0.009 & 0.033 & 0.003 & 0.471 & 0.218 \\
\hline
\end{tabular}

\begin{tabular}{|c|c|c|c|c|c|c|c|c|}
\hline Exclusão Outliers & 1) ICEI & $\begin{array}{c}\text { 2) ICEI } \\
\text { Expectativa }\end{array}$ & 3) Num F & F\&As & $\begin{array}{l}\text { 4) Retorno } \\
\text { Ibovespa }\end{array}$ & $\begin{array}{l}\text { 5) Util. C } \\
\text { Instalac }\end{array}$ & $\begin{array}{l}\text { Cap. } \\
\text { da }\end{array}$ & 6) IBC-BR \\
\hline Mercado em Alta & $-0.4 \%$ & $-0.4 \%$ & $0.1 \%$ & & $-0.6 \%$ & $-0.6 \%$ & & $-0.3 \%$ \\
\hline Mercado Neutro & $-0.4 \%$ & $-0.2 \%$ & $0.5 \%$ & & $-0.3 \%$ & $-1.7 \%$ & $* * *$ & $0.9 \%$ \\
\hline \multicolumn{9}{|l|}{ Variáveis de Controle } \\
\hline ValorMerc / ValorCont & $0.0 \%$ & $0.0 \%$ & $0.0 \%$ & & $0.0 \%$ & $0.0 \%$ & & $0.0 \%$ \\
\hline Endiv / Ativos Totais & $0.5 \%$ & $0.2 \%$ & $0.7 \%$ & & $0.1 \%$ & $0.2 \%$ & & $0.4 \%$ \\
\hline Tam Rel Operacao & $1.4 \%$ & $1.6 \%$ & $1.2 \%$ & & $1.7 \%$ & $1.7 \%$ & & $2.8 \%$ \\
\hline Tam Adquirente & $0.1 \%$ & $0.1 \%$ & $0.1 \%$ & & $0.2 \%$ & $0.1 \%$ & & $0.1 \%$ \\
\hline Empresas Relacionadas & $0.7 \%$ & $0.6 \%$ & $0.8 \%$ & $*$ & $0.7 \%$ & $0.5 \%$ & & $0.5 \%$ \\
\hline Momento (Ebitda / Ativ Total) & $-3.8 \%$ & $-3.9 \%$ & $-3.4 \%$ & & $-3.3 \%$ & $-2.3 \%$ & & $-3.9 \%$ \\
\hline Aquisição Internacional & $0.2 \%$ & $0.2 \%$ & $0.1 \%$ & & $0.2 \%$ & $0.2 \%$ & & $0.4 \%$ \\
\hline Aquisição Controle & $0.1 \%$ & $0.0 \%$ & $0.2 \%$ & & $0.1 \%$ & $0.1 \%$ & & $0.4 \%$ \\
\hline Recenticidade & $-1.0 \%$ & $-0.8 \%$ & $-1.0 \%$ & & $-0.7 \%$ & $-0.8 \%$ & & $-1.2 \%$ \\
\hline Experiência & $-0.2 \%$ & $-0.2 \%$ & $-0.2 \%$ & & $-0.2 \%$ & $-0.2 \%$ & & $-0.2 \%$ \\
\hline Sem Sobreposição Eventos & $-0.1 \%$ & $-0.2 \%$ & $0.0 \%$ & & $-0.1 \%$ & $-0.1 \%$ & & $0.1 \%$ \\
\hline$-\overline{\text { Tamanho }} \overline{\text { Amostra }}----$ & $-\overline{342}-$ & $-\overline{341}--$ & $-\overline{342}$ & - - & $\overline{341}--$ & $-\overline{341}-$ & - & $-\frac{-}{287}-$ \\
\hline $\mathrm{R}^{2}$ Ajustado & 0.003 & -0.002 & 0.004 & & 0.000 & 0.025 & & 0.022 \\
\hline Estatítica F & 1.067 & 0.947 & 1.095 & & 1.008 & 1.674 & $*$ & 1.491 \\
\hline Teste Breusch-Pagan & 0.000 & 0.001 & 0.000 & & 0.001 & 0.000 & & 0.006 \\
\hline Teste Reset & 0.077 & 0.136 & 0.402 & & 0.235 & 0.109 & & 0.002 \\
\hline
\end{tabular}

Fonte: Elaborado pelo Autor

Notas: * denota significância estatística: * p-value $<10 \%$; $\quad * *$ p-value $<5 \%$; $\quad * * *$ p-value $<1 \%$ Quando o Teste de Breusch-Pagan indica heterocedasticidade, a significância estatística adota a metodologia de erros robustos.

A tabela apresenta os resultados da regressão cross section do retorno anormal acumulado para a janela de três dias. São apresentados os resultados de seis modelos, cada qual assumindo uma proxy diferente para classificação do estado de mercado. 
Tabela 21 - Análise de Regressão dos Determinantes de Criação de Valor - Janela de Onze Dias - Proxy de Mercado IBRX-50 - Amostra Completa

\begin{tabular}{|c|c|c|c|c|c|c|c|c|c|c|c|c|}
\hline Amostra Completa & 1) ICEI & & $\begin{array}{c}\text { 2) ICEI } \\
\text { Expectati }\end{array}$ & & $\begin{array}{l}\text { 3) Num } \\
\text { F\&As }\end{array}$ & & $\begin{array}{c}\text { 4) } \\
\text { Retorno }\end{array}$ & & $\begin{array}{l}\text { 5) Util. } \\
\text { Cap. }\end{array}$ & & $\begin{array}{c}\text { 6) IBC- } \\
\text { BR }\end{array}$ & \\
\hline Mercado em Alta & $-1.7 \%$ & & $-2.3 \%$ & $* *$ & $0.0 \%$ & & $-1.4 \%$ & & $-0.5 \%$ & & $-1.2 \%$ & \\
\hline Mercado Neutro & $-1.0 \%$ & & $-1.2 \%$ & & $0.2 \%$ & & $0.1 \%$ & & $-3.2 \%$ & $* * *$ & $0.3 \%$ & \\
\hline \multicolumn{13}{|l|}{ Variáveis de Controle } \\
\hline ValorMerc / ValorCont & $0.0 \%$ & & $0.0 \%$ & & $0.0 \%$ & & $0.0 \%$ & & $0.0 \%$ & & $0.0 \%$ & \\
\hline Endiv / Ativos Totais & $-1.1 \%$ & & $-1.1 \%$ & & $-1.1 \%$ & & $-1.2 \%$ & & $-0.8 \%$ & & $-3.7 \%$ & \\
\hline Tam Rel Operacao & $-2.3 \%$ & & $-2.2 \%$ & & $-2.8 \%$ & & $-2.4 \%$ & & $-2.8 \%$ & & $-1.7 \%$ & \\
\hline Tam Adquirente & $0.2 \%$ & & $0.2 \%$ & & $0.2 \%$ & & $0.3 \%$ & & $0.1 \%$ & & $0.1 \%$ & \\
\hline Empresas Relacionadas & $1.2 \%$ & & $1.0 \%$ & & $1.5 \%$ & $*$ & $1.5 \%$ & $* *$ & $1.0 \%$ & & $1.2 \%$ & \\
\hline Momento (Ebitda / Ativ Total) & $1.9 \%$ & & $1.4 \%$ & & $3.4 \%$ & & $4.4 \%$ & & $5.9 \%$ & & $3.3 \%$ & \\
\hline Aquisição Internacional & $-0.6 \%$ & & $-0.6 \%$ & & $-0.5 \%$ & & $-0.6 \%$ & & $-0.7 \%$ & & $-0.3 \%$ & \\
\hline Aquisição Controle & $-0.1 \%$ & & $-0.2 \%$ & & $-0.1 \%$ & & $0.0 \%$ & & $-0.1 \%$ & & $0.2 \%$ & \\
\hline Recenticidade & $2.3 \%$ & $*$ & $2.2 \%$ & & $2.3 \%$ & & $2.4 \%$ & * & $1.9 \%$ & & $1.1 \%$ & \\
\hline Experiência & $-0.4 \%$ & $*$ & $-0.4 \%$ & & $-0.4 \%$ & $*$ & $-0.5 \%$ & $* *$ & $-0.4 \%$ & * & $-0.5 \%$ & \\
\hline Sem Sobreposição Eventos & $0.3 \%$ & & $0.3 \%$ & & $0.5 \%$ & & $0.4 \%$ & & $0.5 \%$ & & $0.5 \%$ & \\
\hline Tamanho Amostra & 346 & & 346 & & $\overline{346}$ & & 346 & & 346 & & 291 & \\
\hline $\mathrm{R}^{2}$ Ajustado & 0.002 & & 0.010 & & -0.006 & & 0.005 & & 0.036 & & -0.011 & \\
\hline Estatítica F & 1.063 & & 1.264 & & 0.837 & & 1.121 & & 2.003 & $* *$ & 0.763 & \\
\hline Teste Breusch-Pagan & 0.000 & & 0.000 & & 0.000 & & 0.001 & & 0.000 & & 0.002 & \\
\hline Teste Reset & 0.289 & & 0.470 & & 0.680 & & 0.823 & & 0.992 & & 0.636 & \\
\hline Exclusão Outliers & 1) ICEI & & $\begin{array}{c}\text { 2) ICEI } \\
\text { Expectati }\end{array}$ & & $\begin{array}{l}\text { 3) Num } \\
\text { F\&As }\end{array}$ & & $\begin{array}{c}\text { 4) } \\
\text { Retorno }\end{array}$ & & $\begin{array}{l}\text { 5) Util. } \\
\text { Cap. }\end{array}$ & & $\begin{array}{c}\text { 6) IBC- } \\
\text { BR } \\
\end{array}$ & \\
\hline Mercado em Alta & $-1.6 \%$ & $*$ & $-2.4 \%$ & $* *$ & $-0.1 \%$ & & $-1.2 \%$ & & $-1.5 \%$ & & $-0.6 \%$ & \\
\hline Mercado Neutro & $-1.0 \%$ & & $-1.4 \%$ & & $0.1 \%$ & & $0.1 \%$ & & $-4.1 \%$ & $* * *$ & $0.3 \%$ & \\
\hline \multicolumn{13}{|l|}{ Variáveis de Controle } \\
\hline ValorMerc / ValorCont & $0.0 \%$ & & $0.0 \%$ & & $0.0 \%$ & & $0.0 \%$ & & $0.0 \%$ & & $0.0 \%$ & \\
\hline Endiv / Ativos Totais & $-3.2 \%$ & & $-3.9 \%$ & & $-1.4 \%$ & & $-1.2 \%$ & & $-4.1 \%$ & & $-4.8 \%$ & \\
\hline Tam Rel Operacao & $2.2 \%$ & & $2.2 \%$ & & $2.6 \%$ & & $2.4 \%$ & & $1.9 \%$ & & $3.9 \%$ & \\
\hline Tam Adquirente & $0.1 \%$ & & $0.2 \%$ & & $0.2 \%$ & & $0.3 \%$ & & $0.1 \%$ & & $0.2 \%$ & \\
\hline Empresas Relacionadas & $1.1 \%$ & & $0.9 \%$ & & $1.4 \%$ & $*$ & $1.6 \%$ & $* *$ & $0.9 \%$ & & $1.2 \%$ & \\
\hline Momento (Ebitda / Ativ Total) & $0.4 \%$ & & $0.0 \%$ & & $3.5 \%$ & & $4.4 \%$ & & $5.0 \%$ & & $3.2 \%$ & \\
\hline Aquisição Internacional & $0.0 \%$ & & $0.0 \%$ & & $0.1 \%$ & & $0.0 \%$ & & $-0.1 \%$ & & $0.3 \%$ & \\
\hline Aquisição Controle & $0.0 \%$ & & $0.1 \%$ & & $-0.1 \%$ & & $-0.1 \%$ & & $0.2 \%$ & & $0.4 \%$ & \\
\hline Recenticidade & $2.6 \%$ & $* *$ & $2.1 \%$ & & $3.0 \%$ & $* *$ & $2.5 \%$ & $* *$ & $1.9 \%$ & & $1.7 \%$ & \\
\hline Experiência & $-0.4 \%$ & $*$ & $-0.5 \%$ & $*$ & $-0.5 \%$ & $*$ & $-0.5 \%$ & $* *$ & $-0.5 \%$ & $* *$ & $-0.6 \%$ & $* *$ \\
\hline Sem Sobreposição Eventos & $0.3 \%$ & & $0.2 \%$ & & $0.3 \%$ & & $0.2 \%$ & & $0.4 \%$ & & $0.2 \%$ & \\
\hline$\overline{\text { Tamanho Amostra }}---$ & $-\overline{343}-$ & - & $-\overline{344}$ & - & $-\overline{344}$ & -- & $-\overline{343}$ & -- & $\overline{344}-$ & - & $-\overline{290}-$ & - \\
\hline $\mathrm{R}^{2}$ Ajustado & 0.003 & & 0.014 & & -0.001 & & 0.004 & & 0.054 & & -0.005 & \\
\hline Estatítica F & 1.089 & & 1.368 & & 0.975 & & 1.100 & & 2.504 & $* * *$ & 0.898 & \\
\hline Teste Breusch-Pagan & 0.156 & & 0.065 & & 0.060 & & 0.079 & & 0.075 & & 0.073 & \\
\hline Teste Reset & 0.198 & & 0.549 & & 0.291 & & 0.437 & & 0.987 & & 0.273 & \\
\hline
\end{tabular}

Fonte: Elaborado pelo Autor

Notas: * denota significância estatística: * p-value $<10 \% ; \quad * *$ p-value $<5 \%$; $\quad * * *$ p-value $<1 \%$

Quando o Teste de Breusch-Pagan indica heterocedasticidade, a significância estatística adota a metodologia de erros robustos. A tabela apresenta os resultados da regressão cross section do retorno anormal acumulado para a janela de onze dias. São apresentados os resultados de seis modelos, cada qual assumindo uma proxy diferente para classificação do estado de mercado. 
Tabela 22 - Análise de Regressão dos Determinantes de Criação de Valor - Janela de Vinte e Um Dias - Proxy de Mercado IBRX-50 - Amostra Completa

\begin{tabular}{|c|c|c|c|c|c|c|c|c|c|c|c|c|}
\hline \multirow{2}{*}{$\begin{array}{l}\text { Amostra Completa } \\
\text { Mercado em Alta }\end{array}$} & \multicolumn{2}{|c|}{ 1) ICEI } & \multicolumn{2}{|c|}{$\begin{array}{c}\text { 2) ICEI } \\
\text { Expectativa }\end{array}$} & \multicolumn{2}{|c|}{ 3) Num F\&As } & \multicolumn{2}{|c|}{$\begin{array}{l}\text { 4) Retorno } \\
\text { Ibovespa }\end{array}$} & \multicolumn{2}{|c|}{$\begin{array}{l}\text { 5) Util. Cap. } \\
\text { Instalada }\end{array}$} & \multicolumn{2}{|c|}{ 6) IBC-BR } \\
\hline & $-2.5 \%$ & $*$ & $-4.0 \%$ & $* * *$ & $-0.4 \%$ & & $-2.1 \%$ & $*$ & $-1.4 \%$ & & $0.1 \%$ & \\
\hline Mercado Neutro & $-0.7 \%$ & & $-2.1 \%$ & $*$ & $-1.7 \%$ & & $0.1 \%$ & & $-5.3 \%$ & $* * *$ & $1.6 \%$ & \\
\hline \multicolumn{13}{|l|}{ Variáveis de Controle } \\
\hline ValorMerc / ValorCont & $0.0 \%$ & & $0.0 \%$ & & $0.1 \%$ & & $0.1 \%$ & & $0.1 \%$ & & $0.0 \%$ & \\
\hline Endiv / Ativos Totais & $-6.7 \%$ & & $-6.6 \%$ & & $-7.4 \%$ & & $-6.9 \%$ & & $-6.5 \%$ & & $-8.8 \%$ & \\
\hline Tam Rel Operacao & $-1.9 \%$ & & $-1.5 \%$ & & $-2.3 \%$ & & $-2.0 \%$ & & $-2.6 \%$ & & $-1.2 \%$ & \\
\hline Tam Adquirente & $-0.2 \%$ & & $-0.2 \%$ & & $-0.3 \%$ & & $0.0 \%$ & & $-0.3 \%$ & & $-0.2 \%$ & \\
\hline Empresas Relacionadas & $2.1 \%$ & $* *$ & $1.8 \%$ & $*$ & $2.4 \%$ & $* * *$ & $2.7 \%$ & $* * *$ & $1.9 \%$ & $* *$ & $1.8 \%$ & $*$ \\
\hline Momento (Ebitda / Ativ Total) & $-12.3 \%$ & & $-13.0 \%$ & & $-10.4 \%$ & & $-8.3 \%$ & & $-5.7 \%$ & & $-10.7 \%$ & \\
\hline Aquisição Internacional & $2.5 \%$ & $*$ & $2.4 \%$ & * & $2.8 \%$ & $* *$ & $2.4 \%$ & $*$ & $2.2 \%$ & $*$ & $2.2 \%$ & \\
\hline Aquisição Controle & $0.0 \%$ & & $-0.1 \%$ & & $0.0 \%$ & & $0.2 \%$ & & $0.1 \%$ & & $0.2 \%$ & \\
\hline Recenticidade & $1.8 \%$ & & $1.6 \%$ & & $1.7 \%$ & & $1.9 \%$ & & $1.3 \%$ & & $1.1 \%$ & \\
\hline Experiência & $-0.1 \%$ & & $-0.1 \%$ & & $-0.2 \%$ & & $-0.3 \%$ & & $-0.2 \%$ & & $-0.2 \%$ & \\
\hline Sem Sobreposição Eventos & $0.5 \%$ & & $0.5 \%$ & & $0.4 \%$ & & $0.6 \%$ & & $0.8 \%$ & & $0.5 \%$ & \\
\hline Tamanho Amostra & 346 & & 346 & & 346 & & 346 & & 346 & & 291 & \\
\hline $\mathrm{R}^{2}$ Ajustado & 0.026 & & 0.042 & & 0.019 & & 0.026 & & 0.075 & & 0.003 & \\
\hline Estatítica F & 1.701 & $*$ & 2.170 & $* *$ & 1.527 & & 1.720 & $*$ & 3.152 & $* * *$ & 1.075 & \\
\hline Teste Breusch-Pagan & 0.000 & & 0.000 & & 0.000 & & 0.000 & & 0.000 & & 0.000 & \\
\hline Teste Reset & 0.646 & & 0.275 & & 0.061 & & 0.940 & & 0.552 & & 0.031 & \\
\hline
\end{tabular}

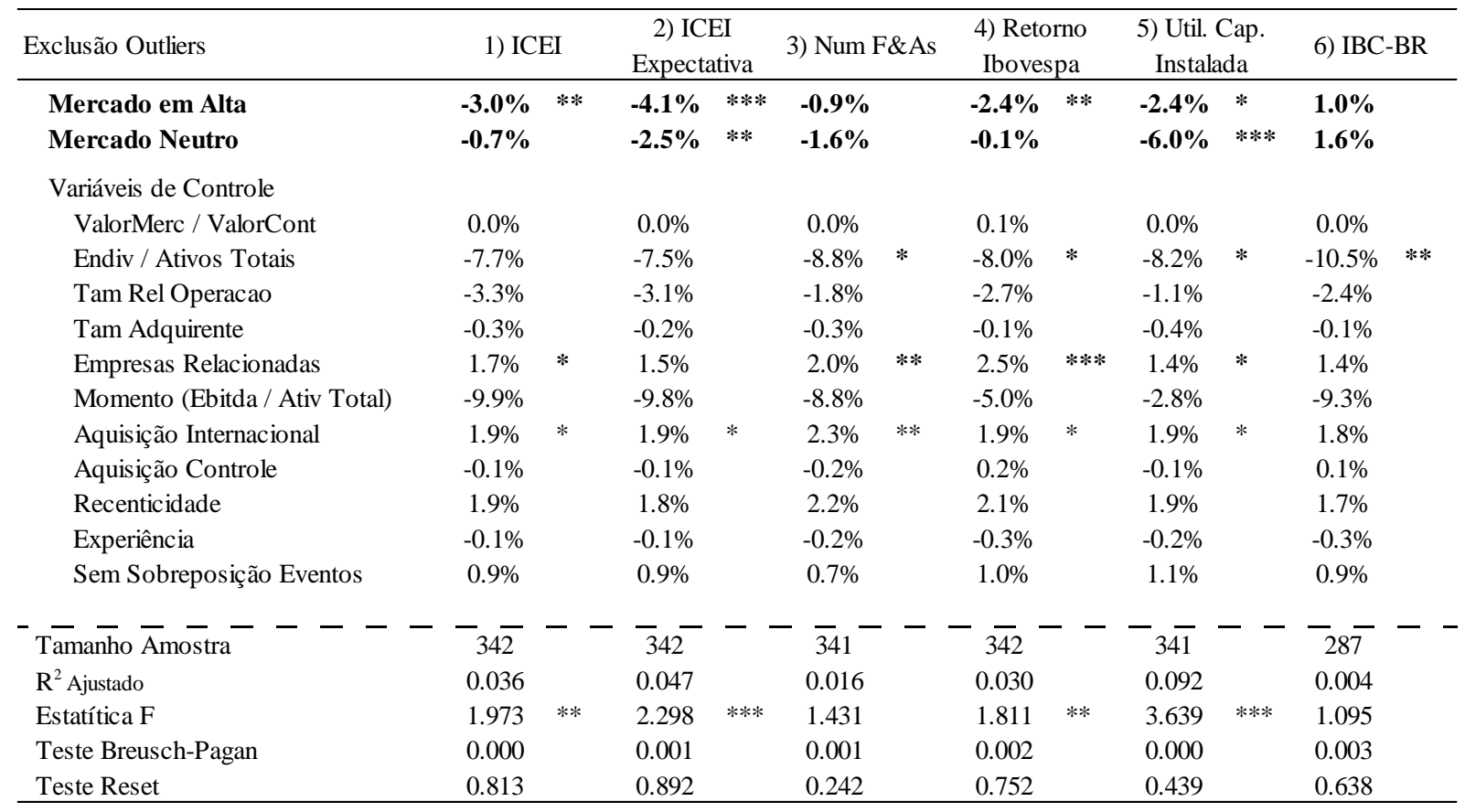

Fonte: Elaborado pelo Autor

Notas: * denota significância estatística: * p-value $<10 \%$; $\quad * *$ p-value $<5 \%$; $\quad * * *$ p-value $<1 \%$

Quando o Teste de Breusch-Pagan indica heterocedasticidade, a significância estatística adota a metodologia de erros robustos A tabela apresenta os resultados da regressão cross section do retorno anormal acumulado para a janela de vinte e um dias. São apresentados os resultados de seis modelos, cada qual assumindo uma proxy diferente para classificação do estado de mercado. 
Apêndice 2 - Classificação Sentimento de Mercado pela Mediana

Tabela 1 - Criação de Valor - Proxy de Mercado Ibovespa e Segmentação Sentimento Mercado pela Mediana

\begin{tabular}{|c|c|c|c|c|c|c|c|c|c|c|c|c|c|c|c|c|c|c|}
\hline \multirow{3}{*}{$\begin{array}{c}\text { Sentimento } \\
\text { de Mercado } \\
\text { Número de } \\
\text { Eventos }\end{array}$} & \multirow[t]{2}{*}{$\begin{array}{c}\text { Amostra } \\
\text { Total }\end{array}$} & \multicolumn{4}{|c|}{ ICEI } & \multicolumn{2}{|c|}{ ICEI Expectativa } & \multicolumn{2}{|c|}{ Retorno Ibovespa } & \multicolumn{3}{|c|}{ Número de F\&As } & \multicolumn{3}{|c|}{$\begin{array}{l}\text { Utilização Capacidade } \\
\text { Instalada }\end{array}$} & \multicolumn{3}{|c|}{ IBC - BR } \\
\hline & & \multicolumn{2}{|l|}{ Alta } & \multicolumn{2}{|c|}{ Baixa } & Alta & Baixa & Alta & Baixa & Alta & \multicolumn{2}{|l|}{ Baixa } & Alta & \multicolumn{2}{|l|}{ Baixa } & Alta & \multicolumn{2}{|l|}{ Baixa } \\
\hline & 113 & 59 & & 54 & & 50 & 63 & 68 & 45 & 72 & 41 & & 76 & 37 & & 56 & 55 & \\
\hline$\underline{D i a}$ & & & & & & & & & & & & & & & & & & \\
\hline-10 & $0.1 \%$ & $0.1 \%$ & & $0.2 \%$ & & $0.0 \%$ & $0.2 \%$ & $-0.1 \%$ & $0.4 \%$ & $0.3 \%$ & $-0.3 \%$ & & $0.3 \%$ & $-0.2 \%$ & & $-0.1 \%$ & $0.3 \%$ & \\
\hline-9 & $0.0 \%$ & $-0.1 \%$ & & $0.2 \%$ & & $-0.2 \%$ & $0.2 \%$ & $-0.1 \%$ & $0.2 \%$ & $0.2 \%$ & $-0.2 \%$ & & $0.2 \%$ & $-0.3 \%$ & & $-0.2 \%$ & $0.4 \%$ & \\
\hline-8 & $-0.1 \%$ & $0.2 \%$ & & $-0.4 \%$ & & $-0.1 \%$ & $-0.1 \%$ & $0.1 \%$ & $-0.3 \%$ & $0.0 \%$ & $-0.3 \%$ & & $0.1 \%$ & $-0.4 \%$ & & $-0.1 \%$ & $-0.1 \%$ & \\
\hline-7 & $0.0 \%$ & $-0.1 \%$ & & $0.0 \%$ & & $-0.1 \%$ & $0.1 \%$ & $-0.3 \%$ & $0.4 \%$ & $0.2 \%$ & $-0.4 \%$ & & $0.1 \%$ & $-0.2 \%$ & & $-0.1 \%$ & $-0.1 \%$ & \\
\hline-6 & $0.2 \%$ & $0.1 \%$ & & $0.3 \%$ & & $0.1 \%$ & $0.2 \%$ & $0.0 \%$ & $0.4 \%$ & $-0.1 \%$ & $0.6 \% * *$ & $\sqrt{ } V$ & $0.2 \%$ & $0.1 \%$ & & $0.5 \% * * \quad \sqrt{ } \sqrt{ }$ & $-0.2 \%$ & \\
\hline-5 & $0.2 \%$ & $0.0 \%$ & & $0.4 \%$ & $\sqrt{ }$ & $0.1 \%$ & $0.3 \%$ & $0.1 \%$ & $0.4 \%$ & $0.3 \%$ & $0.1 \%$ & & $0.3 \%$ & $0.1 \%$ & & $0.1 \%$ & $0.4 \%$ & \\
\hline-4 & $-0.3 \%$ & $-0.2 \%$ & & $-0.4 \%$ & $\sqrt{ } \sqrt{ }$ & $-0.1 \%$ & $-0.5 \% * \quad \sqrt{ } \downarrow$ & $-0.3 \% * \quad \sqrt{ } \sqrt{ }$ & $-0.2 \%$ & $-0.1 \%$ & $-0.5 \% *$ & $\sqrt{ }$ & $-0.3 \% * \quad \sqrt{ } \mathrm{V}$ & $-0.2 \%$ & & $-0.3 \%$ & $-0.3 \%$ & \\
\hline-3 & $-0.1 \%$ & $0.2 \%$ & & $-0.4 \%$ & & $0.4 \%$ & $-0.4 \%$ & $-0.4 \%$ & $0.4 \%$ & $0.1 \%$ & $-0.3 \%$ & & $-0.2 \%$ & $0.2 \%$ & & $-0.5 \% *$ & $0.4 \%$ & \\
\hline-2 & $-0.3 \%$ & $-0.2 \%$ & & $-0.4 \%$ & & $0.1 \%$ & $-0.6 \% *$ & $-0.3 \%$ & $-0.3 \%$ & $-0.3 \%$ & $-0.3 \%$ & & $-0.4 \%$ & $-0.2 \%$ & & $-0.5 \% *$ & $0.0 \%$ & \\
\hline-1 & $0.2 \%$ & $0.7 \% *$ & & $-0.4 \%$ & & $0.7 \%$ & $-0.2 \%$ & $0.1 \%$ & $0.3 \%$ & $0.5 \%$ & $-0.4 \%$ & & $0.4 \%$ & $-0.3 \%$ & & $0.0 \%$ & $0.4 \%$ & \\
\hline $\begin{array}{l}\text { Anúncio } \\
\text { Evento }\end{array}$ & $0.6 \% * * \quad \sqrt{ }$ & $0.5 \%$ & & $0.6 \%$ & & $0.4 \%$ & $0.7 \% *$ & $0.8 \% * * \quad \sqrt{ }$ & $0.3 \%$ & $0.5 \%$ & $0.6 \%$ & $\checkmark$ & $0.5 \%$ & $0.8 \%$ & $\checkmark$ & $0.6 \% * *$ & $0.5 \%$ & \\
\hline 1 & $0.2 \%$ & $0.1 \%$ & & $0.4 \%$ & & $0.2 \%$ & $0.3 \%$ & $0.2 \%$ & $0.3 \%$ & $-0.1 \%$ & $0.7 \% * *$ & $\sqrt{ }$ & $0.0 \%$ & $0.7 \%$ & & $0.3 \%$ & $0.1 \%$ & \\
\hline 2 & $0.0 \%$ & $0.2 \%$ & & $-0.2 \%$ & & $0.4 \%$ & $-0.3 \%$ & $-0.1 \%$ & $0.1 \%$ & $0.1 \%$ & $-0.1 \%$ & & $0.0 \%$ & $0.1 \%$ & & $-0.1 \%$ & $0.3 \%$ & \\
\hline 3 & $0.1 \%$ & $-0.1 \%$ & & $0.3 \%$ & & $-0.1 \%$ & $0.3 \%$ & $0.0 \%$ & $0.2 \%$ & $0.2 \%$ & $-0.2 \%$ & & $0.1 \%$ & $-0.1 \%$ & & $-0.1 \%$ & $0.4 \%$ & \\
\hline 4 & $0.1 \%$ & $0.0 \%$ & & $0.3 \%$ & & $0.1 \%$ & $0.1 \%$ & $-0.1 \%$ & $0.5 \%$ & $0.2 \%$ & $0.0 \%$ & & $0.3 \%$ & $-0.3 \%$ & & $0.0 \%$ & $0.3 \%$ & \\
\hline 5 & $-0.1 \%$ & $0.0 \%$ & & $-0.1 \%$ & & $0.0 \%$ & $-0.1 \%$ & $0.1 \%$ & $-0.3 \%$ & $-0.3 \%$ & $0.2 \%$ & & $0.2 \%$ & $-0.6 \%$ & $\checkmark$ & $0.3 \%$ & $-0.5 \%$ & v \\
\hline 6 & $-0.3 \%$ & $0.1 \%$ & & $-0.6 \%$ & $\sqrt{ } \sqrt{ }$ & $-0.1 \%$ & $-0.4 \%$ & $-0.1 \%$ & $-0.5 \%$ & $-0.3 \%$ & $-0.2 \%$ & & $-0.3 \%$ & $-0.1 \%$ & & $-0.2 \%$ & $-0.5 \%$ & \\
\hline 7 & $0.3 \% *$ & $0.3 \%$ & & $0.4 \%$ & & $0.1 \%$ & $0.5 \% * *$ & $0.1 \%$ & $0.6 \% * * \quad \sqrt{ }$ & $0.4 \% * \quad \sqrt{ }$ & $0.2 \%$ & & $0.4 \% * *$ & $0.1 \%$ & & $0.3 \%$ & $0.4 \%$ & \\
\hline 8 & $-0.2 \%$ & $-0.4 \%$ & $\checkmark$ & $-0.1 \%$ & & $-0.5 \% * * \quad \sqrt{ } \sqrt{ }$ & $0.0 \%$ & $-0.4 \%$ & $0.0 \%$ & $-0.2 \%$ & $-0.3 \%$ & & $0.1 \%$ & $-0.8 \% * *$ & $\sqrt{ } V$ & $0.0 \%$ & $-0.5 \% *$ & v \\
\hline 9 & $0.1 \%$ & $0.0 \%$ & & $0.2 \%$ & & $0.1 \%$ & $0.1 \%$ & $0.1 \%$ & $0.1 \%$ & $0.1 \%$ & $0.2 \%$ & & $-0.1 \%$ & $0.7 \%$ & & $0.3 \%$ & $-0.2 \%$ & \\
\hline 10 & $0.0 \%$ & $0.1 \%$ & & $-0.1 \%$ & & $-0.2 \%$ & $0.1 \%$ & $0.0 \%$ & $0.1 \%$ & $0.1 \%$ & $-0.1 \%$ & & $0.1 \%$ & $-0.1 \%$ & & $0.0 \%$ & $0.0 \%$ & \\
\hline CAR_3 & $1.0 \% * *$ & $1.3 \% * *$ & $\sqrt{ }$ & $0.6 \%$ & & $1.3 \% * *$ & $0.7 \%$ & $1.0 \% *$ & $0.9 \%$ & $1.0 \%$ & $1.0 \%$ & & $0.9 \% *$ & $1.2 \%$ & & $1.0 \%$ & $0.9 \%$ & \\
\hline CAR_11 & $0.7 \%$ & $1.2 \%$ & & $0.1 \%$ & & $2.1 \% * * * \quad \sqrt{ }$ & $-0.5 \%$ & $0.1 \%$ & $1.6 \%$ & $1.1 \%$ & $-0.1 \%$ & & $0.9 \%$ & $0.2 \%$ & & $-0.2 \%$ & $1.9 \% *$ & \\
\hline CAR_21 & $0.9 \%$ & $1.4 \%$ & & $0.3 \%$ & & $1.3 \%$ & $0.6 \%$ & $-0.5 \%$ & $3.0 \% * * \quad \sqrt{ } \sqrt{ }$ & $1.9 \% * * \quad \checkmark$ & $-0.9 \%$ & & $1.9 \% * * \quad \sqrt{ }$ & $-1.1 \%$ & & $0.3 \%$ & $1.4 \%$ & \\
\hline
\end{tabular}

Fonte: Elaborado pelo Autor

Notas: * denota significância estatística para o teste t: *p-value $<10 \% ; \quad * *$ p-value $<5 \% ; \quad * * *$ p-value $<1 \%$

$\sqrt{ }$ denota significância estatística para o teste de Wilcoxon: $\sqrt{ }$ p-value $<10 \% ; \quad \sqrt{ } \sqrt{p}$-value $<5 \% ; \quad \sqrt{ } \sqrt{ }$ p-value $<1 \%$

A tabela mostra os retornos anormais diários médios (para dez dias em torno do dia do anúncio da F\&A) e acumulado para as janelas de três, onze e vinte e um dias (CAR_3, CAR_11 e CAR_21).

O retorno anormal médio é apresentado para a amostra de eventos sem sobreposição de efeitos de outros fatos relevantes e para sub amostras desses mesmos eventos obtidas com base no estado do sentimento de mercado (em alta ou baixa), quando classificado segundo as proxies: ICEI, ICEI Expectativa, Retorno Ibovespa, Número de F\&A, Nível de Utilização da Capacidade Instalada e IBC-BR 
Tabela 24 - Teste Mann Whitney para Duas Amostras - Proxy de Mercado Ibovespa e Segmentação Sentimento Mercado pela Mediana

\begin{tabular}{|c|c|c|c|c|c|c|}
\hline & ICEI & ICEI Exp & $\begin{array}{l}\text { Retorno } \\
\text { Ibovespa }\end{array}$ & $\begin{array}{c}\text { Número de } \\
\text { F\&As }\end{array}$ & $\begin{array}{l}\text { Utilização Capa- } \\
\text { cidade Instalada }\end{array}$ & IBC-BR \\
\hline \multicolumn{7}{|c|}{ Criação de Valor: Mercado em Alta } \\
\hline Dia Anúncio & $0.5 \%$ & $0.4 \%$ & $0.8 \%$ & $0.5 \%$ & $0.5 \%$ & $0.6 \%$ \\
\hline CAR_3 & $1.3 \%$ & $1.3 \%$ & $1.0 \%$ & $1.0 \%$ & $0.9 \%$ & $1.0 \%$ \\
\hline CAR_11 & $1.2 \%$ & $2.1 \%$ & $0.1 \%$ & $1.1 \%$ & $0.9 \%$ & $-0.2 \%$ \\
\hline CAR_21 & $1.4 \%$ & $1.3 \%$ & $-0.5 \%$ & $1.9 \%$ & $1.9 \%$ & $0.3 \%$ \\
\hline \multicolumn{7}{|c|}{ Criação de Valor: Mercado em Baixa } \\
\hline Dia Anúncio & $0.6 \%$ & $0.7 \%$ & $0.3 \%$ & $0.6 \%$ & $0.8 \%$ & $0.5 \%$ \\
\hline CAR_3 & $0.6 \%$ & $0.7 \%$ & $0.9 \%$ & $1.0 \%$ & $1.2 \%$ & $0.9 \%$ \\
\hline CAR_11 & $0.1 \%$ & $-0.5 \%$ & $1.6 \%$ & $-0.1 \%$ & $0.2 \%$ & $1.9 \%$ \\
\hline CAR_21 & $0.3 \%$ & $0.6 \%$ & $3.0 \%$ & $-0.9 \%$ & $-1.1 \%$ & $1.4 \%$ \\
\hline \multicolumn{7}{|l|}{ P-Value } \\
\hline Dia Anúncio & 0.966 & 0.965 & 0.637 & 0.475 & 0.202 & 0.946 \\
\hline CAR_3 & 0.305 & 0.663 & 0.932 & 0.727 & 0.819 & 0.699 \\
\hline CAR_11 & 0.478 & 0.018 & 0.252 & 0.614 & 0.915 & 0.282 \\
\hline CAR_21 & 0.419 & 0.617 & 0.013 & 0.133 & 0.080 & 0.435 \\
\hline
\end{tabular}

Fonte: Elaborado pelo Autor

Nota. A tabela apresenta o resultado ( $p$-value ) do teste de Mann-Whitney para a hipótese nula de que a criação de valor em momentos de mercado em baixa é igual à criação de valor em momentos de mercado em alta. 
Tabela 25 Análise de Regressão dos Determinantes de Criação de Valor - Dia do Anúncio da F\&A - Proxy de Mercado Ibovespa e Segmentação Sentimento Mercado pela Mediana

\begin{tabular}{|c|c|c|c|c|c|c|}
\hline Amostra Completa & 1) ICEI & $\begin{array}{l}\text { 2) ICEI } \\
\text { Expectativa }\end{array}$ & $\begin{array}{l}\text { 3) Num } \\
\text { F\&As }\end{array}$ & $\begin{array}{l}\text { 4) Retorno } \\
\text { Ibovespa }\end{array}$ & $\begin{array}{l}\text { 5) Util. Cap. } \\
\text { Instalada }\end{array}$ & 6) IBC-BR \\
\hline Mercado em Alta & $0.0 \%$ & $0.0 \%$ & $-0.1 \%$ & $0.5 \%$ & $-0.3 \%$ & $0.0 \%$ \\
\hline \multicolumn{7}{|l|}{ Variáveis de Controle } \\
\hline ValorMerc / ValorCont & $0.0 \%$ & $0.0 \%$ & $0.0 \%$ & $0.0 \%$ & $0.0 \%$ & $0.0 \%$ \\
\hline Endiv / Ativos Totais & $0.7 \%$ & $0.6 \%$ & $0.7 \%$ & $0.5 \%$ & $0.7 \%$ & $0.4 \%$ \\
\hline Tam Rel Operacao & $-1.0 \%$ & $-1.0 \%$ & $-1.0 \%$ & $-1.4 \%$ & $-1.0 \%$ & $-1.0 \%$ \\
\hline Tam Adquirente & $0.2 \%$ & $0.2 \%$ & $0.2 \%$ & $0.2 \%$ & $0.2 \%$ & $0.2 \%$ \\
\hline Empresas Relacionadas & $0.6 \%$ & $0.6 \%$ & $0.6 \%$ & $0.6 \%$ & $0.6 \%$ & $0.6 \%$ \\
\hline Momento (Ebitda / Ativ Total) & $-4.7 \%$ & $-4.7 \%$ & $-4.9 \%$ & $-5.4 \%$ & $-4.6 \%$ & $-4.9 \%$ \\
\hline Aquisição Internacional & $0.4 \%$ & $0.4 \%$ & $0.4 \%$ & $0.3 \%$ & $0.4 \%$ & $0.4 \%$ \\
\hline Aquisição Controle & $0.8 \%$ & $0.8 \%$ & $0.8 \%$ & $0.8 \%$ & $0.9 \%$ & $0.9 \%$ \\
\hline Recenticidade & $-0.4 \%$ & $-0.4 \%$ & $-0.4 \%$ & $-0.3 \%$ & $-0.4 \%$ & $-0.5 \%$ \\
\hline Experiencia & $-0.2 \%$ & $-0.2 \%$ & $-0.2 \%$ & $-0.2 \%$ & $-0.2 \%$ & $-0.2 \%$ \\
\hline$-\overline{\text { Tamanho }} \overline{\text { Amostra }}---$ & $-1 \overline{13}$ & $\overline{113}-$ & $-\overline{113}-$ & $\overline{113}--$ & $-11 \overline{3}-$ & $-\overline{111}-$ \\
\hline $\mathrm{R}^{2}$ Ajustado & -0.046 & -0.046 & -0.046 & -0.041 & -0.044 & -0.047 \\
\hline Estatítica F & 0.551 & 0.551 & 0.553 & 0.601 & 0.572 & 0.555 \\
\hline Teste Breusch-Pagan & 0.088 & 0.069 & 0.121 & 0.084 & 0.127 & 0.096 \\
\hline Teste Reset & 0.453 & 0.424 & 0.451 & 0.498 & 0.558 & 0.571 \\
\hline
\end{tabular}

\begin{tabular}{|c|c|c|c|c|c|c|c|c|c|c|c|c|}
\hline Exclusão Outliers & \multicolumn{2}{|c|}{ 1) ICEI } & \multicolumn{2}{|c|}{$\begin{array}{c}\text { 2) ICEI } \\
\text { Expectativa }\end{array}$} & \multicolumn{2}{|c|}{$\begin{array}{l}\text { 3) Num } \\
\text { F\&As }\end{array}$} & \multicolumn{2}{|c|}{$\begin{array}{l}\text { 4) Retorno } \\
\text { Ibovespa }\end{array}$} & \multicolumn{2}{|c|}{$\begin{array}{l}\text { 5) Util. Cap. } \\
\text { Instalada }\end{array}$} & \multicolumn{2}{|c|}{ 6) IBC-BR } \\
\hline Mercado em Alta & $0.3 \%$ & & $0.3 \%$ & & $-0.2 \%$ & & $0.0 \%$ & & $0.0 \%$ & & $-0.3 \%$ & \\
\hline \multicolumn{13}{|l|}{ Variáveis de Controle } \\
\hline ValorMerc / ValorCont & $0.0 \%$ & & $0.0 \%$ & & $0.0 \%$ & & $0.0 \%$ & & $0.0 \%$ & & $0.0 \%$ & \\
\hline Endiv / Ativos Totais & $0.1 \%$ & & $0.1 \%$ & & $0.2 \%$ & & $-0.3 \%$ & & $0.1 \%$ & & $-0.4 \%$ & \\
\hline Tam Rel Operacao & $-1.7 \%$ & & $-1.9 \%$ & & $-1.7 \%$ & & $-0.9 \%$ & & $-1.7 \%$ & & $-1.9 \%$ & \\
\hline Tam Adquirente & $0.2 \%$ & & $0.2 \%$ & & $0.3 \%$ & & $0.1 \%$ & & $0.3 \%$ & & $0.2 \%$ & \\
\hline Empresas Relacionadas & $0.7 \%$ & & $0.7 \%$ & & $0.6 \%$ & & $0.8 \%$ & & $0.6 \%$ & & $0.6 \%$ & \\
\hline Momento (Ebitda / Ativ Total) & $-7.5 \%$ & $*$ & $-7.8 \%$ & $* *$ & $-7.9 \%$ & $* *$ & $-5.3 \%$ & & $-7.6 \%$ & $* *$ & $-7.4 \%$ & $*$ \\
\hline Aquisição Internacional & $0.6 \%$ & & $0.6 \%$ & & $0.5 \%$ & & $0.6 \%$ & & $0.5 \%$ & & $0.6 \%$ & \\
\hline Aquisição Controle & $0.7 \%$ & & $0.7 \%$ & & $0.7 \%$ & & $0.4 \%$ & & $0.7 \%$ & & $0.8 \%$ & \\
\hline Recenticidade & $-1.5 \%$ & $* *$ & $-1.5 \%$ & $* *$ & $-1.4 \%$ & * & $-1.2 \%$ & $*$ & $-1.5 \%$ & $* *$ & $-1.8 \%$ & $* *$ \\
\hline Experiencia & $-0.1 \%$ & & $-0.1 \%$ & & $-0.2 \%$ & & $-0.1 \%$ & & $-0.1 \%$ & & $-0.1 \%$ & \\
\hline$-\overline{\text { Tamanho }} \overline{\text { Amostra }}---$ & $-11 \overline{0}$ & - & $\overline{110}$ & - & $-\overline{10}$ & & $\overline{109}-$ & - & -110 & & $\overline{108}-$ & - \\
\hline $\mathrm{R}^{2}$ Ajustado & 0.033 & & 0.033 & & 0.030 & & 0.012 & & 0.028 & & 0.041 & \\
\hline Estatítica F & 1.335 & & 1.337 & & 1.303 & & 1.124 & & 1.290 & & 1.415 & \\
\hline Teste Breusch-Pagan & 0.188 & & 0.120 & & 0.283 & & 0.193 & & 0.219 & & 0.319 & \\
\hline Teste Reset & 0.338 & & 0.278 & & 0.662 & & 0.599 & & 0.667 & & 0.380 & \\
\hline
\end{tabular}

Fonte: Elaborado pelo Autor

Notas: * denota significância estatística: * p-value $<10 \% ; \quad * *$ p-value $<5 \%$; $\quad * * *$ p-value $<1 \%$

Quando o Teste de Breusch-Pagan indica heterocedasticidade, a significância estatística adota a metodologia de erros robustos.

A tabela apresenta os resultados da regressão cross section do retorno anormal no dia do anúncio da F\&A. São apresentados os resultados de seis modelos, cada qual assumindo uma proxy diferente para classificação do estado de mercado. 
Tabela 26 - Análise de Regressão dos Determinantes de Criação de Valor - Janela de Três Dias - Proxy de Mercado Ibovespa e Segmentação Sentimento Mercado pela Mediana

\begin{tabular}{|c|c|c|c|c|c|c|c|c|c|c|c|}
\hline Amostra Completa & \multicolumn{2}{|c|}{ 1) ICEI } & \multicolumn{2}{|c|}{$\begin{array}{c}\text { 2) ICEI } \\
\text { Expectativa }\end{array}$} & \multicolumn{2}{|c|}{$\begin{array}{l}\text { 3) Num } \\
\text { F\&As }\end{array}$} & \multicolumn{2}{|c|}{$\begin{array}{l}\text { 4) Retorno } \\
\text { Ibovespa } \\
\end{array}$} & $\begin{array}{l}\text { 5) Util. Cap. } \\
\text { Instalada } \\
\end{array}$ & \multicolumn{2}{|c|}{ 6) IBC-BR } \\
\hline Mercado em Alta & $0.7 \%$ & & $0.7 \%$ & & $0.3 \%$ & & $-0.3 \%$ & & $-0.2 \%$ & $-0.5 \%$ & \\
\hline \multicolumn{12}{|l|}{ Variáveis de Controle } \\
\hline ValorMerc / ValorCont & $0.1 \%$ & & $0.1 \%$ & & $0.1 \%$ & & $0.1 \%$ & & $0.1 \%$ & $0.1 \%$ & \\
\hline Endiv / Ativos Totais & $4.5 \%$ & & $4.5 \%$ & & $4.3 \%$ & & $4.4 \%$ & & $4.4 \%$ & $3.9 \%$ & \\
\hline Tam Rel Operacao & $0.1 \%$ & & $-0.2 \%$ & & $0.4 \%$ & & $0.6 \%$ & & $0.3 \%$ & $0.2 \%$ & \\
\hline Tam Adquirente & $-0.2 \%$ & & $-0.1 \%$ & & $-0.1 \%$ & & $-0.1 \%$ & & $-0.1 \%$ & $-0.1 \%$ & \\
\hline Empresas Relacionadas & $0.0 \%$ & & $0.1 \%$ & & $0.0 \%$ & & $-0.1 \%$ & & $-0.1 \%$ & $-0.1 \%$ & \\
\hline Momento (Ebitda / Ativ Total) & $-5.7 \%$ & & $-6.5 \%$ & & $-5.8 \%$ & & $-5.8 \%$ & & $-6.1 \%$ & $-5.4 \%$ & \\
\hline Aquisição Internacional & $0.5 \%$ & & $0.6 \%$ & & $0.4 \%$ & & $0.5 \%$ & & $0.4 \%$ & $0.6 \%$ & \\
\hline Aquisição Controle & $1.1 \%$ & & $1.1 \%$ & & $1.1 \%$ & & $1.1 \%$ & & $1.1 \%$ & $1.3 \%$ & \\
\hline Recenticidade & $-2.7 \%$ & $*$ & $-2.6 \%$ & $*$ & $-2.8 \%$ & * & $-2.7 \%$ & $*$ & $-2.6 \% \quad *$ & $-3.0 \%$ & $*$ \\
\hline Experiencia & $0.2 \%$ & & $0.2 \%$ & & $0.2 \%$ & & $0.2 \%$ & & $0.2 \%$ & $0.2 \%$ & \\
\hline$-\overline{\text { Tamanho }} \overline{\text { Amostra }}---$ & $-\overline{113}$ & - & $\overline{113}$ & - & $-\overline{113}$ & & $\overline{113}-$ & & $-{ }_{113}-$ & $-\overline{111}-$ & \\
\hline $\mathrm{R}^{2}$ Ajustado & -0.029 & & -0.030 & & -0.034 & & -0.034 & & -0.034 & -0.029 & \\
\hline Estatítica F & 0.711 & & 0.702 & & 0.667 & & 0.667 & & 0.666 & 0.714 & \\
\hline Teste Breusch-Pagan & 0.220 & & 0.342 & & 0.463 & & 0.444 & & 0.265 & 0.279 & \\
\hline Teste Reset & 0.585 & & 0.807 & & 0.476 & & 0.561 & & 0.755 & 0.577 & \\
\hline
\end{tabular}

\begin{tabular}{|c|c|c|c|c|c|c|c|c|c|c|c|c|}
\hline Exclusão Outliers & \multicolumn{2}{|c|}{ 1) ICEI } & \multicolumn{2}{|c|}{$\begin{array}{c}\text { 2) ICEI } \\
\text { Expectativa }\end{array}$} & \multicolumn{2}{|c|}{$\begin{array}{l}\text { 3) Num } \\
\text { F\&As }\end{array}$} & \multicolumn{2}{|c|}{$\begin{array}{l}\text { 4) Retorno } \\
\text { Ibovespa }\end{array}$} & \multicolumn{2}{|c|}{$\begin{array}{l}\text { 5) Util. Cap. } \\
\text { Instalada }\end{array}$} & \multicolumn{2}{|c|}{ 6) IBC-BR } \\
\hline Mercado em Alta & $1.0 \%$ & & $1.1 \%$ & & $-0.2 \%$ & & $-0.7 \%$ & & $-0.4 \%$ & & $-0.9 \%$ & \\
\hline \multicolumn{13}{|l|}{ Variáveis de Controle } \\
\hline ValorMerc / ValorCont & $0.0 \%$ & & $0.0 \%$ & & $0.0 \%$ & & $0.0 \%$ & & $0.0 \%$ & & $0.0 \%$ & \\
\hline Endiv / Ativos Totais & $5.2 \%$ & & $5.2 \%$ & & $5.1 \%$ & & $5.2 \%$ & & $5.1 \%$ & & $4.9 \%$ & \\
\hline Tam Rel Operacao & $0.1 \%$ & & $-0.4 \%$ & & $0.4 \%$ & & $1.0 \%$ & & $0.4 \%$ & & $0.4 \%$ & \\
\hline Tam Adquirente & $0.2 \%$ & & $0.2 \%$ & & $0.3 \%$ & & $0.3 \%$ & & $0.3 \%$ & & $0.2 \%$ & \\
\hline Empresas Relacionadas & $0.6 \%$ & & $0.7 \%$ & & $0.4 \%$ & & $0.4 \%$ & & $0.4 \%$ & & $0.4 \%$ & \\
\hline Momento (Ebitda / Ativ Total) & $-7.7 \%$ & & $-8.9 \%$ & & $-8.6 \%$ & & $-7.3 \%$ & & $-8.2 \%$ & & $-6.6 \%$ & \\
\hline Aquisição Internacional & $0.4 \%$ & & $0.5 \%$ & & $0.2 \%$ & & $0.3 \%$ & & $0.2 \%$ & & $0.5 \%$ & \\
\hline Aquisição Controle & $1.0 \%$ & & $0.9 \%$ & & $0.9 \%$ & & $1.0 \%$ & & $1.0 \%$ & & $1.2 \%$ & \\
\hline Recenticidade & $-3.3 \%$ & $* *$ & $-3.3 \%$ & $* *$ & $-3.2 \%$ & $* *$ & $-3.4 \%$ & $* *$ & $-3.2 \%$ & $* *$ & $-3.7 \%$ & $* *$ \\
\hline Experiencia & $0.1 \%$ & & $0.1 \%$ & & $0.1 \%$ & & $0.1 \%$ & & $0.1 \%$ & & $0.1 \%$ & \\
\hline$-\overline{\text { Tamanho }} \overline{\text { Amostra }}----$ & $-\overline{112}$ & - & $\overline{112}$ & - & $-\overline{112}$ & - & $\overline{112}-$ & - & $-11 \overline{2}$ & - & $\overline{110}$ & 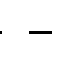 \\
\hline $\mathrm{R}^{2}$ Ajustado & 0.008 & & 0.008 & & -0.005 & & 0.000 & & -0.004 & & 0.005 & \\
\hline Estatítica F & 1.086 & & 1.080 & & 0.949 & & 1.000 & & 0.963 & & 1.046 & \\
\hline Teste Breusch-Pagan & 0.257 & & 0.414 & & 0.399 & & 0.373 & & 0.090 & & 0.329 & \\
\hline Teste Reset & 0.625 & & 0.860 & & 0.732 & & 0.900 & & 0.792 & & 0.690 & \\
\hline
\end{tabular}

Fonte: Elaborado pelo Autor

Notas: * denota significância estatística: * p-value $<10 \% ; \quad * *$ p-value $<5 \%$; $\quad * * *$ p-value $<1 \%$

Quando o Teste de Breusch-Pagan indica heterocedasticidade, a significância estatística adota a metodologia de erros robustos.

A tabela apresenta os resultados da regressão cross section do retorno anormal acumulado para a janela de três dias. São apresentados os resultados de seis modelos, cada qual assumindo uma proxy diferente para classificação do estado de mercado. 
Tabela 27 - Análise de Regressão dos Determinantes de Criação de Valor - Janela de Onze Dias - Proxy de Mercado Ibovespa e Segmentação Sentimento Mercado pela Mediana

\begin{tabular}{|c|c|c|c|c|c|c|c|c|c|}
\hline \multirow{2}{*}{$\frac{\text { Amostra Completa }}{\text { Mercado em Alta }}$} & \multicolumn{2}{|c|}{ 1) ICEI } & \multicolumn{2}{|c|}{$\begin{array}{c}\text { 2) ICEI } \\
\text { Expectativa }\end{array}$} & \multicolumn{2}{|c|}{$\begin{array}{l}\text { 3) Num } \\
\text { F\&As }\end{array}$} & \multirow{2}{*}{$\begin{array}{l}\text { 4) Retorno } \\
\text { Ibovespa } \\
\mathbf{- 1 . 1 \%}\end{array}$} & $\begin{array}{l}\text { 5) Util. Cap. } \\
\text { Instalada } \\
\end{array}$ & 6) IBC-BR \\
\hline & $0.4 \%$ & & $2.6 \%$ & $* *$ & $0.0 \%$ & & & $0.7 \%$ & $-1.1 \%$ \\
\hline \multicolumn{10}{|l|}{ Variáveis de Controle } \\
\hline ValorMerc / ValorCont & $-0.1 \%$ & & $-0.1 \%$ & & $-0.1 \%$ & & $0.0 \%$ & $-0.1 \%$ & $-0.1 \%$ \\
\hline Endiv / Ativos Totais & $3.2 \%$ & & $3.5 \%$ & & $3.1 \%$ & & $3.4 \%$ & $2.9 \%$ & $-0.3 \%$ \\
\hline Tam Rel Operacao & $0.2 \%$ & & $-1.7 \%$ & & $0.3 \%$ & & $1.3 \%$ & $0.4 \%$ & $-1.8 \%$ \\
\hline Tam Adquirente & $0.9 \%$ & & $0.7 \%$ & & $0.9 \%$ & & $1.0 \%$ & $1.0 \%$ & $0.7 \%$ \\
\hline Empresas Relacionadas & $-0.1 \%$ & & $0.5 \%$ & & $-0.1 \%$ & & $-0.1 \%$ & $-0.1 \%$ & $-0.2 \%$ \\
\hline Momento (Ebitda / Ativ Total) & $-19.2 \%$ & $*$ & $-20.7 \%$ & $*$ & $-19.5 \%$ & $*$ & $-17.8 \%$ & $-19.7 \% \quad *$ & $-21.7 \% * *$ \\
\hline Aquisição Internacional & $-1.4 \%$ & & $-0.9 \%$ & & $-1.5 \%$ & & $-1.3 \%$ & $-1.5 \%$ & $-1.2 \%$ \\
\hline Aquisição Controle & $0.4 \%$ & & $0.5 \%$ & & $0.4 \%$ & & $0.5 \%$ & $0.3 \%$ & $0.7 \%$ \\
\hline Recenticidade & $-0.1 \%$ & & $-0.1 \%$ & & $-0.1 \%$ & & $-0.3 \%$ & $-0.2 \%$ & $-1.3 \%$ \\
\hline Experiencia & $-0.6 \%$ & & $-0.6 \%$ & & $-0.7 \%$ & & $-0.6 \%$ & $-0.7 \%$ & $-0.6 \%$ \\
\hline$-\overline{\text { Tamanho }} \overline{\text { Amostra }}---$ & $-\overline{113}$ & & $\overline{113}$ & - & $-\overline{113}$ & & $\overline{113}-$ & $-{ }_{113}-$ & $-\overline{111}--$ \\
\hline $\mathrm{R}^{2}$ Ajustado & -0.005 & & 0.031 & & -0.006 & & 0.001 & -0.004 & 0.017 \\
\hline Estatítica F & 0.946 & & 1.322 & & 0.934 & & 1.007 & 0.964 & 1.175 \\
\hline Teste Breusch-Pagan & 0.012 & & 0.018 & & 0.017 & & 0.021 & 0.014 & 0.124 \\
\hline Teste Reset & 0.054 & & 0.675 & & 0.030 & & 0.058 & 0.063 & 0.142 \\
\hline
\end{tabular}

\begin{tabular}{|c|c|c|c|c|c|c|c|c|c|}
\hline \multirow{2}{*}{$\begin{array}{l}\text { Exclusão Outliers } \\
\text { Mercado em Alta }\end{array}$} & \multicolumn{2}{|l|}{ 1) ICEI } & \multicolumn{2}{|c|}{$\begin{array}{c}\text { 2) ICEI } \\
\text { Expectativa } \\
\end{array}$} & \multicolumn{2}{|c|}{$\begin{array}{l}\text { 3) Num } \\
\text { F\&As }\end{array}$} & \multirow{2}{*}{$\begin{array}{l}\text { 4) Retorno } \\
\text { Ibovespa } \\
\mathbf{- 1 . 1 \%}\end{array}$} & $\begin{array}{l}\text { 5) Util. Cap. } \\
\text { Instalada } \\
\end{array}$ & 6) IBC-BR \\
\hline & $0.4 \%$ & & $2.6 \%$ & $* *$ & $0.0 \%$ & & & $0.7 \%$ & $-1.1 \%$ \\
\hline \multicolumn{10}{|l|}{ Variáveis de Controle } \\
\hline ValorMerc / ValorCont & $-0.1 \%$ & & $-0.1 \%$ & & $-0.1 \%$ & & $0.0 \%$ & $-0.1 \%$ & $-0.1 \%$ \\
\hline Endiv / Ativos Totais & $3.2 \%$ & & $3.5 \%$ & & $3.1 \%$ & & $3.4 \%$ & $2.9 \%$ & $-0.3 \%$ \\
\hline Tam Rel Operacao & $0.2 \%$ & & $-1.7 \%$ & & $0.3 \%$ & & $1.3 \%$ & $0.4 \%$ & $-1.8 \%$ \\
\hline Tam Adquirente & $0.9 \%$ & & $0.7 \%$ & & $0.9 \%$ & & $1.0 \%$ & $1.0 \%$ & $0.7 \%$ \\
\hline Empresas Relacionadas & $-0.1 \%$ & & $0.5 \%$ & & $-0.1 \%$ & & $-0.1 \%$ & $-0.1 \%$ & $-0.2 \%$ \\
\hline Momento (Ebitda / Ativ Total) & $-19.2 \%$ & $*$ & $-20.7 \%$ & $*$ & $-19.5 \%$ & $*$ & $-17.8 \%$ & $-19.7 \% \quad *$ & $-21.7 \% \quad * *$ \\
\hline Aquisição Internacional & $-1.4 \%$ & & $-0.9 \%$ & & $-1.5 \%$ & & $-1.3 \%$ & $-1.5 \%$ & $-1.2 \%$ \\
\hline Aquisição Controle & $0.4 \%$ & & $0.5 \%$ & & $0.4 \%$ & & $0.5 \%$ & $0.3 \%$ & $0.7 \%$ \\
\hline Recenticidade & $-0.1 \%$ & & $-0.1 \%$ & & $-0.1 \%$ & & $-0.3 \%$ & $-0.2 \%$ & $-1.3 \%$ \\
\hline Experiencia & $-0.6 \%$ & & $-0.6 \%$ & & $-0.7 \%$ & & $-0.6 \%$ & $-0.7 \%$ & $-0.6 \%$ \\
\hline$-\overline{\text { Tamanho }} \overline{\text { Amostra }}---$ & $-1 \overline{3}$ & & $\overline{113}$ & . & $-\overline{113}$ & & $\overline{113}-$ & $-{ }_{113}-$ & $\overline{111}--$ \\
\hline $\mathrm{R}^{2}$ Ajustado & -0.005 & & 0.031 & & -0.006 & & 0.001 & -0.004 & 0.017 \\
\hline Estatítica F & 0.946 & & 1.322 & & 0.934 & & 1.007 & 0.964 & 1.175 \\
\hline Teste Breusch-Pagan & 0.012 & & 0.018 & & 0.017 & & 0.021 & 0.014 & 0.124 \\
\hline Teste Reset & 0.054 & & 0.675 & & 0.030 & & 0.058 & 0.063 & 0.142 \\
\hline
\end{tabular}

Fonte: Elaborado pelo Autor

Notas: * denota significância estatística: * p-value $<10 \% ; \quad * *$ p-value $<5 \%$; $\quad * * *$ p-value $<1 \%$

Quando o Teste de Breusch-Pagan indica heterocedasticidade, a significância estatística adota a metodologia de erros robustos.

A tabela apresenta os resultados da regressão cross section do retorno anormal acumulado para a janela de onze dias. São apresentados os resultados de seis modelos, cada qual assumindo uma proxy diferente para classificação do estado de mercado. 
Tabela 28 Análise de Regressão dos Determinantes de Criação de Valor - Janela de Vinte e Um Dias - Proxy de Mercado Ibovespa e Segmentação Sentimento Mercado pela Mediana

\begin{tabular}{|c|c|c|c|c|c|c|c|c|c|c|c|c|}
\hline \multirow{2}{*}{$\begin{array}{l}\text { Amostra Completa } \\
\text { Mercado em Alta }\end{array}$} & \multicolumn{2}{|c|}{ 1) ICEI } & \multicolumn{2}{|c|}{$\begin{array}{c}\text { 2) ICEI } \\
\text { Expectativa } \\
\end{array}$} & \multicolumn{2}{|c|}{$\begin{array}{l}\text { 3) Num } \\
\text { F\&As }\end{array}$} & \multicolumn{2}{|c|}{$\begin{array}{l}\text { 4) Retorno } \\
\text { Ibovespa }\end{array}$} & \multicolumn{2}{|c|}{$\begin{array}{l}\text { 5) Util. Cap. } \\
\text { Instalada }\end{array}$} & \multicolumn{2}{|c|}{ 6) IBC-BR } \\
\hline & $1,5 \%$ & & $2,1 \%$ & & $1,8 \%$ & & $-2,2 \%$ & & $2,7 \%$ & $*$ & $0,2 \%$ & \\
\hline \multicolumn{13}{|l|}{ Variáveis de Controle } \\
\hline ValorMerc / ValorCont & $-0,2 \%$ & & $-0,2 \%$ & $*$ & $-0,1 \%$ & & $-0,1 \%$ & & $-0,1 \%$ & & $-0,2 \%$ & \\
\hline Endiv / Ativos Totais & $-5,7 \%$ & & $-5,6 \%$ & & $-6,6 \%$ & & $-5,4 \%$ & & $-6,6 \%$ & & $-6,5 \%$ & \\
\hline Tam Rel Operacao & $-13,8 \%$ & $* *$ & $-15,1 \%$ & $* *$ & $-13,2 \%$ & $* *$ & $-11,5 \%$ & $* *$ & $-13,2 \%$ & $* *$ & $-13,6 \%$ & $* *$ \\
\hline Tam Adquirente & $-0,5 \%$ & & $-0,5 \%$ & & $-0,5 \%$ & & $-0,3 \%$ & & $-0,2 \%$ & & $-0,4 \%$ & \\
\hline Empresas Relacionadas & $0,6 \%$ & & $1,0 \%$ & & $0,7 \%$ & & $0,5 \%$ & & $0,6 \%$ & & $0,3 \%$ & \\
\hline Momento (Ebitda / Ativ Total) & $-32,2 \%$ & $* * *$ & $-34,2 \%$ & $* * *$ & $-30,3 \%$ & $* *$ & $-29,9 \%$ & $* *$ & $-34,0 \%$ & $* * *$ & $-34,1 \%$ & $* * *$ \\
\hline Aquisição Internacional & $1,2 \%$ & & $1,4 \%$ & & $1,0 \%$ & & $1,3 \%$ & & $0,9 \%$ & & $0,9 \%$ & \\
\hline Aquisição Controle & $0,3 \%$ & & $0,2 \%$ & & $0,3 \%$ & & $0,4 \%$ & & $-0,1 \%$ & & $0,2 \%$ & \\
\hline Recenticidade & $1,9 \%$ & & $1,9 \%$ & & $1,1 \%$ & & $1,4 \%$ & & $1,5 \%$ & & $1,9 \%$ & \\
\hline Experiencia & $-0,3 \%$ & & $-0,3 \%$ & & $-0,2 \%$ & & $-0,3 \%$ & & $-0,3 \%$ & & $-0,3 \%$ & \\
\hline$-\overline{\text { Tamanho }} \overline{\text { Amostra }}----$ & $-\overline{113}$ & - - & $-\overline{113}$ & - - & $-\overline{113}$ & - & $-\overline{113}-$ & - & -113 & -- & $-11 \overline{1}$ & - \\
\hline $\mathrm{R}^{2}$ Ajustado & 0,039 & & 0,047 & & 0,041 & & 0,048 & & 0,057 & & 0,026 & \\
\hline Estatítica F & 1,411 & & 1,500 & & 1,431 & & 1,512 & & 1,616 & & 1,264 & \\
\hline Teste Breusch-Pagan & 0,012 & & 0,015 & & 0,043 & & 0,037 & & 0,033 & & 0,008 & \\
\hline Teste Reset & 0,143 & & 0,072 & & 0,024 & & 0,012 & & 0,103 & & 0,020 & \\
\hline Exclusão Outliers & 1) IC & & $\begin{array}{r}2) \mathrm{IC} \\
\text { Expecta }\end{array}$ & & $\begin{array}{l}\text { 3) Num } \\
\text { F\&As }\end{array}$ & & $\begin{array}{l}\text { 4) Retorl } \\
\text { Ibovesp }\end{array}$ & & $\begin{array}{l}\text { 5) Util. } \\
\text { Instal }\end{array}$ & $\begin{array}{l}\text { Cap. } \\
\text { ada }\end{array}$ & 6) IBC & $-B R$ \\
\hline Mercado em Alta & $1,5 \%$ & & $2,1 \%$ & & $1,8 \%$ & & $-2,2 \%$ & & $2,7 \%$ & $*$ & $0,2 \%$ & \\
\hline \multicolumn{13}{|l|}{ Variáveis de Controle } \\
\hline ValorMerc / ValorCont & $-0,2 \%$ & & $-0,2 \%$ & $*$ & $-0,1 \%$ & & $-0,1 \%$ & & $-0,1 \%$ & & $-0,2 \%$ & \\
\hline Endiv / Ativos Totais & $-5,7 \%$ & & $-5,6 \%$ & & $-6,6 \%$ & & $-5,4 \%$ & & $-6,6 \%$ & & $-6,5 \%$ & \\
\hline Tam Rel Operacao & $-13,8 \%$ & $* *$ & $-15,1 \%$ & $* *$ & $-13,2 \%$ & $* *$ & $-11,5 \%$ & $* *$ & $-13,2 \%$ & $* *$ & $-13,6 \%$ & $* *$ \\
\hline Tam Adquirente & $-0,5 \%$ & & $-0,5 \%$ & & $-0,5 \%$ & & $-0,3 \%$ & & $-0,2 \%$ & & $-0,4 \%$ & \\
\hline Empresas Relacionadas & $0,6 \%$ & & $1,0 \%$ & & $0,7 \%$ & & $0,5 \%$ & & $0,6 \%$ & & $0,3 \%$ & \\
\hline Momento (Ebitda / Ativ Total) & $-32,2 \%$ & $* * *$ & $-34,2 \%$ & $* * *$ & $-30,3 \%$ & $* *$ & $-29,9 \%$ & $* *$ & $-34,0 \%$ & $* * *$ & $-34,1 \%$ & $* * *$ \\
\hline Aquisição Internacional & $1,2 \%$ & & $1,4 \%$ & & $1,0 \%$ & & $1,3 \%$ & & $0,9 \%$ & & $0,9 \%$ & \\
\hline Aquisição Controle & $0,3 \%$ & & $0,2 \%$ & & $0,3 \%$ & & $0,4 \%$ & & $-0,1 \%$ & & $0,2 \%$ & \\
\hline Recenticidade & $1,9 \%$ & & $1,9 \%$ & & $1,1 \%$ & & $1,4 \%$ & & $1,5 \%$ & & $1,9 \%$ & \\
\hline Experiencia & $-0,3 \%$ & & $-0,3 \%$ & & $-0,2 \%$ & & $-0,3 \%$ & & $-0,3 \%$ & & $-0,3 \%$ & \\
\hline Tamanho $\overline{\text { Amostra }}----$ & $-11 \overline{3}$ & - - & $-\overline{113}$ & - - & -113 & - & $-\overline{113}-$ & - & $\overline{11}{ }^{-}$ & -- & $-11 \overline{1}$ & - \\
\hline $\mathrm{R}^{2}$ Ajustado & 0,039 & & 0,047 & & 0,041 & & 0,048 & & 0,057 & & 0,026 & \\
\hline Estatítica F & 1,411 & & 1,500 & & 1,431 & & 1,512 & & 1,616 & & 1,264 & \\
\hline Teste Breusch-Pagan & 0,012 & & 0,015 & & 0,043 & & 0,037 & & 0,033 & & 0,008 & \\
\hline Teste Reset & 0,143 & & 0,072 & & 0,024 & & 0,012 & & 0,103 & & 0,020 & \\
\hline
\end{tabular}

Fonte: Elaborado pelo Autor

Notas: * denota significância estatística: * p-value < 10\%; $\quad * *$ p-value $<5 \%$; $\quad * * *$ p-value $<1 \%$

Quando o Teste de Breusch-Pagan indica heterocedasticidade, a significância estatística adota a metodologia de erros robustos

A tabela apresenta os resultados da regressão cross section do retorno anormal acumulado para a janela de vinte e um dias. São apresentados os resultados de seis modelos, cada qual assumindo uma proxy diferente para classificação do estado de mercado. 
Tabela 29 - Análise de Regressão dos Determinantes de Criação de Valor - Dia do Anúncio da F\&A - Proxy de Mercado Ibovespa e Segmentação Sentimento Mercado pela Mediana - Amostra Completa

\begin{tabular}{|c|c|c|c|c|c|c|c|c|c|c|c|c|c|}
\hline \multirow{2}{*}{$\begin{array}{l}\text { Amostra Completa } \\
\text { Mercado em Alta }\end{array}$} & \multicolumn{2}{|c|}{ 1) ICEI } & \multicolumn{2}{|c|}{$\begin{array}{c}\text { 2) ICEI } \\
\text { Expectativa }\end{array}$} & \multicolumn{2}{|c|}{ 3) Num F\&As } & \multicolumn{2}{|c|}{$\begin{array}{l}\text { 4) Retorno } \\
\text { Ibovespa }\end{array}$} & \multicolumn{3}{|c|}{$\begin{array}{l}\text { 5) Util. Cap. } \\
\text { Instalada }\end{array}$} & \multicolumn{2}{|c|}{ 6) IBC-BR } \\
\hline & $-0.3 \%$ & & $-0.7 \%$ & $* *$ & $0.5 \%$ & & $0.3 \%$ & & & $0.4 \%$ & & $-0.5 \%$ & \\
\hline \multicolumn{14}{|l|}{ Variáveis de Controle } \\
\hline ValorMerc / ValorCont & $0.0 \%$ & & $0.0 \%$ & & $0.0 \%$ & & $0.0 \%$ & & & $0.0 \%$ & & $0.0 \%$ & \\
\hline Endiv / Ativos Totais & $0.3 \%$ & & $0.6 \%$ & & $0.4 \%$ & & $0.4 \%$ & & & $0.6 \%$ & & $0.0 \%$ & \\
\hline Tam Rel Operacao & $-1.3 \%$ & & $-1.2 \%$ & & $-1.1 \%$ & & $-1.5 \%$ & & & $-1.3 \%$ & & $-0.8 \%$ & \\
\hline Tam Adquirente & $0.0 \%$ & & $0.0 \%$ & & $0.0 \%$ & & $0.0 \%$ & & & $0.0 \%$ & & $0.0 \%$ & \\
\hline Empresas Relacionadas & $0.7 \%$ & $* *$ & $0.6 \%$ & $*$ & $0.8 \%$ & $* *$ & $0.7 \%$ & $* *$ & & $0.8 \%$ & $* *$ & $0.7 \%$ & $* *$ \\
\hline Momento (Ebitda / Ativ Total) & $-3.7 \%$ & & $-4.3 \%$ & & $-2.5 \%$ & & $-3.8 \%$ & & & $-3.5 \%$ & & $-1.2 \%$ & \\
\hline Aquisição Internacional & $-0.3 \%$ & & $-0.3 \%$ & & $-0.4 \%$ & & $-0.3 \%$ & & & $-0.3 \%$ & & $0.1 \%$ & \\
\hline Aquisição Controle & $0.2 \%$ & & $0.2 \%$ & & $0.2 \%$ & & $0.2 \%$ & & & $0.2 \%$ & & $0.3 \%$ & \\
\hline Recenticidade & $-0.6 \%$ & & $-0.7 \%$ & & $-0.8 \%$ & & $-0.7 \%$ & & & $-0.7 \%$ & & $-0.5 \%$ & \\
\hline Experiência & $-0.1 \%$ & & $-0.1 \%$ & & $-0.1 \%$ & & $-0.1 \%$ & & & $-0.1 \%$ & & $-0.1 \%$ & \\
\hline Sem Sobreposição Eventos & $0.0 \%$ & & $0.0 \%$ & & $0.0 \%$ & & $0.0 \%$ & & & $0.0 \%$ & & $0.0 \%$ & \\
\hline$-\overline{\text { Tamanho Amostra }}----$ & $-\overline{346}$ & - & $-\overline{346}$ & -- & $-\overline{346}$ & -- & $-\overline{346}-$ & - & - & $\overline{346}-$ & - & $\overline{2} 91$ & - \\
\hline $\mathrm{R}^{2}$ Ajustado & -0.003 & & 0.007 & & 0.000 & & -0.002 & & & -0.001 & & -0.012 & \\
\hline Estatítica F & 0.912 & & 1.201 & & 0.991 & & 0.936 & & & 0.982 & & 0.704 & \\
\hline Teste Breusch-Pagan & 0.000 & & 0.000 & & 0.000 & & 0.000 & & & 0.000 & & 0.000 & \\
\hline Teste Reset & 0.848 & & 0.160 & & 0.143 & & 0.518 & & & 0.388 & & 0.829 & \\
\hline Exclusão Outliers & \multicolumn{2}{|c|}{ 1) ICEI } & \multicolumn{2}{|c|}{$\begin{array}{c}\text { 2) ICEI } \\
\text { Expectativa }\end{array}$} & \multicolumn{2}{|c|}{ 3) Num F\&As } & \multicolumn{2}{|c|}{$\begin{array}{l}\text { 4) Retorno } \\
\text { Ibovespa }\end{array}$} & \multicolumn{3}{|c|}{$\begin{array}{l}\text { 5) Util. Cap. } \\
\text { Instalada }\end{array}$} & \multicolumn{2}{|c|}{ 6) IBC-BR } \\
\hline Mercado em Alta & $0.5 \%$ & $* *$ & $-0.1 \%$ & & $0.2 \%$ & & $0.1 \%$ & & & $0.2 \%$ & & $-0.8 \%$ & $* * *$ \\
\hline \multicolumn{14}{|l|}{ Variáveis de Controle } \\
\hline ValorMerc / ValorCont & $0.0 \%$ & & $0.0 \%$ & & $0.0 \%$ & & $0.0 \%$ & & & $0.0 \%$ & & $0.0 \%$ & \\
\hline Endiv / Ativos Totais & $-0.5 \%$ & & $-0.7 \%$ & & $-0.5 \%$ & & $-0.5 \%$ & & & $-0.6 \%$ & & $-1.3 \%$ & \\
\hline Tam Rel Operacao & $3.2 \%$ & & $3.0 \%$ & & $3.1 \%$ & & $3.0 \%$ & & & $3.0 \%$ & & $3.8 \%$ & \\
\hline Tam Adquirente & $0.1 \%$ & & $0.1 \%$ & & $0.1 \%$ & & $0.1 \%$ & & & $0.1 \%$ & & $0.1 \%$ & \\
\hline Empresas Relacionadas & $0.5 \%$ & $* *$ & $0.4 \%$ & & $0.5 \%$ & $*$ & $0.4 \%$ & $*$ & & $0.4 \%$ & & $0.4 \%$ & \\
\hline Momento (Ebitda / Ativ Total) & $-5.4 \%$ & $* *$ & $-5.5 \%$ & $* *$ & $-5.6 \%$ & $* *$ & $-6.1 \%$ & $* *$ & & $-5.4 \%$ & $* *$ & $-2.6 \%$ & \\
\hline Aquisição Internacional & $0.3 \%$ & & $0.3 \%$ & & $0.2 \%$ & & $0.3 \%$ & & & $0.3 \%$ & & $0.8 \%$ & $* *$ \\
\hline Aquisição Controle & $-0.1 \%$ & & $-0.1 \%$ & & $-0.1 \%$ & & $-0.1 \%$ & & & $-0.1 \%$ & & $0.1 \%$ & \\
\hline Recenticidade & $-0.9 \%$ & $* *$ & $-0.9 \%$ & $* *$ & $-0.9 \%$ & $* *$ & $-0.9 \%$ & $* *$ & & $-1.0 \%$ & $* *$ & $-0.9 \%$ & \\
\hline Experiência & $0.0 \%$ & & $0.0 \%$ & & $0.0 \%$ & & $0.0 \%$ & & & $0.0 \%$ & & $-0.1 \%$ & \\
\hline Sem Sobreposição Eventos & $0.2 \%$ & & $0.2 \%$ & & $0.2 \%$ & & $0.2 \%$ & & & $0.2 \%$ & & $0.3 \%$ & \\
\hline$\overline{\text { Tamanho Amostra }}----$ & $-\overline{336}-$ & - & $-\overline{337}-$ & - & $-\overline{3} 36$ & -- & $-{ }_{336}$ & - & - & $-\overline{3} \overline{7}$ & -- & $-\overline{282}$ & -- \\
\hline $\mathrm{R}^{2}$ Ajustado & 0.059 & & 0.037 & & 0.048 & & 0.046 & & & 0.038 & & 0.071 & \\
\hline Estatítica F & 2.741 & $* * *$ & 2.089 & $* *$ & 2.401 & $* * *$ & 2.359 & $* * *$ & & 2.114 & $* *$ & 2.781 & $* * *$ \\
\hline Teste Breusch-Pagan & 0.000 & & 0.000 & & 0.000 & & 0.000 & & & 0.000 & & 0.000 & \\
\hline Teste Reset & 0.007 & & 0.004 & & 0.005 & & 0.004 & & & 0.003 & & 0.002 & \\
\hline
\end{tabular}

Fonte: Elaborado pelo Autor

Notas: * denota significância estatística: * p-value $<10 \% ; \quad * *$ p-value $<5 \% ; \quad * * *$ p-value $<1 \%$

Quando o Teste de Breusch-Pagan indica heterocedasticidade, a significância estatística adota a metodologia de erros robustos.

A tabela apresenta os resultados da regressão cross section do retorno anormal no dia do anúncio da F\&A. São apresentados os resultados de seis modelos, cada qual assumindo uma proxy diferente para classificação do estado de mercado. 
Tabela 30 - Análise de Regressão dos Determinantes de Criação de Valor - Janela de Três Dias - Proxy de Mercado Ibovespa e Segmentação Sentimento Mercado pela Mediana - Amostra Completa

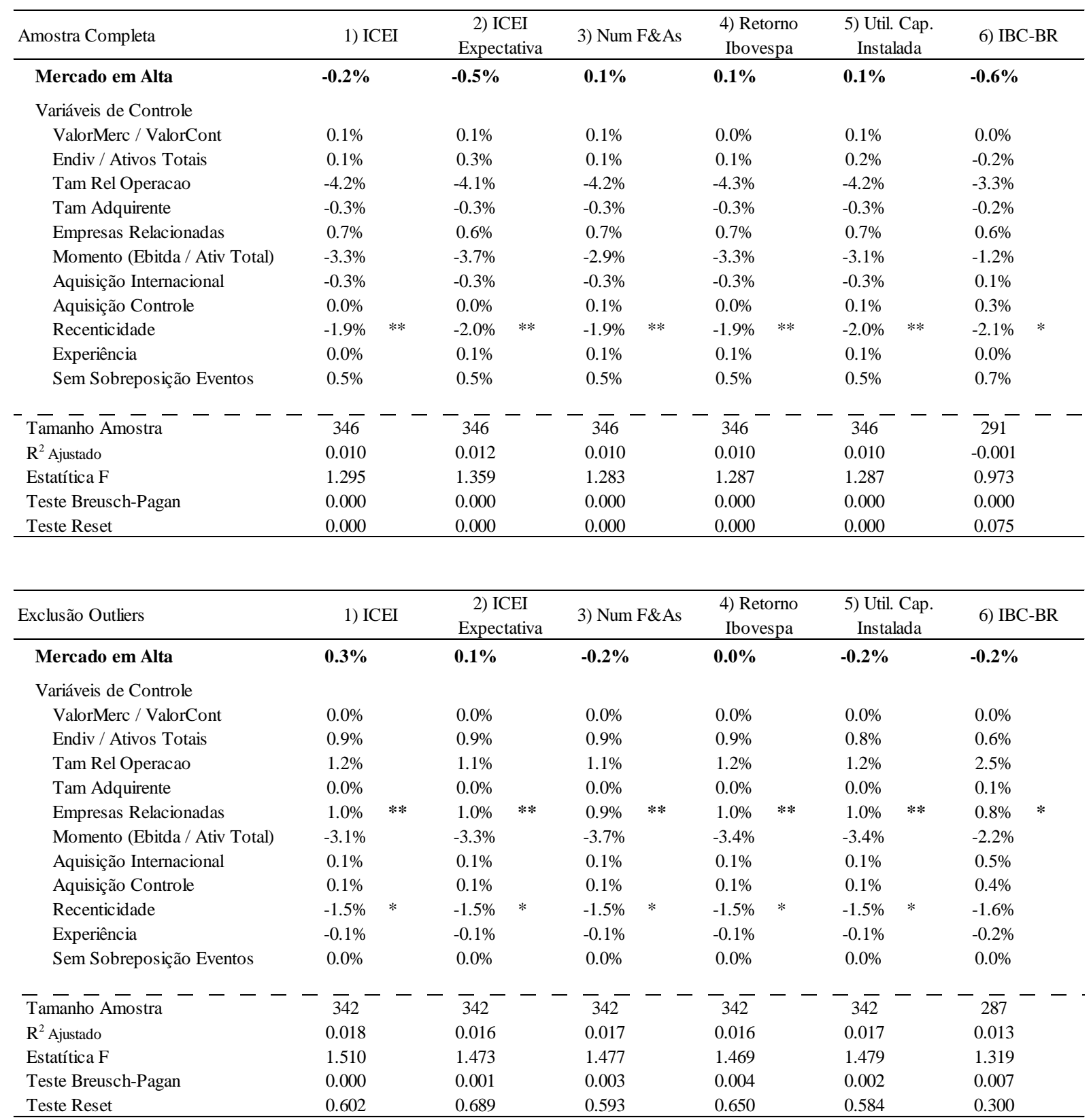

Fonte: Elaborado pelo Autor

Notas: * denota significância estatística: * p-value $<10 \% ; \quad * *$ p-value $<5 \%$; $\quad * * *$ p-value $<1 \%$

Quando o Teste de Breusch-Pagan indica heterocedasticidade, a significância estatística adota a metodologia de erros robustos.

A tabela apresenta os resultados da regressão cross section do retorno anormal acumulado para a janela de três dias. São apresentados os resultados de seis modelos, cada qual assumindo uma proxy diferente para classificação do estado de mercado. 
Tabela 31 - Análise de Regressão dos Determinantes de Criação de Valor - Janela de Onze Dias - Proxy de Mercado Ibovespa e Segmentação Sentimento Mercado pela Mediana - Amostra Completa

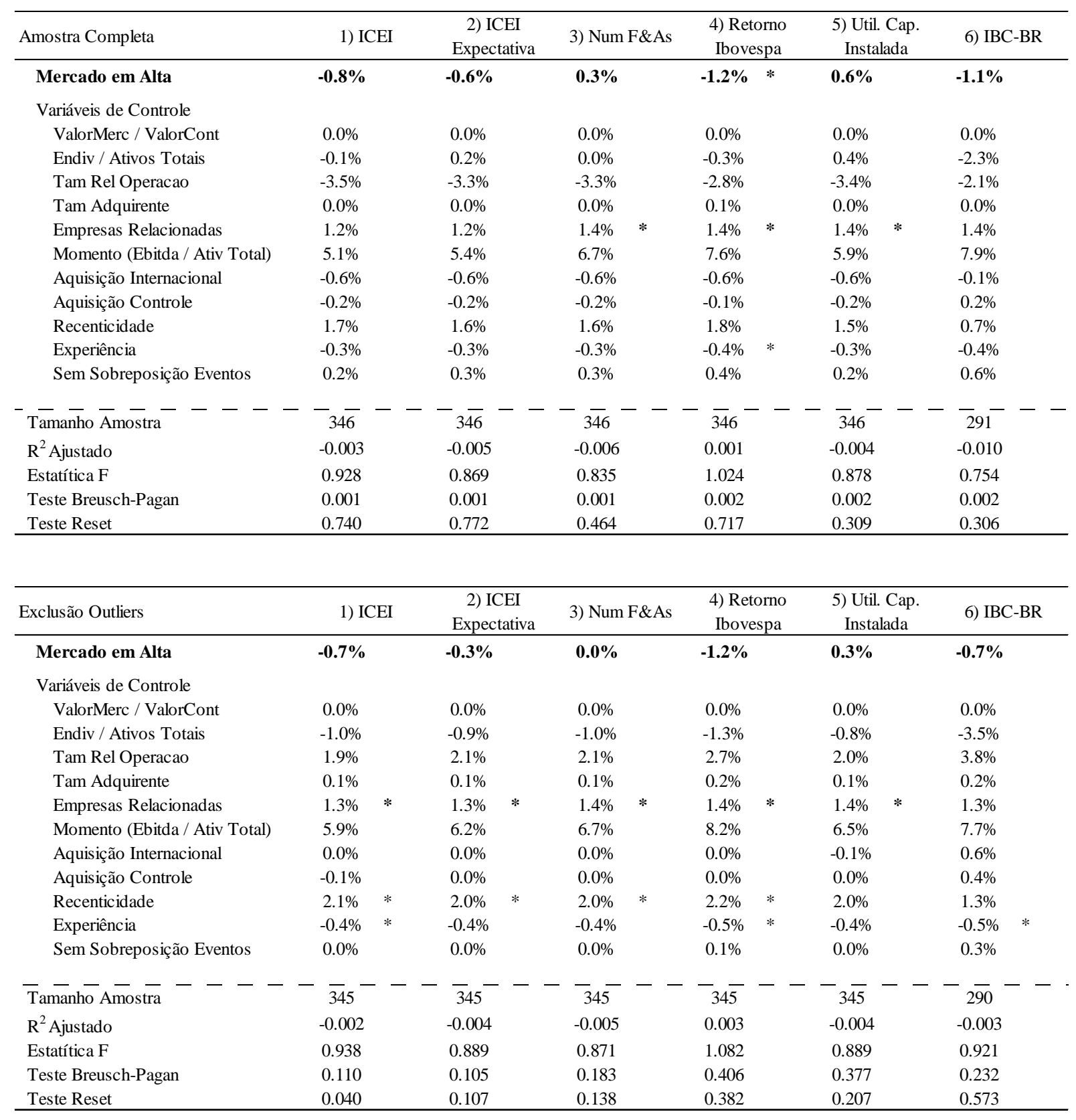

Fonte: Elaborado pelo Autor

Notas: * denota significância estatística: * p-value $<10 \% ; \quad * *$ p-value $<5 \%$; $\quad * * *$ p-value $<1 \%$

Quando o Teste de Breusch-Pagan indica heterocedasticidade, a significância estatística adota a metodologia de erros robustos.

A tabela apresenta os resultados da regressão cross section do retorno anormal acumulado para a janela de onze dias. São apresentados os resultados de seis modelos, cada qual assumindo uma proxy diferente para classificação do estado de mercado. 
Tabela 32 - Análise de Regressão dos Determinantes de Criação de Valor - - Janela de Vinte e Um Dias - Proxy de Mercado Ibovespa e Segmentação Sentimento Mercado pela Mediana - Amostra Completa

\begin{tabular}{|c|c|c|c|c|c|c|c|c|c|c|c|c|}
\hline \multirow{2}{*}{$\begin{array}{l}\text { Amostra Completa } \\
\text { Mercado em Alta }\end{array}$} & \multicolumn{2}{|c|}{ 1) ICEI } & \multicolumn{2}{|c|}{$\begin{array}{c}\text { 2) ICEI } \\
\text { Expectativa }\end{array}$} & \multicolumn{2}{|c|}{ 3) Num F\&As } & \multicolumn{2}{|c|}{$\begin{array}{l}\text { 4) Retorno } \\
\text { Ibovespa }\end{array}$} & \multicolumn{2}{|c|}{$\begin{array}{l}\text { 5) Util. Cap. } \\
\text { Instalada }\end{array}$} & \multicolumn{2}{|c|}{ 6) IBC-BR } \\
\hline & $-1.2 \%$ & & $-1.4 \%$ & & $-0.1 \%$ & & $-1.8 \%$ & * & $0.9 \%$ & & $-0.7 \%$ & \\
\hline \multicolumn{13}{|l|}{ Variáveis de Controle } \\
\hline ValorMerc / ValorCont & $0.0 \%$ & & $0.0 \%$ & & $0.0 \%$ & & $0.0 \%$ & & $0.0 \%$ & & $0.0 \%$ & \\
\hline Endiv / Ativos Totais & $-3.6 \%$ & & $-3.0 \%$ & & $-3.6 \%$ & & $-4.0 \%$ & & $-2.9 \%$ & & $-5.9 \%$ & \\
\hline Tam Rel Operacao & $-3.7 \%$ & & $-3.4 \%$ & & $-3.6 \%$ & & $-2.6 \%$ & & $-3.6 \%$ & & $-1.7 \%$ & \\
\hline Tam Adquirente & $-0.5 \%$ & & $-0.6 \%$ & & $-0.5 \%$ & & $-0.4 \%$ & & $-0.5 \%$ & & $-0.3 \%$ & \\
\hline Empresas Relacionadas & $2.2 \%$ & $* *$ & $2.1 \%$ & $* *$ & $2.4 \%$ & $* *$ & $2.5 \%$ & $* * *$ & $2.4 \%$ & $* * *$ & $2.1 \%$ & * \\
\hline Momento (Ebitda / Ativ Total) & $-4.7 \%$ & & $-5.2 \%$ & & $-3.6 \%$ & & $-1.0 \%$ & & $-3.6 \%$ & & $-1.0 \%$ & \\
\hline Aquisição Internacional & $2.6 \%$ & $* *$ & $2.6 \%$ & $*$ & $2.7 \%$ & $* *$ & $2.7 \%$ & ** & $2.6 \%$ & $*$ & $2.8 \%$ & * \\
\hline Aquisição Controle & $0.0 \%$ & & $0.0 \%$ & & $0.0 \%$ & & $0.1 \%$ & & $0.0 \%$ & & $0.4 \%$ & \\
\hline Recenticidade & $1.1 \%$ & & $1.0 \%$ & & $1.1 \%$ & & $1.3 \%$ & & $0.8 \%$ & & $0.7 \%$ & \\
\hline Experiência & $0.0 \%$ & & $0.0 \%$ & & $0.0 \%$ & & $-0.1 \%$ & & $0.0 \%$ & & $-0.2 \%$ & \\
\hline Sem Sobreposição Eventos & $0.2 \%$ & & $0.3 \%$ & & $0.3 \%$ & & $0.4 \%$ & & $0.2 \%$ & & $0.5 \%$ & \\
\hline$-\underset{\text { Tamanho Amostra }}{-}---$ & $-\overline{346}$ & & $-\frac{}{346}$ & - & $-\overline{346}-$ & -- & $-\overline{346}$ & - & $\overline{346}-$ & & $\overline{2} 91$ & - \\
\hline $\mathrm{R}^{2}$ Ajustado & 0.010 & & 0.012 & & 0.006 & & 0.016 & & 0.008 & & -0.004 & \\
\hline Estatítica F & 1.283 & & 1.339 & & 1.162 & & 1.463 & & 1.239 & & 0.902 & \\
\hline Teste Breusch-Pagan & 0.000 & & 0.000 & & 0.000 & & 0.000 & & 0.000 & & 0.000 & \\
\hline Teste Reset & 0.642 & & 0.126 & & 0.798 & & 0.511 & & 0.362 & & 0.977 & \\
\hline Exclusão Outliers & \multicolumn{2}{|c|}{ 1) ICEI } & \multicolumn{2}{|c|}{$\begin{array}{c}\text { 2) ICEI } \\
\text { Expectativa }\end{array}$} & \multicolumn{2}{|c|}{ 3) Num F\&As } & \multicolumn{2}{|c|}{$\begin{array}{l}\text { 4) Retorno } \\
\text { Ibovespa }\end{array}$} & \multicolumn{2}{|c|}{$\begin{array}{l}\text { 5) Util. Cap. } \\
\text { Instalada }\end{array}$} & \multicolumn{2}{|c|}{ 6) IBC-BR } \\
\hline Mercado em Alta & $-1.4 \%$ & & $-1.7 \%$ & $*$ & $-0.9 \%$ & & $-2.2 \%$ & $* *$ & $0.2 \%$ & & $0.2 \%$ & \\
\hline \multicolumn{13}{|l|}{ Variáveis de Controle } \\
\hline ValorMerc / ValorCont & $0.0 \%$ & & $0.0 \%$ & & $0.0 \%$ & & $0.0 \%$ & & $0.0 \%$ & & $0.0 \%$ & \\
\hline Endiv / Ativos Totais & $-4.7 \%$ & & $-4.0 \%$ & & $-4.8 \%$ & & $-5.2 \%$ & & $-4.5 \%$ & & $-7.8 \%$ & \\
\hline Tam Rel Operacao & $-4.5 \%$ & & $-4.1 \%$ & & $-4.3 \%$ & & $-2.9 \%$ & & $-4.0 \%$ & & $-2.0 \%$ & \\
\hline Tam Adquirente & $-0.5 \%$ & & $-0.6 \%$ & & $-0.5 \%$ & & $-0.4 \%$ & & $-0.6 \%$ & & $-0.2 \%$ & \\
\hline Empresas Relacionadas & $1.9 \%$ & $* *$ & $1.8 \%$ & $*$ & $2.0 \%$ & $* *$ & $2.2 \%$ & $* *$ & $2.2 \%$ & $* *$ & $1.6 \%$ & \\
\hline Momento (Ebitda / Ativ Total) & $-2.1 \%$ & & $-2.7 \%$ & & $-2.0 \%$ & & $2.5 \%$ & & $-0.5 \%$ & & $-0.9 \%$ & \\
\hline Aquisição Internacional & $2.3 \%$ & $* *$ & $2.2 \%$ & $*$ & $2.4 \%$ & $* *$ & $2.3 \%$ & $* *$ & $2.3 \%$ & $* *$ & $2.3 \%$ & $*$ \\
\hline Aquisição Controle & $-0.1 \%$ & & $-0.1 \%$ & & $0.0 \%$ & & $0.1 \%$ & & $0.0 \%$ & & $0.2 \%$ & \\
\hline Recenticidade & $1.3 \%$ & & $1.1 \%$ & & $1.6 \%$ & & $1.6 \%$ & & $1.2 \%$ & & $1.4 \%$ & \\
\hline Experiência & $0.0 \%$ & & $0.1 \%$ & & $-0.1 \%$ & & $-0.1 \%$ & & $0.0 \%$ & & $-0.3 \%$ & \\
\hline Sem Sobreposição Eventos & $0.5 \%$ & & $0.6 \%$ & & $0.7 \%$ & & $0.8 \%$ & & $0.6 \%$ & & $0.8 \%$ & \\
\hline$\overline{\text { Tamanho Amostra }}---$ & $-\overline{342}-$ & - & $-\overline{342}-$ & - & $-\frac{-}{342}$ & -- & $-\overline{342}$ & -- & $-\overline{342}$ & -- & $-\frac{-}{287}-$ & - - \\
\hline $\mathrm{R}^{2}$ Ajustado & 0.013 & & 0.016 & & 0.008 & & 0.022 & & 0.006 & & -0.003 & \\
\hline Estatítica F & 1.366 & & 1.464 & & 1.219 & & 1.652 & $*$ & 1.158 & & 0.939 & \\
\hline Teste Breusch-Pagan & 0.035 & & 0.015 & & 0.006 & & 0.077 & & 0.047 & & 0.035 & \\
\hline Teste Reset & 0.849 & & 0.259 & & 0.373 & & 0.307 & & 0.470 & & 0.622 & \\
\hline
\end{tabular}

Fonte: Elaborado pelo Autor

Notas: * denota significância estatística: *p-value $<10 \% ; \quad * *$ p-value $<5 \%$; $\quad * * *$ p-value $<1 \%$

Quando o Teste de Breusch-Pagan indica heterocedasticidade, a significância estatística adota a metodologia de erros robustos.

A tabela apresenta os resultados da regressão cross section do retorno anormal acumulado para a janela de vinte e um dias. São apresentados os resultados de seis modelos, cada qual assumindo uma proxy diferente para classificação do estado de mercado. 